NICOLE MEDEIROS GUIMARÃES EBOLI

\title{
Maternidade adotiva e infertilidade: contribuições da avaliação psicológica
}

Tese apresentada ao Programa de PósGraduação em Psicologia da Faculdade de Filosofia, Ciências e Letras de Ribeirão Preto da USP, como parte das exigências para obtenção do título de Doutor em Ciências, Área: Psicologia.

Orientadora: Profa. Dra. Sonia Regina Pasian 
Autorizo a reprodução e divulgação total ou parcial deste trabalho, por qualquer meio convencional ou eletrônico, para fins de estudo e pesquisa, desde que citada a fonte.

Guimarães-Eboli, Nicole Medeiros

Maternidade adotiva e infertilidade: contribuições da avaliação psicológica. Ribeirão Preto, 2017.

204 p. : il. ; $30 \mathrm{~cm}$

Tese de Doutorado, apresentada à Faculdade de Filosofia, Ciências e Letras de Ribeirão Preto/USP. Área de concentração: Psicologia.

Orientadora: Pasian, Sonia Regina.

1. Adoção. 2. Infertilidade. 3. Avaliação Psicológica. 4.Questionário Desiderativo. 5. Rorschach.

Foto da capa: Título: Afeto, autor: Augusto Higa

retirada da internet, em: http://www3.al.sp.gov.br/repositorio/noticia/03-2008/obra\%20-\%20afeto.jpg 


\section{FOLHA DE APROVAÇÃO}

\section{Nome: Nicole Medeiros Guimarães Eboli}

Título: Maternidade adotiva e infertilidade: contribuições da avaliação psicológica

Tese apresentada ao Programa de PósGraduação em Psicologia da Faculdade de Filosofia, Ciências e Letras de Ribeirão Preto da USP, como parte das exigências para obtenção do título de Doutor em Ciências, Área: Psicologia.

Aprovado em:

\section{Banca Examinadora}

Prof. Dr.:

Instituição: Assinatura:

Prof. Dr.:

Instituição: Assinatura:

Prof. Dr.:

Instituição: Assinatura:

Prof. Dr.: Instituição: Assinatura:

Prof. Dr.:

Instituição: Assinatura: 



\section{Dedicatória}

Dedico este trabalho a Ícaro e Betina, que, ao nascerem, me pariram como mãe. 

"À medida que uma mulher vai assumindo a própria sombra, observa-a, indaga, investiga, questiona a si mesma, libera o filho da manifestação dessa sombra." (Laura Gutman) 



\section{Agradecimentos}

Ao meu grande companheiro de vida e jornada, Rodrigo, que acompanhou de perto todos os anos do Doutorado, por todo o amor, respeito, compreensão diante das minhas ausências. Por ter assumido sozinho os cuidados dos pequenos por tantas e tantas vezes, por todo o apoio emocional, logístico, computacional, e, sobretudo, por acreditar tanto em mim e em meu potencial.

Aos meus filhos, Ícaro e Betina, que me fizeram saber mais forte e capaz do que podia imaginar, e com quem mais aprendo que ensino, todos os dias, sobre mim mesma, sobre a vida.

Aos meus pais, Márcio e Marilene, por terem me amado tanto e com tal profundidade, que aprendi a sempre buscar reconhecer o que de melhor existe em mim. E também por terem me ensinado a buscar meu desenvolvimento pessoal e profissional, o valor da autonomia e independência, e também a perseverar para alcançar meus objetivos.

Aos meus queridos amigos Thaís Reis, Adriana Ricci, Juliana Nascimento, Denise Zanin, Helena Junqueira, Thais Sucissi, Carlos Silva, Pedro Mantovani, Alessandra Dal Bello e outros que, cada um a seu modo, de perto ou de longe, em vários momentos nesta jornada, mostraram-se presentes de uma maneira especial, contribuindo de maneira fraterna e calorosa para tornar minha vida mais plena e feliz.

À minha querida orientadora, Profa. Dra. Sonia Pasian, que, após tantos anos de trabalho conjunto, posso dizer que também é um pouco amiga, um pouco mãe. A ela, que me recebeu como orientanda quando ainda era uma pós-adolescente, que testemunhou diversos momentos importantes da minha vida, e que sempre teve uma palavra acolhedora e pacificadora para oferecer. Pelo forte exemplo de competência e seriedade na pesquisa, pelos votos de confiança que me deu diante de cada desafio nesta trajetória como pesquisadora, por todo o incentivo e liberdade para conduzir o trabalho sem amarras ou cobranças desmedidas, elementos fundamentais para meu desenvolvimento profissional e intelectual.

À professora Dra. Sonia Regina Loureiro, por sua pronta disponibilidade em nos receber para discutir o projeto, por emprestar um pouco de sua sabedoria e oferecer um olhar competente e experiente sobre meus resultados, e pelas preciosas sugestões na análise do material. Sua participação como expert na Análise de Conteúdo do Desiderativo e como integrante da banca examinadora no exame de Qualificação foram fundamentais para o desenrolar do trabalho.

À profa. Dra. Leila Tardivo, pela importante colaboração por ocasião do exame de Qualificação, com seu conhecimento e experiência, enriquecendo a discussão sobre a pesquisa. 
A todos os colegas do Centro de Pesquisas em Psicodiagnóstico, pela parceria em nossas reuniões e discussões, permitindo o aprendizado conjunto, e em especial, às queridas Carmem Coury, Érika Okino, Fabiana Freitas e Fernanda Pizeta, pelo tempo e energia dispendidos ao colaborarem como examinadoras independentes, com tanto cuidado e dedicação.

Às caras psicólogas e experientes avaliadoras Simone Bianchi, Flávia Osório, Marcelle Freitas e Maria Luisa Maran, pela relevante colaboração como experts na Análise de Conteúdo do Desiderativo.

À colega Maíra Colombaroli, pela rápida e cuidadosa revisão do abstract.

Ao colega Jorge Sinval, pelas preciosas colaborações com o ensino da estatística e do manejo do SPSS, e também pelas precisas dicas para acessar os artigos científicos que fundamentam esta tese.

À minha amiga e colega de profissão, Helena Junqueira, que muito colaborou indicando as participantes do grupo das mães biológicas, selecionadas dentre suas ex clientes, e intermediando nosso contato.

Às minhas preciosas colaboradoras na coleta de dados, Bruna Palermo e Gisele Cury, por todo o esforço em aprender os instrumentos, pelo compromisso, pontualidade e capricho no cuidado ético com as participantes e também com a precisão técnica.

Aos colegas do Setor Técnico do Fórum de Ribeirão Preto, pela amizade e apoio durante estes anos de trabalho conjunto, e em especial, ao Walter Cassin e Simone Felipe, que me auxiliaram a lidar com o banco de dados e a ter acesso às futuras participantes da pesquisa. Agradecimento especial também às colegas assistentes sociais com quem atuei conjuntamente, que muito me ajudaram com os prazos e relatórios, sobretudo nos momentos críticos em que eu estive imersa no doutorado, sem condições de cumprir outras tarefas a contento.

Às 60 mulheres participantes desta pesquisa, que receberam a mim e às minhas colaboradoras em suas casas e dedicaram um pouco de seu (sempre escasso) tempo para colaborar, confiando a nós informações preciosas sobre si mesmas, suas histórias de vida e nos permitindo adentrar seu mundo interno por meio da avaliação psicológica.

Ao meu chefe, Dr. Paulo César Gentile, pela autorização que garantiu meu acesso aos dados judiciais necessários para contato e convite às participantes da pesquisa.

E, finalmente, mas não menos importante, ao Programa de Pós-Graduação em Psicologia da Faculdade de Filosofia, Ciências e Letras de Ribeirão Preto da USP, por me acolher como aluna e propiciar meu acesso ao aprendizado e formação profissional. 


\section{RESUMO}

Guimarães-Eboli, N. M. (2017) Maternidade adotiva e infertilidade: contribuições da avaliação psicológica. Tese de doutorado, Faculdade de Filosofia, Ciências e Letras de Ribeirão Preto, Universidade de São Paulo, Ribeirão Preto.

Os processos judiciais de adoção são pautados por muitas expectativas e dificuldades técnicas, envolvendo complexos fatores. O presente trabalho objetivou contribuir com a área por meio do estudo de características de personalidade de mulheres inférteis que buscam a adoção de crianças como forma de vivenciar a maternidade. Em complemento, objetivou-se examinar indicadores psicométricos (precisão e validade) acerca do Questionário Desiderativo enquanto método projetivo de avaliação da personalidade. O delineamento do estudo foi transversal, descritivo-comparativo de grupos e correlacional, a partir de instrumentos de avaliação psicológica. Foram avaliadas 60 mulheres voluntárias (30 a 50 anos), em união conjugal, com escolaridade média ou superior. Destas, 40 não tinham filhos biológicos, sendo 20 pretendentes à adoção (Grupo $1=\mathrm{G} 1$ ) e 20 mães adotivas (Grupo 2=G2). As 20 restantes eram mães biológicas, constituindo grupo de comparação (Grupo 3=G3). Responderam, individualmente, a uma bateria de instrumentos psicológicos, incluindo Self-Reporting Questionnaire (SRQ-20), Bateria Fatorial de Personalidade (BFP), Questionário Desiderativo (QD) e Psicodiagnóstico de Rorschach (escola francesa), aplicados e avaliados conforme diretrizes técnicas de seus respectivos manuais. Os dados foram submetidos à análise estatística descritiva e inferencial, comparando-se resultados médios ou frequências das variáveis nos grupos (ANOVA e Kruskall-Wallis, com post-hoc de Bonferroni ou teste Quiquadrado), além da análise de associação entre variáveis e avaliação de concordância entre examinadores (Kappa e correlação de Spearman), considerando-se $p \leq 0,05$. Os achados apontaram elevados índices de precisão no Rorschach e no Desiderativo, com altos índices de concordância entre examinadores independentes, conferindo-lhes confiabilidade. A comparação de resultados médios entre os grupos apontou reduzido número de diferenças estatisticamente significativas, sugerindo homogeneidade nas características de personalidade das mulheres avaliadas, bem como ausência de indicadores psicopatológicos (SRQ-20). O padrão geral de respostas aos instrumentos mostrou-se compatível com referenciais normativos dos instrumentos utilizados, independente da diferenciada experiência das mulheres em termos de maternidade. Dentre os fatores de personalidade avaliados pela BFP, houve diferença estatisticamente significativa em apenas uma de suas facetas: Liberalismo (maior em G3). No Rorschach houve indicadores de preservado funcionamento lógico e afetivo, com raros marcadores específicos entre os grupos. No tocante ao Desiderativo foi possível aprimorar seu sistema avaliativo, com positivos indicadores de precisão e de validade, como inicialmente proposto. Os resultados enriqueceram-se a partir das análises correlacionais entre os três instrumentos avaliativos, identificando-se importantes e variadas correlações entre variáveis do Desiderativo e Rorschach, bem como entre Desiderativo e BFP, evidenciando indicadores de validade entre construtos relacionados, fortalecendo possibilidades avaliativas de características de personalidade a partir desta bateria técnica, integrando métodos projetivos e de autorrelato. Houve diferentes resultados de variáveis com correlação estatisticamente significativa em cada grupo de participantes, sugerindo que a combinação entre os instrumentos pôde detectar especificidades no funcionamento psicodinâmico destas participantes, a depender de suas condições frente à maternidade, não reveladas pela análise isolada das variáveis. Os resultados ilustram a relevância de se considerar componentes da personalidade em processos de avaliação psicológica forense voltados à adoção, visto que variáveis relacionadas às vivências psíquicas da infertilidade (ou não) podem interferir em seus resultados. Por fim, o trabalho aponta para as possibilidades informativas dos instrumentos padronizados de avaliação psicológica, sobretudo de sua utilização conjunta e complementar neste contexto da prática profissional do psicólogo.

Palavras-chave: Adoção, Maternidade, Infertilidade, Personalidade, Métodos Projetivos. 



\begin{abstract}
Guimarães-Eboli, N. M. (2017). Adoptive motherhood and infertility: contributions from psychological evaluation. Thesis (PhD degree), Faculty of Philosophy, Sciences and Letters of Ribeirão Preto, University of São Paulo, Ribeirão Preto.

The adoption judicial processes are based on many expectations and technical difficulties, involving complex factors. The present work aimed to contribute to the area through the study of infertile women's personality features who seek children's adoption as a way of experiencing motherhood. In addition, we aimed to examine psychometric indicators (reliability and validity) of the Desiderative Questionnaire as a projective method for assessment of the personality. The study design was cross-sectional, descriptive, comparative between groups, and correlational, based on psychological assessment instruments. Sixty female volunteers (30 to 50 years old), in a conjugal union, with average or higher education were assessed. Forty women did not have biological children: 20 were waiting for adoption (Group $1=\mathrm{G} 1$ ) and 20 were adoptive mothers (Group 2 = G2). The remaining 20 were biological mothers, constituting a comparison group (Group $3=\mathrm{G} 3$ ). They individually answered to a battery of psychological tests, including SelfReporting Questionnaire (SRQ-20), Factorial Personality Battery (BFP), Desiderative Questionnaire (QD) and Rorschach Psychodiagnosis (French Approach), administered and interpreted according to technical guidelines from their respective manuals. Data were submitted to descriptive and inferential statistical analysis, comparing mean scores or variable's frequencies in the groups (ANOVA and Kruskall-Wallis, with Bonferroni posthoc, or Chi-square test), as well as the analysis of the association between variables and agreement between examiners (Kappa and Spearman correlation), considering $p \leq 0.05$. The findings indicated high indicators of reliability in the Rorschach and Desiderative, with high agreement between independent examiners. The of means between the groups indicated a small number of statistically significant differences, suggesting homogeneity in the personality characteristics of the women evaluated, as well as the absence of psychopathological indicators (SRQ-20). The general pattern of responses to the instruments was compatible with the instruments' normative references, regardless of the differentiated women's experience in maternity terms. Among the personality factors evaluated by BFP, there was a statistically significant difference in only one of its facets: Liberalism (higher in G3). In the Rorschach, there were indicators of preserved logical and affective functioning, with rare specific markers between groups. Regarding the Desiderative, it was possible to improve its evaluation system, with positive indicators of reliability and validity, as initially proposed. The results were enriched from the correlational analyses between the three evaluation instruments, identifying important and varied correlations between the Desiderative and Rorschach's variables, as well as between Desiderative and BFP, evidencing validity indicators between related constructs, strengthening evaluation possibilities of personality characteristics from this technical battery, integrating projective and self-report methods. There were different results from variables with significant correlation in each group of participants, suggesting that the instruments' combination could detect specificities in the psychodynamic functioning of these participants, depending on their conditions in relation to motherhood, not revealed by the isolated analysis of the variables. The results illustrate the relevance of considering personality components in forensic psychological evaluation processes aimed at adoption since variables related to psychological experiences related to infertility (or not) might interfere with their results. Finally, the research points to the informative possibilities of the standardized instruments of psychological evaluation, especially their conjunction and complementary use in this context on the psychological professional practice.
\end{abstract}

Key words: Adoption, Maternity, Infertility, Personality, Projective methods. 



\section{LISTA DE TABELAS}

Tabela 1. Distribuição (em frequência simples) das participantes $(n=60)$ em função da

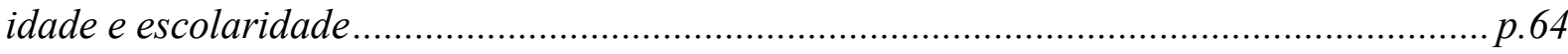

Tabela 2. Perfil etário (em meses) dos filhos das participantes de G2 (n=20) e de G3 $(n=20)$

Tabela 3. Resultados descritivos do SRQ-20 (escores brutos) em função dos grupos de mulheres $(n=60)$

Tabela 4. Resultados descritivos e comparação estatística do Fator Neuroticismo e suas facetas (escores brutos) em função dos grupos de mulheres $(n=60)$.

Tabela 5. Descrição (em percentis) dos valores médios no Fator Neuroticismo e suas facetas em função dos grupos de mulheres $(n=60)$.

Tabela 6. Resultados descritivos e comparação estatística do Fator Extroversão e suas facetas (escores brutos) em função dos grupos de mulheres $(n=60)$.

Tabela 7. Descrição (em percentis) dos valores médios no Fator Extroversão e suas facetas em função dos grupos de mulheres $(n=60)$.

Tabela 8. Resultados descritivos e comparação estatística do Fator Socialização e suas facetas (escores brutos) em função dos grupos de mulheres $(n=60)$.

Tabela 9. Descrição (em percentis) dos valores médios no Fator Socialização e suas facetas em função dos grupos de mulheres $(n=60)$.

Tabela 10. Resultados descritivos e comparação estatística do Fator Realização e suas facetas (escores brutos) em função dos grupos de mulheres $(n=60)$.

Tabela 11. Descrição (em percentis) dos valores médios no Fator Realização e suas facetas em função dos grupos de mulheres $(n=60)$.

Tabela 12. Resultados descritivos e comparação estatística do Fator Abertura e suas facetas (escores brutos) em função dos grupos de mulheres $(n=60)$.

Tabela 13. Descrição (em percentis) dos valores médios no Fator Abertura e suas facetas em função dos grupos de mulheres $(n=60)$

Tabela 14. Resultados descritivos da Análise de Concordância entre examinadores independentes (Kappa), referentes à classificação das respostas ao Método de Rorschach $(n=15)$

Tabela 15. Resultados descritivos e comparação estatística das variáveis referentes à produtividade e ritmo no Rorschach, em função dos grupos de mulheres $(n=60)$. p.98

Tabela 16. Descrição (em percentis) dos valores médios nas variáveis de produtividade do Rorschach em função dos grupos de mulheres $(n=60)$ 
Tabela 17. Resultados descritivos e comparação estatística das variáveis referentes à Localização no Rorschach, em função dos grupos de mulheres $(n=60)$..... p. 100

Tabela 18. Descrição (em percentis) dos valores médios nas variáveis de localização do Rorschach em função dos grupos de mulheres $(n=60)$ p. 101

Tabela 19. Resultados descritivos e comparação estatística das variáveis referentes aos determinantes formais no Rorschach, em função dos grupos de mulheres $(n=60)$....... p. 102

Tabela 20. Descrição (em percentis) dos valores médios nas variáveis de Determinantes formais do Rorschach, em função dos grupos de mulheres $(n=60)$ p. 103

Tabela 21. Resultados descritivos e comparação estatística das variáveis referentes aos Determinantes do tipo Movimento (cinestesias) no Rorschach, em função dos grupos de mulheres $(n=60)$......

Tabela 22. Distribuição das mulheres em função do uso de grandes ou pequenas cinestesias no Rorschach $(n=60)$

Tabela 23. Resultados descritivos e comparação estatística das variáveis referentes aos Determinantes cromáticos no Rorschach, em função dos grupos de mulheres $(n=60)$......p.106

Tabela 24. Distribuição das mulheres em função da qualidade formal dos determinantes cromáticos no Rorschach $(n=60)$

Tabela 25. Resultados descritivos e comparação estatística das variáveis referentes aos Determinantes do tipo Estompage (sombreado) no Rorschach, em função dos grupos de mulheres $(n=60)$.....

Tabela 26. Distribuição das mulheres em função da qualidade formal dos determinantes de sombreado (estompage) no Rorschach $(n=60)$. p. 108

Tabela 27. Resultados descritivos e comparação estatística das variáveis referentes aos Conteúdos animais e humanos no Rorschach, em função dos grupos de mulheres $(n=60) p .109$

Tabela 28. Descrição (em percentis) dos valores médios nos conteúdos A\% e H\% do Rorschach, em função dos grupos de mulheres $(n=60)$

Tabela 29. Resultados descritivos e comparação estatística das variáveis referentes aos Conteúdos no Rorschach, em função dos grupos de mulheres $(n=60)$

Tabela 30. Resultados descritivos e comparação estatística das Banalidades no Rorschach, em função dos grupos de mulheres $(n=60)$ p.114

Tabela 31. Distribuição das mulheres em função do Tipo de Ressonância Íntima (TRI) no Rorschach $(n=60)$

Tabela 32. Distribuição das mulheres em função da segunda fórmula afetiva (Tendências Latentes) do Rorschach $(n=60)$

Tabela 33. Resultados descritivos e comparação estatística da Fórmula da Angústia e Terceira Fórmula, no Rorschach, em função dos grupos de mulheres $(n=60)$. 
Tabela 34. Descrição da Análise de Conteúdo (experts, $n=5$ ) referente aos mecanismos de defesa do Questionário Desiderativo

Tabela 35: Resultados descritivos da Análise de Concordância entre examinadores independentes (em porcentagem), referentes à classificação das respostas ao Questionário Desiderativo $(n=60)$ p.123

Tabela 36. Resultados das análises de Correlação (Spearman) entre as classificações das respostas ao Desiderativo pelos examinadores independentes $(n=60)$ p.124

Tabela 37. Resultados descritivos e comparação estatística das variáveis referentes à Adequação ao Real no Desiderativo, em função dos grupos de mulheres $(n=60)$..... p. 125

Tabela 38. Resultados descritivos (em porcentagem) e comparação estatística das variáveis referentes ao Funcionamento Lógico no Desiderativo, em função dos grupos de mulheres $(n=60$ p. 127

Tabela 39. Resultados descritivos (em porcentagem) e comparação estatística das variáveis referentes às Manifestações Afetivas no Desiderativo, em função dos grupos de mulheres $(n=60)$ p.129

Tabela 40. Resultados descritivos (em porcentagem) e comparação estatística das variáveis referentes às Defesas Instrumentais no Desiderativo, em função dos grupos de mulheres $(n=60)$

Tabela 41. Resultados descritivos (em porcentagem) e comparação estatística dos mecanismos de defesa no Desiderativo, em função dos grupos de mulheres $(n=60) \ldots \ldots . . . p .135$

Tabela 42. Correlações estatisticamente significativas entre variáveis do Desiderativo e Rorschach no total de mulheres avaliadas $(n=60)$

Tabela 43. Correlações estatisticamente significativas entre variáveis do Desiderativo e Rorschach em função dos grupos de mulheres avaliadas

Tabela 44. Variáveis da Bateria Fatorial de Personalidade (BFP) e Desiderativo com correlação (Spearman) significativa entre si, considerando-se o total de mulheres avaliadas $(n=60)$ p.142

Tabela 45. Variáveis da Bateria Fatorial de Personalidade (BFP) e Desiderativo com correlação (Spearman) significativa entre si, considerando-se os subgrupos de mulheres avaliadas $(n=60)$ 



\section{SUMÁRIO}

\section{INTRODUÇÃ̃O}

I.1. Psicologia Jurídica: a complexidade dos processos de Adoção …………………………......21

I.2. Adoção e Infertilidade: evidências da literatura científica.................................................27

I.2.1. Infertilidade associada a sofrimento emocional e elemento motivador da adoção .........27

I.2.2. Evidências da literatura científica internacional ......................................................... 31

I.2.2.1. Sobre motivações para a maternidade (biológica e adotiva)..........................................32

I.2.2.2. Sobre infertilidade, reprodução assistida e suas repercussões .......................................35

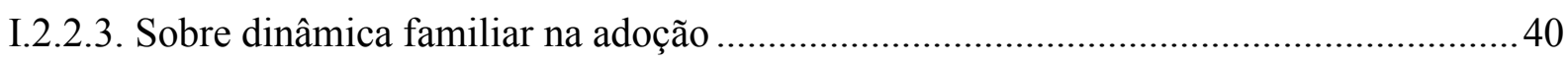

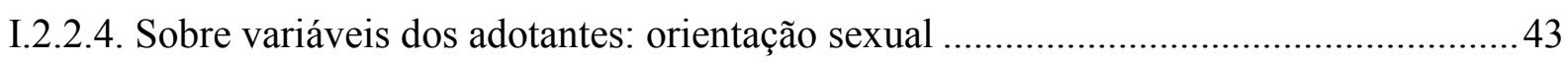

I.2.2.5. Sobre outras soluções frente à infertilidade e o desejo de ter filhos .............................4

I.2.2.6. Síntese do levantamento da literatura científica sobre adoção e infertilidade ..............45

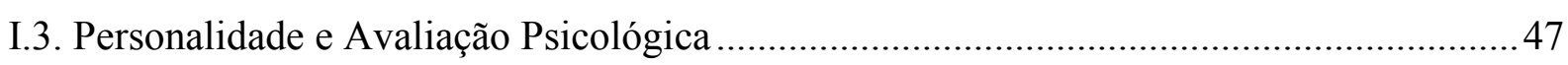

I.4. Avaliação psicológica como recurso investigativo da personalidade: instrumentos e

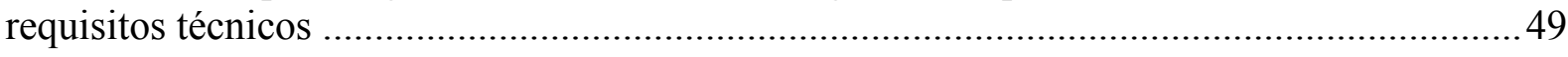

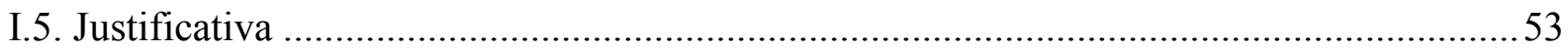

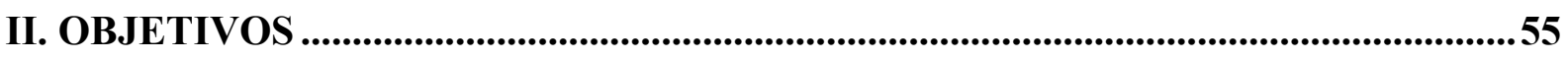

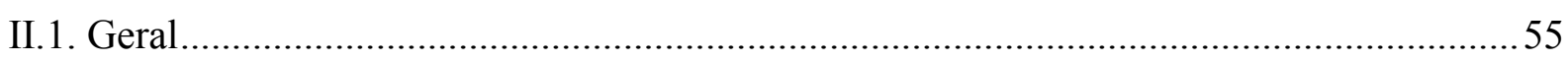

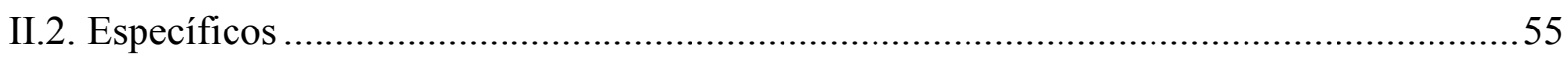

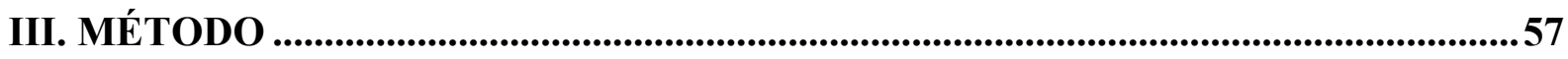

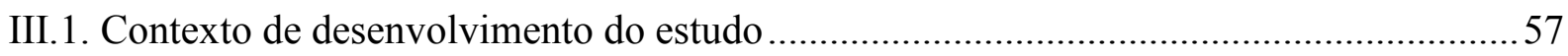

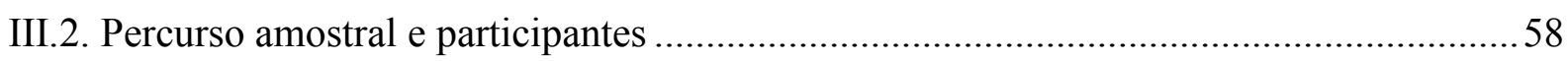

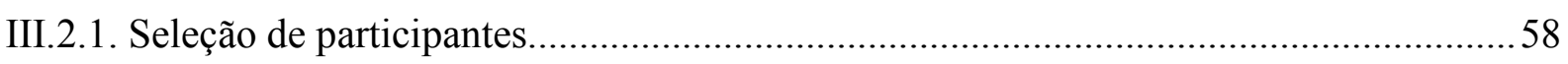

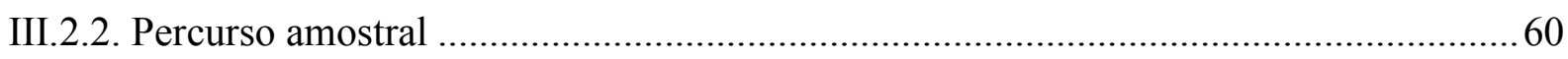

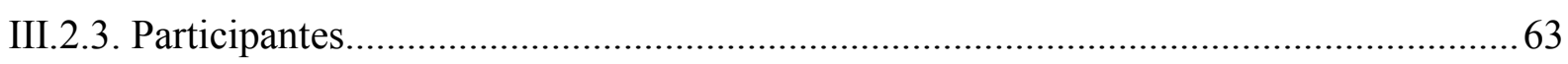

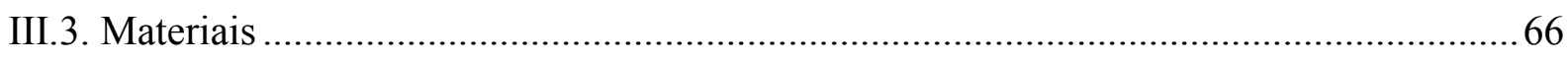

III.3.1. Termo de Consentimento Livre e Esclarecido (TCLE)...............................................66

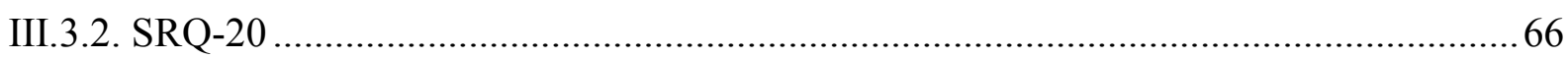

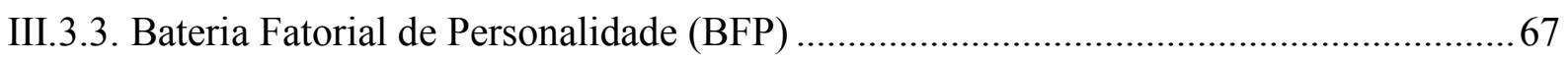

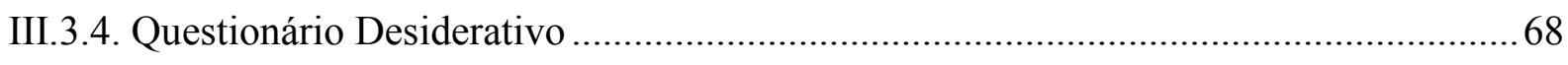

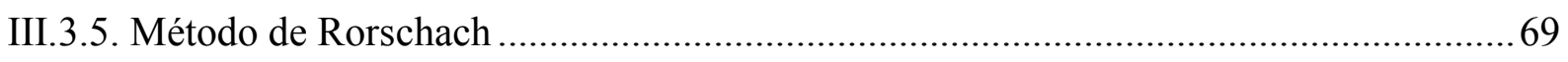

III.3.6. Programas computacionais para registro e análise dos dados, a saber...........................71 


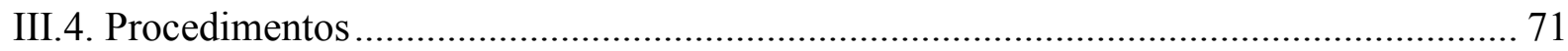

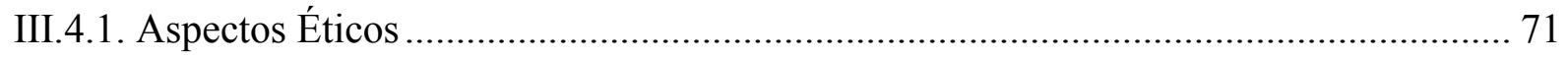

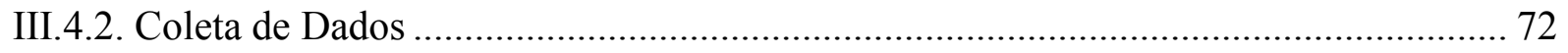

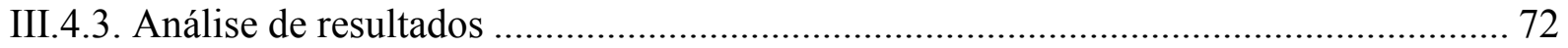

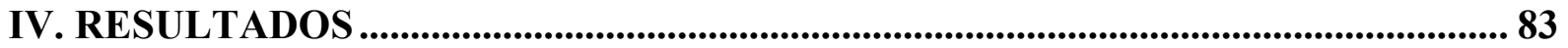

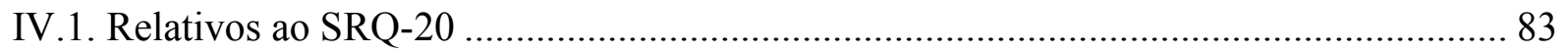

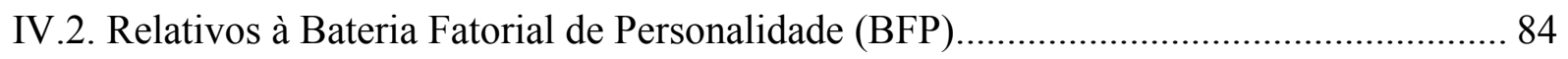

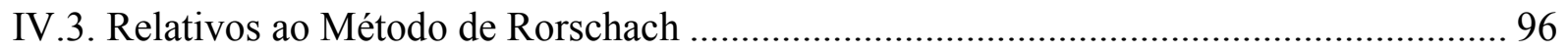

IV.4. Relativos ao Questionário Desiderativo ...................................................................... 118

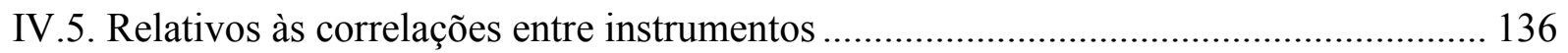

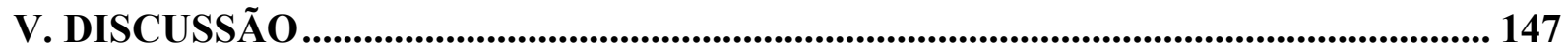

V.1. Caracterização psicológica de mulheres com e sem experiência de maternidade .......... 150

V.2. Especificidades de características de personalidade de mulheres envolvidas na adoção

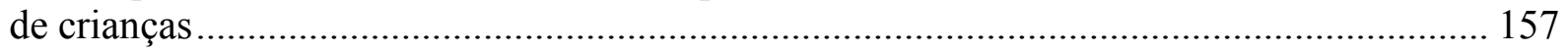

V.3. Evidências psicométricas sobre o Questionário Desiderativo ...................................... 162

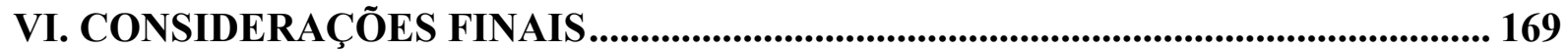

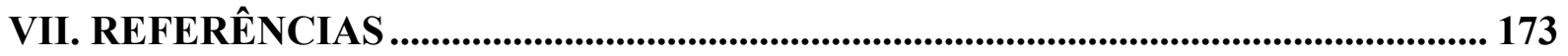

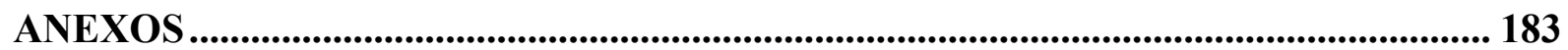

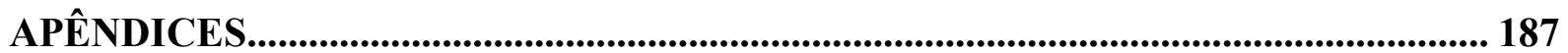




\section{INTRODUÇÃO}

\section{I.1. Psicologia Jurídica: a complexidade dos processos de Adoção}

Dentre as diferentes realidades que psicólogos brasileiros vivenciam em suas práticas, a área da Psicologia Jurídica é caracterizada por temáticas e desafios bastante específicos, que demandam constantes e aprofundados estudos sobre o desenvolvimento psicológico dos indivíduos e dos elementos intervenientes nas relações interpessoais. O psicólogo judiciário, quando inserido em uma Vara da Infância e Juventude, enfrenta questões relacionadas ao chamado risco psicossocial nas famílias, bem como lida com a realidade da vitimização de crianças e adolescentes. Nestes contextos, o psicólogo deve usar seus conhecimentos técnicocientíficos para compreender estes fenômenos e emitir pareceres que irão subsidiar decisões judiciais voltadas para as chamadas "medidas de proteção" destes infantes, nas quais pode estar incluído o encaminhamento para famílias substitutas (Fábio, Melão \& Jorge, 2005).

Ainda dentre as atribuições dos psicólogos judiciários encontra-se a seleção e a preparação destas famílias substitutas, desenvolvendo atividades de orientação e de aconselhamento aos pretendentes à adoção. $\mathrm{Na}$ avaliação técnica sobre as características psíquicas e socioafetivas destes pretendentes, os psicólogos necessitam seguir diretrizes apontadas pelo Estatuto da Criança e do Adolescente (ECA, Lei Federal no 8.069 de 13 de julho de 1990). Segundo o ECA, pretendentes à adoção (e futuros pais adotivos) podem ser homens e mulheres, maiores de 18 anos de idade, não importando o seu estado civil, desde que sejam (no mínimo) 16 anos mais velhos do que o adotado e ofereçam um "ambiente familiar adequado". Apenas não podem adotar os avós e irmãos do adotando.

O ECA define apenas um critério objetivo do que seja um ambiente familiar inadequado para adoção: presença de pessoas dependentes de álcool e de drogas. Porém, na avaliação realizada pela equipe profissional da Vara da Infância e da Juventude, necessitam ser considerados outros aspectos que deem indícios de um ambiente salutar para a criança/adolescente, aspectos estes que não estão claramente pré-definidos nas diretrizes regulamentadas oficialmente (Paiva, 2004).

No geral, considera-se que, na constituição de uma nova família, é fundamental proporcionar para as crianças/adolescentes que já sofreram uma ruptura afetiva anterior, um ambiente acolhedor e favorecedor do estabelecimento de novos vínculos. A preocupação nestes casos é de inspecionar, por meio de cuidadosa análise, se os pretendentes à adoção podem vir a receber, de forma emocionalmente saudável, uma criança na condição de filho. 
Assim, cabe aos psicólogos judiciários (em trabalho multidisciplinar com os assistentes sociais) a tarefa de receber estes candidatos, compreender os determinantes (conscientes e inconscientes) envolvidos em sua motivação para tornarem-se pais e mães adotivos, bem como avaliar se, por suas características pessoais, de personalidade e disposição pessoal, estariam dentro do considerado "perfil adequado" para o desempenho de tal papel.

Não há muitas referências na literatura científica acerca do que seria exatamente este "perfil adequado", muito embora alguns autores tenham se esforçado por listar elementos psicológicos relevantes para uma adoção bem-sucedida. Como exemplo, pode-se citar o trabalho de Wasinski (2015), que enumera alguns desafios como fundamentais a serem alcançados por pretendentes à adoção, antes de concretizarem seu intento. Dentre estes, estão: aceitação da infertilidade (sua e/ou do parceiro); libertar-se do significado de família como apenas associado a laços consanguíneos; informar seus parentes e amigos próximos de sua decisão; estar pronto para aceitar a criança com todas as suas características próprias, de maneira incondicional; criar uma visão e atitude positiva em relação aos pais biológicos da criança, desenvolvendo empatia pelos mesmos, entre outros.

Além disso, existe a preparação destes casais, com o encaminhamento a programas de orientação e grupos de auxílio, sempre procurando otimizar e qualificar os processos de adoção (Shine, 2005). No Brasil, a legislação preconiza que os candidatos à adoção participem de programas oferecidos pela Justiça da Infância e Juventude, visando sua preparação psicológica e a orientação dos mesmos (Lei n $\left.{ }^{\circ} 12.010,2009\right)$.

Neste âmbito de atuação profissional, os psicólogos lançam mão de seus instrumentos e métodos para realizar a avaliação destes pretendentes à adoção, na tentativa de alcançar o máximo de informações e de indicadores que permitam a elaboração de inferências a respeito das chances de sucesso desse processo. Além disso, o psicólogo irá realizar intervenções necessárias para o estreitamento dos vínculos familiares entre pais e filhos adotivos (Paiva, 2004). Trata-se de tarefa bastante complexa, exigindo criterioso trabalho do profissional de Psicologia e seu constante aprimoramento, visando à garantia da qualidade deste tipo de avaliação psicológica num campo de elevada complexidade, pela multiplicidade de variáveis envolvidas.

A adoção é, portanto, tema bastante complexo, conforme apontam alguns autores, por exemplo, Levinzon (2006). Para esta autora a ação de adotar proporciona à criança uma família, um lar onde receberá carinho e cuidados para crescer sadiamente, incluída numa base social segura. Aos pais, a adoção oportuniza que realizem o desejo de ter um filho. 
Em estudo nacional, apresentado por Otuka, Scorsolini-Comin e Santos (2012), são destacados ganhos e possibilidades deste tipo de iniciativa para as crianças que se encontram desprovidas de possibilidades de permanência junto de suas famílias biológicas. Nas palavras dos autores:

“O desafio, portanto, passa pela necessidade de que a nova família seja capaz de oferecer um ambiente seguro e estável no qual a criança possa crescer, identificar-se, tomar contato com a sua história e, enfim, criar a sua própria experiência” (p. 56).

No Brasil, o tema tem despertado interesse de pesquisadores que se dedicaram a estudar a adoção de crianças na perspectiva da Psicologia, produzindo investigações e estudos de caso que contribuem para o incremento do conhecimento na área. Assim, colaboram para que a atuação dos psicólogos esteja suficientemente subsidiada do ponto de vista científico.

Cassin (2000), por exemplo, realizou análise de processos judiciais referentes ao cadastro de pretendentes à adoção no Fórum de Ribeirão Preto (SP), tomando como objeto de estudo seus respectivos relatórios psicológicos. Verificou que a maioria dos candidatos à adoção era composta de casais, brancos, idade em torno de 35 anos, sem filhos, com escolaridade fundamental e média. A maior parte dos casais estava buscando a adoção em função de problemas de infertilidade e almejavam um bebê de até um ano de idade, saudável, e com características físicas semelhantes às suas. No tocante aos procedimentos utilizados na avaliação desenvolvida pelos profissionais de Psicologia, verificou que os aspectos relativos à personalidade dos pretendentes à adoção foram elementos relevantes, seja como subsídio para aprovação tanto quanto para desaprovação dos mesmos. Dentre os atributos diferenciais, considerados elementos favoráveis à adoção, foram destacados por Cassin (2000): controle emocional, disponibilidade para a parentalidade e flexibilidade frente a outros pontos de vista. Por outro lado, o pesquisador destacou carência de critérios objetivos e claros na avaliação psicológica e psicossocial destes casais, e apontou a necessidade de maior transparência em relação aos itens de avaliação realizada nestes processos.

Já Campos e Costa (2004) buscaram investigar fatores que podem interferir no trabalho desenvolvido por psicólogos judiciários no campo da adoção legal de crianças. Segundo as pesquisadoras, a realização do chamado "estudo psicossocial" se mostra causador de desconforto, medo e ansiedade, inclusive nos profissionais que realizam os estudos e acompanham os casos. As autoras destacam ainda que fatores subjetivos podem interferir negativamente na realização deste tipo de trabalho, sendo que, segundo os resultados de sua 
pesquisa, muitas vezes os próprios profissionais reconhecem uma postura preconceituosa, estereotipada e até mesmo moralista, em relação à concepção sócio-histórica da família. Tais concepções seriam norteadas, entre outros fatores, pelos próprios valores socioculturais dos profissionais responsáveis pela avaliação destes pretendentes à adoção (Campos \& Costa, 2004). Estes aspectos apontam elementos preocupantes nesse contexto e a necessidade de investimentos em pesquisa que possam subsidiar a realização de avaliações psicológicas cientificamente fundamentadas, evitando a possível ocorrência de abusos de poder ou decisões pouco embasadas na realidade.

Mariano e Rossetti-Ferreira (2008) realizaram estudo semelhante ao de Cassin (2000), analisando processos judiciais referentes à adoção de crianças na cidade de Ribeirão Preto (SP). Verificaram que a maioria dos adotantes pertencia às camadas econômicas baixa e média, e teriam relatado, dentre as principais motivações para a adoção, a infertilidade, assim como verificado por outros pesquisadores (Cassin, 2000; Sonego \& Lopes, 2009). As autoras destacaram a necessidade de investigações sobre as motivações dos adotantes, a fim de que se possa explorar e compreender seus possíveis efeitos sobre as relações pais-filhos adotivos.

Em seu trabalho com pretendentes à adoção em situação de espera pela criança, Huber e Siqueira (2010) versaram sobre a "gestação adotiva". Este processo dar-se-ia durante o período de espera pela criança/adolescente, configurando-se numa gestação simbólica, marcada por angústias e fragilidades, durante a qual seria necessário elaborar uma série de fantasias, valores, desejos e expectativas em relação à parentalidade. Os pretendentes à adoção ainda revelaram, na citada investigação científica, reconhecer que precisam de ajuda e apoio profissional para superarem estas preocupações e dilemas internos. Segundo este trabalho, na opinião dos indivíduos, a responsabilidade por tais serviços deveria ser dos profissionais da Psicologia Jurídica, diretamente envolvidos nos processos de adoção.

As pesquisas brasileiras abordadas até o momento destacaram, primeiramente, a complexidade dos fatores envolvidos na adoção de crianças, ao mesmo tempo em que apontaram para a relevância da pormenorizada investigação dos aspectos psicológicos relacionados à decisão de adotar uma criança/adolescente. Outro ponto levantado é a necessidade do estabelecimento de embasados critérios técnico-científicos para fundamentar as ações dos psicólogos nesta área, evitando avaliações arbitrárias e pouco fidedignas. Destacou-se ainda a necessidade de acompanhamento psicológico destes pretendentes à adoção, visando sempre proteger os vínculos estabelecidos entre pais e filhos adotivos.

Num panorama amplo, considera-se que o encaminhamento de crianças para famílias substitutas, seja como medida definitiva (adoção) ou provisória (guarda, tutela), configura-se 
como potencialmente atenuador de riscos ao desenvolvimento de crianças cujas histórias de vida trazem marcas de vitimização, abandono e ruptura de vínculos. No entanto, embora o encaminhamento de crianças para famílias substitutas seja considerado tecnicamente e judicialmente uma medida de proteção, há elementos que apontam para possíveis riscos ao desenvolvimento nestes processos, relacionados a diferentes situações e contextos, conforme indicam alguns pesquisadores.

Lee e Matarazzo (2001), por exemplo, verificaram que crianças adotivas são frequentemente levadas a serviços de saúde mental no Brasil, além de referirem que tal constatação foi apresentada por diversos outros pesquisadores nos últimos 30 anos. Segundo os autores, esta observação sugere que, mesmo sendo benéfica à maioria das crianças e dos adolescentes adotivos, a condição de viver em um lar substituto parece aumentar, de alguma forma, a possibilidade de desenvolvimento de conflitos psicológicos.

Segundo Chaves (2002), apesar de não haver consenso na literatura científica, a maior parte das pesquisas considera existir associação positiva entre vulnerabilidade psicológica e histórico de adoção. Tais pesquisas apontam para diversas origens de referidos problemas: fatores biossociais ou genéticos, patogênese dos processos de adoção, efeitos em longo prazo dos cuidados pré-adotivos e problemas nas relações pais-criança adotiva. Assim, são destacadas as possibilidades de interferências de diversos fatores como possíveis geradores de problemas nas adoções: tanto aqueles relativos à origem biológica da criança, como elementos relativos aos pais adotivos, seus sentimentos e modos de se relacionar com os filhos que acolhem.

Ainda no estudo de Chaves (2002), em sua comparação dos cuidados maternos em mães adotivas e biológicas, verificou tendência das mães adotivas a apresentarem comportamentos que denotavam maior intrusividade e responsividade, elementos que podem vir a interferir na capacidade de individuação do bebê, afetando seu processo de separação. Por outro lado, no mesmo estudo, identificaram sinais de maior expressão de afeto por parte das mães adotivas no contato com seus filhos, quando comparadas às mães biológicas.

Como possível explicação para estes resultados, a autora aponta que as expectativas das mães adotivas, em sua trajetória diferenciada rumo ao exercício da maternidade, podem conduzi-las a um nível de envolvimento mais intenso com seu bebê, resultando em maior intrusividade e maior necessidade de sucesso no desenvolvimento de seu filho, e, portanto, de seu desempenho como mãe (Chaves, 2002). Trata-se de uma situação peculiar de maternidade, envolvendo aspectos afetivos que precisam ser devidamente examinados e cuidados ao longo deste processo. 
Ao analisarmos produções científicas brasileiras voltadas para os processos de adoção, verifica-se a relevância do exame de aspectos relativos aos sentimentos e comportamentos de pais adotivos. Isso porque esses componentes têm sido apontados como fatores cruciais nas possibilidades de sucesso das adoções, bem como relevantes elementos intervenientes no desenvolvimento e saúde mental das crianças encaminhadas para famílias substitutas.

No âmbito internacional também é possível identificar interesse dos pesquisadores em um olhar mais atento para os pais adotivos, pois suas características de personalidade e comportamento podem interferir sobre o desenvolvimento psicossocial dos filhos. Neste contexto, pesquisadores de diversas partes do mundo têm focalizado indicadores de efeitos ambientais (convivência com os pais adotivos) sobre o desenvolvimento emocional das crianças, agindo de forma a proteger ou exacerbar os riscos biológicos para psicopatologias e/ou abuso de substâncias, por exemplo. Assim, tem sido reconhecida a relevância da qualidade e estilo da parentalidade adotiva na proteção das crianças encaminhadas para adoção.

Dentre as características parentais na adoção, a saúde mental dos pais foi apontada por alguns autores como elemento interferente no relacionamento conjugal e familiar, podendo atuar negativamente sobre o desenvolvimento dos filhos que já possuem histórico genético favorável a psicopatologias ou vitimização prévia (Pemberton, Neiderhiser, Leve, Natsuaki, Shaw, Reiss, \& Ge, 2010; Roisko, Wahlberg, Hakko, Wynne, \& Tienari, 2011). Deste modo, o sofrimento emocional dos pais adotivos se mostrou elemento comprometedor da qualidade do diálogo familiar e também da supervisão exercida junto aos filhos, exacerbando vulnerabilidades já existentes.

Outro aspecto enfocado por estudiosos em âmbito internacional, no que se refere às filiações adotivas, são os comportamentos parentais, tais como disciplina excessivamente rígida ou padrão educacional muito diretivo e controlador. Tais características podem ser consideradas como potencialmente prejudiciais nos casos de crianças adotivas que não apresentam riscos biológicos específicos para problemas de comportamento ou psicopatologias (Leve, Harold, Ge, Neiderhiser, Shaw, Caramella, \& Reiss, 2009; Lipscomb, Leve, Shaw, Neiderhiser, Scaramella, Ge, Conger, Reid, \& Reiss, 2012; Riggins-Caspers, Cadoret, Knutson, \& Langbehn, 2003). Assim, os estilos parentais se mostram como fatores relevantes para o desenvolvimento infantil nas filiações adotivas, podendo configurar-se como elementos facilitadores ou promotores de dificuldades, a depender das situações vivenciadas nas famílias.

Especificamente no caso de crianças que possuem histórico de vitimização de ordem sexual e/ou negligência, ou ainda aquelas que frequentaram diferentes lares substitutos antes do encaminhamento para adoção, há estudos apontando que estas requerem maior estabilidade 
emocional e conjugal por parte dos pais adotivos, bem como atitudes de acolhimento e supervisão suficientes, visando minimizar as possibilidades de concretização dos riscos existentes (Simmel, 2007). Tais apontamentos sugerem a importância dos pais adotivos terem conhecimento acerca do histórico de vida de seus filhos, a fim de que possam manejar a situação de forma adequada, buscando assim a efetiva proteção destes infantes.

A partir desses apontamentos oriundos de publicações científicas internacionais da área, é possível concluir que, assim como ocorre no âmbito das famílias biológicas, o estilo da parentalidade adotiva exercida, a saúde mental dos adotantes e suas atitudes em relação aos filhos se mostram elementos relevantes (como fatores intervenientes) no desenvolvimento e saúde mental das crianças encaminhadas para adoção. Fica reiterada, portanto, a relevância de adequado processo de seleção, preparo e acompanhamento psicológico dos pais adotivos. Nesse processo, os elementos relativos à saúde mental e características comportamentais e de personalidade dos pais adotivos surgem como foco relevante de investigação e intervenção psicológicas, como forma de garantir às crianças adotivas a inserção num ambiente emocionalmente adequado e que possa protegê-la, garantindo o suprimento de suas necessidades, inclusive afetivas.

Diante do exposto, neste momento destaca-se um dos aspectos relevantes apontados pelos pesquisadores desta área de estudo (Cassin, 2000; Mariano \& Rossetti-Ferreira, 2004; Scorsolini-Comin, Amato \& Santos, 2006; Sonego \& Lopes, 2009): o perfil dos candidatos pretendentes à adoção. Em sua maioria são pessoas que vivenciam situação de infertilidade, seja ela primária (nunca tiveram filhos) ou secundária (já geraram crianças, mas no momento não conseguem). Tais indivíduos buscam a Justiça para alcançarem a possibilidade de se tornarem pais por meio da adoção, uma vez que suas condições biológicas limitam sua realização pessoal enquanto pais, naquele momento de vida.

A seguir, portanto, focalizar-se-á a questão das possíveis relações entre a adoção e a infertilidade, a partir das evidências da literatura científica da área da Psicologia.

\section{I.2. Adoção e Infertilidade: evidências da literatura científica}

\section{I.2.1. Infertilidade associada a sofrimento emocional e elemento motivador da adoção}

Num olhar para a temática da infertilidade no âmbito nacional de pesquisas científicas, Nascimento e Térzis (2010) ressaltam que tem havido, nas últimas décadas, um fenômeno do adiamento da constituição das famílias, seja em função de projetos de trabalho ou de outros 
planos tidos como condição para criar a prole. No entanto, muitas vezes este adiamento encontra obstáculos nas condições biológicas relacionadas à reprodução, pois apesar do avanço das técnicas de reprodução assistida pode resultar na impossibilidade de concepção de uma criança.

Conforme referidos autores, de acordo com a Organização Mundial de Saúde, o casal pode ser considerado infértil após um ano de tentativas frustradas de conceber uma criança. Destacam que a infertilidade tende a aumentar com a idade e que as chances de uma mulher engravidar reduzem drasticamente após os 35 anos. Embora o homem, do ponto de vista biológico, não esteja tão limitado do ponto de vista etário para a paternidade, no geral após os 40-50 anos tem sua vitalidade e disposição diminuída para os cuidados exigidos por uma criança pequena. Tal situação pode trazer dificuldades na família quando associada à tendência atual de postergação da parentalidade (Nascimento \& Térzis, 2010).

A experiência da infertilidade tende a ser traumática, segundo Nascimento e Térzis (2010), pois rompe com as chamadas "transições normais" da vida de um casal, podendo com isso gerar prejuízos diversos na vida conjugal. Ainda, no estudo desenvolvido por estes autores, foram verificados sentimentos de culpa, inferioridade e baixa autoestima nos casais inférteis, confirmando evidências de que a infertilidade pode representar profunda ferida emocional.

O trabalho de Trindade e Enumo (2002) examinou repercussões sociais relacionadas à infertilidade feminina. Destacou que, mesmo com as muitas transformações e avanços no tratamento contra a infertilidade, "a condição de infértil tem se constituído em um anátema para as mulheres, atravessando séculos de história e rompendo limites geográficos e culturais" (Trindade \& Enumo, 2002, p. 2). Neste contexto, os autores consideram que conflitos emocionais vivenciados por casais inférteis tendem a ser consequência e não causa da infertilidade, e esta tem sido reconhecida como uma das principais variáveis disparadoras de crises na vida pessoal e conjugal. Nas considerações desses autores, há evidências de que a infertilidade se relaciona a diferentes efeitos psicológicos sobre as mulheres, abrangendo desde estresse, sentimentos de perda e prejuízos na autoestima, até problemas para o relacionamento conjugal, implicando em dificuldades no relacionamento social mais amplo.

A experiência da infertilidade pode ser elaborada de diferentes modos, podendo ser agravada, nas considerações de Ramírez-Galvez (2009), quando se adota uma perspectiva reducionista dos processos de reprodução humana a eventos biológicos que podem ser manipulados e fragmentados, às vezes presente no discurso médico. Neste contexto, as técnicas de reprodução assistida assumem o status de plena realização do sonho reprodutivo, 
de um modo considerado normal e natural. A adoção, em contrapartida, poderia ser tratada como forma de aliviar, embora em menor grau, a frustração de casais ou pessoas sem filhos, correndo o risco de se tornar uma forma de satisfação incompleta (Ramírez-Galvez, 2009).

Ao focalizar o estudo das características de pais adotivos, temos no Brasil trabalhos como o de Rosa (2008), que aborda aspectos inconscientes destes genitores. Ao analisar fantasias que podem emergir ao se decidir pela adoção diante da impossibilidade de gerar filhos biológicos, a pesquisadora sugere que os componentes internos exercem interferência no adequado estabelecimento de vínculos com os filhos e, assim, podem desfavorecer a efetivação da adoção afetiva. Segundo a autora:

“Uma gestação simbólica só pode ser realizada com sucesso depois que o luto pelo filho biológico que não veio for trabalhado internamente, para não deixar na vida familiar esse espaço como não-dito, referenciando a todo instante o filho real ao filho ideal. Articulada à idealização dos pais, reafirma-se a rejeição sentida pelo filho, e o ciclo continua" (Rosa, 2008, p. 107).

Há necessidade de intervenções e apoio psicológico junto às famílias adotivas, sobretudo ao se considerar a elevada frequência de adoções disparadas por situação de infertilidade dos pais (Rosa, 2008). Embora existam muitos casais que adotam mesmo possuindo filhos biológicos, a infertilidade, na visão desta autora, pode incluir complicadores afetivos. De seu ponto de vista, possíveis intervenções profissionais deveriam incluir também a família adotante (e não somente as crianças adotadas), com a finalidade de evitar possíveis problemas que ameaçariam o sucesso da adoção.

Maux e Dutra (2009) estudaram casais adotantes nos quais o homem (e não a mulher) era o infértil na relação. Afirmaram que há evidências na literatura nacional que "confirmam o sentido de completude e realização que a maternidade exerce na vida das mulheres, mesmo com todas as mudanças e rupturas em sua imagem e em seu papel social ao longo do tempo" (Maux \& Dutra, 2009, p. 113). Referidos autores versaram sobre a história da maternidade no Brasil e de como o papel materno foi representado ao longo do tempo, bem como suas repercussões sobre a autoimagem e saúde emocional da mulher. De acordo com esses autores, quando o casal se depara com a situação de infertilidade, a histórica relação estabelecida entre a capacidade biológica de conceber um filho e o instinto materno tenderia a promover, na mulher, culpa e responsabilização pelo fracasso de uma não gestação. Prova disso é que, quando um casal não consegue gerar filhos, a mulher é, quase sempre, a primeira a se 
submeter a exames médicos (Maux \& Dutra, 2009). Diante das situações em que as técnicas médicas de reprodução assistida falham, a adoção surge como alternativa para o exercício da maternidade.

Neste contexto, a adoção, embora presente desde a Antiguidade, ainda é considerada por muitos como uma "filiação de segunda linha", levada a cabo por pessoas que não conseguem gerar os próprios filhos. A infertilidade é o motivo mais frequente para casais se inscreverem em serviços institucionais de adoção de crianças (Maux \& Dutra, 2009). As autoras destacam ainda que sentimentos de completude e realização, apontados pela literatura científica como presentes em mulheres que têm filhos, são também descritos pelas mães adotivas.

Levinzon (2006), em seu relato de caso de atendimento psicoterapêutico de pais adotivos, apresenta características comumente presentes na dinâmica psíquica do casal, apontando que muitos procuram tratamento psicológico em função de problemas vivenciados no contato e educação dos filhos. $\mathrm{O}$ artigo ressalta que "a adoção pode ser um problema quando os sentimentos e fantasias inconscientes não estão suficientemente discriminados e elaborados" (p. 25). Destaca que a infertilidade é frequente em um ou em ambos integrantes do casal adotante, e que tal característica exige a renúncia à imagem do filho biológico que se pareceria com eles, para que possam adentrar no mundo da adoção, permitindo, então, a verdadeira ligação com o filho adotivo.

O estudo de Levinzon (2006) também argumenta sobre possíveis problemas na relação entre pais e filhos adotivos quando a infertilidade dos primeiros permanece como ferida narcísica, "que castra a fantasia de continuidade biológica e imortalidade dos pais" (p. 26). Esta vivência, segundo o autor, contribuiria para a existência de sentimentos ambivalentes e até hostilidade inconsciente em relação ao filho adotivo, pois a criança, por si mesma, lembraria a limitação dos pais.

Ghirardi (2008) reforça esta linha de argumentação, destacando que, no caso da adoção motivada pela infertilidade, é necessário avaliar em que medida estas vivências foram devidamente elaboradas pelos adotantes, uma vez que, na ausência deste luto, a experiência adotiva estaria irremediavelmente ligada às perdas. Nestes casos, a criança adotada receberia uma função de aplacar a ferida narcísica dos pais, com a sobrecarga de ter que corresponder a expectativas idealizadas. Neste contexto, segundo a autora, a criança teria a constituição de seu psiquismo e subjetividade colocados em risco, em função de experimentar vivências ameaçadoras no contato com os pais adotivos. 
Em alguns casos, conforme Goia, Diniz e Valente (2010), a adoção claramente se revela como busca de resolução de problemas gerados pela infertilidade. Estes autores também publicaram relato de atendimento psicoterapêutico de um casal de pais adotivos, os quais buscaram ajuda profissional por vivenciarem infertilidade, disfunções no relacionamento sexual e dificuldades no relacionamento conjugal (afastamento interpessoal). Nesse caso, a adoção surgiu como tentativa de resolução dessas dificuldades interpessoais, sem indicadores de genuíno desejo pela maternidade por parte da analisanda. Os autores enfatizaram, por meio deste relato clínico, a necessidade da devida avaliação e acompanhamento psicológico nestes casos, visando à elaboração de perdas vivenciadas pelo casal, preferencialmente antes do início do processo da adoção.

Diante das evidências e das argumentações apresentadas, ainda que breves e relativas à produção científica nacional, ressalta-se a possibilidade de desfechos insatisfatórios em processos de adoção, do ponto de vista psicológico, quando não se dá a devida atenção à infertilidade e seus efeitos sobre o psiquismo das pessoas, deixando-se de examinar suas marcas afetivas. Trata-se, portanto, de relevante temática no âmbito da Psicologia, merecendo a atenção de profissionais e pesquisadores, como proposto na presente investigação.

\section{I.2.2. Evidências da literatura científica internacional}

A hipótese da infertilidade como disparadora da busca de adoção infantil, bem como possível fator interveniente nas relações entre pais e filhos adotivos, apontadas por autores brasileiros (Cassin, 2000; Mariano \& Rossetti-Ferreira, 2008; Sonego \& Lopes, 2009), estimulou, na presente investigação, busca sistemática a respeito deste tema na literatura científica internacional vinculada à Psicologia. Procurou-se identificar pesquisas realizadas em torno desta temática por meio de um levantamento da literatura científica realizado em março de 2017 na base de dados internacional PsycInfo. Foram utilizados os seguintes cruzamentos de termos: "infertility" e "adoptive mothers", depois "adoptive parents" $\mathrm{e}$ "infertility" e, por fim, "mother child relations" e "infertility", englobando o período compreendido entre 2012 e 2017, ou seja, os últimos cinco anos.

Desse processo resultaram 21 artigos em periódicos no período, excluídas publicações duplicadas e/ou em outra modalidade (que não artigos). A maioria das publicações identificadas ocorreu nos anos de 2012 e 2013 (respectivamente com cinco e seis artigos cada). Nos anos seguintes, esse número variou: cinco trabalhos em 2014, três em 2015 e dois 
em 2016, com aparente queda no número de publicações nesta temática ao longo destes últimos anos, nesta base de dados pesquisada.

A metade das publicações identificadas neste levantamento foi desenvolvida em países da Europa, com destaque para a França (quatro publicações) e Itália (duas publicações). Um terço dos trabalhos (32\%) foi realizado na América do Norte (sobretudo EUA), mas houve publicações isoladas originárias de países da Ásia (Israel, Japão e Taiwan) e um artigo produzido na América do Sul (Brasil).

Passaremos a descrever, de modo sintético, o conjunto desses estudos identificados no atual levantamento da literatura científica internacional, de modo a embasar futura análise comparativa entre os achados. A ordem de apresentação dos trabalhos seguirá a lógica de seu conteúdo temático e a sequência cronológica das publicações.

\section{I.2.2.1. Sobre motivações para a maternidade (biológica e adotiva)}

Analisando-se os 21 trabalhos indicados pelo presente levantamento da literatura científica internacional, observou-se que quatro deles buscaram compreender motivações para a maternidade, principalmente adotiva, mas também biológica.

Numa abordagem generalista voltada à compreensão do nível de conhecimento de mulheres adultas, profissionais da saúde, acerca de fertilidade feminina e também de suas práticas pessoais envolvendo métodos contraceptivos, Mortensen, Hegaard, Andersen e Bentzen (2012) examinaram o tema do planejamento familiar envolvendo mulheres da Dinamarca. Os autores referiram, assim como já observado em outros estudos da área, queda nas taxas de natalidade, acompanhada de aumento da postergação da parentalidade nas últimas décadas. Referido fenômeno aumenta os riscos de infertilidade, bem como a probabilidade das pessoas constituírem famílias menores que as inicialmente desejadas, razão para sua pesquisa sobre planejamento familiar. Para este trabalho 863 mulheres entre 20 e 40 anos, profissionais da saúde, responderam a um questionário que abordava informações sobre formação familiar, importância e impacto da maternidade, conhecimento sobre fertilidade, fatores sócio demográficos e histórico reprodutivo.

Os resultados apontaram que a maioria das entrevistadas pretendia ter dois ou três filhos, considerando a maternidade elemento importante em seu planejamento de vida, sendo que apenas a minoria afirmava não desejar ter filhos. Em relação à idade com a qual planejavam ter filhos, cerca de metade tinha intenção de ter seu último filho após os 35 anos, idade na qual há natural declínio da fertilidade feminina. 
Para estas mulheres, os requisitos relatados para formar uma família foram: estar num relacionamento estável, ter completado os estudos, favorável situação financeira, ter emprego e mantê-lo mesmo tendo filhos, acesso a creche pública, a possibilidade de viajar (Mortensen et al., 2012). Diante destes dados, os autores concluem que a maioria das entrevistadas, apesar de serem profissionais de saúde, subestimava o impacto da idade no declínio da fertilidade, ou superestimava as taxas de sucesso de técnicas de reprodução assistida, ao pensar sobre seu próprio planejamento familiar. Os autores apontaram ser necessário maior divulgação realista acerca dos riscos e possibilidades contraceptivas após os 35 anos, como forma de otimizar o planejamento familiar de mulheres na contemporaneidade.

O estudo de Klevan (2012), por sua vez, focalizou a questão racial dentro do rol de motivações envolvendo adoções de crianças. Referido trabalho informou que, no contexto da adoção de crianças nos Estados Unidos, a maioria das adoções inter-raciais envolve pais brancos adotando crianças não brancas. Seu estudo utilizou análise qualitativa para avançar no conhecimento teórico acerca de como os pais adotivos fazem escolhas raciais no momento da adoção. O objetivo primário deste trabalho era compreender como pais adotivos interpretavam retrospectivamente suas trajetórias envolvendo a construção de suas famílias, focalizando diferentes aspectos, dentre eles a infertilidade e a questão racial.

A metodologia utilizada neste trabalho envolveu o instrumento "Life Story Interview", na qual a pessoa entrevistada é solicitada a pensar sobre sua vida como um livro ou romance, descrevendo os capítulos, cenas chave e pontos altos e baixos (Klevan, 2012). Os participantes foram 15 casais heterossexuais que adotaram uma criança após vivenciarem situação de infertilidade, sendo individualmente entrevistados. $\mathrm{O}$ autor concluiu que as trajetórias individuais dos participantes foram decisivas para sua decisão em adotar crianças, destacando a variável racial e dando pouca ênfase à infertilidade como foco de análise, ao menos neste trabalho em específico.

Apesar da infertilidade se encontrar presente na maioria dos casos de busca pela adoção, Bègue (2013) buscou conhecer o perfil e as expectativas inconscientes de pais adotivos sem problemas de fertilidade. Segundo os pesquisadores, na França, a adoção internacional corresponde a $80 \%$ das adoções realizadas no país, ficando atrás apenas dos Estados Unidos e Itália no que se refere ao acolhimento, mediante adoção, de crianças de outros países. Nesse contexto, apenas a minoria das adoções envolvem crianças nascidas na própria França.

Nesta realidade, Bègue (2013) procurou compreender motivações de casais que já têm filhos e que buscam a adoção. Participaram do estudo 52 casais que tinham tanto filhos 
biológicos quanto adotivos, sem histórico de dificuldades para engravidar. Foram realizadas entrevistas individuais semidirigidas, o teste projetivo Desenho da Árvore, seguido do desenho da árvore genealógica de cada família. Seus achados apontaram que as mulheres foram as principais responsáveis pelo surgimento e pela alimentação do planejamento da adoção. Os casais estudados apresentavam características bastante peculiares, tais como: tinham mais filhos biológicos, mais anos de escolaridade e eram participantes ativos de associações de solidariedade, sindicatos ou religiosas.

A partir do método projetivo, os autores ressaltaram ter observado que, nestes casais, tanto homens como mulheres apresentaram sinais de afastamento em relação à realidade, indicadores sugestivos de feridas narcísicas, de desejo de se tranquilizar, de necessidade de apoio, sinais de dependência e insegurança (Bègue, 2013). Já com relação às entrevistas, emergiram elementos como forte valor altruísta, projeto de família numerosa, bem como o desejo de se doar a uma causa nobre.

Além disso, os casais estudados por Bègue (2013) tinham relevantes marcas de tristeza em suas histórias de vida, relacionadas a perdas ocorridas pelo casal ou mesmo durante a infância e adolescência de ambos. As expectativas inconscientes envolvendo a adoção pareceram relacionadas a: reparar a injustiça da perda vivida pelo casal e pela criança adotada, e ainda "pagar um débito" inconsciente pessoal ou transgeracional.

Dentro desta temática das expectativas em relação à maternidade, Wasinski (2015) analisou motivações para adotar no contexto de experiências de vida de casais sem filhos. $\mathrm{O}$ autor destacou que a fertilidade é vista, na sociedade ocidental contemporânea, como virtude naturalmente dada a todos os que alcançam a maturidade sexual. Assim, para a maioria, caberia à pessoa decidir se quer ou não procriar. No entanto, os participantes de seu estudo não tiveram esta possibilidade de escolha, situação que geraria desconforto emocional, bem como dificuldades sociais advindas do constrangimento de não corresponder à expectativa social de formarem uma família biologicamente concebida, gerando o que ele chama de tabu social da adoção. Neste contexto, muitas vezes, a adoção tenderia a ser vivenciada como confirmação social de seu fracasso em procriar, gerando profundo desconforto psicológico.

Seu estudo envolveu entrevistas do tipo narrativas biográficas, nas quais os futuros pais adotivos tinham a oportunidade de falar sobre pensamentos e sentimentos acerca de sua experiência diante da ausência de filhos e da busca pela adoção. Participaram da pesquisa casais inférteis que concluíram procedimentos para inscrição como pretendentes à adoção na Polônia. Os achados apontaram como motivo central para a adoção nestes casais sem filhos: dar amor a uma criança não nascida deles próprios, forte desejo de ter filhos, completar a 
família (vista como incompleta sem filhos), oferecer vida melhor para uma criança abandonada, garantir a continuidade e a transmissão dos modelos e valores familiares (Wasinski, 2015).

Nota-se, desse modo, que o tema dos motivos que levam à busca pela adoção perpassa diferentes trabalhos científicos contemporâneos, pautados por variadas estratégias técnicas. No entanto, os artigos foram unânimes em apontar a relevância do exercício da maternidade (biológica e adotiva), com determinantes psíquicos e sociais nem sempre conscientes.

\section{I.2.2.2. Sobre infertilidade, reprodução assistida e suas repercussões}

Neste tópico serão abordados estudos internacionais, identificados no presente levantamento bibliográfico, voltados para as possíveis repercussões emocionais da reprodução assistida em mulheres com histórico de infertilidade, bem como sobre o relacionamento entre mães e filhos concebidos via intervenções médicas. Esta temática foi a mais frequente neste levantamento, incluindo 10 artigos do total de 21 identificados.

Um dos trabalhos apresentou análise de caso clínico de uma mulher com infertilidade, desenvolvido numa abordagem psicanalítica (Kite, 2012). A autora, enquanto psicanalista, atendeu esta mulher desde o período em que descobriu e buscou tratar a infertilidade, bem como durante a gestação e parto do bebê, e ainda após o nascimento, quando a paciente chegou a levar concretamente o bebê para a análise, consigo. O estudo ilustra as fantasias da paciente acerca da infertilidade, percebida como sinal de que seria mãe ruim e tóxica, tal como foi a sua própria. Em face de abortos espontâneos vivenciados pela analisanda, o artigo retrata sua profunda frustração e desesperança, beirando um quadro de depressão psicótica, e alcançando pensamentos suicidas. Superado o momento de crise, a paciente acabou engravidando naturalmente, e deu à luz a um menino, o qual, conforme a autora: "em sua mente, salvou sua sanidade, a redimiu como pessoa e agora, aos três anos de idade, representa sua própria vida e seu lugar legítimo nela" (Kite, 2012, p. 503). A autora ressaltou o relevante papel do filho no mundo interno desta paciente, após o sofrido período de vivência e superação da infertilidade.

Um grupo de pesquisadores do Japão relatou sua trajetória para elaborar um protocolo técnico adequado para estimular e promover o exercício do papel materno entre mulheres submetidas à reprodução assistida (Iwata, Mori, Maekawa, Maehara, Sakajo, Ozawa \& Morita, 2012). Os autores descrevem no artigo os passos para a produção deste material, partindo do levantamento bibliográfico sobre o tema, até a produção de um modelo piloto 
deste material, produzido em colaboração com duas mulheres grávidas (uma por reprodução assistida) e sete enfermeiras que atendiam pacientes nestes tratamentos. O modelo piloto deste portifólio foi testado, com positivo feedback, sendo o resultado final patenteado no Japão.

Este Portifólio para a Maternidade (por reprodução assistida) ficou constituído como um livreto de 40 páginas, que continha uma seção informativa e outra com comentários das pacientes. Os autores sugeriram o uso deste material junto a mulheres grávidas, sobretudo no primeiro trimestre da gestação, durante os exames pré-natais, nos quais seriam submetidas a intervenções da enfermagem voltadas para promover informações e estimular práticas para o exercício do papel materno. Segundo os pesquisadores, para as mulheres que concebem via reprodução assistida, este tipo de intervenção faz-se especialmente necessária, dada a forma especial pela qual conceberam. Argumentaram que a infertilidade prévia e a reprodução assistida poderiam impactar negativamente o exercício dos cuidados maternos com o bebê, razão para a proposta de uso deste portifólio nesse contexto.

Em outro trabalho desenvolvido com mulheres inférteis submetidas a atendimento psicoterapêutico, Weismann-Arcache (2013) analisou o impacto de técnicas de reprodução assistida sobre as teorias sexuais infantis e familiares. Aspectos do significado inconsciente da infertilidade materna e do tratamento médico para reprodução foram levantados pela autora, a partir do atendimento grupal dos filhos concebidos. Questões edípicas foram discutidas neste trabalho, ilustrando-as ao examinar uma filha adolescente perguntando à mãe sobre a qualidade de seus óvulos, diante das dificuldades para a mesma conceber um segundo filho. A autora discute questões sobre culpa materna diante da infertilidade (ainda que secundária) e o impacto destes sentimentos sobre o papel representado pelos filhos no contexto das relações familiares.

Ainda neste tema relacionado à reprodução assistida e suas possíveis repercussões emocionais sobre mulheres com histórico de infertilidade, identificou-se trabalho desenvolvido em Taiwan (Kuo et al., 2013). Investigaram apego materno-fetal em diferentes momentos da gestação em mulheres que engravidaram mediante fertilização in vitro. $\mathrm{O}$ desenvolvimento de significativo vínculo afetivo entre a mãe e o feto, durante a gestação, é elemento relevante para a qualidade das relações mãe-filho e também para a saúde emocional da criança nos anos seguintes, pouco se sabendo sobre como se dá este vínculo em mulheres submetidas à reprodução assistida. Assim, foi realizado estudo longitudinal, envolvendo a avaliação das gestantes em três momentos diferentes da gravidez, a saber: nove, 12 e 20 semanas de gestação. Foram estudadas 160 mulheres que haviam concebido mediante fertilização in vitro, recrutadas em um centro de medicina reprodutiva, avaliadas por uma 
bateria de instrumentos de autorrelato (Maternal-Foetal Attachment Scale; Symptoms Checklist; Pregnancy-related Anxiety Scale; Social Support Apgar; Chinese childbearing attitude Questionnaire; Awareness of Foetus Scale). Seus achados apontaram que o apego entre mãe e feto cresceu com o passar da gestação. Os autores ponderaram como relevante uma educação pré-natal desde os primeiros estágios da gestação, incorporando mais informações sobre o desenvolvimento do bebê a fim de que a mãe possa, assim, visualizar mentalmente seu futuro filho e desenvolver seu vínculo com o mesmo.

A questão da idade ao conceber e seu impacto no exercício da maternidade foi investigada por Guedes e Canavarro (2014), em Portugal. Descreveram o ajustamento psicossocial de mulheres primíparas de idade avançada, bem como seus parceiros, em comparação a grupo controle, abordando sua transição para a parentalidade. Assim como em outros estudos já mencionados, estes autores constataram o aumento da idade das mães ao terem seu primeiro filho, situação associada com maior amadurecimento psicológico e estabilidade financeira, mas também com desafios específicos, principalmente os relacionados à fertilidade, bem como a dificuldade em coordenar funções maternas com demandas profissionais. Os pesquisadores argumentam que, muitas vezes, mulheres com 35 anos ou mais no momento do nascimento do seu primeiro filho experimentam alto nível de ansiedade e maiores dificuldades para se adaptarem aos papéis parentais. Relataram ser comum declínio na qualidade do relacionamento conjugal nos últimos meses da gestação e nos primeiros meses pós-parto, bem como diminuição do nível geral de satisfação com a vida. Esta pesquisa contou com 58 casais, formando o grupo de primíparas de idade avançada (35 anos ou mais no parto) e 41 casais no grupo de comparação (mulheres primíparas entre 20 e 34 anos). Cada integrante dos casais respondeu ao Brief Symptom Inventory-18, ao Eurohis-QoL-8 e ao Dyadic Adjusment Scale. As avaliações mediante autorrelato ocorreram durante o terceiro trimestre da gravidez, e também após um mês e seis meses do parto.

$\mathrm{O}$ estudo encontrou mais similaridades que diferenças entre os grupos de primíparas, no que se refere ao ajustamento psicossocial durante a transição para a parentalidade. Os autores ponderaram que a similaridade entre os grupos, no que se refere às variáveis sociodemográficas e status de relacionamento, pode ter contribuído para as convergências encontradas. O estudo observou que a parentalidade pode ser mais estressante para as mães do que para os pais, uma vez que as mulheres experimentam mudanças mais concretas e intensas que os homens. Desde a vivência concreta da gestação em si até o fato de deixarem ou diminuírem atividades laborais para cuidar dos filhos, as mulheres relataram maiores níveis de ansiedade e depressão, quando comparadas aos pais. 
O artigo de Leben-Loison (2014) abordou a questão da infertilidade feminina e suas associações com a relação mãe-filha. Este trabalho teve enfoque psicanalítico, baseado em estudos de caso de atendimento psicoterapêutico de duas mulheres inférteis, sem causas médicas conhecidas. A autora explora as relações destas mulheres com suas mães, bem como os aspectos inconscientes envolvidos nestas relações. $\mathrm{O}$ estudo apresenta e discute questões relacionadas ao mundo interno dessas mulheres inférteis, tais como a impossibilidade das mesmas usarem seu pai para se separarem de suas mães, hipotetizando que a infertilidade funcionou para elas como uma forma de conseguirem se diferenciar de suas mães.

Ainda dentro da referida temática, Accioly, Patti, Peron e Barbieri (2014) abordaram aspectos inconscientes ligados ao desejo pela maternidade e às dificuldades do feminino em lidar com a infertilidade. Referidos autores destacaram que, do ponto de vista da Psicanálise: "a experiência da infertilidade pode promover um abalo na estrutura narcísica do sujeito, pois o projeto de imortalidade do eu e do casal encontra-se ameaçado, abalando os referenciais narcísicos de cada sujeito" (p. 388-389). Para este trabalho foram entrevistadas 200 mulheres em tratamento de reprodução assistida, com idade entre 18 e 43 anos, em variadas condições sociodemográficas. Quatro entrevistas (abordagem psicanalítica) foram realizadas com cada participante, num contexto de diagnóstico e avaliação de potenciais, efetivadas anteriormente ao início do tratamento de reprodução.

Dentre os resultados deste estudo destaca-se a observação, em uma das participantes, de associação entre o desejo de ter um filho e a busca de uma identificação feminina por meio da maternidade. Retomando textos de Freud, os autores mencionaram que "a maternidade viabilizaria a abertura do caminho à feminilidade" (Accioly, Patti, Peron, \& Barbieri, 2014, p. 390). Entretanto, diante da infertilidade, tem-se o impedimento à realização desse desejo e a impossibilidade de tornar-se mulher por esta via. Dentre as conclusões do artigo destaca-se a observação de que a infertilidade apareceu, em muitas das mulheres, como falta causadora de imenso sofrimento psíquico, expresso em grande mal-estar e prejuízos de ordem biopsicossocial.

No campo das técnicas de reprodução assistida, Chen e Landau (2015) desenvolveram em Israel um estudo voltado para compreender implicações psicossociais, em longo prazo, do nascimento do primogênito após a idade fértil natural, mediante reprodução assistida. Os autores destacam a reprodução assistida como forma de assegurar às mulheres a possibilidade de vivenciarem a maternidade (ainda tida como um dos principais papéis femininos na atualidade, sobretudo em Israel) mesmo após a idade fértil ou diante de problemas na fertilidade. 
Em referido país, por questões culturais e religiosas, a infertilidade se mostra especialmente ligada a um senso de anormalidade e baixa autoestima, sobretudo entre mulheres (Chen \& Landau, 2015). Tanto que, conforme os autores, as políticas de saúde pública garantem acesso total e irrestrito a tratamentos de reprodução assistida até que duas crianças tenham nascido, como garantido por lei no país. A questão da idade ao conceber foi levantada no artigo, relacionada à tendência contemporânea em postergar a maternidade, também observada em Israel.

Este estudo de Chen e Landau (2015) seguiu abordagem qualitativa, a partir de entrevistas analisadas num paradigma construtivista-naturalista. Avaliou 20 mulheres, com idade média de 45 anos ao nascer seu primeiro filho, concebido mediante reprodução assistida. Os resultados apontaram que o senso de anormalidade referido pelas participantes foi sentido por elas próprias em função da gestação e parto em idade mais avançada, mas também foi percebido por seus filhos. Por estas razões, os autores sugerem ser fundamental aconselhamento a mulheres que pretendem engravidar após a idade fértil, a fim de que tais sentimentos sejam devidamente acolhidos e trabalhados, evitando sua transmissão intergeracional.

No trabalho de Monzani (2015), o enfoque foi dado aos aspectos psicológicos envolvidos na inseminação artificial com doador. Trata-se de um estudo de caso que retrata o longo tratamento psicoterapêutico de uma criança nascida por essa técnica reprodutiva. $\mathrm{O}$ autor discorre sobre o rápido crescimento e banalização da procriação assistida por técnicas médicas em casos de infertilidade, sobretudo a partir da dissociação que é introduzida nestes procedimentos entre sexualidade e procriação. Segundo o autor, este processo transformou totalmente as representações de filiações e relações de parentesco, levantando questões do tipo: “o que é uma mãe?”, “o que é um pai?”, ou ainda “o que é uma família?” Segundo este autor, a filiação via inseminação artificial com doador compartilha muitas características com a filiação via adoção e, assim como outras técnicas de reprodução assistida, engendram questões específicas para as famílias, muito embora, segundo ele, não sejam necessariamente determinantes para o destino dos filhos que chegam por estas vias.

Monzani (2015) revisa diversos estudos sobre as vidas futuras das crianças nascidas por meio desta forma específica de reprodução assistida, discutindo o tema a partir de um ponto de vista psicanalítico, elencando aspectos como o status psíquico do pai estéril, particularmente em relação a seu filho durante o período da adolescência. No estudo de caso clínico apresentado, o autor discorre sobre as dificuldades encontradas pelo seu paciente e as relaciona às especificidades de ser geneticamente filho de um pai desconhecido, diferente do homem que exerce funções paternas em seu cotidiano. Algumas destas questões podem estar 
presentes também nas relações de pais e filhos adotivos, passando pela elaboração do luto pela infertilidade (no caso, paterna), e suas possíveis repercussões sobre o desenvolvimento e vivência da sexualidade do filho, na adolescência.

Ainda com foco na análise de concepções sobre a infertilidade, Fernandez-Sola et al. (2016) buscaram descrever e compreender experiências e percepções de mulheres submetidas a um exame denominado histerossalpingografia. Este trabalho corresponde a um estudo qualitativo do tipo fenomenológico, a partir de entrevistas abertas com dez mulheres espanholas (entre 30 e 37 anos, em sua maioria com nível educacional médio ou alto), com diagnóstico de infertilidade, submetidas ao referido exame, conhecido por ser bastante doloroso e temido pelas pacientes. Dentre os resultados apresentados neste estudo merece destaque a observação do significado atribuído à maternidade por essas mulheres. A maternidade emergiu como objetivo de vida para estas participantes, bem como algo de que necessitavam para se sentirem completas como mulheres. Em associação a estas constatações, a infertilidade surgiu, no discurso destas mulheres, associada a diversos sentimentos negativos, como culpa por ter protelado a gravidez, além de preocupação e medo de falharem no intuito de gerar e dar à luz um filho, além de ansiedade, desesperança, raiva, estresse e frustração. Estas mulheres vivenciavam sua infertilidade de forma a acreditar ser algo que não deveria ser tornado público, razão pela qual falavam pouco deste problema, guardando seus sentimentos para si mesmas.

Mais uma vez é possível notar diversidade metodológica e técnica ao estudar o tema da infertilidade e suas repercussões, sobretudo diante de tratamentos médicos com objetivo de possibilitar a gravidez (técnicas de reprodução assistida). Apesar dessa variedade de abordagens, parece existir consenso na literatura científica da área com relação ao impacto que a infertilidade exerce nas pessoas, sobretudo em mulheres, em diferentes contextos socioculturais, motivando busca por procedimentos médicos para possibilitar a experiência da maternidade. Em complemento, os profissionais da área médica destacam a relevância das variáveis psicossociais envolvidas no tratamento da infertilidade e no exercício da maternidade por meio de reprodução assistida, com pontos de similaridade aos processos de adoção, constituindo campo complexo de estudos, ainda insuficientemente explorado.

\section{I.2.2.3. Sobre dinâmica familiar na adoção}

A partir do levantamento da literatura científica internacional ora realizado foi possível identificar quatro artigos voltados ao estudo da dinâmica familiar em casos de 
adoção. Alguns abordaram o relacionamento conjugal, enquanto outros examinaram relações entre pais e filhos adotivos.

A dinâmica familiar e emocional e seus possíveis efeitos no relacionamento entre pais e filhos adotivos foi objeto do artigo de Callegari, Fusacchia e Re (2012). O estudo focalizou o período da adolescência, argumentando sobre mudanças inerentes a esta etapa, onde as alterações no desenvolvimento físico, social e psicológico exigem elaboração de diversas emoções e alterações no humor. Referido cenário cria desafios específicos para pais adotivos, que lidam com crianças que foram removidas de sua família biológica e podem trazer consigo marcas afetivas destas rupturas.

O referido artigo apresenta casos clínicos nos quais os filhos adotivos revivem dolorosas memórias de ausência de amor e afeto, bem como lidam com questões novas referentes à sexualidade, trazidas à baila pelo advento da puberdade. Como resultado, Callegari, Fusacchia e Re (2012) relataram que os pais adotivos podem vivenciar níveis elevados ou até mesmo insustentáveis de ansiedade, adotando atitude defensiva em relação aos filhos, chegando a pensar em removê-los para instituição de acolhimento por não conseguirem lidar com a situação. O trabalho destaca que estas situações de devolução de filhos adotivos adolescentes mostram-se ligadas às próprias experiências pessoais dos pais, as quais não foram devidamente consideradas e manejadas durante o estágio de procedimentos avaliativos para adoção. Os autores levantam questões sobre características de personalidade do casal adotante, tais como perfis narcisistas, os quais estariam ligados a sua decisão por adotar e que também, por outro lado, estariam relacionadas a este insucesso na adoção.

Numa perspectiva psicanalítica, este trabalho evidenciou, por casos clínicos, a necessidade dos futuros pais adotivos elaborarem suficientemente suas próprias questões pessoais, sobretudo emoções e fantasias que permeiam a infertilidade. Com isso, os autores afirmam que diminuiriam as chances de emergência das próprias fantasias infantis ou edípicas (comprometedoras do vínculo entre pais-adolescentes) ao encararem a adolescência dos filhos (Callegari, Fusacchia \& Re, 2012).

Nesta mesma linha investigativa, Bejenaru e Roth (2012) focalizaram a típica família adotiva no contexto da Romênia, com o objetivo de explorar suas demandas específicas durante diferentes estágios do processo de adoção, bem como os recursos sociais e psicológicos usados pelos pais adotivos durante o processo de adaptação. Este estudo tomou como base a chamada "teoria do desenvolvimento familiar", que descreve as mudanças que ocorrem dentro de uma família ao longo dos estágios de seu ciclo de vida, bem como as 
respostas familiares de adaptação e ajustamento, ou seja, recursos do meio familiar para lidar com situações desafiadoras e estressantes.

Os autores destacaram que a adoção teria como função trazer a família para o escopo da normalidade, uma vez que a infertilidade a havia retirado deste curso. Segundo este trabalho, o diagnóstico da infertilidade, seguido por tratamentos e tentativas falhas de conceber, bem como a decisão por adotar, o processo da adoção em si e as incertezas e ansiedades que permeiam esta trajetória, associados às atitudes de familiares e amigos diante destes desafios, são elementos que afetam a família nos primeiros estágios de sua formação, e merecem a atenção de pesquisadores. Em sua perspectiva teórica, a adoção em si criaria nos pais uma série de dúvidas e incertezas acerca do estabelecimento do vínculo emocional com o filho, e sobre o que seria um comportamento adequado deles próprios, enquanto pais adotivos. Outros fatores geradores de estresse nestas famílias seriam a revelação para a criança de sua origem adotiva, bem como a curiosidade dos filhos sobre sua família biológica. Diante disso, segundo os autores, a ausência de adequado preparo e de acompanhamento destes pais poderia contribuir para acentuação do estresse e para o fracasso da adoção em si.

Bejenaru e Roth (2012) estudaram nove mães adotivas, com filhos de idade entre cinco meses e cinco anos, realizando entrevistas narrativas, examinadas qualitativamente por meio da análise de conteúdo temática. Dentre os resultados apontados, os autores ressaltaram que o afeto manifesto pelos filhos em relação aos pais adotivos é um dos principais recursos favoráveis ao estreitamento destas relações. Por outro lado, observaram evitação, por parte dos pais adotivos, em falar abertamente com os filhos sobre a adoção em si e sobre sua família biológica, com o objetivo de diminuir o estresse familiar, situação que pode gerar problemas futuros.

Já no trabalho de South, Foli e Lim (2013) foram explorados possíveis preditores da satisfação com o relacionamento conjugal em mães adotivas. Os autores argumentaram que os efeitos da transição para a parentalidade (em pais biológicos) já foram foco de muitos estudos, entretanto com menor investimento em pesquisas voltadas para este tema com pais adotivos. Os pesquisadores argumentam que o declínio na satisfação conjugal com a chegada do primeiro filho biológico é reconhecido na literatura científica da área, mas não se sabe ao certo qual o impacto da chegada do filho adotivo sobre o relacionamento conjugal, embora alguns estudos apontem para aumento de depressão e insatisfação conjugal também entre pais adotivos. Trata-se, segundo os autores, de relevante tema de pesquisa, uma vez que a qualidade do relacionamento conjugal tende a impactar a saúde mental e bem-estar dos filhos (South, Foli \& Limm 2013). 
Neste contexto, avaliaram 251 mães que haviam adotado uma criança nos últimos 24 meses, recorrendo aos dados da forma reduzida do instrumento Dyadic Adjustment Scale (DAS-7). Esta escala focalizou especificamente alguns fatores de vulnerabilidade (envolvendo variáveis demográficas e de saúde mental), processo da adoção (entusiasmo e apoio do cônjuge, percebidos pela mãe) e estressores (tipo de adoção, etnia da criança adotada, se a criança possuía necessidades especiais, se havia histórico de infertilidade, entre outros aspectos). Os resultados apontaram como significativos preditores de satisfação com o relacionamento: maior status socioeconômico e maior apoio e entusiasmo do parceiro com a parentalidade adotiva. Já a infertilidade e os fatores relacionados com o processo da adoção em si tiveram menor influência sobre a satisfação das mães com seu relacionamento conjugal após a chegada do filho adotivo.

Um dos trabalhos ora identificados, desenvolvido na Itália (Pace et al., 2014), buscou estudar casais que buscavam a adoção, focalizando o apego ao parceiro como variável relevante para o sucesso do processo da adoção. Participaram da pesquisa 39 casais sem filhos e pretendentes à adoção, além de 39 casais como grupo de comparação, todos com idade entre 35 e 45 anos, avaliados por meio do Adult Attachment Interview (AAI) e Current Relationship Interview (CRI). Houve diferenças estatisticamente significativas entre os grupos no que se refere a índices de apego seguro ao parceiro, sendo que os futuros pais adotivos apresentaram maiores valores nessa variável comparativamente aos que não pretendiam adotar. No geral, os casais adotantes mostraram valorizar mais o apego nos relacionamentos, quando comparados aos não adotantes, elemento que foi considerado importante para uma adoção bem-sucedida.

Em síntese esses quatro estudos identificados no atual levantamento da literatura científica apontaram efeitos da adoção na dinâmica familiar. As perspectivas dos estudos foram diversas, porém depreende-se consenso sobre a interação entre relações interpessoais na família e seu impacto nos processos de adoção, reafirmando a necessidade de consideração destas variáveis nesse campo de investigação científica.

\section{I.2.2.4. Sobre variáveis dos adotantes: orientação sexual}

Do conjunto de 21 estudos identificados no levantamento da literatura científica dos últimos cinco anos, dois focalizaram processos de adoção realizados por pais com orientação sexual diferente da heterossexual. Dentre estes, foi identificado o trabalho de Jennings, Mellish, Tasker, Lamb \& Golombok (2014). Estes pesquisadores iniciam seu estudo argumentando sobre o estigma social envolto no tema adoção, caracterizando processo de 
menor valia para formar uma família, comparativamente à constituição biológica. Por esta razão, muitos casais heterossexuais buscariam adotar crianças apenas após tentarem seus próprios filhos biológicos.

A partir deste panorama, a preocupação dos pesquisadores voltou-se ao estudo de comparar casais gays, lésbicos e heterossexuais do Reino Unido em sua motivação para adotar crianças, levando em consideração suas experiências em relação à fertilidade. Realizaram entrevistas semiestruturadas com 41 famílias adotivas formadas por pais gays, 40 famílias com mães lésbicas e outras 49 famílias adotivas com pais heterossexuais, focalizando questões relativas à decisão por adotar e sobre possíveis tentativas prévias de conceberem um filho biológico. Os resultados apontaram que casais formados por gays ou lésbicas apresentaram motivações semelhantes entre si para adotarem, aparentemente dando menor importância para laços consanguíneos na formação das famílias. Já em relação aos casais heterossexuais, a questão genética da parentalidade se mostrou mais relevante, sendo que a razão mais comum para estes buscarem a adoção foi o insucesso em conceberem biologicamente, mesmo mediante técnicas de reprodução assistida (Jennings et al., 2014).

Já Gibson (2014) estudou o processo de adoção por homens gays em Ontário (Canadá). Para tanto, a autora examinou documento produzido pelo "Ministério das Crianças e Serviços para a Infância" de Ontário, versando sobre diretrizes para adoção e intitulado "Raising Expectations: Recommendations of the Expert Panel on Infertility and Adoption", sendo que seu foco foi a análise de aspectos referentes à adoção por homossexuais. Na perspectiva dessa pesquisadora, tensões entre a simples tolerância e o verdadeiro apoio à adoção por casais homossexuais permeiam este processo e necessitam ser compreendidas e trabalhadas no âmbito dos profissionais que lidam com esta temática. O artigo levanta discussões sobre tolerância a diversas formações familiares e respeito ao diferente, envolvendo aspectos culturais e sociais, que, segundo a mesma, precisam ser aprofundados e compreendidos para subsidiar políticas públicas a respeito da adoção. Não houve ênfase na questão da motivação para adotar, tampouco na infertilidade como relacionada à adoção em referido trabalho, portanto, sua discussão não será aprofundada neste momento.

\section{I.2.2.5. Sobre outras soluções frente à infertilidade e o desejo de ter filhos}

Um interessante estudo encontrado no atual levantamento da literatura científica foi desenvolvido por Zyl e Walker (2013), abordando relações comerciais e sentimentos de altruísmo na prática da chamada "barriga de aluguel". Os autores argumentam que referida 
prática é comum nos Estados Unidos e Índia, mas é severamente restrita em outros locais, nos quais se estimula a gravidez altruísta (não comercial), na qual outra mulher se oferece para gerar o filho de um casal, sem envolvimento financeiro (sem pagamento). De acordo com este trabalho, alguns segmentos médicos apoiam tal medida como forma de driblar a infertilidade.

Trata-se de artigo teórico sobre o tema, no qual são tecidas argumentações envolvendo questões históricas e sociais da "barriga de aluguel", incluindo aspectos da ordem da moralidade, do altruísmo nessas relações, em contraposição ao modelo comercial, no qual uma mulher recebe dinheiro para vivenciar a gestação de um filho que não será seu. Por fim, Van Zyl e Walker (2013) concluem pela defesa de uma proposta de categoria profissional envolvendo a maternidade via "barriga de aluguel", como alternativa a outras formas de solução diante do desejo de formar uma família em situações de infertilidade.

\section{I.2.2.6. Síntese do levantamento da literatura científica sobre adoção e infertilidade}

Diante deste percurso investigativo, há alguns elementos que podem ser destacados a partir da literatura científica identificada em torno do tema infertilidade e adoção. Um dos aspectos presentes na maioria dos estudos analisados é a infertilidade vista como associada a indicadores de sofrimento emocional e prejuízos sociais de diversas ordens, sobretudo em mulheres. Segundo estas referências da literatura científica, boa parte das mulheres parece ainda ver, na maternidade, relevante fonte de realização pessoal, constituindo elemento central para suas relações familiares e sociais.

Outro elemento que emergiu da literatura científica é o fenômeno do adiamento da parentalidade, dado destacado por diversos autores como realidade contemporânea em diferentes contextos, relacionado a maior risco de infertilidade, em especial no caso das mulheres. Neste contexto, tornar-se mãe (biológica ou adotiva) com idade mais avançada foi elemento apontado por alguns estudos como possível fator de impacto negativo sobre relações mãe-filho e também sobre a saúde emocional da própria criança.

Apesar do desejo pela maternidade na maioria das mulheres, segundo os estudos identificados, o tornar-se mãe (via adoção ou concepção biológica) pode exercer impactos ambivalentes em suas vidas. Por um lado, a chegada do filho pode configurar relevante conquista e realização pessoal, com incremento na autoestima e bem-estar geral (sobretudo após histórico de infertilidade). Entretanto, pode também associar-se a aumento no nível de estresse e insatisfação pessoal e no relacionamento conjugal, mediante as profundas mudanças de vida que acompanham a chegada do primeiro filho. 
Alguns estudos apontaram também a necessidade de se atentar para características afetivas e de personalidade das mulheres que buscam a adoção, sobretudo aquelas com vivência prévia de infertilidade. Isto porque estas variáveis parecem associadas às chances do sucesso na futura adoção, com possível impacto sobre o relacionamento conjugal e também sobre o vínculo entre mães e filhos adotivos.

A descrição dos principais resultados deste levantamento temático da literatura científica dos últimos cinco anos evidencia sustentação para a hipótese de que a impossibilidade de gerar filhos (infertilidade) pode afetar concretamente a vida das pessoas, disparando iniciativas de busca por adoção de crianças. Essas precisariam ser adequadamente compreendidas para favorecer a satisfação e melhoria na qualidade de vida dos indivíduos (crianças e adultos). Foi possível notar esforços internacionais e nacionais, no âmbito da pesquisa científica em Psicologia, para compreender possíveis relações entre a infertilidade e características individuais (sobretudo relacionadas à personalidade) de adotantes, bem como sobre sua forma de lidar com emoções e estabelecer vínculos interpessoais. Deste conjunto inicial de evidências empíricas e teóricas desdobra-se um corolário: o impacto da vivência da infertilidade sobre a própria personalidade, em especial nas mulheres que desejam exercer a maternidade.

Diante dos achados trazidos pela literatura nacional e internacional na área, é possível compreender que a decisão por adotar configura-se, algumas vezes, como iniciativa permeada por vivências de perdas significativas ao longo do desenvolvimento pessoal, repercutindo no exercício da parentalidade. Culturalmente, na sociedade ocidental contemporânea, estes elementos parecem se mostrar mais nítidos no universo feminino e na questão da maternidade, podendo a busca pela adoção (maternidade adotiva) caracterizar-se como tentativa de reparação destas perdas individuais vividas.

Neste contexto e ao constatar a relevância do papel do psicólogo formalmente instituído nos processos de adoção de crianças e de adolescentes, ressalta-se a importância do aprimoramento de seu conhecimento científico referente à temática da infertilidade e seus efeitos sobre a personalidade dos indivíduos. Isso visa ao alcance de informações que possam subsidiar o trabalho cotidiano dos profissionais de Psicologia com a devida qualificação e responsabilidade social.

A partir das considerações preliminares sobre o tema, retiradas de estudos no âmbito nacional e internacional, a pesquisa sistemática relativa à vivência da infertilidade e de seus possíveis impactos na personalidade feminina e na maternidade adotiva pode ser considerado importante alvo de estudos na realidade atual, propósito geral da presente investigação 
científica. Restaria pensar em estratégias técnicas necessárias para operacionalizar e adequadamente fundamentar esta veia investigativa. Neste caso buscou-se, em recursos teóricos e técnicos no âmbito da avaliação psicológica no campo da personalidade, fundamentos e instrumentos para implementação da proposta, como argumentado a seguir.

\section{I.3. Personalidade e Avaliação Psicológica}

O estudo da personalidade tem sido foco de interesse de diversos pensadores e pesquisadores ao longo da história e também na atualidade. De maneira geral, os teóricos têm focalizado, como marcador da personalidade, os complexos padrões de comportamento humano, sobretudo os padrões persistentes de reação que caracterizam determinado indivíduo, e que, por sua vez, o diferenciam das demais pessoas (Jabur, 2011).

Uma concepção teórica classicamente reconhecida e utilizada mundialmente, na tentativa de explicar os processos subjacentes à personalidade dos indivíduos, intitula-se genericamente como "psicodinâmica", baseada na determinação inconsciente dos comportamentos (Kaplan, Sadock \& Grebb, 1997). Nesse campo podem ser englobadas várias concepções teóricas, incluindo teoria das pulsões, teoria das relações objetais, psicologia do ego, teoria do apego e a psicologia do self (Gorgati, Holcberg \& Oliveira, 2002). Sendo assim, embora a teoria psicodinâmica não apresente uma definição conceitual única e precisa, ela tem o objetivo de auxiliar as pessoas a compreenderem os significados inconscientes dos comportamentos manifestos.

$\mathrm{Na}$ concepção psicodinâmica de personalidade exercem papel fundamental os mecanismos de defesa do ego. Podem ser concebidos como processos mentais inconscientes e, algumas vezes patológicos, que têm a finalidade de resolver conflitos entre necessidades pulsionais ou aprendidas, as regras e proibições internalizadas e a realidade externa (Oliveira, 2000). Os processos defensivos teriam a função de equilibrar o funcionamento interno às demandas da realidade, de modo a preservar a integridade individual e sua adaptação ao contexto.

Nesta abordagem teórica, considera-se que existem diferentes mecanismos de defesa, com diversas denominações, operando de modo inconsciente e por meio da manipulação de representações (Gabbard, 1998; Oliveira, 2000). As defesas psíquicas se mostram fundamentais enquanto recursos internos, sinalizando níveis e estratégias de adaptação dos indivíduos à realidade externa, conteúdos essenciais em processos de avaliação psicológica. 
Outro ponto central da abordagem psicodinâmica da personalidade é a consideração das relações objetais. Segundo Laplanche e Pontalis (1990) correspondem, de maneira geral, ao modo de relação global do sujeito com o seu mundo. Nesta concepção, não seriam apenas os relacionamentos interpessoais concretos que configurariam suas relações objetais, mas também a maneira específica da sua relação com os chamados objetos internos. Nesta perspectiva, focaliza-se a transformação das relações interpessoais em representações internalizadas de relacionamentos (Gabbard, 1998), ampliando e aprofundando, assim, a compreensão acerca da personalidade dos indivíduos.

Trata-se, portanto, de concepção teórica que focaliza determinações inconscientes do comportamento, bem como a dinâmica interna subjacente ao funcionamento da personalidade dos indivíduos. Deste modo, a abordagem psicodinâmica se configura relevante modelo teórico no âmbito da avaliação psicológica, sobretudo no campo dos métodos projetivos, e contribui para fundamentar intervenções em diversas áreas de atuação da Psicologia (Hutz, Bandeira, Trentini \& Krug, 2016).

Para além dessa clássica concepção teórica, um dos modelos mais difundidos para descrever a estrutura da personalidade, do ponto de vista psicométrico, é o modelo dos Cinco Grandes Fatores da personalidade, também conhecido como "Modelo Big Five". É considerada uma teoria explicativa e preditiva da personalidade humana e de suas relações com a conduta (Silva \& Nakano, 2011).

O trabalho de Hutz, Nunes, Silveira, Serra, Anton e Wieczorek (1998) destacou que, na análise fatorial de vários instrumentos existentes para avaliação de personalidade, independente de sua fundamentação teórica, os fatores emergentes são consistentes com o modelo teórico de personalidade denominado "Cinco Grandes Fatores". Desse modo, apontaram que se trata de modelo bastante útil no campo da avaliação psicológica, passível de diálogo com outras abordagens teóricas.

Referidos autores argumentam que a identificação dos Cinco Grandes Fatores da personalidade foi acidental, tendo suas origens na análise da linguagem utilizada para descrever pessoas (Hutz et al., 1998). Nesta concepção, os termos linguísticos utilizados pelos indivíduos leigos para descrever características individuais (adjetivos) foram foco de pesquisadores por serem considerados relevantes para o estudo dos agrupamentos semânticos representativos dos traços básicos da personalidade humana (Hauck Filho, Machado, Teixeira, $\&$ Bandeira, 2012).

Os fatores (componentes) da personalidade corresponderiam a elementos relevantes na busca de informações específicas quando se vai interagir com as pessoas. Sendo assim, dentre 
os elementos relevantes acerca da personalidade e modo de ser das pessoas, no momento das interações sociais, importaria saber se o indivíduo é:

“(...) 1) ativo e dominante ou passivo e submissivo; 2) socialmente agradável ou desagradável, amigável ou frio, distante; 3) responsável ou negligente; 4) "louco", imprevisível ou "normal", estável; 5) esperto ou um tolo, aberto a novas experiências ou desinteressado por tudo aquilo que não diz respeito à experiência do cotidiano" (Hutz et al., 1998, p. 401).

Deste modo, as dimensões da personalidade preconizadas pelo modelo dos Cinco Grandes Fatores corresponderiam a elementos relevantes no âmbito social, expressando-se no relacionamento interpessoal. Portanto, abordam elementos de grande importância no âmbito da avaliação psicológica, fundamentando instrumentos específicos. Esse modelo teórico tem desempenhado importante papel nas pesquisas sobre assuntos relacionados à personalidade no contexto brasileiro, existindo diversos instrumentos de autorrelato (como a Bateria Fatorial de Personalidade - Nunes, Hutz \& Nunes, 2010) e outros ainda em desenvolvimento (Hauck Filho et al., 2012). Deste amplo conjunto técnico, a seguir serão destacados elementos voltados à compreensão da personalidade de mulheres, um dos focos da presente investigação.

\section{I.4. Avaliação psicológica como recurso investigativo da personalidade: instrumentos e requisitos técnicos}

O conjunto das considerações prévias sugere a necessidade de uma avaliação pormenorizada de componentes conscientes e inconscientes da dinâmica psíquica de pretendentes à adoção, visando ao alcance de informações sobre sua personalidade e modo de vivenciar os afetos, uma vez que tais elementos tendem a interferir na qualidade e tipo de vínculos a ser estabelecido com a criança/adolescente adotado. Dentre os recursos técnicos disponíveis ao psicólogo para a realização deste trabalho, destacam-se os instrumentos específicos de avaliação psicológica, cuja qualidade necessita ser alvo de constante investigação e cuidado técnico-científico (Hutz, 2009; Nunes \& Primi, 2010; Primi \& Nunes, 2010; Hutz, Bandeira, Trentini \& Krug, 2016).

Há, na realidade atual brasileira, diversidade de técnicas e de instrumentos de avaliação psicológica utilizados para atender a demanda de investigação de diversas variáveis 
psicológicas. Cada instrumento é dotado de atributos positivos, mas também possui limitações técnicas, cabendo ao psicólogo a tarefa de analisá-los para optar por utilizá-lo ou não em sua prática profissional (Fensterseifer \& Werlang, 2008). No aprimoramento dos instrumentos de avaliação psicológica se faz constante, buscando sua qualidade e adequado uso (Noronha, Primi \& Alchieri, 2005). Estes estudos enfatizam, portanto, a necessidade de permanente revisão técnico-científica dos instrumentos psicológicos em uso no Brasil, como apontam Mansur-Alves, Silva e Fernandes (2016); Oliveira, Noronha, Dantas e Santarém (2005); Noronha e Vendramini (2003), entre outros.

Em relação aos instrumentos disponíveis para o trabalho dos psicólogos, os métodos projetivos de avaliação psicológica se destacam na medida em que permitem obter informações acerca do dinamismo da personalidade, bem como a recursos internos de adaptação à realidade e ao modo de vivenciar e lidar com as emoções (Anzieu, 1986; Azoulay et al., 2007; Hutz, Bandeira, Trentini \& Krug, 2016). Deste modo, considera-se que os métodos projetivos podem ser relevantes ferramentas na avaliação psicológica, tanto da personalidade quanto de outros elementos fundamentais para a compreensão da pessoa em si ou de uma situação experienciada ou percebida por ela, como dinâmica familiar e relações interpessoais (Fensterseifer \& Werlang, 2008), incluindo sua própria identidade. Podem, portanto, ser importante meio de acesso a informações relevantes em processos avaliativos relacionados à adoção de crianças/adolescentes, sobretudo na seleção e preparação dos pretendentes.

Dentre os diferentes métodos projetivos utilizados e investigados no Brasil, o Questionário Desiderativo tem sido reconhecido como relevante instrumento no acesso a informações referentes ao funcionamento psicodinâmico dos indivíduos (Brêga, Frazatto \& Loureiro, 2000; Guimarães, Pasian \& Loureiro, 2008; Ocampo, Arzeno \& Piccolo, 1985; Paulo, 2005). É um instrumento aplicável a grande parcela da população, dado exigir apenas recursos verbais e de compreensão verbal para a atividade, além de ter seu uso favorecido por sua brevidade enquanto procedimento técnico (rápida aplicação) e por não exigir habilidades complexas para respondê-lo. Essas características destacam este método projetivo como um instrumento bastante promissor para o campo da avaliação psicológica (Nijamkin \& Braude, 1996/2000), sobretudo no tocante à identidade e recursos internos de organização defensiva, embora ainda não aprovado para uso no Brasil em função da necessidade de mais estudos empíricos relativos a suas qualidades psicométricas. Por esta razão, até o momento encontrase com parecer desfavorável a seu uso pelo Conselho Federal de Psicologia, não sendo, 
portanto, um instrumento acessível aos psicólogos em sua prática cotidiana, a não ser em contextos de ensino e pesquisa.

Nijamkin e Braude (1996/2000) desenvolveram um sistema avaliativo detalhado para o Questionário Desiderativo. Por sua vez, Brêga, Frazatto e Loureiro (2001) elaboraram uma esquematização das principais funções psicológicas avaliadas por este método projetivo de avaliação psicológica, com base na citada proposição de Nijamkin e Braude, e organizaram um protocolo de codificação das respostas. Uma breve sistematização destes procedimentos de codificação e análise foi detalhada por Guimarães, Pasian e Loureiro (2008), podendo servir como base para avaliações futuras por meio deste instrumento.

Conforme informações obtidas a partir da literatura científica nacional, o Questionário Desiderativo tem sido usado em diversos contextos (clínicos ou não) e em pessoas com diferentes características (Capitão \& Zampronha, 2004; Felício, 2002; Paulo, 2005). Em termos gerais os autores apontaram o Desiderativo como um instrumento bastante rico e informativo (Tardivo, 1999) e, por isso, interessante para avaliar o funcionamento da personalidade (Paulo, 2005). Por outro lado, apesar dos indicadores do Questionário Desiderativo como instrumento relevante e promissor no que se refere à avaliação do funcionamento psicodinâmico dos indivíduos, ainda é pouco conhecido em âmbito mais geral em nosso país (Noronha, Primi \& Alchieri, 2005). Diante dos argumentos apresentados, reforça-se a necessidade de investimento atual em pesquisas com o Questionário Desiderativo, de modo a alcançar subsídios científicos que possam respaldar sua adequada utilização pelos psicólogos brasileiros.

Nessa direção foi desenvolvido na região de Ribeirão Preto (SP) um estudo normativo referente ao Questionário Desiderativo, realizado com adolescentes (Guimarães \& Pasian, 2009), obtendo-se resultados favorecedores de sua utilização em nosso contexto, tendo por base a proposição avaliativa de Nijamkin e Braude (2000), conforme adaptação realizada por Brêga et al. (2000). Estes achados forneceram subsídios científicos iniciais favorecedores à utilização desse instrumento projetivo em avaliações psicológicas no Brasil, conforme preconizado pelo Sistema de Avaliação de Testes Psicológicos (SATEPSI) do Conselho Federal de Psicologia (CFP), ressaltando suas possibilidades informativas acerca do funcionamento psíquico. Embora com essa contribuição, ressalta-se a necessidade de mais investimentos em pesquisas voltadas para a investigação de indicadores de validade do Questionário Desiderativo como técnica de avaliação de personalidade no contexto sociocultural brasileiro. Além disso, estudos voltados para elaboração de normas para outros grupos e/ou faixas etárias tornam-se necessários, com o objetivo de torná-lo um instrumento 
acessível à utilização (cientificamente fundamentada), por psicólogos de nosso país (Guimarães \& Pasian, 2009).

Dentre os diferentes métodos científicos para verificação da validade de instrumentos de avaliação psicológica, tem-se o "procedimento da validade concorrente ou convergentediscriminante, que pressupõe que testes que avaliam um mesmo construto devam se correlacionar significativamente entre si" (Franco \& Villemor-Amaral, 2009, p. 50). Referido procedimento busca comparar o desempenho dos sujeitos em diferentes instrumentos de avaliação psicológica que se proponham a avaliar os mesmos aspectos da personalidade, sendo que um deles necessariamente deve possuir indicadores de validade já averiguados e confirmados pela literatura científica. Neste contexto, considerando-se a necessidade de realização de estudos sobre evidências de validade do Questionário Desiderativo em nosso país, o Método de Rorschach pode servir de base comparativa para o desempenho dos indivíduos, pois se destaca dentre os instrumentos projetivos disponíveis e tecnicamente embasados para utilização dos psicólogos.

O Método de Rorschach é instrumento projetivo de avaliação de personalidade mundialmente utilizado e cuja validade na avaliação psicodinâmica dos indivíduos já é amplamente reconhecida pela comunidade científica, em diversos contextos (Chabert, 2004; Pasian, 2000; Pianowski \& Villemor-Amaral, 2010). Este instrumento se propõe a fornecer informações acerca dos aspectos da estrutura e da dinâmica da personalidade (Weiner, 2000; Werlang, Villemor-Amaral \& Nascimento, 2010), "por meio da análise de processos perceptivos envolvidos na produção de respostas" (Werlang, Villemor-Amaral \& Nascimento, 2010, p. 89). Além do reconhecimento internacional em diversas áreas de aplicação, este método avaliativo apresenta indicadores de validade em diferentes contextos socioculturais, o que reforça sua possibilidade de contribuição científica para a compreensão do funcionamento psíquico dos indivíduos (Nascimento, 2002; Pasian, 2000). Deste modo, por suas características e alcance avaliativo, o Método de Rorschach tem sido utilizado como referência em relação ao padrão de respostas de indivíduos em outros instrumentos projetivos, tais como realizado por Xavier (2009), ao comparar a avaliação de aspectos cognitivos por meio do CAT-A, o Desenho da Figura Humana e o Rorschach. Outro estudo nacional, realizado por Villemor-Amaral e Cardoso (2012), utilizou o Zulliger e o Rorschach, buscando validar indicadores do primeiro no contexto do Brasil.

Diante deste percurso argumentativo que focaliza características de personalidade e a perspectiva instrumental de acesso a esse construto, considera-se relevante buscar evidências de validade do Questionário Desiderativo aplicado à população adulta, recorrendo-se a 
indicadores obtidos por meio do Método de Rorschach. Novos achados empíricos relativos a este tópico poderão suscitar a reavaliação deste instrumento projetivo (Questionário Desiderativo) por parte do Conselho Federal de Psicologia, podendo culminar com a aprovação de seu uso na realidade nacional, ampliando os recursos disponíveis aos profissionais brasileiros nesse campo complexo da avaliação da personalidade.

Cabe ainda comentar que outra estratégia técnica para estudos de validação de instrumentos de avaliação psicológica pode ser o uso concomitante de métodos com base no autorrelato e de natureza projetiva, como comentado por Primi (2010). Ele aponta que estas duas abordagens técnicas (autorrelato e projetiva) não deveriam ser consideradas contrárias, mas sim complementares, representando diferentes facetas do raciocínio científico da Psicologia, ao buscar medir e avaliar características individuais e de grupos, visando a compreensão do ser humano. Conforme referido autor, os métodos psicométricos (de autorrelato) têm um papel relevante para validar os construtos (traços) e seus indicadores, pois possibilitam a produção de medidas estatísticas específicas. Por outro lado, os métodos projetivos contribuem com indicadores referentes a uma caracterização mais global de cada indivíduo, refletindo construtos clínicos, baseados em estudos das semelhanças entre perfís de indivíduos (Primi, 2010). Deste modo, justifica-se a utilização, no presente estudo, de instrumentos tanto psicométricos como projetivos, buscando-se aprimorá-los e alcançar, assim, indicadores igualmente relevantes e complementares acerca de características da personalidade de mulheres envolvidas em processos de adoção.

\section{I.5. Justificativa}

A complexidade das decisões profissionais do psicólogo que atua no campo judiciário, além de desafiadoras, exigem contínuas investigações na área para responder, com a devida qualidade técnico-científica, às demandas e expectativas da população relativas à Psicologia e sua contribuição à vida dos indivíduos. Dentre as áreas de atuação dos psicólogos judiciários, a adoção de crianças é um dos temas que possui grande relevância e complexidade, necessitando, portanto, constante aprimoramento profissional dos psicólogos para que possam responder adequadamente às questões envolvidas nestas demandas, com o necessário embasamento científico.

A literatura científica no campo da adoção aponta que a infertilidade é um dos principais elementos motivadores da busca por esse processo, em diversos contextos socioculturais, incluindo o brasileiro. Também é reconhecido que a infertilidade exerce 
relevante influência sobre a personalidade das mulheres, podendo se associar a sofrimento psíquico e rebaixamento na autoestima, gerando dificuldades adicionais no campo socioafetivo.

Diversos estudos, tanto em âmbito nacional quanto internacional, apontaram a necessidade de se considerar variáveis relativas à personalidade das mulheres que pretendem ser mães adotivas, diante do reconhecido impacto que suas características psíquicas exercem sobre o relacionamento mãe-filho, favorecendo (ou não) o sucesso no processo de adoção. Assim, o psicólogo judiciário é colocado diante de complexas variáveis humanas e institucionais em sua realidade cotidiana de trabalho nas demandas judiciais de adoção.

Nesse contexto, esforços para incrementar o conhecimento científico atual que embasa a atuação dos psicólogos judiciários tornam-se relevantes em nossa realidade. Com base nessa diretriz justifica-se o propósito geral desta investigação científica, voltada à pesquisa sistemática da vivência da infertilidade e de seus possíveis impactos na personalidade feminina e na maternidade adotiva. Para tanto, os recursos da avaliação psicológica têm se mostrado relevantes instrumentos profissionais, que necessitam, por sua vez, de constante aprimoramento com o objetivo de garantir a qualidade e precisão de suas informações.

Unindo estas duas vertentes de trabalho investigativo, o presente estudo buscou também colecionar e sistematizar indicadores psicométricos (validade e de precisão) do Questionário Desiderativo. Procurou-se reunir evidências empíricas de sua utilidade enquanto método projetivo para identificar e compreender características pessoais marcadoras da personalidade e implicadas nos papéis sociais assumidos pelos indivíduos, neste caso, na opção pela maternidade concretizada por meio da adoção de crianças. Esta pesquisa, portanto, tem uma dupla perspectiva: tanto metodológica, investigando instrumento de avaliação psicológica (Questionário Desiderativo), quanto clínica, enquanto aplicação da avaliação psicológica no campo da adoção, podendo vir a contribuir para a prática profissional do psicólogo no Brasil. 


\section{OBJETIVOS}

\section{II.1. Geral}

O presente estudo tem por objetivo geral identificar características da estrutura e do funcionamento da personalidade de mulheres inférteis, envolvidas em processos de busca da realização da maternidade por meio da adoção, visando contribuir para o conhecimento científico na área e para embasar ações profissionais nesse campo.

\section{II.2. Específicos}

Almeja-se alcançar, com maior especificidade, os seguintes objetivos no presente estudo:

II.2.1. Identificar características da personalidade de mulheres com e sem experiência de maternidade, a partir da avaliação psicológica por meio dos métodos projetivos (Psicodiagnóstico de Rorschach e Questionário Desiderativo) e por instrumento de autorrelato (Bateria Fatorial de Personalidade).

II.2.2. Comparar características afetivas e de funcionamento da personalidade em três grupos distintos de vivências da maternidade: mulheres inférteis judicialmente habilitadas para adoção e que aguardam a chegada da criança, mulheres inférteis e que são mães adotivas (legalmente instituídas), e mães sem problemas de infertilidade (grupo de comparação).

II.2.3. Sistematizar indicadores de precisão e evidências de validade do Questionário Desiderativo enquanto instrumento adequado e cientificamente fundamentado para auxiliar processos de avaliação psicológica no campo da Psicologia Judiciária no Brasil, especificamente no âmbito dos processos de adoção. 


\section{MÉTODO}

O presente trabalho se constituiu enquanto investigação científica com delineamento transversal, caracterizando-se como estudo descritivo-comparativo de grupos e correlacional, a partir de evidências empíricas. Foram pesquisados indicadores quantitativos e qualitativos, advindos de instrumentos padronizados de avaliação psicológica, em mulheres agrupadas em condições consideradas como caso (mães adotivas) e controle (mães biológicas). O referencial teórico adotado no estudo se pauta na concepção psicodinâmica de personalidade, onde se consideram elementos inconscientes e seus derivados como componentes do comportamento e das ações humanas.

\section{III.1. Contexto de desenvolvimento do estudo}

O presente trabalho foi desenvolvido na região de Ribeirão Preto, interior do Estado de São Paulo, por questões de ordem prática e para tornar viável a proposta. Nesta comarca existe cadastro específico para pretendentes à adoção de crianças, sob responsabilidade do Juiz da Infância e Juventude, que por sua vez também cuida de crianças retiradas de suas famílias biológicas por estarem em situação de risco, bem como da colocação destes casos em famílias substitutas. Este trabalho é desenvolvido juntamente com os assistentes sociais e psicólogos judiciários lotados na referida comarca, envolvendo aproximadamente 30 profissionais. Este serviço judiciário está disponível na maioria das cidades da região de Ribeirão Preto (SP). Entretanto, dada a inexistência de profissionais de Psicologia no judiciário em diversas cidades, há a necessidade de deslocamento destes psicólogos para atendimento das demandas da região, além da cidade sede. A responsável por este estudo é uma dessas psicólogas judiciárias de Ribeirão Preto (SP), o que tornou viável a realização desta pesquisa neste contexto, tendo em vista os vários procedimentos administrativos e éticos necessários para sua efetivação.

A partir dos objetivos propostos para a presente investigação e sua viabilidade em termos operacionais, buscou-se inicialmente levantar características sociais e demográficas de pretendentes à adoção e já inscritos no Cadastro da Comarca de Ribeirão Preto (SP), contexto regional deste estudo, de modo a embasar diretrizes para delineamento dos casos da amostra. Para tanto, realizou-se consulta aos dados constantes no mencionado cadastro, em janeiro de 2012, mediante autorização verbal prévia do Juiz da Infância e Juventude da referida comarca (ANEXO 1). 
Este levantamento revelou que aproximadamente $87 \%$ dos 132 inscritos para adoção, em janeiro de 2012, eram casais e o restante composto de pessoas solteiras. Dentre os pretendentes à adoção, a média etária das mulheres girava em torno de 40 anos de idade, sendo sua escolaridade entre ensino médio completo (31\%) e ensino superior completo (24\%). A infertilidade foi apontada em $83 \%$ dos casos como razão para a busca da inscrição no cadastro de pretendentes à adoção, confirmando o perfil já apontado por investigações científicas prévias.

Diante destas informações, para a realização do presente estudo buscou-se compor amostra com casos de características semelhantes ao perfil sociodemográfico médio das pretendentes à adoção de Ribeirão Preto. Paralelamente a esses casos, seria composto grupo de comparação, conforme critérios de seleção que permitissem futura comparação dos grupos estudados.

\section{III.2. Percurso amostral e participantes}

\section{III.2.1. Seleção de participantes}

A amostra foi delineada por conveniência, composta por 60 mulheres, entre 30 e 50 anos de idade, que tinham ao menos concluído o ensino médio e que estavam inseridas em união conjugal (relacionamento conjugal estável há pelo menos um ano). Referidas participantes foram distribuídas em três grupos numericamente equitativos, a saber:

- Grupo 1 (G1 = pretendentes à adoção): 20 mulheres em situação de infertilidade primária (até o momento não conseguiram ter filho biológico, mesmo após um ano de tentativas para engravidar), que estavam judicialmente habilitadas como pretendentes à adoção na Comarca de Ribeirão Preto (SP).

- Grupo 2 (G2 = mães adotivas): 20 mulheres em situação de infertilidade primária, que tinham ao menos um filho adotivo. Os critérios para inclusão na amostra foram: histórico de convívio com este filho há pelo menos um ano (de modo a permitir a experiência concreta da maternidade adotiva), e idade do filho entre um e 12 anos de idade, ou seja, crianças.

- Grupo 3 (G3 = mães biológicas - grupo de comparação): 20 mulheres sem problemas de infertilidade, com ao menos um filho biológico (que tivesse, na data da avaliação, entre um e 12 anos de idade). Em referido grupo foram incluídas apenas mulheres que não apresentaram, no momento da pesquisa, indicadores de transtornos de saúde mental, avaliadas por instrumento específico (SRQ-20). 
Para o processo de seleção das participantes do estudo, tendo em vista seus objetivos, iniciou-se o trabalho a partir da composição de G1 e de G2. Foi realizado levantamento de possíveis participantes a partir dos cadastros das pessoas habilitadas para adoção, armazenados no cartório da Vara da Infância e Juventude da Comarca de Ribeirão Preto (SP), mediante autorização prévia do Juiz da respectiva Vara. Buscou-se identificar mulheres que preenchessem os requisitos delineados para compor G1, ou seja, mulheres inférteis aguardando filho adotivo, na faixa etária de 30 a 50 anos, casadas ou em união estável, possuindo ao menos ensino médio completo.

Também foi realizado um segundo levantamento dos cadastros de adoção inativos ou já arquivados e armazenados no cartório da Vara da Infância e Juventude da Comarca de Ribeirão Preto (SP), ou seja, daqueles casais que já não mais se encontravam em situação de espera pelo filho adotivo. Buscou-se, desta forma, identificar mulheres que preenchessem as características de G2, ou seja, aquelas que, embora também tenham buscado a adoção motivadas pela infertilidade, já tinham adotado ao menos uma criança e já exerciam a função materna (por adoção) há pelo menos um ano.

Ressalta-se que o Setor Técnico do Fórum de Ribeirão Preto mantém banco de dados digital com as principais informações sociodemográficas e de contato das pessoas cadastradas para adoção e também das que concluíram adoção, o que permitiu a seleção prévia dos casos a serem consultados. Sendo assim, a partir deste banco de dados, foi possível pré-selecionar possíveis voluntárias ao estudo, considerando-se os critérios de inclusão estabelecidos para esta pesquisa. Em seguida, para detalhamento e confirmação do preenchimento ou não dos critérios de inclusão na amostra, a pesquisadora, mediante autorização do Juiz responsável pela Comarca, acessou os relatórios técnicos contidos nos respectivos autos judiciais. Os casos em que as informações estavam completas e indicativas de preenchimento de critérios para inclusão no estudo foram registrados pela pesquisadora, sendo posteriormente realizado contato telefônico com essas mulheres para convidá-las a participar da pesquisa.

$\mathrm{Na}$ impossibilidade do acesso aos respectivos autos judiciais (caso de processos já arquivados cuja solicitação para consulta demandaria intensa tramitação administrativa e tempo considerável), a pesquisadora realizou algumas perguntas rápidas no contato telefônico com a eventual participante, a fim de confirmar se a candidata preenchia ou não os critérios de inclusão no estudo. As perguntas envolviam confirmação da idade e nível de escolaridade, bem como outras acerca de seu histórico de infertilidade (presença ou não de filhos biológicos e, em caso negativo, se a origem dos problemas para engravidar era conhecida - se provinha da mulher, do marido, ou de ambos), além da checagem de seu estado civil. 
A partir das consultas, seleções e contatos realizados pela pesquisadora, foram incluídas no estudo aquelas que aceitaram espontaneamente a proposta. Estas participantes foram buscadas em ordem cronológica de sua habilitação no Cadastro de Pretendentes à Adoção, até ser completado o número de 20 mulheres em G1 e em G2.

Para a composição de G3 $(n=20$, grupo de comparação, composto por mães biológicas), foram selecionadas mulheres em união estável (casadas ou não), sem problemas de infertilidade, com o mesmo perfil de idade e escolaridade que as demais anteriormente selecionadas e participantes do estudo, buscando-se balancear suas características demográficas principais e permitir futura comparação de seus dados. Para selecionar as eventuais voluntárias de G3 a pesquisadora utilizou da técnica de "bola de neve", partindo de sua rede social de contatos, sem que houvesse proximidade socioafetiva comprometedora da objetividade da avaliação. As indicações dessas mulheres foram facilitadas por meio do contato com uma profissional consultora em amamentação (atua como "doula" na cidade), a qual ofereceu possíveis voluntárias à pesquisa que, na maioria dos casos, aceitaram a proposta. Nesse sentido, o percurso necessário para compor G3 foi mais breve.

\section{III.2.2. Percurso amostral}

Conforme explanado anteriormente, com o objetivo de compor a amostra pretendida para o estudo, os registros pertencentes ao Setor Técnico do Fórum Estadual de Ribeirão Preto (SP) foram consultados, a fim de selecionar pretendentes à adoção e mães adotivas que pudessem colaborar com a pesquisa. Essas consultas foram realizadas durante os anos de 2012 e 2013.

Para se alcançar o total de 20 participantes em G1 foi preciso analisar o perfil sociodemográfico das 86 primeiras pretendentes à adoção inscritas e com cadastro ativo na comarca de Ribeirão Preto (em fevereiro/março de 2013). Desse total a pesquisadora selecionou 71 possíveis voluntárias que preenchiam os critérios de idade, nível de escolaridade e relacionamento conjugal. Destas, foram analisados dados referentes à presença ou não de histórico de infertilidade a partir dos relatórios técnicos contidos nos processos judiciais, sendo selecionadas 55 mulheres, excluindo-se aquelas com filhos biológicos, ou que já estavam exercendo a maternidade adotiva em relação a algum sobrinho ou enteado, ou cujos maridos é que vivenciavam dificuldades relativas à infertilidade. Desse conjunto inicial de eventuais participantes, a pesquisadora conseguiu efetivar o contato com 52 mulheres. 
Apenas em três casos os dados de contato estavam desatualizados, não possibilitando o convite da pesquisadora.

Dentre estas 52 candidatas à adoção contatadas e convidadas pela pesquisadora (por telefone) para o estudo, 40 verbalizaram o aceite para a participação. Houve 12 casos em que a pessoa preferiu não participar, apresentando como razões a falta de tempo, ou aparentando algum temor de que a pesquisa pudesse interferir em seu processo de adoção, ou mesmo não apresentando qualquer motivo específico. Cumpre-nos reiterar que, no momento do convite, a pesquisadora tomou os devidos cuidados éticos em garantir liberdade para as mulheres emitirem ou não seu aceite ao estudo, sem qualquer tipo de constrangimento em caso negativo. Enfatizou-se claramente, no convite por telefone, a garantia de inexistência de relação entre sua participação ou não na pesquisa e o andamento de seu processo jurídico de pedido de adoção.

Do grupo de 40 mulheres que aceitaram participar do estudo, foi possível realizar o agendamento da coleta de dados com 32 voluntárias, sendo que as demais não mais atenderam as ligações telefônicas da pesquisadora e/ou não ofereceram o retorno combinado. Das 32 candidatas à adoção que efetivamente agendaram sua participação na pesquisa, em 12 casos houve desistência posterior e/ou impossibilidade de participação. Em cinco desses casos houve contato telefônico da possível participante com a pesquisadora justificando sua desistência, apesar do agendamento inicial. Nos outros sete casos, não houve qualquer comunicação da voluntária, registrando-se apenas sua ausência no momento agendado de coleta de dados. A partir deste percurso, foi possível completar o número de 20 mulheres candidatas à adoção avaliadas para esta pesquisa, compondo G1.

Para a composição de G2 foram analisados os dados referentes ao perfil sociodemográfico de 105 mães adotivas cujos dados de cadastro estavam arquivados nos registros do Setor Técnico do Fórum, partindo-se das que haviam recebido crianças mais recentemente, para os casos mais antigos. Desse conjunto inicial foram selecionadas (pelo perfil sociodemográfico) 90 possíveis participantes, em relação às quais foram pesquisados dados referentes ao histórico ou não de infertilidade nos relatórios técnicos contidos nos autos judiciais. Entretanto, essa investigação foi possível em apenas 67 casos, estando os demais já arquivados em outra comarca, sem cópia disponível do relatório para verificação destas variáveis individuais.

Priorizou-se, então, contatar as mulheres que, com base nos relatórios técnicos acessados, preenchiam os critérios de inclusão no estudo, o que totalizou 51 possíveis voluntárias. A pesquisadora conseguiu efetivamente realizar contato telefônico com 35 desses 
casos, uma vez que os dados de contato das demais estavam desatualizados (adoções já concluídas há anos).

Após convite à pesquisa com essas 35 mães adotivas, 24 casos aderiram à proposta. Dentre as razões apresentadas pelas 11 mulheres que recusaram a pesquisa foram relatados: falta de tempo (dois casos) e temor diante da possibilidade de quebra de sigilo relativo à origem de seu filho adotivo (nove casos). Foi possível observar que, apesar do cuidado da pesquisadora em se identificar e explanar as razões do estudo, a autorização prévia do Juiz para contato com as mesmas, bem como a garantia dos cuidados com o sigilo das informações, houve relevante apreensão por parte destas mães adotivas, culminando em maiores dificuldades para efetivar a coleta com este grupo de mulheres.

Das 24 mulheres que inicialmente aceitaram participar da pesquisa, foi possível efetivar o agendamento da coleta de dados com apenas 17 casos. Como ocorreu em G1, as demais passaram a não atender as ligações telefônicas e nem retornaram as ligações como combinado. Do conjunto de 17 voluntárias agendadas foi possível concluir a coleta de dados com 15 casos, com duas desistências.

Faltavam, então, cinco casos para completar G2 desse estudo, razão pela qual buscamos contato telefônico com outras nove mães adotivas cujos relatórios técnicos não estavam disponíveis, e, portanto, não houve confirmação prévia de suas condições de inclusão ou não no estudo. A checagem dos dados necessários para incluir a possível voluntária na pesquisa foi realizada via telefone, mediante perguntas da pesquisadora visando confirmar idade, escolaridade, estado civil, status atual de relacionamento conjugal, além de histórico ou não de infertilidade. Dessas mulheres sete preenchiam os critérios de seleção no estudo, sendo que cinco concordaram em participar. Desta vez, não houve desistências, sendo possível concluir a coleta de dados. Foi possível observar que, dentre os casos de adoção mais antigos, houve maior receptividade por parte das mães e menor sensação de ameaça do sigilo em torno da adoção realizada. A partir deste percurso, foi possível realizar a avaliação psicológica de 20 mães adotivas, alcançando-se a composição pretendida para G2 no presente estudo.

Para a composição de G3 (mães biológicas), obtivemos indicações de 27 mulheres a partir das ex-clientes de uma profissional (psicóloga) que atuava como "doula" e consultora em amamentação em Ribeirão Preto (SP). A pesquisadora fez um primeiro contato com essas eventuais voluntárias por meio de telefonema, onde foi apresentada a proposta da pesquisa. Nesse momento também foram buscadas informações relativas a idade, escolaridade, estado civil e idade dos filhos, de modo a checar se eram compatíveis com os critérios de inclusão na amostra. Dessas 27 indicações apenas 16 mulheres preenchiam os critérios de seleção de 
participantes do estudo, sendo que todas aceitaram participar da pesquisa, concluindo integralmente o processo de coleta de dados, sem desistências.

Para concluir a composição de G3, a pesquisadora solicitou indicações de pessoas de sua rede social de contatos, mas sem proximidade afetiva que pudesse prejudicar a qualidade da avaliação psicológica a ser realizada. Foram convidadas quatro mulheres nessa condição, sendo que todas preenchiam os critérios de inclusão e concordaram em participar do estudo. Desse modo, foi possível totalizar as 20 mães biológicas pretendidas para G3.

A partir das estratégias descritas foi possível concluir com êxito a avaliação psicológica do conjunto de 60 mulheres, amostra pretendida para a presente investigação. Em termos sintéticos o percurso amostral dos três grupos do estudo pode ser visualizado na Figura 1.

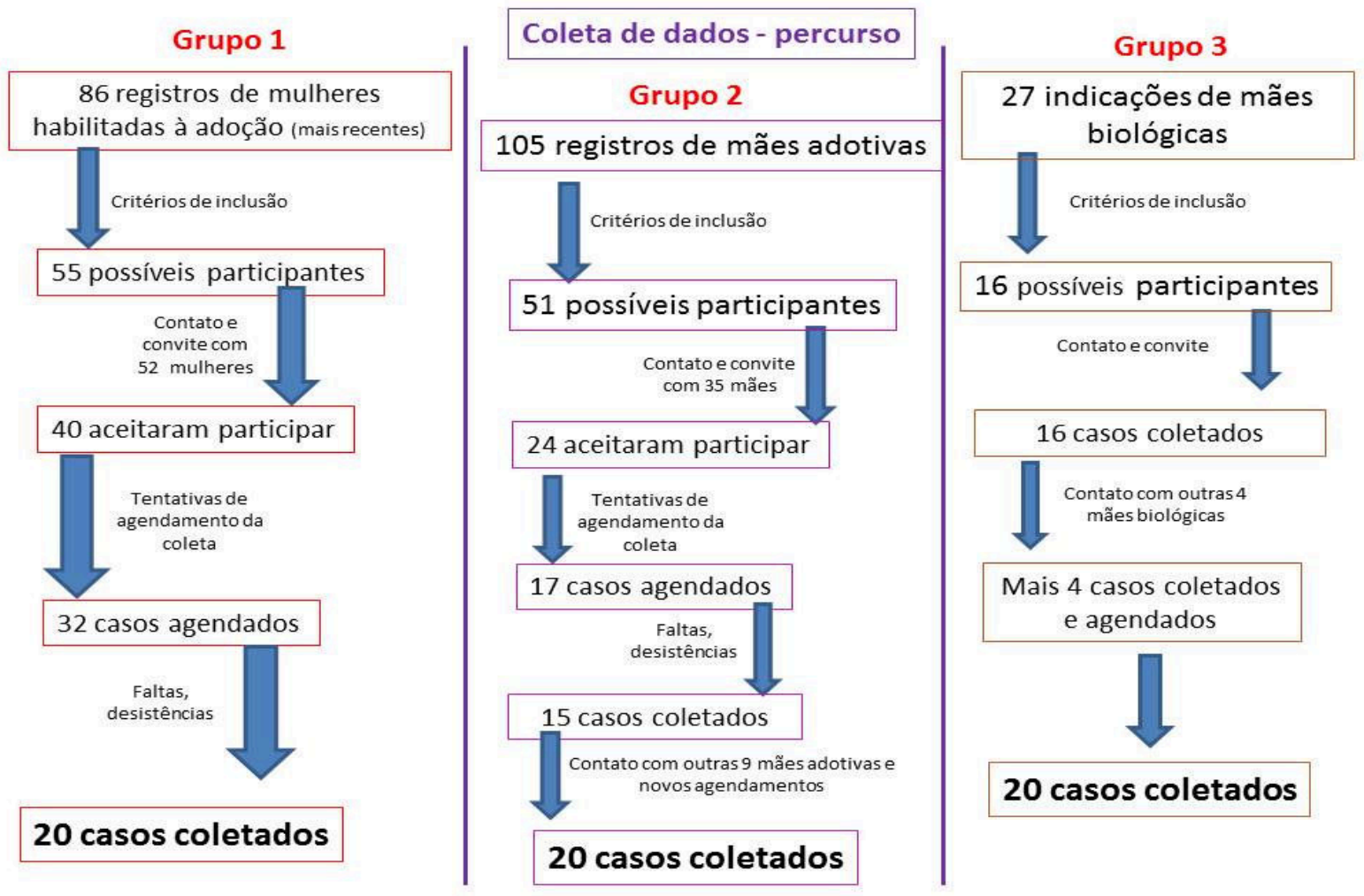

Figura 1. Percurso amostral do presente estudo $(n=60)$ em função dos grupos de mulheres.

\section{III.2.3. Participantes}

Diante desse processo de seleção das voluntárias ao estudo, a amostra composta caracteriza-se como não aleatória, obtida por conveniência, de modo a tornar viável a concretização da presente proposta investigativa. Com o objetivo de caracterizar a amostra 
alcançada neste trabalho, elaborou-se a Tabela 1. Essa tabela retrata a idade e a escolaridade das mulheres avaliadas, nos três grupos analisados.

Tabela 1. Distribuição (em frequência simples) das participantes $(n=60)$ em função da idade e escolaridade.

\begin{tabular}{|c|c|c|c|c|c|c|}
\hline \multirow{3}{*}{ GRUPOS } & \multirow{2}{*}{\multicolumn{2}{|c|}{$\begin{array}{l}\text { IDADE } \\
\text { (anos) }\end{array}$}} & \multicolumn{3}{|c|}{ ESCOLARIDADE } & \\
\hline & & & Nível & \multicolumn{3}{|c|}{ Superior (universitária) } \\
\hline & 30 a 40 & 41 a 50 & Médio & Incompleta & Completa & Pós-graduação \\
\hline G1 & 5 & 15 & 5 & - & 14 & 1 \\
\hline $\mathrm{G} 2$ & 4 & 16 & 5 & 1 & 10 & 4 \\
\hline G3 & 17 & 3 & 2 & 1 & 12 & 5 \\
\hline Subtotal & 26 & 34 & 12 & 2 & 36 & 10 \\
\hline Total & \multicolumn{2}{|c|}{60} & \multicolumn{4}{|c|}{60} \\
\hline
\end{tabular}

Em relação à idade das participantes, verificou-se que, na amostra como um todo houve equilíbrio entre o número de mulheres abaixo e acima de 40 anos de idade, retratando um perfil etário adequado em relação aos objetivos deste projeto, ou seja, semelhante ao perfil médio de mulheres pretendentes à adoção na comarca de Ribeirão Preto (idade em torno de 40 anos). O grupo total alcançou idade média de 39,4 anos (DP = 5,7), mas com especificidades etárias como se pode notar pela idade média de cada grupo, a saber: G1 $=41,9$ anos (DP $=$ $5,4) ; \mathrm{G} 2=42,4 \operatorname{anos}(\mathrm{DP}=3,5) ; \mathrm{G} 3=34,1$ anos $(\mathrm{DP}=3,7)$.

Foi possível observar que as mães biológicas, em sua maioria, apresentaram idade menor que 40 anos de idade, sendo, portanto, o subgrupo mais jovem na amostra presentemente estudada. Cabe destacar, no entanto, que se buscou, para compor o G3, mães biológicas acima de 30 anos de idade no momento da avaliação, de forma a tentar aproximar a faixa etária dos grupos a serem comparados. A comparação estatística (por meio de análise da variância) da idade média das participantes dos três grupos apontou diferença significativa ( $F$ $=23,804 ; p \leq 0,001)$, sendo G3 composto por mães mais jovens, apesar do esforço de balancear essa variável (idade) na composição dos grupos do estudo. Contudo, essa realidade retrata a experiência efetiva dessas mulheres em termos de distribuição etária, sendo aceita para o presente trabalho.

Em relação ao nível de escolaridade, a maioria das participantes (aproximadamente 75\%) possuía ensino superior completo e/ou pós-graduação, sem grandes discrepâncias neste 
quesito entre os três grupos estudados. É relevante lembrar que o critério da escolaridade foi tomado como balizador na seleção das participantes, visto que, no cadastro das pretendentes a adoção, o padrão acadêmico mais comum é o de alta escolaridade (pelo menos ensino médio ou superior). Esse critério foi seguido nesse trabalho, de modo a favorecer a comparação dos grupos em termos de escolaridade, conforme inicialmente delineado.

Em relação às ocupações desempenhadas pelas participantes, foi possível verificar que, no conjunto de mulheres avaliadas $(n=60), 85 \%$ exerciam atividade remunerada fora de casa, enquanto $15 \%$ classificaram sua ocupação como sendo "do lar", ou seja, dedicavam-se exclusivamente à casa e à família. Importante destacar que, nos dois grupos formados por mulheres em exercício da maternidade (G2 e G3), houve maior incidência de mulheres que não exerciam atividade remunerada, com cinco casos entre mães adotivas (G2) e três casos nas mães biológicas (G3). No grupo das pretendentes à adoção (ainda sem filhos, G1), apenas uma mulher não trabalhava fora do lar. Esse grupo marcou-se, assim, por predomínio de mulheres em atividades profissionais remuneradas.

No que se refere à constituição familiar, conforme critérios prévios, todas estavam vivenciando união conjugal no momento da avaliação, independentemente de sua formalização (casadas ou união estável). As integrantes de G1 não tinham filhos nem estavam exercendo o papel materno (enteados, sobrinhos ou cuidado com outra criança), caracterizando uma situação de ausência de filhos biológicos e/ou adotivos, sendo a família nuclear formada apenas pelo casal.

Em G2 e em G3 as mulheres eram mães, adotivas (G2) ou biológicas (G3), sendo o grupo familiar constituído, portanto, pelo casal e sua prole. No que se refere ao número de filhos, a maioria das mães adotivas possuía apenas um filho (90\%), enquanto no grupo de mães biológicas a maioria tinha um (45\%) ou dois filhos (40\%). Um delineamento do perfil etário dos filhos das participantes de G2 e de G3 pode ser visualizado na Tabela 2. Para essa tabulação, considerou-se apenas a idade do primeiro filho, uma vez que a maioria das mães adotivas só tinha um(a) filho(a).

Tabela 2. Perfil etário (em meses) dos filhos das participantes de G2 (n=20) e de G3 (n=20).

$$
\text { IDADE }
$$

\begin{tabular}{ccccc} 
GRUPO & Média & Mínima & Máxima & Média na adoção \\
\hline G2 & 57 & 19 & 105 & 2 \\
G3 & 64 & 20 & 147 & - \\
\hline
\end{tabular}


Pode-se notar que, no geral, a média de idade dos filhos esteve em torno de 61 meses, ou seja, cerca de cinco anos no momento desse estudo. O perfil etário das crianças girou entre 19 e 147 meses, respeitando-se os critérios inicialmente delineados para a pesquisa (entre um e 12 anos de idade). Houve, ainda, equilíbrio entre as médias etárias dos filhos de G2 e G3 no momento da avaliação, alcançando-se adequado balanceamento no perfil etário dos filhos das participantes desses dois grupos, conforme planejado nessa pesquisa.

Quanto ao tempo de convívio com o filho adotivo, conforme seleção prévia das participantes, todas as mães de G2 estavam exercendo a efetiva guarda das crianças há pelo menos 12 meses. No geral, os filhos de G2 foram adotados logo após o nascimento, sendo que a média de idade por ocasião da adoção foi de dois meses de vida. Desse modo, as participantes de G2 se encontravam no exercício da maternidade adotiva, na maioria dos casos, há alguns anos, atendendo aos critérios delineados para compor esse grupo de mulheres no estudo.

\section{III.3. Materiais}

Diante dos objetivos propostos para o presente estudo foram necessários os seguintes materiais:

\section{III.3.1. Termo de Consentimento Livre e Esclarecido (TCLE)}

O TCLE para este estudo (APÊNDICE A) foi formulado de modo a que as voluntárias recebessem as informações básicas sobre os objetivos e os procedimentos desta pesquisa, além de seus direitos enquanto participante, incluindo a possibilidade de desistir do estudo a qualquer momento. Trata-se de documento essencial, visando a garantia de sua proteção ética, inerente às pesquisas com seres humanos. Referido documento contou com a devida identificação da pesquisadora responsável, sendo assinado em duas vias por aquelas que concordaram com a participação no trabalho, permanecendo uma cópia com elas e outra com a pesquisadora.

\section{III.3.2. SRQ-20}

O Self-Reporting Questionnaire (SRQ) é um instrumento de autorrelato voltado para a avaliação de indicadores relativos à saúde mental, desenvolvido pela Organização Mundial de Saúde (OMS, 2001). Esse instrumento foi objeto específico de estudo de validação e de padronização brasileira por Santos, Araújo e Oliveira (2009), sendo composto por vinte itens, 
com bons índices psicométricos na realidade nacional. Conforme referidos autores, a avaliação da consistência interna atestou alta correlação entre as questões (Alfa de Cronbach $=0,81$ ), apontando adequada precisão do instrumento. Sua análise fatorial permitiu a extração de quatro fatores, com variância explicada de 59,6\% no total. Deste modo, foi considerado que o SRQ-20 apresenta desempenho psicométrico adequado para avaliar os transtornos mentais comuns, servindo como instrumento de rastreamento da saúde mental (Santos, Araújo \& Oliveira, 2009).

Suas questões devem ser respondidas com "sim" ou "não" e buscam avaliar indicadores da presença de sintomas relacionados a transtornos não psicóticos, tais como insônia, fadiga, irritabilidade, esquecimento, dificuldade de concentração e queixas somáticas. O SRQ tornou-se instrumento amplamente utilizado para suspeição diagnóstica dos transtornos mentais comuns e já foi traduzido para oito idiomas diferentes, sendo um dos instrumentos mais utilizados para triagem de morbidade psíquica em adultos nos estudos brasileiros.

$\mathrm{Na}$ avaliação do SRQ são atribuídos pontos para os itens assinalados positivamente, sendo que, pelo referido estudo brasileiro (Santos, Araújo \& Oliveira, 2009), são casos prováveis de transtornos mentais os indivíduos que tiverem resultado superior a sua nota de corte (sete itens positivos). Esse instrumento foi aplicado em formato de entrevista no presente estudo, permitindo inicial contato e estabelecimento de rapport com as participantes. Além disso, em G3 (mães biológicas), o SRQ foi utilizado como triagem e seleção de participantes, buscando-se compor este grupo com mulheres saudáveis do ponto de vista psíquico, de modo que funcionasse efetivamente como grupo de comparação frente aos demais casos avaliados.

\section{III.3.3. Bateria Fatorial de Personalidade (BFP)}

Trata-se de instrumento psicológico com base em autorrelato, construído no Brasil (Nunes, Hutz \& Nunes, 2010), que busca a avaliação da personalidade por meio da concepção teórica dos "Cinco Grandes Fatores” (CGF). É constituído por escalas que buscam avaliar as cinco dimensões básicas da personalidade: extroversão (subescalas: comunicação, altivez, dinamismo e interações sociais), socialização (subescalas: amabilidade, pró-sociabilidade e confiança nas pessoas), realização (subescalas: competência, ponderação/prudência e empenho/comprometimento), neuroticismo (subescalas: vulnerabilidade, instabilidade emocional, passividade/falta de energia e depressão) e abertura a experiências (subescalas: abertura a ideias, liberalismo e busca por novidades). Os resultados em cada uma dessas 
escalas (e suas respectivas subescalas) caracterizam marcadores individuais, retratando psiquicamente os indivíduos em termos de componentes da personalidade. Seus conteúdos serão descritos de modo detalhado na seção dos resultados, de modo a facilitar o processo interpretativo dos achados desta pesquisa. Trata-se, portanto, de uma perspectiva fatorial e descritiva da constituição individual no tocante à personalidade, obtida por meio do autorrelato, ou seja, a partir da visão do próprio respondente.

O instrumento está composto por 126 sentenças (itens) que solicitam do respondente um posicionamento numa escala Likert de sete pontos, sendo que o ponto 1 significaria “descreve-me muito mal” e o ponto 7 significaria “descreve-me muito bem”. No que se refere aos indicadores psicométricos de referido instrumento, descritos no manual, a consistência interna das cinco dimensões da personalidade e suas facetas apontou indicadores de precisão por Alfa de Cronbach entre 0,58 e 0,89, sendo estes resultados considerados satisfatórios para seu uso na população brasileira. Foram realizados estudos normativos com amostras adultas, de ambos os sexos, em cinco diferentes estados, buscando-se, assim, representar as diversas regiões do país, sendo apresentados os valores centrais e percentis acerca de seu padrão de respostas diante deste instrumento. No manual também constam estudos de correlação entre BFP e outros instrumentos de avaliação de personalidade, sendo obtidos indicadores de validade concorrente favoráveis ao uso de referido instrumento no Brasil.

Na presente investigação, a BFP foi aplicada e codificada de acordo com as instruções constantes em seu manual técnico brasileiro (Nunes, Hutz \& Nunes, 2010). Foi utilizada como instrumento de avaliação de personalidade a partir do ponto de vista dos próprios respondentes (autorrelato), sendo por eles individualmente preenchido.

\section{III.3.4. Questionário Desiderativo}

O Questionário Desiderativo caracteriza-se como método projetivo de avaliação psicológica, verbal, de rápida aplicação, constituído por conjunto específico de questões que devem ser respondidas livremente pelo examinando, a partir de suas associações espontâneas e imediatas. As questões promovem escolhas individuais (denominadas como catexes) quanto à identidade, avaliando sua flexibilidade e seus pilares de sustentação, autorreferidos a partir das justificativas verbalizadas em cada questão. Teoricamente estão previstas seis perguntas básicas, estimulando três escolhas positivas (catexes positivas) e três rejeições (catexes negativas), devendo contemplar diferentes níveis de preservação da vida em suas justificativas, passando pelos reinos animal, vegetal e inanimado (Cabrera, 1999). Após cada 
escolha ou cada rejeição solicita-se justificativa para o símbolo escolhido, racionalização que subsidiará o acesso a aspectos da dinâmica da personalidade do indivíduo. Nas catexes positivas, conforme Nijamkin e Braude (2000), o respondente sinaliza elementos ligados àquilo que o Ego deseja preservar, ou seja, mecanismos que o indivíduo utiliza para se manter integrado e que são reconhecidos pelo indivíduo como próprios (fantasias inconscientes de defesa). Nas catexes negativas, as respostas referem-se ao que a pessoa teme acontecer caso suas defesas falhem, além dos conteúdos dos quais ela, projetivamente, se defende. Trata-se, portanto, de instrumento projetivo de avaliação da personalidade, pautado por uma concepção psicodinâmica (Nijamkim \& Braude, 2000).

O Questionário Desiderativo informa, portanto, sobre características de personalidade, defesas, conflitos básicos, força do Ego, aspectos afetivos, relações objetais, entre outras informações relevantes em avaliação psicodiagnóstica de abordagem psicodinâmica. Para o presente estudo, utilizar-se-á o trabalho de Guimarães, Pasian e Loureiro (2008) como subsídio técnico para análise da produção das participantes.

O Questionário Desiderativo dispõe de estudo normativo no Brasil (Guimarães \& Pasian, 2009), desenvolvido com adolescentes, no qual se obteve bons indicadores de precisão (acordo total e/ou parcial entre examinadores independentes em todas as categorias avaliativas utilizadas, à exceção das defesas). Referido estudo foi efetuado com base na proposição avaliativa de Nijamkin e Braude (2000), conforme detalhado em Guimarães, Pasian e Loureiro (2008). Esse sistema avaliativo utilizado está apresentado no APÊNDICE B.

No entanto, ressalta-se, ainda, a necessidade de mais investimentos em pesquisas voltadas para a investigação das bases psicométricas do Questionário Desiderativo como técnica de avaliação de personalidade no contexto sociocultural brasileiro, com o objetivo de torná-lo instrumento cientificamente fundamentado para diferentes etapas do desenvolvimento (Guimarães \& Pasian, 2009). Trata-se, como proposto, de um objetivo específico do presente estudo: evidenciar dados empíricos a respeito da precisão e da validade do Questionário Desiderativo, a partir de suas relações com outros instrumentos de avaliação da personalidade (construtos relacionados).

\section{III.3.5. Método de Rorschach}

Trata-se de método projetivo de avaliação psicológica, composto por conjunto de dez cartões (padronizados) com manchas de tinta, que, de acordo com sua fundamentação teórica, permite a avaliação de características estruturais e funcionais da personalidade (Pasian, 2000; 
Weiner, 2000). Os cartões são apresentados um a um, solicitando-se do respondente que diga com o que os estímulos podem parecer. Para a aplicação do instrumento, além dos cartões, são necessárias folhas para registro dos dados, folha padronizada de localização das respostas, folha para codificação das respostas e cronômetro para registro do ritmo do trabalho do respondente.

O Método de Rorschach dispõe de diferentes sistemas avaliativos, desenvolvidos ao longo de sua história (Jardim-Maran, 2011). No presente trabalho optou-se pelo referencial técnico-científico do Rorschach descrito por Ombredane e Canivet, conhecido como a Escola Francesa ou Escola de Paris, conforme proposição apresentada classicamente por Rausch de Traubenberg (1998) e Anzieu (1986), e mais recentemente por Azoulay et al. (2007), demonstrando as adequadas bases teóricas e empíricas deste método projetivo para avaliação da personalidade. Trata-se de perspectiva psicodinâmica para análise dos componentes internos e seu funcionamento psíquico individual, possibilitando acesso a informações sobre a capacidade produtiva, componentes lógicos e afetivos, relacionamentos interpessoais e características da organização defensiva.

Foram desenvolvidos estudos com a abordagem francesa do Rorschach na região de Ribeirão Preto (SP), objetivando atualização dos padrões normativos para crianças, adolescentes e adultos no contexto do Brasil (Casillo-Jardim, 2011; Cury-Jacquemin, 2012; Fernandes, 2010; Freitas, 2016; Pasian, 2000; Raspantini, 2010). Nessas pesquisas recorreu-se à análise dos casos por examinadores independentes como forma de avaliar a precisão deste sistema avaliativo do Rorschach, sendo alcançados indicadores superiores a $90 \%$ de concordância na maioria dos grupos de variáveis examinadas (localizações, determinantes, conteúdos e banalidades), fornecendo indicativos relevantes de fidedignidade para este instrumento projetivo. Sendo assim, há trabalhos recentes atestando a qualidade das avaliações psicológicas realizadas por meio da Escola Francesa do Rorschach, bem como referenciais normativos atualizados, o que confere segurança na escolha deste instrumento projetivo para compor o material utilizado na presente investigação.

Para análise dos casos deste estudo foram utilizados os referenciais normativos do Rorschach desenvolvidos por Pasian (2000), englobando adultos da região de Ribeirão Preto (SP), compatíveis, portanto, com a faixa etária aqui focalizada. Diante da amplitude de variáveis inerentes ao sistema da Escola Francesa do Rorschach (Rausch de Traubenberg, 1998), no presente estudo procurou-se caracterizar o perfil geral de variáveis técnicas relacionadas à produtividade $(\mathrm{R}, \mathrm{RA}, \mathrm{Rec}, \mathrm{Den})$, aos modos de apreensão (G, D, Dd, Dbl), aos 
determinantes (forma, cor, sombreado e movimento), conteúdos e banalidades, na expectativa de exploração geral da personalidade dos três grupos de mulheres avaliadas.

\section{III.3.6. Programas computacionais para registro e análise dos dados, a saber}

Foram utilizados planilhas Excel para Windows (Microsoft) e software IBM SPSS Statistic (v. 22, IBM SPSS, Chicago, IL).

\section{III.4. Procedimentos}

\section{III.4.1. Aspectos Éticos}

O presente estudo foi apreciado pelo Comitê de Ética em Pesquisa da Faculdade de Filosofia, Ciências e Letras de Ribeirão Preto da Universidade de São Paulo (CAAE no. 09267012.1.0000.5407), recebendo aprovação para sua realização (ANEXO 2). O processo de coleta de dados teve início, como previsto, posteriormente ao recebimento dessa aprovação da proposta investigativa.

Os devidos cuidados técnicos e éticos inerentes a qualquer avaliação psicológica foram tomados com as participantes, as quais foram informadas quanto aos objetivos da pesquisa e consultadas sobre a possibilidade de participação neste trabalho. Desse modo, foram garantidos o sigilo e a liberdade de participação nesta pesquisa, que se caracterizou por ser voluntária e não remunerada. Após adequado convite individual e aceite da proposta, o Termo de Consentimento Livre e Esclarecido (TCLE) foi assinado pelas voluntárias para, então, efetivar a coleta de dados.

Às interessadas foi oferecida a possibilidade de agendamento de entrevistas devolutivas a respeito dos resultados obtidos nas avaliações individuais, como um meio de oferecer possível contribuição a sua participação na pesquisa. Cabe ainda ressaltar que, caso fossem identificadas necessidades de auxílio profissional ao bem-estar emocional destas mulheres, a pesquisadora as encaminharia a serviços específicos de Saúde em seus respectivos órgãos de referência de atendimento psicológico na cidade em estudo. Apesar dessa proposição inicial, no presente trabalho não foi necessário efetivar qualquer encaminhamento profissional das participantes para serviços de atendimento psicológico, dentro dos limites das informações alcançadas. 


\section{III.4.2. Coleta de Dados}

Nos três grupos de participantes, na maioria das vezes, a coleta de dados se deu na residência das mesmas (51 casos), além de ter sido utilizado o local de trabalho (em seis casos) e, em apenas três casos, as informações foram coletadas nas dependências do Centro de Psicologia Aplicada da FFCLRP-USP. Em todos os casos, a aplicação dos instrumentos de avaliação psicológica foi precedida pela devida leitura e assinatura do Termo de Consentimento Livre e Esclarecido (TCLE) ao estudo. $\mathrm{O}$ trabalho foi realizado individualmente, em contextos ambientais que contavam com a devida privacidade e silêncio, necessários a qualquer processo de avaliação psicológica.

Os instrumentos propostos para este estudo foram aplicados na seguinte ordem: SRQ20, Bateria Fatorial de Personalidade (BFP), Questionário Desiderativo e Rorschach (Escola Francesa), utilizando-se para tanto as diretrizes preconizadas em seus respectivos manuais técnicos ou manuscritos de referência técnico-científica. O processo de coleta de dados teve duração média de 90 minutos, realizado em sessão única.

Por fim, cumpre destacar que, para o processo de coleta de dados (aplicação dos instrumentos de avaliação psicológica) foi possível contar com a colaboração de duas colaboradoras (psicólogas com experiência em avaliação psicológica e previamente treinadas em relação aos instrumentos utilizados), que executaram 25\% das avaliações (15 casos), enquanto a pesquisadora realizou os demais 75\% (45 casos). Também se faz necessário destacar que os casos de G2 (mães adotivas) foram exclusivamente avaliados pela pesquisadora, tendo em vista os cuidados especiais necessários com essas participantes, de modo a protegê-las de contatos adicionais com outras psicólogas.

\section{III.4.3. Análise de resultados}

Após a finalização da coleta dos dados, deu-se início à análise dos resultados obtidos por meio dos instrumentos utilizados. Para tanto, realizou-se a classificação da produção individual das mulheres em cada técnica de avaliação psicológica, baseando-se, para isso, nos respectivos manuais ou trabalhos científicos de referência, conforme anteriormente descrito.

Como forma de caracterizar a produção das mulheres nos instrumentos realizou-se a estatística descritiva de cada grupo avaliativo, incluindo valores de média, mediana, desvio padrão, mínimo e máximo. Buscou-se verificar se os dados correspondiam a uma distribuição normal, mediante teste estatístico Shappiro-Wilk (adequado para grupos com $\mathrm{n}<50$ ), para 
posterior escolha da estatística inferencial apropriada (paramétrica ou não paramétrica) para análise comparativa dos grupos. Nas variáveis em que foi detectada distribuição normal dos dados, utilizou-se Anova na comparação entre os grupos, enquanto nas demais foi usado o teste de Kruskal-Wallis. Na análise inferencial de variáveis nominais ou categóricas utilizouse Qui-quadrado na comparação entre os grupos. Adotou-se o nível de significância de 5\% nas análises estatísticas efetivadas.

Houve, no entanto, especificidades relativas à análise de dados dos vários instrumentos, a seguir descritas. Procurou-se delinear algumas hipóteses relativas às variáveis examinadas por cada um dos recursos técnicos usados no estudo, de modo a facilitar posterior interpretação e discussão dos achados.

\section{Sobre a BFP}

Referido instrumento foi utilizado neste estudo com a finalidade de caracterizar a personalidade por meio de autorrelato, pautando-se por cinco domínios conforme a fundamentação teórica do instrumento (Teoria dos Cinco Grandes Fatores de Personalidade). Com base neste referencial, os escores brutos das participantes de cada grupo foram sistematizados para as dimensões da personalidade: Extroversão, Socialização, Realização, Neuroticismo e Abertura a experiências, detalhados em função de suas subescalas.

Fundamentando-se na literatura científica alcançada, a partir de revisão bibliográfica, foi possível elaborar a premissa de que a maternidade (biológica ou adotiva) se configura como experiência relevante da identidade feminina. Diante disso e com relação a indicadores da BFP foram formuladas as seguintes hipóteses:

(1) As mulheres inférteis e candidatas à adoção (G1) poderiam apresentar resultados mais elevados nas subescalas componentes do Fator Neuroticismo. Isto porque, conforme proposição teórica associada ao instrumento, índices elevados nesta escala significariam propensão maior "a vivenciar, de forma mais intensa, sofrimento psicológico, instabilidade emocional e vulnerabilidade" (Nunes, Hutz \& Nunes, 2010, p. 126).

(2) Dado que as mulheres de G2, apesar de inférteis, já estão vivenciando a maternidade adotiva, bem como que em G3 as mulheres possuem seus próprios filhos biológicos, os indicadores de Neuroticismo de G1 seriam maiores que em G2 e estes, por sua vez, seriam maiores que em G3. 


\section{Sobre o Método de Rorschach}

Com o objetivo de garantir a precisão das análises realizadas neste estudo, optou-se por realizar a análise por examinadores independentes (Pasquali, 2010). Sendo assim, cada protocolo coletado $(n=60)$ foi classificado por dois juízes independentes. Nos casos em que houve desacordo na classificação das respostas, um terceiro examinador (orientadora do estudo) realizou o desempate. A partir das codificações independentes e posterior desempate, foi elaborada uma folha final de classificação do protocolo do Rorschach para cada caso, composta a partir do consenso entre as classificações realizadas.

A tarefa de codificação do conjunto de protocolos de Rorschach que compõe a presente amostra foi processada por cinco psicólogos, sendo um deles a própria pesquisadora e os demais colaboradores do grupo do Centro de Pesquisas em Psicodiagnóstico (CPP) da FFCLRP-USP, todos com experiência prévia no Método de Rorschach. Entretanto, a despeito dos profissionais colaboradores já terem prática de pesquisa no uso deste instrumento, cada psicólogo passou por treino específico para o desenvolvimento deste trabalho, buscando-se homogeneizar a codificação das respostas.

Com a finalidade de realizar este preparo inicial dos examinadores independentes, foi realizado um estudo-piloto, no qual cada um dos cinco psicólogos codificou, de maneira independente, três protocolos do Rorschach, retirados do banco de dados existente no Centro de Pesquisas em Psicodiagnóstico (CPP). Após a codificação independente destes protocolos, calculou-se o índice de acordo (porcentagem de concordância) entre os cinco examinadores para as quatro categorias de classificação das respostas (localização, determinante/qualidade formal, conteúdo e banalidades). Foram adotadas as orientações de Weiner (1991) e Fernterseifer e Werlang (2008), verificando se os colaboradores estariam aptos para iniciar o processo de codificação do conjunto de protocolos $(n=60)$.

Foi considerado acordo total quando a codificação da resposta foi idêntica entre os cinco examinadores. $\mathrm{O}$ acordo parcial foi considerado quando três ou quatro psicólogos atribuíram as mesmas codificações ao segmento da resposta. Já o desacordo foi caracterizado quando apenas um ou dois atribuíram aquela classificação para cada componente da resposta ao Rorschach. O "acordo total" e o "acordo parcial" foram considerados concordância entre os avaliadores independentes. Nesta análise inicial do estudo-piloto, os valores de acordo atingidos nas quatro principais categorias de classificação das respostas da Escola Francesa do Rorschach foram os seguintes: (a) localizações $=94,0 \%$; (b) determinantes $=81,0 \%$; (c) conteúdos=87,5\%; (d) banalidades $=95,0 \%$. Esses índices de concordância entre os 
examinadores foram superiores a $80 \%$, considerados bastante adequados, segundo recomendação de Weiner (1991).

Após o alcance do índice de acordo necessário entre os cinco examinadores, iniciou-se a análise dos protocolos de Rorschach que compõem a presente amostra. Cada caso foi avaliado por dois examinadores independentes, contando, ao final, com o desempate de eventuais desacordos pela orientadora do estudo. A própria pesquisadora exerceu a função de primeiro juiz independente e avaliou os 60 protocolos de Rorschach. Os demais quatro examinadores receberam, cada um, 15 protocolos para avaliação, sem dados que permitissem a identificação das mulheres examinadas (às cegas).

Após conclusão do processo de codificação dos casos coletados para este estudo, foi calculado o índice final de precisão entre os examinadores. Para averiguação do índice final de acordo (Kappa) no Rorschach foram selecionados, de forma aleatória, 25\% dos casos (15 protocolos).

Para o presente trabalho, realizou-se a estatística descritiva e inferencial dos principais indicadores do Rorschach, a saber: variáveis de produtividade (R, RA, Rec e Den), de localização (G, D, Dd, Dbl e Do), dos determinantes (F\%, F+, F+extenso, K, kan, kob, kp, FC, CF, C, FE, EF, E, FClob, ClobF e Clob), bem como dos Conteúdos [H, (H), Hd, (Hd), A, (A), Ad, (Ad), Anat, Bot, Obj, Geo, Sg, Sex, Arq, Art, Simb, Frag, Elem), além das fórmulas vivenciais [Tipo de Ressonância Íntima (TRI), Fórmula das Tendências Latentes (TL), Reatividade Afetiva e Fórmula da Angústia].

Além da descrição específica dessas variáveis entre os grupos, com sua análise estatística comparativa, também se examinou a distribuição dos casos de G1, G2 e G3 em relação aos parâmetros normativos do Rorschach, classificando-as em "abaixo da média" ou "acima/na média". Essa análise complementar procurou identificar a posição que cada participante ocupava em relação ao esperado para seu grupo de referência, comparando-se (por meio do Teste Qui-quadrado, $p \leq 0,05$ ) essa distribuição dos casos entre os grupos aqui delineados.

Algumas hipóteses, baseadas na literatura científica disponível, foram formuladas sobre os dados do Rorschach. Foram elas:

(1) Mulheres inférteis e candidatas à adoção (G1) sinalizariam mais indicadores de angústia no Rorschach, a saber: maior uso do detalhe branco (Dbl) nas localizações das respostas; maior proporção de determinantes do tipo sombreado e com disforia; maior frequência de conteúdos Anat, Sex, Hd, (Hd), Elem Fog, Frag em suas respostas. Esses 
indicadores destacados seriam mais frequentes em G1 do que em G2 e, por sua vez, menores em G3.

(2) Presença de resultados médios com mais indicadores de angústia em G1 nos cartões simbolicamente associados a identidade e feminilidade no Rorschach, a saber: cartão V (identidade superficial), cartão IX (identidade profunda), cartão VI (sexualidade) e cartão VII (imago feminina).

\section{Sobre o Questionário Desiderativo}

Um dos objetivos do presente estudo voltou-se ao aprimoramento do sistema avaliativo do Questionário Desiderativo, testando-o com grupos de adultos. Tem-se, do estudo de Guimarães, Pasian e Loureiro (2008), que a maioria dos itens avaliativos do Questionário Desiderativo (com base no modelo de Nijamkim \& Braude, 2000) ofereceu índices satisfatórios de precisão, a partir da análise da concordância entre examinadores. Entretanto, no tocante aos mecanismos de defesa houve baixo índice de acordo entre examinadores por ocasião do estudo anterior, talvez pela variabilidade no repertório de mecanismos listados e identificados por cada profissional.

Diante desse contexto, definiu-se estratégia para aprimorar esse quesito avaliativo, recorrendo a tentativa de validação de conteúdo no tocante aos mecanismos de defesa por meio da consulta a profissionais experientes (experts) no Questionário Desiderativo (Pasquali, 2010). Na literatura científica disponível sobre esse método projetivo de avaliação psicológica nenhum procedimento empírico para definição de critérios avaliativos sobre mecanismos de defesa foi encontrado, razão da presente proposição.

Partiu-se de uma listagem dos mecanismos de defesa apresentados em clássico compêndio de Psiquiatria (Kaplan, Saddock \& Grebb, 1997), selecionado por seu caráter operacional na descrição desses processos psíquicos. A pesquisadora, em análise conjunta com sua orientadora, listou os mecanismos de defesa apresentados nesse compêndio de referência, com base no critério de sua possível aplicação prática para a análise pelo Questionário Desiderativo. Essa listagem de estratégias defensivas, juntamente com suas respectivas definições (segundo Kaplan, Saddock \& Grebb, 1997), foi transposta para uma tabela descritiva que serviu de base para a análise do conteúdo dos especialistas (APÊNDICE C).

Em seguida, foram convidados para participar dessa análise de conteúdo (mecanismos de defesa para análise do Questionário Desiderativo) cinco profissionais considerados experts na área, psicólogos com vasta experiência clínica e de pesquisa em avaliação psicológica com 
base psicodinâmica. Todos aceitaram participar dessa etapa da pesquisa. Eles receberam o material do APÊNDICE C (apenas com as definições das defesas), acrescido da tarefa de avaliar a pertinência da inclusão de cada um dos mecanismos defensivos no protocolo avaliativo do Questionário Desiderativo, visando a sua adequada e precisa codificação por outros profissionais no futuro. Solicitou-se também que oferecessem exemplos concretos de cada mecanismo de defesa no Desiderativo, a partir de sua prática de avaliação psicológica, a fim de ilustrar estes fenômenos tal como aparecem na prática clínica. Foi solicitado ainda que, caso o examinador considerasse que a defesa listada não devesse configurar na lista de itens avaliativos do Desiderativo, justificasse sua sugestão de não inclusão do referido mecanismo de defesa no protocolo. Por fim, solicitou-se aos experts que incluíssem (com a devida justificativa) outros mecanismos de defesa que considerassem relevantes e/ou pertinentes na análise das respostas ao Questionário Desiderativo.

A classificação dos experts foi pautada em sua própria experiência clínica e seu domínio teórico próprio, ocasionando variabilidade analítica e divergências quanto à classificação e definição sobre os mecanismos de defesa. Desse modo, esses itens (tipos defensivos) com reduzido acordo foram descartados, restando no protocolo avaliativo apenas aqueles onde houve consenso sobre a relevância do mecanismo defensivo entre os especialistas consultados. Deste modo, chegou-se ao Protocolo de Codificação do Desiderativo apresentado no APÊNDICE D, utilizado para a presente investigação.

A partir deste protocolo e do sistema avaliativo proposto por Nijamkim e Braude (2000), sistematizado de forma didática em Guimarães, Pasian e Loureiro (2008), bem como de critérios estabelecidos pela pesquisadora em casos de dúvidas na codificação (detalhados no APÊNDICE E), realizou-se o treinamento avaliativo dos examinadores independentes. Foi novamente realizado treino de codificação de casos retirados de banco de dados existente no Centro de Pesquisas em Psicodiagnóstico (CPP), realizando-se discussões desses casos clínicos entre a equipe de colaboradores deste estudo.

Para tanto, cada um de cinco psicólogos codificou, de maneira independente, três protocolos do Desiderativo, calculando-se o índice de acordo entre os examinadores para as categorias de classificação das respostas (Adequação ao Real, Conteúdo do Pensamento, Manifestações afetivas, Defesas Instrumentais e Outros mecanismos defensivos). Foi considerado acordo quando houve ao menos quatro codificações iguais dentre os cinco examinadores; já o desacordo foi caracterizado quando houve mais de uma codificação diferente em cada item avaliativo do Desiderativo. Nesta análise inicial, os valores de acordo atingidos nas quatro principais categorias de classificação das respostas foram os seguintes: 
(a) Adequação ao Real=100,0\%; (b) Conteúdo do Pensamento = 88,8\%; (c) Manifestações Afetivas $=92,5 \%$ (d) Defesas instrumentais $=92,5 \%$; e) Outras defesas $=86,7 \%$. Os índices de concordância entre os examinadores encontrados neste estudo-piloto do Desiderativo foram superiores a 80,0\%, considerados adequados segundo recomendação de Weiner (1991).

Após o alcance do índice de acordo necessário entre os cinco examinadores, iniciou-se a efetiva análise dos protocolos de Desiderativo que compõem a presente amostra. Cada caso recebeu duas classificações independentes, chegando-se a uma codificação final a partir do consenso das avaliações prévias. Ao se detectar alguma discordância, os casos foram avaliados por um terceiro examinador (orientadora desse estudo), de modo a selecionar a codificação mais apropriada às respostas obtidas.

A pesquisadora exerceu a função de primeiro juiz independente e concluiu a avaliação dos 60 protocolos do Questionário Desiderativo que compõem a presente amostra. Os demais quatro examinadores receberam, cada um, 15 protocolos para avaliação, sem dados que permitissem a identificação das mulheres examinadas (às cegas). A concordância entre os examinadores foi avaliada, tal como no estudo piloto, calculando-se a proporção de acordo (em porcentagem) entre examinadores em cada variável em estudo, além do cálculo de correlação entre as classificações independentes, considerando-se o total de casos avaliados ( $n=60)$ (Cohen, Swedlik \&Sturman, 2014).

Os resultados referentes ao Desiderativo foram organizados a partir das seguintes variáveis: Adequação ao Real (Tempo de Reação Médio, Sequência das Escolhas, Necessidade de Indução, Respostas Antropomórficas); Conteúdo do Pensamento (Funcionamento Lógico, Nível de Organização, Distinção entre realidade interna e externa); Manifestações Afetivas (Autopercepção, Associação Ideoafetiva, Interações); Defesas Instrumentais (Racionalização, Dissociação e Identificação Projetiva) e Outras Defesas (Negação, Sedução, Idealização, Formação Reativa e Sublimação). Seguiu-se, portanto, o modelo de Nijamkim e Braude (2000), exposto e adaptado por Guimarães, Pasian e Loureiro (2008).

A partir da literatura científica alcançada referente à temática da maternidade adotiva, infertilidade e suas possíveis repercussões na personalidade, formulou-se a seguinte hipótese no que se refere ao Desiderativo:

(1) As mulheres de G1, ainda sem exercício da maternidade, poderiam apresentar sinais de sobrecarga interna, relacionadas a possível sofrimento e ferida narcísica, expressas por alterações na eficiência defensiva. Os indicadores do Desiderativo possíveis de expressar tais especificidades funcionais seriam: 
a) tempos de resposta (desviantes para cima ou para baixo em G1);

b) sequência das escolhas (com falhas em G1);

c) falhas nas defesas instrumentais (em G1);

d) frequência diferenciada no uso dos mecanismos de defesa entre os três grupos, com predomínio de defesas mais primitivas em G1.

\section{Sobre análises correlacionais entre BFP, Rorschach e Desiderativo}

$\mathrm{Na}$ sequência das análises deste estudo buscou-se elaborar estratégias compatíveis com o objetivo específico de evidenciar indicadores de validade do Questionário Desiderativo. Nesta perspectiva de evidenciar sinais empíricos de associação entre os indicadores técnicos dos vários instrumentos de avaliação psicológica utilizados, voltados ao exame de características de personalidade, recorreu-se a análises de correlação entre suas variáveis. Embora com pressupostos teóricos diversos, os três instrumentos de avaliação psicológica abordam construtos relacionados, sendo possível utilizar da estratégia correlacional para apontar pontos de convergência entre seus resultados, fortalecendo-os mutuamente.

Como apontam Nunes e Primi (2010): “Alguns estudos utilizam outros testes como variáveis externas que avaliam construtos teórica ou logicamente relacionados ao instrumento, mas que não são construtos convergentes nem discriminantes. Nesse caso, são esperadas correlações moderadas (entre 0,20 a 0,50) entre esses testes" (p. 119). Partiu-se desse delineamento para buscar possíveis associações entre os achados obtidos com a BFP, com o Rorschach e com o Desiderativo no presente estudo. Desse modo, poder-se-ia identificar evidências de validade do Questionário Desiderativo, visto que os demais instrumentos já são fortemente suportados pela literatura científica como válidos para exame de características da personalidade.

Nesse processo foram realizadas análises de correlação de Spearman entre alguns dos principais indicadores técnicos da BFP, do Rorschach e do Desiderativo para o grupo total de mulheres ( $n=60)$, bem como para cada grupo específico (G1, G2 e G3), conforme detalhado abaixo. Mais uma vez adotou-se o nível de significância de 5\% nas análises estatísticas efetivadas.

Com o objetivo de nortear a realização destas análises de correlação, buscou-se hipotetizar algumas correlações específicas entre os indicadores dos métodos projetivos. Essas associações, teoricamente plausíveis entre as variáveis do Rorschach e do Desiderativo, estão descritas abaixo. Dentre as variáveis da Bateria Fatorial de Personalidade, optou-se por utilizar as cinco principais facetas (Neuroticismo, Extroversão, Socialização, Realização e 
Abertura) nas análises, sem o estabelecimento de hipóteses específicas para estas últimas, apenas utilizando-as em caráter exploratório.

Sendo assim, as hipóteses referentes aos estudos de correlação entre os métodos de avaliação psicológica foram:

Indicadores de produtividade (associações interpretativas):

a) O número de respostas no Rorschach estaria positivamente associado ao número de induções no Desiderativo (induções produzem respostas adicionais) e, por outro lado, negativamente ao número de recusas também no Desiderativo (estas últimas sinalizando inibições ao responder).

b) O número de recusas no Rorschach estaria associado positivamente ao número de recusas no Desiderativo (ambos indicadores de inibições ao responder).

Indicadores referentes ao modo de interação com o ambiente:

a) O índice de respostas ao Rorschach localizadas no espaço branco (Dbl) teria associação positiva com a ocorrência de respostas antropomórficas e perseverações de reino no Desiderativo, pois todas remetem ao significado de oposição às instruções.

Indicadores referentes ao funcionamento lógico (raciocínio)

a) Os indicadores do Rorschach $\mathrm{F}+\%$ e $\mathrm{F}+\operatorname{ext} \%$ estariam positivamente relacionados a indicadores do Desiderativo ligados teoricamente ao uso da razão e da repressão na adaptação à realidade, como: Racionalização adequada, Conteúdo lógico do pensamento, Distinção adequada entre realidade interna e externa, Sublimação.

b) Hipotetizou-se associação negativa entre $\mathrm{F}+\%$ e $\mathrm{F}+\mathrm{ext} \%$ do Rorschach com as defesas Negação e Idealização, vistos que estas se pautam na negação da realidade, portanto, contrariam o ajuste lógico.

$\underline{\text { Indicadores referentes à coordenação/controle dos afetos }}$

a) Os indicadores do Rorschach porcentagem de respostas $\mathrm{FC}$, porcentagem de $\mathrm{CF}+\mathrm{C}$ e porcentagem de $\mathrm{EF}+\mathrm{E}$ apresentariam associação positiva com indicadores do Desiderativo relacionados a adequações lógicas e a coordenação entre ideias e afetos, como: Associação ideoafetiva (adequada), Racionalização adequada, Conteúdo Lógico do pensamento, Distinção adequada entre realidade interna e externa e Dissociação adequada. 


\section{Indicadores relativos à Identidade}

a) Os indicadores do Rorschach $\mathrm{H} \%$ (Identificação com o humano), $[\mathrm{H}+(\mathrm{H})] \%$ (figuras humanas inteiras), $\mathrm{A} \%$ e $[\mathrm{A}+(\mathrm{A})] \%$, bem como Bot e Anat $\%$ estariam associados positivamente a indicadores do Desiderativo que apontam para a integração da personalidade e também para a busca pelo contato com o outro, como: Dissociação adequada, Identificação Projetiva adequada, Interações de aproximação.

As tentativas analíticas de correlação entre os diversos indicadores técnicos dos instrumentos de avaliação psicológica tiveram por finalidade ilustrar pontos de convergência entre os achados, visto que as três técnicas (Rorschach, Desiderativo e BFP) abordam características de personalidade. Dessa análise exploratória advieram resultados promissores, complementando a clássica análise comparativa entre resultados médios dos três grupos de mulheres na BFP, no Rorschach e no Desiderativo, ampliando perspectivas de reflexão sobre seus alcances informativos a respeito de personalidade em indivíduos adultos. 


\section{RESULTADOS}

\section{IV.1. Relativos ao SRQ-20}

O SRQ-20 serviu, na presente pesquisa, ao propósito de caracterizar a amostra estudada em termos de indicadores relativos a saúde mental, bem como critério de seleção das integrantes do grupo de comparação (G3). Estas não deveriam atingir a nota de corte no SRQ20 (pontuação maior que sete, conforme Santos, Araújo \& Oliveira, 2009) representando, assim, mulheres com funcionamento psicológico sem marcas de relevante prejuízo ou com caráter psicopatológico.

A sistematização dos resultados obtidos no SRQ-20 encontra-se na Tabela 3. São apresentados os dados descritivos nesse instrumento, em função de cada grupo de mulheres presentemente avaliado.

Tabela 3. Resultados descritivos do SRQ-20 (escores brutos) em função dos grupos de mulheres $(n=60)$.

\begin{tabular}{cccc}
\hline Resultado SRQ & Grupo 1 & Grupo 2 & Grupo 3 \\
\hline Média & 2,55 & 1,65 & 2,75 \\
Desvio-padrão & 2,45 & 1,59 & 2,38 \\
Mediana & 2,00 & 1,50 & 2,00 \\
Mínimo & 0 & 0 & 0 \\
Máximo & 10,00 & 6,00 & 6,00 \\
\hline
\end{tabular}

Nos três grupos estudados a média de pontuação no SRQ-20 permaneceu abaixo da nota de corte estabelecida na literatura, ou seja, no geral, a amostra estudada não apresenta características psicopatológicas. Especificamente na composição de G3 (mães biológicas), não houve nenhum caso de voluntária inicial que tenha alcançado escore acima de sete. Assim foi possível compor um grupo de mulheres saudáveis do ponto de vista psíquico, de modo a funcionar efetivamente como grupo de comparação frente aos demais casos avaliados.

Houve apenas um caso entre as pretendentes à adoção (G1) que pontuou acima da nota de corte do SRQ-20, totalizando dez pontos. Por outro lado, observou-se que no grupo das mães biológicas (G3) houve a maior média de pontuação no referido instrumento, valor este bastante próximo ao encontrado no grupo das pretendentes à adoção (G1). As mães adotivas (G2), por sua vez, obtiveram escores médios menores que os demais grupos analisados. 
A partir da análise de normalidade $(W=0,842 ; p \leq 0,001)$, verificou-se a necessidade de utilizar estatística não paramétrica na comparação entre os resultados médios dos três grupos (Kruskal-Wallis, valor de estatística $\mathrm{Z}=0,008$ e $p=0,366$ ). Depreende-se ausência de diferenças estatisticamente significativas entre os três grupos estudados no que se refere à presença de indicadores psicopatológicos, conforme avaliação pelo SRQ-20. Deste modo, é possível concluir que os três grupos retratam mulheres saudáveis do ponto de vista psíquico, sem indicadores psicopatológicos evidentes, sugerindo homogeneidade entre os grupos quanto a este quesito.

\section{IV.2. Relativos à Bateria Fatorial de Personalidade (BFP)}

Frente aos objetivos propostos para a presente investigação, as mulheres participantes foram avaliadas por meio da Bateria Fatorial de Personalidade (BFP), conforme Nunes, Hutz e Nunes (2010), com o objetivo de caracterização de sua personalidade por meio do autorrelato. Foram consideradas os cinco fatores definidos pelo instrumento, conforme detalhamento a seguir.

Um dos fatores componentes da personalidade, a partir da BFP, denomina-se Neuroticismo. Sinaliza propensão do indivíduo "a vivenciar, de forma mais intensa, sofrimento psicológico, instabilidade emocional e vulnerabilidade" (Nunes, Hutz \& Nunes, 2010, p. 126). Segundo os autores, este fator também estaria relacionado, quando em níveis elevados, à ocorrência de sintomas associados a depressão e ansiedade.

De acordo com o manual técnico da BFP, o fator Neuroticismo é composto por quatro facetas, cada qual examinada por uma subescala específica nesse instrumento. São elas:

a) Vulnerabilidade: subescala que busca avaliar o padrão comportamental relativo a quanto o indivíduo vivencia sofrimento emocional em decorrência da sua percepção de como os outros o aceitam. É indicativo de maior ou menor flexibilidade em relação à dependência emocional e à dificuldade para tomar decisões em função do medo de decepcionar as pessoas.

b) Instabilidade emocional: os escores nesta subescala descrevem o padrão comportamental das pessoas no que se refere a como cada um se percebe irritável e nervoso, apresentando maiores ou menores variações de humor em determinadas situações. Avalia ainda a impulsividade em tomar decisões e grau de tolerância a frustrações.

c) Passividade: busca avaliar possíveis dificuldades das pessoas em serem proativas, bem como em iniciar e concluir tarefas importantes. Visa também identificar possíveis dificuldades para tomar decisões de maneira ágil e em concretizar suas motivações para realizar seus planos. 
d) Depressão: esta subescala busca identificar possíveis dificuldades em reconhecer eventos negativos e avaliar problemas, bem como para identificar soluções e implementá-las. Avalia o grau em que as expectativas em relação ao futuro estão mais otimistas ou pessimistas, com base na capacidade individual percebida para resolver problemas.

As informações referentes a cada uma dessas facetas do Fator Neuroticismo estão apresentadas na Tabela 4. Os resultados estão organizados em termos de cada subescala e pontuação total nesse domínio da personalidade, comparando-se dados médios dos grupos.

Tabela 4. Resultados descritivos e comparação estatística do Fator Neuroticismo e suas facetas (escores brutos) na BFP em função dos grupos de mulheres $(n=60)$.

\begin{tabular}{|c|c|c|c|c|c|c|}
\hline Escalas BFP & Resultados & Grupo 1 & Grupo 2 & Grupo 3 & Estatística & $p$ \\
\hline \multirow{5}{*}{ Vulnerabilidade } & Média & 2,86 & 3,22 & 3,14 & $1,559 *$ & 0,459 \\
\hline & Desvio-padrão & 0,88 & 1,09 & 1,07 & & \\
\hline & Mediana & 2,67 & 2,83 & 3,33 & & \\
\hline & Mínimo & 1,78 & 2,0 & 1,11 & & \\
\hline & Máximo & 4,56 & 6,33 & 5,22 & & \\
\hline \multirow{5}{*}{$\begin{array}{c}\text { Instabilidade } \\
\text { emocional }\end{array}$} & Média & 2,74 & 3,11 & 3,73 & $3,958 *$ & 0,138 \\
\hline & Desvio-padrão & 1,14 & 1,47 & 1,54 & & \\
\hline & Mediana & 2,66 & 2,91 & 3,16 & & \\
\hline & Mínimo & 1,33 & 1,00 & 1,5 & & \\
\hline & Máximo & 4,83 & 6,00 & 6,0 & & \\
\hline \multirow{4}{*}{ Passividade } & Média & 3,00 & 3,09 & 3,31 & $0,420 * *$ & 0,659 \\
\hline & Desvio-padrão & 0,84 & 1,26 & 1,21 & & \\
\hline & Mediana & 3,00 & 2,83 & 3,00 & & \\
\hline & Mínimo & 1,17 & 1,17 & 1,17 & & \\
\hline \multirow{6}{*}{ Depressão } & Máximo & 4,33 & 5,67 & 5,83 & & \\
\hline & Média & 1,79 & 2,05 & 1,91 & $1,116^{*}$ & 0,572 \\
\hline & Desvio-padrão & 0,74 & 0,94 & 0,73 & & \\
\hline & Mediana & 1,5 & 2,00 & 1,81 & & \\
\hline & Mínimo & 1,0 & 1,0 & 1,00 & & \\
\hline & Máximo & 3,5 & 4,75 & 4,38 & & \\
\hline \multirow{5}{*}{ Neuroticismo } & Média & 2,59 & 2,87 & 3,02 & $1,305 * *$ & 0,279 \\
\hline & Desvio-padrão & 0,63 & 0,95 & 0,91 & & \\
\hline & Mediana & 2,39 & 2,98 & 2,90 & & \\
\hline & Mínimo & 1,72 & 1,42 & 1,61 & & \\
\hline & Máximo & 3,64 & 5,52 & 1,59 & & \\
\hline
\end{tabular}

* Teste Kruskal-Wallis

** ANOVA. 
Não houve diferenças estatisticamente significativas entre os grupos avaliados nas subescalas e no fator de personalidade Neuroticismo da BFP. Deste modo, tanto pretendentes à adoção, como mães adotivas e biológicas pareceram descrever seus comportamentos e formas de vivenciar suas emoções de maneira semelhante, no que se refere às características de vulnerabilidade, instabilidade emocional, passividade e depressão, componentes da vertente chamada Neuroticismo.

Os resultados da BFP também podem ser expressos em termos de posições percentílicas. A fim de localizar a produção das mulheres avaliadas no presente estudo em relação ao padrão de referência constante no manual do instrumento (Nunes, Hutz \& Nunes, 2010, p. 212), elaborou-se a Tabela 5.

Tabela 5. Descrição (em percentis) dos valores médios no Fator Neuroticismo e suas facetas na BFP em função dos grupos de mulheres $(n=60)$.

\begin{tabular}{cccc}
\hline Escalas BFP & Grupo 1 & Grupo 2 & Grupo 3 \\
\hline Vulnerabilidade & 30 & 35 & 35 \\
Instabilidade emocional & 25 & 40 & 55 \\
Passividade & 45 & 45 & 50 \\
Depressão & 25 & 35 & 30 \\
Neuroticismo & 25 & 35 & 40 \\
\hline
\end{tabular}

É possível observar que as mulheres avaliadas neste estudo apresentaram pontuação inferior à mediana de seu grupo de referência, com exceção da subescala de Passividade, na qual os três grupos apresentaram escores próximos ao percentil 50. Desse modo, pode-se afirmar que possuem tendência a serem independentes emocionalmente em relação aos demais, sendo que a opinião dos outros e a necessidade de agradá-los exercem pouca influência em suas ações e escolhas diárias. Os indicadores encontrados sugerem ainda que estas mulheres apresentaram humor relativamente estável, com poucas manifestações de impulsividade e suficiente tolerância a frustrações, o que se mostrou mais claro em G3. Em G1 a classificação do resultado médio atingiu o percentil 25 , ou seja, sinalizador de que as mulheres pretendentes à adoção presentemente avaliadas podem, em alguns momentos, ter dificuldades para perceber quando estão diante de reais problemas, com disposição limitada para resolvê-los. 
Outro fator da personalidade avaliado pela BFP é a Extroversão. Este domínio se relaciona a uma tendência geral para a comunicabilidade e o contato com as pessoas, associando-se a características de liderança, tais como a externalização de suas opiniões e crenças, acompanhada de dominância. Referido fator é composto, segundo os pressupostos teóricos trazidos por Nunes, Hutz e Nunes (2010), por quatro facetas, que compõem as quatro subescalas desse componente da BFP. São elas:

a) Nível de comunicação: refere-se a maior ou menor facilidade para falar em público, conhecer novas pessoas e estabelecer relações íntimas. Avalia ainda o grau de iniciativa para conversar com os outros, expressar suas opiniões e interesses quando em grupo, bem como seu nível de constrangimento percebido em situações sociais.

b) Altivez: avalia a percepção de opiniões externas sobre suas capacidades, valores, características pessoais e bens materiais. Também avalia a necessidade percebida de receber atenção dos demais.

c) Dinamismo/assertividade: avalia padrões comportamentais relativos ao interesse/necessidade de se envolver em atividades, manter-se ocupado. Avalia também características relativas a tendência à liderança e desejo de fazer valer suas opiniões e pontos de vista.

d) Interações sociais: voltado para a percepção acerca do interesse/capacidade em agir de forma a agregar pessoas, e para manter contato com seus conhecidos. Refere-se também ao interesse/predisposição a buscar atividades em grupo e se envolver com outras pessoas.

A sistematização dos resultados referentes ao fator Extroversão e suas facetas na BFP pode ser visualizada na Tabela 6. Ela traz os resultados descritivos em função dos três grupos de mulheres presentemente avaliadas, bem como a comparação estatística das médias obtidas pelos grupos. 
Tabela 6. Resultados descritivos e comparação estatística do Fator Extroversão e suas facetas (escores brutos) na BFP em função dos grupos de mulheres $(n=60)$.

\begin{tabular}{|c|c|c|c|c|c|c|}
\hline Escalas BFP & Resultados & Grupo 1 & Grupo 2 & Grupo 3 & Estatística & $p$ \\
\hline $\begin{array}{c}\text { Nível de } \\
\text { comunicação }\end{array}$ & $\begin{array}{l}\text { Média } \\
\text { Desvio-padrão } \\
\text { Mediana } \\
\text { Mínimo } \\
\text { Máximo }\end{array}$ & $\begin{array}{l}4,99 \\
1,01 \\
5,08 \\
3,33 \\
6,50\end{array}$ & $\begin{array}{l}4,94 \\
0,73 \\
4,91 \\
3,83 \\
6,17\end{array}$ & $\begin{array}{l}4,89 \\
1,27 \\
5,00 \\
2,33 \\
6,67\end{array}$ & $0,470 * *$ & 0,954 \\
\hline Altivez & $\begin{array}{l}\text { Média } \\
\text { Desvio-padrão } \\
\text { Mediana } \\
\text { Mínimo } \\
\text { Máximo }\end{array}$ & $\begin{array}{l}3,44 \\
0,60 \\
3,43 \\
2,14 \\
4,71\end{array}$ & $\begin{array}{l}3,70 \\
0,84 \\
3,92 \\
2,14 \\
4,71\end{array}$ & $\begin{array}{l}4,12 \\
1,02 \\
4,14 \\
2,43 \\
5,71\end{array}$ & $4,662^{*}$ & 0,097 \\
\hline Dinamismo & $\begin{array}{l}\text { Média } \\
\text { Desvio-padrão } \\
\text { Mediana } \\
\text { Mínimo } \\
\text { Máximo }\end{array}$ & $\begin{array}{c}5,42 \\
0,66 \\
5,40 \\
4,4 \\
6,8\end{array}$ & $\begin{array}{c}5,43 \\
0,75 \\
5,40 \\
3,6 \\
6,8\end{array}$ & $\begin{array}{c}5,21 \\
0,57 \\
5,40 \\
4,2 \\
6,0\end{array}$ & $1,017^{*}$ & 0,661 \\
\hline Interações sociais & $\begin{array}{l}\text { Média } \\
\text { Desvio-padrão } \\
\text { Mediana } \\
\text { Mínimo } \\
\text { Máximo }\end{array}$ & $\begin{array}{l}5,42 \\
0,85 \\
5,57 \\
3,57 \\
6,43\end{array}$ & $\begin{array}{l}5,29 \\
0,79 \\
5,29 \\
3,29 \\
6,43\end{array}$ & $\begin{array}{c}5,50 \\
1,03 \\
5,43 \\
3,0 \\
7,0\end{array}$ & $0,271 * *$ & 0,763 \\
\hline Extroversão & $\begin{array}{l}\text { Média } \\
\text { Desvio-padrão } \\
\text { Mediana } \\
\text { Mínimo } \\
\text { Máximo }\end{array}$ & $\begin{array}{l}4,82 \\
0,61 \\
4,96 \\
3,51 \\
5,60\end{array}$ & $\begin{array}{l}4,84 \\
0,47 \\
4,80 \\
4,04 \\
5,61\end{array}$ & $\begin{array}{l}4,93 \\
0,63 \\
5,08 \\
3,72 \\
6,04\end{array}$ & $0,203^{*}$ & 0,817 \\
\hline
\end{tabular}

* Teste Kruskal-Wallis

** ANOVA.

Conforme o manual do instrumento (Nunes, Hutz \& Nunes, 2010), o fator Extroversão abrange tipos e quantidade de interações interpessoais preferidas, bem como nível de atividade, necessidade de estimulação e capacidade de alegrar-se. Notou-se que, neste fator, as mulheres apresentaram perfil semelhante, sem a ocorrência de diferenças estatisticamente significativas entre os grupos avaliados.

Foi possível classificar as respostas das mulheres deste estudo com o padrão de referência constante no manual da BFP (Nunes, Hutz \& Nunes, 2010, p. 212). Desse modo, têm-se os dados apresentados na Tabela 7, referentes às notas percentis das médias grupais. 
Tabela 7. Descrição (em percentis) dos valores médios no Fator Extroversão e suas facetas na BFP em função dos grupos de mulheres $(n=60)$.

\begin{tabular}{cccc}
\hline Escalas BFP & Grupo 1 & Grupo 2 & Grupo 3 \\
\hline Nível de comunicação & 70 & 70 & 65 \\
Altivez & 45 & 60 & 75 \\
Dinamismo & 75 & 75 & 70 \\
Interações Sociais & 70 & 65 & 75 \\
Extroversão & 75 & 75 & 80 \\
\hline
\end{tabular}

As mulheres presentemente avaliadas, no geral, apresentaram escores acima da mediana na maioria das escalas referentes ao Fator Extroversão, conforme sua avaliação pela BFP. Conforme o manual do instrumento pode-se afirmar que, no geral, as participantes deste estudo:

“(...) tendem a ser falantes e buscam contato com pessoas, mesmo que as conheçam pouco. Tendem a ter um senso de intimidade maior que os demais, contando fatos íntimos e confiando em pessoas que conhecem relativamente pouco. Além disso, são pessoas ativas e que externalizam suas preferências e crenças para os demais, podendo apresentar certa dominância" (Nunes, Hutz \& Nunes, 2010, p. 130).

Em continuidade às análises referentes aos resultados das mulheres presentemente avaliadas pela BFP, passou-se ao Fator Socialização, que está associado à capacidade e disposição para confiar nas outras pessoas, bem como a tendência à lealdade e altruísmo. Referida dimensão da personalidade, na BFP, é composta por três facetas (compondo as subescalas), conforme detalhamento a seguir.

a) Amabilidade: relativa a quão atenciosas, compreensivas e empáticas as pessoas acreditam ser com as demais. Além disso, indica quão agradáveis as pessoas buscam ser em relação aos outros, observando suas opiniões, sendo educadas com elas e se importando com suas necessidades.

b) Pró-sociabilidade: busca refletir o padrão comportamental acerca de comportamentos de risco, concordância ou confronto com leis e regras sociais, moralidade e agressividade. Também engloba indicadores relativos a possíveis tendências para manipular pessoas ao seu redor, bem como níveis de hostilidade. 
c) Confiança nas pessoas: avalia o quanto as pessoas confiam nos demais e acreditam que os outros não as prejudicarão. Focaliza ainda a percepção do indivíduo sobre os demais (se é realista ou não) e sobre sua capacidade de desenvolver intimidade nas relações interpessoais.

Com base nos resultados referentes a esse fator (e suas facetas) da BFP elaborou-se a Tabela 8. Ela traz as informações referentes às respostas dos três grupos de mulheres diante do fator Socialização desse instrumento de avaliação psicológica, comparando-se seus resultados médios.

Tabela 8. Resultados descritivos e comparação estatística do Fator Socialização e suas facetas (escores brutos) na BFP em função dos grupos de mulheres $(n=60)$.

\begin{tabular}{|c|c|c|c|c|c|c|}
\hline Escalas BFP & Resultados & Grupo 1 & Grupo 2 & Grupo 3 & Estatística & $p$ \\
\hline \multirow{5}{*}{ Amabilidade } & Média & 6,23 & 5,97 & 5,91 & $3,937^{*}$ & 0,140 \\
\hline & Desvio-padrão & 0,40 & 0,64 & 0,53 & & \\
\hline & Mediana & 6,12 & 6,08 & 5,92 & & \\
\hline & Mínimo & 5,58 & 4,33 & 5,08 & & \\
\hline & Máximo & 7,00 & 6,83 & 6,92 & & \\
\hline \multirow{5}{*}{ Pró-sociabilidade } & Média & 6,54 & 6,23 & 6,25 & $2,634 *$ & 0,268 \\
\hline & Desvio-padrão & 0,29 & 0,66 & 0,54 & & \\
\hline & Mediana & 6,63 & 6,50 & 6,38 & & \\
\hline & Mínimo & 5,88 & 4,63 & 5,13 & & \\
\hline & Máximo & 7,00 & 7,00 & 7,00 & & \\
\hline \multirow{5}{*}{ Confiança } & Média & 5,04 & 5,10 & 5,17 & $0,128 * *$ & 0,880 \\
\hline & Desvio-padrão & 0,66 & 0,82 & 0,95 & & \\
\hline & Mediana & 5,25 & 5,38 & 5,31 & & \\
\hline & Mínimo & 3,75 & 3,75 & 3,25 & & \\
\hline & Máximo & 6,38 & 6,63 & 6,75 & & \\
\hline \multirow{5}{*}{ Socialização } & Média & 5,93 & 5,78 & 5,78 & $0,144 * *$ & 0,326 \\
\hline & Desvio-padrão & 0,28 & 0,44 & 0,44 & & \\
\hline & Mediana & 5,94 & 5,71 & 5,80 & & \\
\hline & Mínimo & 5,35 & 5,10 & 4,83 & & \\
\hline & Máximo & 6,47 & 5,72 & 6,60 & & \\
\hline
\end{tabular}

* Teste Kruskal-Wallis

** ANOVA.

Não houve diferença estatisticamente significativa entre os grupos avaliados no que se refere às escalas do Fator Socialização. Pode-se, assim, inferir que mães biológicas (G3), adotivas $(\mathrm{G} 2)$ e pretendentes à adoção $(\mathrm{G} 1)$ relataram, de forma similar, disponibilidade para confiar nas outras pessoas e também para a lealdade e o altruísmo. 
Ao se comparar sua produção em relação ao grupo de referência (Nunes, Hutz \& Nunes, 2010, p. 214) é possível chegar aos dados compilados na Tabela 9. Seus resultados médios foram organizados em notas percentis.

Tabela 9. Descrição (em percentis) dos valores médios no Fator Socialização e suas facetas na BFP em função dos grupos de mulheres $(n=60)$.

\begin{tabular}{cccc}
\hline Escalas BFP & Grupo 1 & Grupo 2 & Grupo 3 \\
\hline Amabilidade & 70 & 60 & 60 \\
Pró-sociabilidade & 80 & 70 & 70 \\
Confiança & 60 & 65 & 65 \\
Socialização & 80 & 70 & 70 \\
\hline
\end{tabular}

Os dados apontam que as mulheres presentemente avaliadas apresentaram escores superiores à média para seu grupo de referência nas subescalas e na escala de Socialização. Houve indicadores, portanto, de que os três conjuntos de mulheres avaliadas apresentaram "tendência a confiar nos demais, acreditando no seu lado positivo e raramente suspeitando de suas intenções" (Nunes, Hutz \& Nunes, 2010, p. 137). Ainda, segundo os mesmos autores, pessoas com níveis altos em Socialização "apresentam preocupação e desejo em ajudar os demais, tendo um alto nível de altruísmo" (p. 137).

Outro fator examinado pela BFP denomina-se Realização. Segundo o manual do instrumento se refere à "motivação para o sucesso, perseverança, capacidade de planejamento de ações em função de uma meta, bem como nível de organização e pontualidade" (Nunes, Hutz \& Nunes, 2010, p. 139). Esse domínio da personalidade está composto, na BFP, por três aspectos examinados em subescalas do fator Realização. São elas:

a) Competência: avalia se a pessoa sinaliza objetivos claros de vida, comportamentos favorecedores da concretização destas metas e se possui visão favorável sobre sua capacidade de realizar estas atividades.

b) Ponderação/Prudência: busca avaliar nível de cuidados tomados ao expressar opiniões e defender interesses, bem como ao avaliar possíveis consequências de suas ações.

c) Empenho/Comprometimento: descreve dedicação em relação às atividades profissionais e acadêmicas, bem como esforços para alcançar reconhecimento, além de possível tendência ao perfeccionismo. 
Os dados derivados das respostas dos três grupos de mulheres a esse fator da BFP estão organizados na Tabela 10, juntamente com a comparação estatística de suas médias. Esses resultados aparecem em função dos escores brutos no instrumento.

Tabela 10. Resultados descritivos e comparação estatística do Fator Realização e suas facetas (escores brutos) na BFP em função dos grupos de mulheres $(n=60)$.

\begin{tabular}{|c|c|c|c|c|c|c|}
\hline Escalas BFP & Resultados & Grupo 1 & Grupo 2 & Grupo 3 & Estatística & $p$ \\
\hline \multirow{5}{*}{ Competência } & Média & 5,73 & 5,75 & 5,57 & $2,044 *$ & 0,360 \\
\hline & Desvio-padrão & 0,55 & 0,92 & 0,67 & & \\
\hline & Mediana & 5,85 & 5,85 & 5,60 & & \\
\hline & Mínimo & 4,20 & 2,60 & 4,00 & & \\
\hline & Máximo & 6,80 & 6,90 & 6,70 & & \\
\hline \multirow{5}{*}{$\begin{array}{c}\text { Ponderação / } \\
\text { Prudência }\end{array}$} & Média & 5,15 & 5,31 & 4,98 & & \\
\hline & Desvio-padrão & 1,40 & 0,73 & 1,33 & $0,370 * *$ & 0,693 \\
\hline & Mediana & 5,50 & 5,50 & 4,87 & & \\
\hline & Mínimo & 1,75 & 4,00 & 1,75 & & \\
\hline & Máximo & 7,00 & 6,50 & 7,00 & & \\
\hline \multirow{5}{*}{$\begin{array}{c}\text { Empenho / } \\
\text { Comprometimento }\end{array}$} & Média & 5,41 & 5,15 & 5,19 & $0,457 * *$ & 0,635 \\
\hline & Desvio-padrão & 0,81 & 1,08 & 0,84 & & \\
\hline & Mediana & 5,50 & 5,07 & 5,14 & & \\
\hline & Mínimo & 3,86 & 3,29 & 3,29 & & \\
\hline & Máximo & 7,00 & 7,00 & 6,71 & & \\
\hline \multirow{5}{*}{ Realização } & Média & 5,43 & 5,40 & 5,25 & $0,462 * *$ & 0,279 \\
\hline & Desvio-padrão & 0,60 & 0,67 & 0,64 & & \\
\hline & Mediana & 5,49 & 5,40 & 5,10 & & \\
\hline & Mínimo & 4,10 & 3,84 & 3,58 & & \\
\hline & Máximo & 6,35 & 6,40 & 6,40 & & \\
\hline
\end{tabular}

* Teste Kruskal-Wallis

** ANOVA.

Não foram encontradas diferenças estatisticamente significativas entre os grupos avaliados nesse fator da BFP. As mulheres pretendentes à adoção (G1), as mães adotivas $(\mathrm{G} 2)$ e as biológicas (G3) tenderam a apresentar relato semelhante acerca de seus sentimentos e comportamentos no tocante aos elementos examinados por essas subescalas e domínio geral (realização).

Ao localizar a produção média destas participantes em relação aos padrões normativos do instrumento, trazidos pelo manual da BFP (Nunes, Hutz \& Nunes, 2010, p. 215), tem-se os 
resultados apresentados na Tabela 11. Mais uma vez esses dados médios foram transportados para notas percentílicas.

Tabela 11. Descrição (em percentis) dos valores médios no Fator Realização e suas facetas na BFP em função dos grupos de mulheres $(n=60)$.

\begin{tabular}{cccc}
\hline Escalas BFP & Grupo 1 & Grupo 2 & Grupo 3 \\
\hline Competência & 60 & 60 & 50 \\
Ponderação & 55 & 60 & 50 \\
Empenho & 65 & 50 & 50 \\
Realização & 65 & 60 & 50 \\
\hline
\end{tabular}

Pode-se observar que os três grupos avaliados sinalizaram percentis próximos ao valor da mediana normativa. Deste modo, as mães (adotivas e biológicas, respectivamente G2 e G3) e as mulheres ainda sem filhos (G1) presentemente avaliadas sinalizaram autopercepção compatível com positiva capacidade de realização de acordo com o contexto, não se mostrando exageradamente confiantes, nem tampouco autodepreciativas. Evidenciaram sinais de uso de ponderação ao falar e ao agir, sem ações irrefletidas, na maioria das ocasiões. Apresentaram indicadores de mediana motivação e mediano envolvimento com suas atividades acadêmicas/laborativas, compatível com a realização adequada e suficiente de planejamento para atingir seus objetivos (Nunes, Hutz \& Nunes, 2010).

O último componente da personalidade avaliado pela BFP é denominado como Abertura. Esse fator da personalidade está relacionado a comportamentos exploratórios e de reconhecimento da importância de novas experiências na vida dos indivíduos. Pretende examinar nível de imaginação e criatividade, correlacionando-se com nível intelectual.

De acordo com os autores, o fator Abertura contempla três facetas complementares. Em termos gerais, podem ser descritas como abaixo relatado.

a) Abertura a ideias: avalia disponibilidade individual para conhecer e explorar novos conceitos ou ideias, incluindo posições filosóficas, arte, bem como uso da imaginação e fantasia.

b) Liberalismo: busca verificar em que medida as pessoas se encontram abertas para novos valores morais e sociais. Revela o quanto as pessoas creem que aspectos tidos como verdades tendem a mudar ao longo do tempo, assim como regras e costumes. 
c) Busca por novidades: retrata o quanto a pessoa tolera/prefere rotinas e tarefas repetitivas, ou se apresenta tendência a ficar entediado quando não pode vivenciar eventos novos.

$\mathrm{Na}$ presente investigação, os escores obtidos no Fator Abertura (e suas subescalas) também foram submetidos a análise estatística descritiva e comparativa das médias entre os grupos. Esses dados compõem a Tabela 12.

Tabela 12. Resultados descritivos e comparação estatística do Fator Abertura e suas facetas (escores brutos) na BFP em função dos grupos de mulheres $(n=60)$.

\begin{tabular}{|c|c|c|c|c|c|c|}
\hline Escalas BFP & Resultados & Grupo 1 & Grupo 2 & Grupo 3 & Estatística & $p$ \\
\hline \multirow{5}{*}{ Abertura a ideias } & Média & 4,55 & 4,26 & 4,62 & $0,766^{* *}$ & 0,469 \\
\hline & Desvio-padrão & 1,00 & 0,94 & 0,94 & & \\
\hline & Mediana & 4,50 & 4,20 & 4,70 & & \\
\hline & Mínimo & 2,30 & 2,70 & 3,00 & & \\
\hline & Máximo & 6,30 & 5,80 & 6,30 & & \\
\hline \multirow{5}{*}{ Liberalismo } & Média & 4,42 & 4,22 & 5,05 & $4,944 * *$ & $\mathbf{0 , 0 1 0}$ \\
\hline & Desvio-padrão & 0,89 & 0,90 & 0,80 & & \\
\hline & Mediana & 4,43 & 4,21 & 5,07 & & \\
\hline & Mínimo & 2,86 & 2,46 & 3,57 & & \\
\hline & Máximo & 6,00 & 5,86 & 6,57 & & \\
\hline \multirow{5}{*}{$\begin{array}{l}\text { Busca por } \\
\text { novidades }\end{array}$} & Média & 4,10 & 4,04 & 4,29 & $0,077^{*}$ & 0,962 \\
\hline & Desvio-padrão & 0,61 & 1,06 & 1,04 & & \\
\hline & Mediana & 4,17 & 4,16 & 4,25 & & \\
\hline & Mínimo & 3,00 & 2,15 & 2,83 & & \\
\hline & Máximo & 5,00 & 5,33 & 6,83 & & \\
\hline \multirow{5}{*}{ Abertura } & Média & 4,34 & 4,18 & 4,65 & $3,038 * *$ & 0,056 \\
\hline & Desvio-padrão & 0,49 & 0,61 & 0,74 & & \\
\hline & Mediana & 4,36 & 4,12 & 4,65 & & \\
\hline & Mínimo & 3,04 & 3,04 & 3,30 & & \\
\hline & Máximo & 5,31 & 5,51 & 5,90 & & \\
\hline
\end{tabular}

* Teste Kruskal-Wallis

** ANOVA.

Foi possível identificar diferença estatisticamente significativa entre os grupos na faceta Liberalismo (magnitude de efeito, Eta parcial $=0,148$ ) e tendência à significância no fator geral de Abertura. Por meio do teste post-hoc de Bonferroni notou-se que a efetiva diferença significativa encontrada, no que se refere à faceta Liberalismo, ocorreu entre G2 e G3 (diferença média $=0,828 ; p=0,012$ ), sendo que as maiores médias foram encontradas entre as mães biológicas (G3). Não houve diferença estatisticamente significativa entre G1 e G2 
nesse fator e suas facetas. Assim, pode-se inferir que as mulheres de G3 (mães biológicas) apresentaram maior propensão que as mães adotivas (G2) a considerar que os valores sociais, éticos e legais podem ser relativizados, bem como a compreender que não existem verdades absolutas ou valores inquestionáveis.

Ao se comparar os dados médios dessas mulheres no fator Abertura (e suas subescalas) ao padrão de respostas apresentado pelo manual do instrumento (p. 216), têm-se os resultados apresentados na Tabela 13. Mais uma vez esses resultados se encontram expressos em percentis.

Tabela 13. Descrição (em percentis) dos valores médios no Fator Abertura e suas facetas na BFP em função dos grupos de mulheres $(n=60)$.

\begin{tabular}{cccc}
\hline Escalas BFP & Grupo 1 & Grupo 2 & Grupo 3 \\
\hline Abertura a ideias & 60 & 50 & 60 \\
Liberalismo & 35 & 30 & 60 \\
Busca por novidades & 40 & 35 & 45 \\
Abertura & 40 & 35 & 55 \\
\hline
\end{tabular}

Nota-se que as mulheres presentemente avaliadas evidenciaram autorrelato sobre sua abertura a ideias como compatível ao padrão mediano do grupo de referência. No tocante ao liberalismo, G1 e G2 mostraram resultados classificados em nível inferior ao padrão mediano normativo, diferenciando-se de G3. Já no tocante à busca por novidades e abertura geral, os resultados estão bem próximos da tendência central normativa, embora sempre mais elevados em G3. Sendo assim, é possível afirmar que as mulheres avaliadas na presente investigação referiram padrão de curiosidade e criatividade comparável a seu grupo de referência, conseguindo acompanhar a tendência normativa de relativa propensão a colocar em cheque suas próprias crenças e valores, não se mostrando excessivamente conservadoras ou demasiadamente liberais.

$\mathrm{Na}$ tentativa de organizar uma síntese descritiva sobre os achados obtidos por meio da BFP nos três grupos de mulheres avaliadas, poder-se-ia dizer que, no geral, apresentaram resultados bastante similares nessas características de personalidade expressas por meio de autorrelato, como é o caso desse instrumento de avaliação psicológica. Uma única particularidade a destacar seria relativa à subescala Liberalismo, onde foram identificadas diferenças estatisticamente significativas entre G1, G2 e G3, com resultados superiores no grupo de mães biológicas (G3). 


\section{IV.3. Relativos ao Método de Rorschach}

O Método de Rorschach foi utilizado na presente investigação com o objetivo de caracterizar as mulheres avaliadas em relação a componentes estruturais e funcionais de sua personalidade, considerando-se o caráter projetivo deste instrumento. Foram avaliados indicadores referentes à Produtividade, Localizações, Determinantes, Conteúdos, Banalidades e Fórmulas Vivenciais, conforme detalhamento a seguir.

Inicialmente, no entanto, faz-se necessário apresentar os dados resultantes da análise de concordância entre examinadores independentes sobre a classificação das respostas ao Rorschach na presente pesquisa. Esses achados compõem a Tabela 14.

Tabela 14. Resultados descritivos da Análise de Concordância entre examinadores independentes (Kappa), referentes à classificação das respostas ao Método de Rorschach $(n=15)$.

\begin{tabular}{ccc}
\hline \multicolumn{2}{c}{ Variáveis do Rorschach } & Valores de Kappa \\
\hline \multirow{3}{*}{ Localização } & $\mathrm{G}$ & 0,993 \\
& $\mathrm{D}$ & 0,943 \\
$\mathrm{Dd}$ & 0,905 \\
$\mathrm{Dbl}$ & 0,932 \\
Média & 0,943 \\
& Forma & \\
& Cor & 0,920 \\
Determinantes & Estompage (sombreado) & 0,877 \\
& K (movimentos) & 0,842 \\
& Média & 0,890 \\
& & 0,876 \\
Qualidade Formal & Positiva (bem vista) & 0,709 \\
& Negativa (mal vista) & 0,712 \\
& Média & 0,710 \\
& & 0,979 \\
& A & 0,947 \\
& H & 0,852 \\
& Anat & 0,873 \\
& Obj & 1,000 \\
& Bot & 0,726 \\
& Outros & 0,896 \\
& &
\end{tabular}


Os indicadores de concordância entre examinadores independentes (Kappa) nas variáveis do Rorschach alcançaram valores entre 0,709 a 1,000. A grande maioria esteve acima de 0,80, valores que, segundo Fonseca, Silva e Silva (2007) podem ser considerados excelentes. Desse modo, têm-se evidências empíricas de suficiente precisão nas análises realizadas, fortalecendo indicadores psicométricos da Escola Francesa do Rorschach no Brasil.

Para além das análises da precisão avaliativa, de crucial importância para este estudo é a realização da estatística descritiva e analítica das variáveis do Método de Rorschach, com o objetivo de alcançar indicadores acerca da estrutura e funcionamento da personalidade das mulheres avaliadas. Optou-se por sua apresentação em tópicos específicos, para facilitar o processo interpretativo das múltiplas variáveis. A Tabela 15 traz os dados referentes à produtividade e ao ritmo de trabalho no Rorschach, em função dos grupos. 
Tabela 15. Resultados descritivos e comparação estatística das variáveis referentes à produtividade e ritmo no Rorschach, em função dos grupos de mulheres $(n=60)$.

\begin{tabular}{|c|c|c|c|c|c|c|}
\hline $\begin{array}{l}\text { Variáveis } \\
\text { Rorschach }\end{array}$ & Resultados & Grupo 1 & Grupo 2 & Grupo 3 & Estatística & $p$ \\
\hline \multirow{5}{*}{$\mathrm{R}$} & Média & 22,4 & 17,5 & 21,4 & $4,870^{*}$ & 0,080 \\
\hline & Mediana & 20,5 & 16,0 & 21,5 & & \\
\hline & Desvio-padrão & 9,5 & 5,7 & 6,9 & & \\
\hline & Mínimo & 9,0 & 11,0 & 10,0 & & \\
\hline & Máximo & 47,0 & 32,0 & 36,0 & & \\
\hline \multirow{5}{*}{ RA } & Média & 0,3 & 0,5 & 0,2 & $2,300 *$ & 0,304 \\
\hline & Mediana & 0 & 0 & 0 & & \\
\hline & Desvio-padrão & 0,6 & 0,7 & 0,5 & & \\
\hline & Mínimo & 0 & 0 & 0 & & \\
\hline & Máximo & 2,0 & 2,0 & 2,0 & & \\
\hline \multirow{5}{*}{ Rec } & Média & 0,1 & 0,3 & 0,1 & $4,980 *$ & 0,083 \\
\hline & Mediana & 0 & 0 & 0 & & \\
\hline & Desvio-padrão & 0,4 & 0,4 & 0,3 & & \\
\hline & Mínimo & 0 & 0 & 0 & & \\
\hline & Máximo & 2,0 & 0 & 1,0 & & \\
\hline \multirow{5}{*}{ Den } & Média & 0 & 0,1 & 0,1 & $1,050^{*}$ & 0,589 \\
\hline & Mediana & 0 & 0 & 0 & & \\
\hline & Desvio-padrão & 0,2 & 0,3 & 0,4 & & \\
\hline & Mínimo & 0 & 0 & 0 & & \\
\hline & Máximo & 1,0 & 1,0 & 2,0 & & \\
\hline \multirow[t]{5}{*}{ TLm } & Média & 23,1 & 14,7 & 16,4 & $7,905 * *$ & 0,001 \\
\hline & Mediana & 22,8 & 14,0 & 15,9 & & \\
\hline & Desvio-padrão & 8,2 & 5,8 & 6,8 & & \\
\hline & Mínimo & 10,2 & 7,1 & 6,4 & & \\
\hline & Máximo & 44,0 & 28,8 & 27,0 & & \\
\hline \multirow[t]{5}{*}{$\mathrm{TRm}$} & Média & 49,3 & 51,4 & 45,1 & $0,666^{* *}$ & 0,518 \\
\hline & Mediana & 44,2 & 48,9 & 39,8 & & \\
\hline & Desvio-padrão & 19,1 & 14,2 & 18,6 & & \\
\hline & Mínimo & 18,8 & 31,25 & 20,3 & & \\
\hline & Máximo & 96,6 & 87,15 & 79,5 & & \\
\hline
\end{tabular}

* Teste Kruskal-Wallis

** ANOVA. 
Notou-se diferença estatisticamente significativa apenas na variável TLm (tempo de latência médio), com moderada magnitude de efeito (Eta parcial $=0,217$ ). Para clarificar essa especificidade entre os grupos realizou-se o teste post-hoc de Bonferroni, que apontou diferença entre G1 e G2 (diferença média=8,405; $p=0,001$ ), bem como entre G1 e G3 (diferença média=6,701; $p=0,012$ ). Na comparação entre G2 e G3 não foram verificadas diferenças estatisticamente significativas (diferença média=1,704, $p=1,000$ ).

Deste modo, no que se refere ao número total de respostas emitidas diante do Rorschach, à frequência de ocorrência de respostas adicionais, recusas e denegações, bem como em relação ao tempo de reação médio, tanto as pretendentes à adoção (G1), como as mães adotivas (G2) e biológicas (G3) apresentaram padrões similares de resposta. Entretanto, foi possível verificar que as pretendentes à adoção (G1) apresentaram tempo de latência médio mais elevado que as demais. Ou seja, este grupo de mulheres levou mais tempo, em média, para processar internamente as instruções da técnica, bem como para absorver o impacto afetivo diante do instrumento antes de emitir uma resposta ao Rorschach, quando comparada aos demais grupos avaliados.

Além dos achados apontados, faz-se necessário comparar a produção das mulheres presentemente avaliadas com o seu grupo de referência, a fim de localizar sua produção diante do padrão normativo. Para tanto, utilizou-se o trabalho de Pasian (2000), no qual existem parâmetros percentílicos para localização das respostas referentes à produtividade. A partir de referida comparação, elaborou-se a Tabela 16.

Tabela 16. Descrição (em percentis) dos valores médios nas variáveis de produtividade do Rorschach em função dos grupos de mulheres $(n=60)$.

\begin{tabular}{cccc}
\hline $\begin{array}{c}\text { Variáveis } \\
\text { Rorschach }\end{array}$ & Grupo 1 & Grupo 2 & Grupo 3 \\
\hline R & $>60$ & 60 & $>60$ \\
RA & $<40$ & $<40$ & $<40$ \\
Rec & 50 & 50 & 50 \\
Den & 50 & 50 & 50
\end{tabular}

Percebe-se que o conjunto de mulheres avaliadas para este estudo $(n=60)$, apresentou um número médio de respostas ao Rorschach superior à mediana de seu grupo de referência, alcançando percentis acima de 60. Por outro lado, no que se refere à ocorrência de respostas adicionais, os escores das participantes da presente investigação ficaram abaixo dos padrões normativos. Já no que se refere à ocorrência de recusas e denegações, conforme mostra o estudo de Pasian (2000), estes fenômenos não seriam esperados para esta população, e, de 
fato, foram raros nas mulheres presentemente avaliadas, correspondendo estes resultados, portanto, ao apontado pelo padrão de referência.

A frequência de casos em que as participantes estiveram acima, abaixo ou na média em relação a seu grupo de referência, nos indicadores de produtividade do Rorschach, foi semelhante em todos os grupos. Não houve diferenças estatisticamente significativas entre G1, G2 e G3 nessa distribuição dos casos, conforme análise via Qui-quadrado $(5,126 ; p=0,146)$.

Em prosseguimento às análises referentes aos indicadores do Rorschach, elaborou-se a Tabela 17. Nela constam os resultados médios (em porcentagem) nos indicadores referentes à localização das respostas das participantes deste estudo.

Tabela 17. Resultados descritivos e comparação estatística das variáveis referentes à Localização no Rorschach, em função dos grupos de mulheres $(n=60)$.

\begin{tabular}{|c|c|c|c|c|c|c|}
\hline $\begin{array}{l}\text { Variáveis } \\
\text { Rorschach }\end{array}$ & Resultados & Grupo 1 & Grupo 2 & Grupo 3 & Estatística & $p$ \\
\hline \multirow{5}{*}{ G\% } & Média & 35,4 & 42,6 & 25,9 & $1,471^{*}$ & 0,479 \\
\hline & Mediana & 34,5 & 28,2 & 28,2 & & \\
\hline & Desvio-padrão & 15,1 & 20,9 & 23,3 & & \\
\hline & Mínimo & 9,0 & 8,0 & 10,0 & & \\
\hline & Máximo & 58,0 & 80,0 & 100,0 & & \\
\hline \multirow{5}{*}{$\mathrm{D} \%$} & Média & 38,8 & 38,4 & 35,3 & $0,295 * *$ & 0,746 \\
\hline & Mediana & 36,7 & 33,3 & 32,3 & & \\
\hline & Desvio-padrão & 13,2 & 15,1 & 19,2 & & \\
\hline & Mínimo & 19,0 & 20,0 & 0 & & \\
\hline & Máximo & 72,0 & 72,0 & 76,0 & & \\
\hline \multirow{5}{*}{$\mathrm{Dd} \%$} & Média & 24,6 & 18,4 & 27,7 & $4,980^{*}$ & 0,083 \\
\hline & Mediana & 26,7 & 18,8 & 27,2 & & \\
\hline & Desvio-padrão & 12,8 & 11,7 & 15,1 & & \\
\hline & Mínimo & 5,0 & 0 & 0 & & \\
\hline & Máximo & 44,00 & 50,0 & 58,0 & & \\
\hline \multirow{5}{*}{$\mathrm{Dbl} \%$} & Média & 1,2 & 0,4 & 0 & $6,128^{*}$ & 0,047 \\
\hline & Mediana & 0 & 0 & 0 & & \\
\hline & Desvio-padrão & 2,3 & 1,4 & 0 & & \\
\hline & Mínimo & 0 & 0 & 0 & & \\
\hline & Máximo & 7,0 & 6,0 & 0 & & \\
\hline \multirow[t]{5}{*}{ Do $\%$} & Média & 0,1 & 0 & 0 & $2,000^{*}$ & 0,368 \\
\hline & Mediana & 0,0 & 0 & 0 & & \\
\hline & Desvio-padrão & 0,5 & 0 & 0 & & \\
\hline & Mínimo & 0 & 0 & 0 & & \\
\hline & Máximo & 2,0 & 0 & 0 & & \\
\hline
\end{tabular}

* Teste Kruskal-Wallis

** ANOVA. 
Apenas na variável Dbl\% houve diferença estatisticamente significativa entre os grupos avaliados, com reduzida magnitude de efeito (Eta parcial=0,104). Nas demais variáveis de localização do Rorschach, as mulheres pretendentes à adoção, as mães adotivas e as mães biológicas apresentaram perfil semelhante entre si. Ao examinar a variável Dbl\% pelo teste post-hoc de Bonferroni, verificou-se que a diferença estatisticamente significativa ocorreu entre o grupo de pretendentes à adoção (G1) e o das mães biológicas $(\mathrm{G} 3)(p=0,042)$, sendo que os maiores escores encontravam-se no grupo de pretendentes à adoção.

Em síntese, pode-se dizer que, nas análises realizadas a partir dos principais índices de Localização nos protocolos de Rorschach das mulheres presentemente avaliadas, houve mínima diferenciação entre os grupos. As pretendentes à adoção apresentaram frequência maior de respostas em detalhes brancos (Dbl) dos cartões, o que pode sugerir alguma tendência a oposição às instruções.

Para compreender a produção das mulheres presentemente avaliadas em relação ao seu grupo de referência, utilizou-se o trabalho de Pasian (2000), no qual existem parâmetros percentílicos para localização das respostas referentes aos modos de apreensão. A partir de referida comparação, elaborou-se a Tabela 18.

Tabela 18. Descrição (em percentis) dos valores médios nas variáveis de localização do Rorschach em função dos grupos de mulheres $(n=60)$.

\begin{tabular}{cccc}
\hline $\begin{array}{c}\text { Variáveis } \\
\text { Rorschach }\end{array}$ & Grupo 1 & Grupo 2 & Grupo 3 \\
\hline G & $<40$ & $<40$ & $<40$ \\
D & 60 & 60 & 50 \\
Dd & $>60$ & $>60$ & $>60$ \\
Dbl & $>60$ & $50<\mathrm{P}<60$ & 50 \\
Do & 50 & 50 & 50
\end{tabular}

$\mathrm{Na}$ maioria desses indicadores relativos aos modos de apreensão dos estímulos do Rorschach, as mulheres apresentaram escores dentro ou acima da mediana. Apenas no índice de respostas globais, houve tendência geral a resultado inferior ao grupo de referência. Comparando-se a distribuição das mulheres de cada grupo em relação aos parâmetros normativos (mulheres abaixo ou acima/na média em cada grupo), apenas na variável Dbl houve diferença estatisticamente significativa (Qui-quadrado=6,146; $p=0,046$ ), com predomínio de casos acima da média em G1. 
Deste modo, pode-se dizer que, conforme a presente avaliação do Rorschach, as participantes deste estudo apresentaram modo de apreensão dos estímulos predominantemente vinculado aos detalhes relevantes e às minúcias, menos marcada por uma captação generalista da realidade, quando comparadas ao seu grupo de referência. Os detalhes brancos (Dbl) chamaram significativamente mais a atenção do grupo das pretendentes à adoção, quando comparadas às mães biológicas. Neste momento percebeu-se também que, especificamente, as pretendentes à adoção apresentaram maiores índices Dbl inclusive que a média populacional de referência. A despeito da baixa frequência de ocorrência deste modo de apreensão diante do total de respostas, estas diferenças podem representar um marcador específico para estas mulheres, atentando-se para o seu significado psicodinâmico ligado à angústia e ao temor diante do vazio, com tendência à oposição.

$\mathrm{Na}$ sequência da análise dos indicadores do Rorschach, elaborou-se a Tabela 19. Ela apresenta os achados relativos aos determinantes formais presentes nas respostas das participantes, bem como a comparação estatística entre os grupos.

Tabela 19. Resultados descritivos e comparação estatística das variáveis referentes aos determinantes formais no Rorschach, em função dos grupos de mulheres $(n=60)$.

\begin{tabular}{|c|c|c|c|c|c|c|}
\hline $\begin{array}{l}\text { Variáveis } \\
\text { Rorschach }\end{array}$ & Resultados & Grupo 1 & Grupo 2 & Grupo 3 & Estatística & $p$ \\
\hline \multirow{5}{*}{$\mathrm{F} \%$} & Média & 25,5 & 27,5 & 26,0 & $0,929 *$ & 0,629 \\
\hline & Mediana & 20,5 & 22,7 & 23,2 & & \\
\hline & Desvio-padrão & 16,8 & 12,7 & 12,6 & & \\
\hline & Mínimo & 8,0 & 6,0 & 8,0 & & \\
\hline & Máximo & 67,0 & 50,0 & 57,0 & & \\
\hline \multirow{5}{*}{$\mathrm{F}+\%$} & Média & 73,2 & 66,3 & 75,7 & $0,100 *$ & 0,905 \\
\hline & Mediana & 81,2 & 66,7 & 77,5 & & \\
\hline & Desvio-padrão & 29,2 & 29,9 & 20,1 & & \\
\hline & Mínimo & 0 & 0 & 33,0 & & \\
\hline & Máximo & 100,0 & 100,0 & 100,0 & & \\
\hline \multicolumn{7}{|l|}{$\mathrm{F}+$ extenso $\%$} \\
\hline & Média & 74,6 & 72,8 & 72,9 & $0,170 * *$ & 0,844 \\
\hline & Mediana & 75,2 & 71,2 & 71,1 & & \\
\hline & Desvio-padrão & 11,0 & 11,4 & 10,5 & & \\
\hline & Mínimo & 46,0 & 55,0 & 55,0 & & \\
\hline & Máximo & 89,0 & 100,0 & 95,0 & & \\
\hline & Máximo & 1,0 & 0 & 2,0 & & \\
\hline
\end{tabular}


A comparação dos resultados médios dos grupos nos determinantes formais do Rorschach apontou inexistir diferenças estatisticamente significativas. Ressalta-se, ainda, que, mesmo a análise referente à posição de cada participante frente ao padrão normativo (acima, abaixo/na média), no que se refere à frequência de respostas determinadas unicamente pela forma, também se mostrou semelhante entre os três grupos de mulheres, sem diferenças estatisticamente significativas (Qui-quadrado $=1,445 ; p=0,836$ ). A Tabela 20 ilustra os dados da posição percentílica dos grupos a partir de seus resultados médios nestas variáveis do Rorschach.

Tabela 20. Descrição (em percentis) dos valores médios nas variáveis de Determinantes formais do Rorschach, em função dos grupos de mulheres $(n=60)$.

\begin{tabular}{cccc}
\hline $\begin{array}{c}\text { Variáveis } \\
\text { Rorschach }\end{array}$ & Grupo 1 & Grupo 2 & Grupo 3 \\
\hline $\mathrm{F} \%$ & $<40$ & $40<\mathrm{P}<50$ & $<40$ \\
$\mathrm{~F}+\%$ & $>60$ & $40<\mathrm{P}<50$ & $>60$ \\
$\mathrm{~F}+\%$ extenso & $>60$ & $50<\mathrm{P}<60$ & $50<\mathrm{P}<60$ \\
\hline
\end{tabular}

Observou-se que as participantes do estudo, em sua totalidade, assim como seu grupo de referência, utilizaram os contornos formais dos estímulos para responder ao instrumento em cerca de um terço das respostas emitidas. Em relação à qualidade formal das respostas, pode-se dizer que o total de mulheres participantes desta pesquisa apresentaram suficientes recursos lógicos e de raciocínio para se adaptarem ao meio em que vivem, denotando eficiente teste da realidade e boa precisão perceptiva.

Em prosseguimento à análise dos Determinantes no Rorschach, elaborou-se a T Tabela 21. Ela traz os indicadores referentes às respostas determinadas pelos vários tipos de movimento (respostas cinestesia no Rorschach). 
Tabela 21. Resultados descritivos e comparação estatística das variáveis referentes aos Determinantes do tipo Movimento (cinestesias) no Rorschach, em função dos grupos de mulheres $(n=60)$.

\begin{tabular}{|c|c|c|c|c|c|c|}
\hline $\begin{array}{l}\text { Variáveis } \\
\text { Rorschach }\end{array}$ & Resultados & Grupo 1 & Grupo 2 & Grupo 3 & Estatística & $p$ \\
\hline \multirow{5}{*}{$\mathrm{K}$} & Média & 2,4 & 2,1 & 1,9 & $0,104 *$ & 0,604 \\
\hline & Mediana & 2,0 & 2,0 & 2,0 & & \\
\hline & Desvio-padrão & 1,9 & 1,3 & 1,2 & & \\
\hline & Mínimo & 0 & 0 & 0 & & \\
\hline & Máximo & 8,0 & 5,0 & 5,0 & & \\
\hline \multirow{5}{*}{ kan } & Média & 3,7 & 3,0 & 3,0 & $0,564 *$ & 0,754 \\
\hline & Mediana & 3,0 & 3,0 & 3,0 & & \\
\hline & Desvio-padrão & 2,8 & 1,7 & 1,8 & & \\
\hline & Mínimo & 0 & 0 & 0 & & \\
\hline & Máximo & 9,0 & 6,0 & 7,0 & & \\
\hline \multirow{4}{*}{ kob } & Média & 0,2 & 0,1 & 0,2 & $0,600^{*}$ & 0,741 \\
\hline & Mediana & 0,0 & 0,0 & 0,0 & & \\
\hline & Desvio-padrão & 0,3 & 0,3 & 0,5 & & \\
\hline & Mínimo & 0 & 0 & 0 & & \\
\hline \multirow{6}{*}{$\mathrm{kp}$} & Máximo & 1,0 & 1,0 & 2,0 & & \\
\hline & Média & 0,1 & 0,1 & 0,3 & $2,464 *$ & 0,292 \\
\hline & Mediana & 0 & 0 & 0 & & \\
\hline & Desvio-padrão & 0,3 & 0,3 & 0,5 & & \\
\hline & Mínimo & 0 & 0 & 0 & & \\
\hline & Máximo & 1,0 & 1,0 & 2,0 & & \\
\hline
\end{tabular}

*Teste Kruskal-Wallis.

A análise comparativa dos resultados médios dos grupos nestas variáveis do Rorschach mostrou ausência de diferenças estatisticamente significativas nas respostas vinculadas a determinantes cinestésicos. Buscando-se detalhar o uso das grandes cinestesias (respostas $\mathrm{K}$ ) ou pequenas cinestesias (soma de respostas kan, kob, $\mathrm{kp}$ ) entre as mulheres avaliadas, elaborou-se a Tabela 22. 
Tabela 22. Distribuição das mulheres em função do uso de grandes ou pequenas cinestesias no Rorschach $(n=60)$.

\begin{tabular}{ccccccc}
\hline $\begin{array}{c}\text { Relação entre os } \\
\text { tipos de cinestesia }\end{array}$ & Grupo 1 & Grupo 2 & Grupo 3 & Total & Estatística & $p$ \\
\hline $\mathrm{K}>$ soma kan, kob, kp & 4 & 4 & 5 & 13 & $0,873^{*}$ & 0,928 \\
$\mathrm{~K}<$ soma kan, kob, kp & 13 & 12 & 13 & 38 & & \\
$\mathrm{~K}$ = soma kan, kob, kp & 3 & 4 & 2 & 9 & & \\
\hline
\end{tabular}

*Teste Kruskal-Wallis.

Conforme se depreende das duas tabelas anteriores, no que se refere à frequência de ocorrência de respostas cinestésicas no Rorschach, os três grupos de mulheres foram muito semelhantes entre si, sugerindo equivalentes possibilidades imaginativas e de dinamismo psíquico. Estes indicadores, por sua vez, encontram-se também próximos do apresentado pela média geral do grupo de referência, com pequenas variações (Pasian, 2000), sinalizando tratar-se de grupo de pessoas sem indicadores desviantes específicos nestes quesitos.

Para além da similaridade entre os grupos, o que se pode depreender das análises relacionadas às respostas movimento destas mulheres, é que houve predomínio de pequenas cinestesias (sobretudo movimento animal) sobre as grandes cinestesias (movimento humano), o que também se equipara ao padrão de referência. Referido indicador aponta para características de espontaneidade da vida psíquica e imaginativa destas mulheres, em detrimento da elaboração reflexiva sobre os impulsos, que também está presente, porém em menor intensidade.

Em continuidade à análise dos Determinantes elaborou-se a Tabela 23. Ela descreve os resultados referentes ao uso da cor pelas participantes para responder ao Rorschach. 
Tabela 23. Resultados descritivos e comparação estatística das variáveis referentes aos Determinantes cromáticos no Rorschach, em função dos grupos de mulheres $(n=60)$.

\begin{tabular}{|c|c|c|c|c|c|c|}
\hline $\begin{array}{l}\text { Variáveis } \\
\text { Rorschach }\end{array}$ & Resultados & Grupo 1 & Grupo 2 & Grupo 3 & Estatística & $p$ \\
\hline \multirow{5}{*}{$\mathrm{FC}$} & Média & 3,0 & 2,3 & 3,2 & $1,401^{*}$ & 0,496 \\
\hline & Mediana & 3,0 & 2,0 & 2,5 & & \\
\hline & Desvio-padrão & 2,2 & 1,3 & 1,9 & & \\
\hline & Mínimo & 0,0 & 0,0 & 1,0 & & \\
\hline & Máximo & 8,0 & 5,0 & 6,0 & & \\
\hline \multirow{5}{*}{$\mathrm{CF}$} & Média & 1,7 & 1,0 & 1,9 & $2,824 *$ & 0,444 \\
\hline & Mediana & 1,5 & 1,0 & 1,0 & & \\
\hline & Desvio-padrão & 1,2 & 1,0 & 1,9 & & \\
\hline & Mínimo & 0,0 & 0,0 & 0,0 & & \\
\hline & Máximo & 5,0 & 3,0 & 7,0 & & \\
\hline \multirow{5}{*}{$\mathrm{C}$} & Média & 0,5 & 0,2 & 0,1 & $1,305^{*}$ & 0,321 \\
\hline & Mediana & 0,0 & 0,0 & 0,0 & & \\
\hline & Desvio-padrão & 0,2 & 0,5 & 0,3 & & \\
\hline & Mínimo & 0,0 & 0,0 & 0,0 & & \\
\hline & Máximo & 1,0 & 2,0 & 1,0 & & \\
\hline
\end{tabular}

*Teste Kruskal-Wallis.

A análise comparativa desses dados médios apontou para ausência de diferenças estatisticamente significativas entre os grupos nas respostas envolvendo determinantes cromáticos no Rorschach. A Tabela 24 acrescenta informações nesta direção, com indicadores dos determinantes cromáticos em sua associação à qualidade formal.

Tabela 24. Distribuição das mulheres em função da qualidade formal dos determinantes cromáticos no Rorschach $(n=60)$.

\begin{tabular}{ccccccc}
\hline Variável Rorschach & Grupo 1 & Grupo 2 & Grupo 3 & Total & Estatística & $p$ \\
\hline $\mathrm{FC}>\mathrm{CF}+\mathrm{C}$ & 14 & 12 & 12 & 38 & $0,911^{*}$ & 0,923 \\
$\mathrm{FC}<\mathrm{CF}+\mathrm{C}$ & 3 & 4 & 3 & 10 & & \\
$\mathrm{FC}=\mathrm{CF}+\mathrm{C}$ & 3 & 4 & 5 & 12 & & \\
\hline
\end{tabular}

*Teste Kruskal-Wallis.

De acordo com os referidos indicadores, as pretendentes à adoção e as mães adotivas e biológicas avaliadas apresentaram boas habilidades em coordenar racionalmente os afetos, com predomínio do uso da cor associada a positiva qualidade formal na maioria das respostas. 
Referidas características colaboram, assim, para reforçar a compreensão deste grupo de mulheres como possuidor de suficientes recursos adaptativos internos, independentemente de terem ou não filhos biológicos ou adotivos. Essa interpretação ganha força quando comparamos os resultados médios destes grupos com os apresentados pelo referencial normativo (Pasian, 2000), reforçando a noção de recursos adaptativos de controle da impulsividade pela razão.

Em seguida, foram examinados os Determinantes do Rorschach associados com o sombreado (estompage). Esses dados compõem a Tabela 25.

Tabela 25. Resultados descritivos e comparação estatística das variáveis referentes aos Determinantes do tipo Estompage (sombreado) no Rorschach, em função dos grupos de mulheres $(n=60)$.

\begin{tabular}{|c|c|c|c|c|c|c|}
\hline $\begin{array}{l}\text { Variáveis } \\
\text { Rorschach** }\end{array}$ & Resultados & Grupo 1 & Grupo 2 & Grupo 3 & Estatística & $p$ \\
\hline \multirow{5}{*}{ FE } & Média & 3,1 & 2,3 & 2,8 & $0,747^{*}$ & 0,478 \\
\hline & Mediana & 3,0 & 2,0 & 2,0 & & \\
\hline & Desvio-padrão & 1,9 & 2,1 & 1,7 & & \\
\hline & Mínimo & 0 & 0 & 0 & & \\
\hline & Máximo & 8,0 & 9,0 & 7,0 & & \\
\hline \multirow{5}{*}{$\mathrm{EF}$} & Média & 1,9 & 1,5 & 1,7 & $1,779^{*}$ & 0,411 \\
\hline & Mediana & 1,0 & 1,8 & 2,0 & & \\
\hline & Desvio-padrão & 1,9 & 0,8 & 1,4 & & \\
\hline & Mínimo & 0 & 0 & 0 & & \\
\hline & Máximo & 6,0 & 2,0 & 5,0 & & \\
\hline \multirow{5}{*}{$\mathrm{E}$} & Média & 0,5 & - & - & $2,000 *$ & 0,368 \\
\hline & Mediana & 0 & - & - & & \\
\hline & Desvio-padrão & 0,2 & - & - & & \\
\hline & Mínimo & 0 & - & - & & \\
\hline & Máximo & 1,0 & - & - & & \\
\hline \multirow[t]{5}{*}{ FClob } & Média & 0,2 & - & 0,2 & $4,532 *$ & 0,104 \\
\hline & Mediana & 0 & - & 0 & & \\
\hline & Desvio-padrão & 0,4 & - & 0,5 & & \\
\hline & Mínimo & - & - & 0 & & \\
\hline & Máximo & 1,0 & - & 2,0 & & \\
\hline \multirow[t]{5}{*}{ ClobF } & Média & - & - & 0,1 & $4,069^{*}$ & 0,131 \\
\hline & Mediana & - & - & 0 & & \\
\hline & Desvio-padrão & - & - & 0,3 & & \\
\hline & Mínimo & - & - & 0 & & \\
\hline & Máximo & - & - & 1,0 & & \\
\hline
\end{tabular}

* Teste Kruskal-Wallis.

** A variável Clob foi omitida por não ter ocorrido nos grupos. 
Inexistiram diferenças estatisticamente significativas entre os grupos no tocante a proporção de uso dos determinantes associados ao sombreado. Além disso, notou-se baixa incidência desse tipo de determinantes entre as respostas das participantes, nomeadamente nas categorias E, FClob, ClobF, reforçando o dado de reduzidos indicadores de ansiedade no funcionamento psíquico das mulheres avaliadas. O significado do uso do determinante estompage pode ser visualizado também em função de sua associação com a qualidade formal positiva ou negativa da resposta. Para ilustrar esse dado foi elaborada a Tabela 26.

Tabela 26. Distribuição das mulheres em função da qualidade formal dos determinantes de sombreado (estompage) no Rorschach $(n=60)$.

\begin{tabular}{ccccccc}
\hline Variável Rorschach & Grupo 1 & Grupo 2 & Grupo 3 & Total & Estatística & $p$ \\
\hline FE $>$ EF+E & 11 & 11 & 10 & 32 & $1,063 *$ & 0,900 \\
FE $<$ EF+E & 6 & 4 & 6 & 16 & & \\
FE $=$ EF+E & 3 & 5 & 4 & 12 & & \\
\hline
\end{tabular}

*Teste Kruskal-Wallis.

Em todos os grupos, a maioria das participantes apresentou predomínio de emissão de respostas do tipo estompage associada a positiva qualidade formal, em detrimento de respostas com qualidade formal negativa ou sombreado puro, apresentando, deste modo, adequadas habilidades para conter a angústia por meio da lógica e da razão. Esses achados fortalecem a observação de que nessas participantes existem características psicodinâmicas indicativas de adaptativo funcionamento psicológico, independentemente de suas (im)possibilidades de gerar filhos ou de tê-los (ou não) adotados. Ressalta-se, ainda, que referido desempenho se aproxima ao apresentado pelo referencial normativo geral (Pasian, 2000).

Em prosseguimento à análise dos indicadores do Rorschach, foram sistematizados os achados sobre os Conteúdos presentes nas respostas das participantes a este instrumento. Inicialmente, elaborou-se a Tabela 27 com o objetivo de apresentar a estatística descritiva e comparativa referente aos Conteúdos animais e humanos, dada sua relevância em termos psicodinâmicos. 
Tabela 27. Resultados descritivos e comparação estatística das variáveis referentes aos Conteúdos animais e humanos no Rorschach, em função dos grupos de mulheres $(n=60)$.

\begin{tabular}{|c|c|c|c|c|c|c|}
\hline $\begin{array}{l}\text { Conteúdos } \\
\text { Rorschach }\end{array}$ & Resultados & Grupo 1 & Grupo 2 & Grupo 3 & Estatística & $p$ \\
\hline \multirow{5}{*}{ A } & Média & 7,6 & 6,8 & 7,4 & \multirow[t]{5}{*}{$0,381 * *$} & \multirow[t]{5}{*}{0,827} \\
\hline & Mediana & 7,0 & 7,5 & 7,5 & & \\
\hline & Desvio-padrão & 4,1 & 2,7 & 3,6 & & \\
\hline & Mínimo & 0 & 3,0 & 1,0 & & \\
\hline & Máximo & 16,0 & 12,0 & 13,0 & & \\
\hline \multirow{5}{*}{ (A) } & Média & 0,9 & 0,9 & 1,6 & \multirow[t]{5}{*}{$4,048^{*}$} & \multirow[t]{5}{*}{0,132} \\
\hline & Mediana & 1,0 & 0,9 & 1,0 & & \\
\hline & Desvio-padrão & 0,8 & 1,0 & 1,5 & & \\
\hline & Mínimo & 0 & 0 & 0 & & \\
\hline & Máximo & 3,0 & 4,0 & 7,0 & & \\
\hline \multirow{5}{*}{ Ad } & Média & 1,0 & 1,1 & 1,5 & \multirow[t]{5}{*}{$0,537^{*}$} & \multirow[t]{5}{*}{0,765} \\
\hline & Mediana & 1,0 & 1,0 & 1,0 & & \\
\hline & Desvio-padrão & 0,8 & 1,1 & 1,6 & & \\
\hline & Mínimo & 0 & 0 & 0 & & \\
\hline & Máximo & 3,0 & 3,0 & 6,0 & & \\
\hline \multirow{5}{*}{ (Ad) } & Média & 0,3 & 0,5 & 0,2 & \multirow[t]{5}{*}{$3,540^{*}$} & \multirow[t]{5}{*}{0,170} \\
\hline & Mediana & 0 & 0 & 0 & & \\
\hline & Desvio-padrão & 0,5 & 0,2 & 0,4 & & \\
\hline & Mínimo & 0 & 0 & 0 & & \\
\hline & Máximo & 2,0 & 1,0 & 1,0 & & \\
\hline \multirow[t]{5}{*}{$\mathrm{A} \%$} & Média & 44,1 & 52,2 & 50,9 & \multirow[t]{5}{*}{$4,589^{*}$} & \multirow[t]{5}{*}{0,101} \\
\hline & Mediana & 42,1 & 50,0 & 51,1 & & \\
\hline & Desvio-padrão & 12,1 & 10,7 & 9,8 & & \\
\hline & Mínimo & 21,0 & 36,0 & 36,0 & & \\
\hline & Máximo & 65,0 & 71,0 & 67,0 & & \\
\hline \multirow[t]{5}{*}{$\mathrm{H}$} & Média & 2,2 & 2,0 & 1,8 & \multirow[t]{5}{*}{$0,977^{*}$} & \multirow[t]{5}{*}{0,614} \\
\hline & Mediana & 2,0 & 2,0 & 2,0 & & \\
\hline & Desvio-padrão & 1,5 & 1,1 & 2,3 & & \\
\hline & Mínimo & 0 & 0 & 0 & & \\
\hline & Máximo & 6,0 & 4,0 & 5,0 & & \\
\hline \multirow[t]{5}{*}{$(\mathrm{H})$} & Média & 0,9 & 0,85 & 1,1 & \multirow[t]{5}{*}{$2,237^{*}$} & \multirow[t]{5}{*}{0,327} \\
\hline & Mediana & 0 & 1,0 & 1,0 & & \\
\hline & Desvio-padrão & 1,7 & 0,8 & 1,0 & & \\
\hline & Mínimo & 0 & 0 & 0 & & \\
\hline & Máximo & 7,0 & 3,0 & 4,0 & & \\
\hline
\end{tabular}


Conteúdos Resultados Grupo 1 Grupo 2 Grupo 3 Estatística $p$

Rorschach

\begin{tabular}{|c|c|c|c|c|c|c|}
\hline \multirow[t]{5}{*}{$\mathrm{Hd}$} & Média & 1,0 & 0,8 & 1,3 & \multirow[t]{5}{*}{$0,716^{*}$} & \multirow[t]{5}{*}{0,699} \\
\hline & Mediana & 1,0 & 1,0 & 1,0 & & \\
\hline & Desvio-padrão & 1,1 & 0,9 & 1,0 & & \\
\hline & Mínimo & 0 & 0 & 0 & & \\
\hline & Máximo & 3,0 & 4,0 & 5,0 & & \\
\hline \multirow[t]{5}{*}{ (Hd) } & Média & 0,5 & 0,5 & 0,2 & \multirow[t]{5}{*}{$4,335^{*}$} & \multirow[t]{5}{*}{0,114} \\
\hline & Mediana & 0 & 0 & 0 & & \\
\hline & Desvio-padrão & 0,8 & 0,2 & 0,5 & & \\
\hline & Mínimo & 0 & 0 & 0 & & \\
\hline & Máximo & 3,0 & 1,0 & 2,0 & & \\
\hline \multirow[t]{5}{*}{$\mathrm{H} \%$} & Média & 20,3 & 22,1 & 21,2 & \multirow[t]{5}{*}{$0,223 * *$} & \multirow[t]{5}{*}{0,801} \\
\hline & Mediana & 19,8 & 21,4 & 21,8 & & \\
\hline & Desvio-padrão & 7,7 & 9,9 & 7,8 & & \\
\hline & Mínimo & 10,0 & 0,0 & 4,0 & & \\
\hline & Máximo & 36,0 & 43,0 & 37 & & \\
\hline
\end{tabular}

* Teste Kruskal-Wallis

** ANOVA.

Não houve diferenças estatisticamente significativas entre os grupos avaliados nas variáveis referentes aos conteúdos animais e humanos. Os conteúdos animais predominaram nas respostas das participantes, em todos os grupos, em detrimento dos conteúdos humanos. Referidos indicadores corroboram achados anteriormente mencionados, nos quais o movimento animal prevaleceu sobre movimento humano nos protocolos de Rorschach destas mesmas participantes. Estes achados podem apontar para sinais de alguma imaturidade e projeção de conteúdos mais primitivos da personalidade, bem como percepção mais intuitiva e menos elaborada da realidade.

De modo a localizar a produção destas participantes em relação ao padrão de referência (Pasian, 2000) nos conteúdos animais e humanos no Rorschach, elaborou-se a Tabela 28. Os dados médios dos grupos nas variáveis $\mathrm{A} \%$ e $\mathrm{H} \%$ do Rorschach foram comparados com as normas de adultos, classificando-os em termos de sua posição percentílica. 
Tabela 28. Descrição (em percentis) dos valores médios nos conteúdos $A \%$ e $H \%$ do Rorschach, em função dos grupos de mulheres $(n=60)$.

\begin{tabular}{cccc}
\hline $\begin{array}{r}\text { Variáveis } \\
\text { Rorschach }\end{array}$ & Grupo 1 & Grupo 2 & Grupo 3 \\
\hline $\mathrm{A} \%$ & $<40$ & $40<\mathrm{P}<50$ & $40<\mathrm{P}<50$ \\
$\mathrm{H} \%$ & $40<\mathrm{P}<50$ & $40<\mathrm{P}<50$ & $40<\mathrm{P}<50$ \\
\hline
\end{tabular}

Nota-se que produção média das participantes mostrou-se muito próxima da média de referência. A comparação estatística do número de mulheres abaixo ou acima/na média para a variável $A \%$ (Qui-quadrado=8,151, $p=0,086$ ) e para a variável H\% (Qui-quadrado=3,091, $p=0,593$ ) apontou ausência de diferenças significativas entre os grupos.

A percepção de figuras animais e humanas inteiras e íntegras foi mais frequente que a percepção de partes de corpo humano e animal, bem como mais frequentes que percepções pautadas pela desvitalização. Referidos dados sinalizam preservada identidade das participantes, conforme fundamentação teórica do Rorschach. Estes indicadores somam-se a outros anteriormente apresentados, reforçando a interpretação de que este conjunto de mulheres apresenta indicativos de personalidade em funcionamento compatível com a normalidade, sem sinais de prejuízos ou de descontrole afetivo em nenhum dos grupos, a despeito de suas diferenças em relação às vivências da maternidade.

Os demais itens da classificação dos Conteúdos nos protocolos de Rorschach foram sistematizados na Tabela 29. São apresentados de forma descritiva e em sua comparação estatística entre os grupos desta pesquisa.

Tabela 29. Resultados descritivos e comparação estatística das variáveis referentes aos Conteúdos no Rorschach, em função dos grupos de mulheres $(n=60)$.

\begin{tabular}{ccccccc}
\hline $\begin{array}{c}\text { Conteúdos } \\
\text { Rorschach }\end{array}$ & Resultados & Grupo 1 & Grupo 2 & Grupo 3 & Estatística & $p$ \\
& & & & & & \\
\hline \multirow{3}{*}{ Anat } & Média & 2,1 & 1,5 & 1,8 & $0,668^{*}$ & 0,716 \\
& Mediana & 2,0 & 1,0 & 2,0 & & \\
& Desvio-padrão & 2,4 & 1,4 & 1,9 & & \\
& Mínimo & 0 & 0 & 0 & & \\
& Máximo & 11,0 & 5,0 & 7,0 & & \\
& & & & & \\
& Média & 0,6 & - & - & & \\
& Mediana & 0 & - & - & & \\
& Desvio-padrão & 0,2 & - & - & & \\
& Mínimo & 0 & - & - & & \\
& Máximo & 1,0 & - & - & & \\
& & & & & & \\
& &
\end{tabular}


Conteúdos

Resultados

Grupo 1 Grupo 2 Grupo 3

Estatística

Rorschach

\begin{tabular}{|c|c|c|c|c|c|c|}
\hline \multirow{5}{*}{ Sex } & Média & 0,6 & 0,2 & 0,4 & \multirow[t]{5}{*}{$1,460 *$} & \multirow[t]{5}{*}{0,382} \\
\hline & Mediana & 0 & 0 & 0 & & \\
\hline & Desvio-padrão & 1,2 & 0,5 & 1,1 & & \\
\hline & Mínimo & 0 & 0 & 0 & & \\
\hline & Máximo & 5,0 & 2,0 & 5,0 & & \\
\hline \multirow{5}{*}{ Obj } & Média & 2,45 & 1,5 & 2,1 & \multirow[t]{5}{*}{$1,917^{*}$} & \multirow[t]{5}{*}{0,384} \\
\hline & Mediana & 1,5 & 1,0 & 1,0 & & \\
\hline & Desvio-padrão & 2,1 & 1,6 & 2,4 & & \\
\hline & Mínimo & 0 & 0 & 0 & & \\
\hline & Máximo & 7,0 & 5,0 & 8,0 & & \\
\hline \multirow[t]{5}{*}{ Art } & Média & 0,1 & 0,1 & - & \multirow[t]{5}{*}{$3,530 *$} & \multirow[t]{5}{*}{0,171} \\
\hline & Mediana & 0 & 0 & - & & \\
\hline & Desvio-padrão & 3,6 & 0,4 & - & & \\
\hline & Mínimo & 0 & 0 & - & & \\
\hline & Máximo & 1,0 & 2,0 & - & & \\
\hline \multirow[t]{5}{*}{ Arq } & Média & 0,2 & 0 & 0,3 & \multirow[t]{5}{*}{$4,291 *$} & \multirow[t]{5}{*}{0,117} \\
\hline & Mediana & 0 & 0 & 0 & & \\
\hline & Desvio-padrão & 0,4 & 0,2 & 0,5 & & \\
\hline & Mínimo & 0 & 0 & 0 & & \\
\hline & Máximo & 1,0 & 1,0 & 0,2 & & \\
\hline \multirow[t]{5}{*}{ Símb } & Média & 0,1 & 0,1 & 0,2 & \multirow[t]{5}{*}{$0,316^{*}$} & \multirow[t]{5}{*}{0,854} \\
\hline & Mediana & 0 & 0 & 0 & & \\
\hline & Desvio-padrão & 0,3 & 0,3 & 0,5 & & \\
\hline & Mínimo & 0 & 0 & 0 & & \\
\hline & Máximo & 1,0 & 1,0 & 2,0 & & \\
\hline \multirow[t]{5}{*}{ Abst } & Média & 0,1 & 0,1 & - & \multirow[t]{5}{*}{$2,105^{*}$} & \multirow[t]{5}{*}{0,349} \\
\hline & Mediana & 0 & 0 & - & & \\
\hline & Desvio-padrão & 0,4 & 0,4 & - & & \\
\hline & Mínimo & 0 & 0 & - & & \\
\hline & Máximo & 2,0 & 6,0 & - & & \\
\hline \multirow[t]{5}{*}{ Bot } & Média & 1,2 & 0,4 & 0,4 & \multirow[t]{5}{*}{$6,253^{*}$} & \multirow[t]{5}{*}{0,044} \\
\hline & Mediana & 1,0 & 0 & 0 & & \\
\hline & Desvio-padrão & 1,5 & 0,8 & 0,6 & & \\
\hline & Mínimo & 0 & 0 & 0 & & \\
\hline & Máximo & 6,0 & 3,0 & 2,0 & & \\
\hline \multirow[t]{5}{*}{ Geo } & Média & 0,4 & 0 & 0,2 & \multirow[t]{5}{*}{$4,432 *$} & \multirow[t]{5}{*}{0,109} \\
\hline & Mediana & 0 & 0 & 0 & & \\
\hline & Desvio-padrão & 0,6 & 0,2 & 0,4 & & \\
\hline & Mínimo & 0 & 0 & 0 & & \\
\hline & Máximo & 2,0 & 1,0 & 1,0 & & \\
\hline
\end{tabular}




\begin{tabular}{|c|c|c|c|c|c|c|}
\hline $\begin{array}{l}\text { Conteúdos } \\
\text { Rorschach }\end{array}$ & Resultados & Grupo 1 & Grupo 2 & Grupo 3 & Estatística & $p$ \\
\hline Nat & $\begin{array}{c}\text { Média } \\
\text { Mediana } \\
\text { Desvio-padrão } \\
\text { Mínimo } \\
\text { Máximo }\end{array}$ & $\begin{array}{l}- \\
- \\
- \\
- \\
-\end{array}$ & $\begin{array}{c}0,1 \\
0 \\
0,3 \\
0 \\
1,0\end{array}$ & $\begin{array}{c}0,1 \\
0 \\
0,3 \\
0 \\
1,0\end{array}$ & $2,107^{*}$ & 0,349 \\
\hline Pais & $\begin{array}{c}\text { Média } \\
\text { Mediana } \\
\text { Desvio-padrão } \\
\text { Mínimo } \\
\text { Máximo }\end{array}$ & $\begin{array}{c}0,3 \\
0 \\
0,5 \\
0 \\
2,0\end{array}$ & $\begin{array}{c}0,2 \\
0 \\
0,5 \\
0 \\
2,0\end{array}$ & $\begin{array}{c}0,1 \\
0 \\
0,3 \\
0 \\
1,0\end{array}$ & $0,898^{*}$ & 0,638 \\
\hline Elem & $\begin{array}{c}\text { Média } \\
\text { Mediana } \\
\text { Desvio-padrão } \\
\text { Mínimo } \\
\text { Máximo }\end{array}$ & $\begin{array}{c}0 \\
0 \\
0,2 \\
0 \\
1,0\end{array}$ & $\begin{array}{l}- \\
- \\
- \\
- \\
-\end{array}$ & $\begin{array}{c}0,1 \\
0 \\
0,3 \\
0 \\
1,0\end{array}$ & $3,687^{*}$ & 0,358 \\
\hline Elem (fog) & $\begin{array}{c}\text { Média } \\
\text { Mediana } \\
\text { Desvio-padrão } \\
\text { Mínimo } \\
\text { Máximo }\end{array}$ & $\begin{array}{c}0 \\
0 \\
0,2 \\
0 \\
1,0\end{array}$ & $\begin{array}{l}- \\
- \\
- \\
-\end{array}$ & $\begin{array}{c}0,1 \\
0 \\
0,3 \\
0 \\
1,0\end{array}$ & $2,070^{*}$ & 0,355 \\
\hline Frag & $\begin{array}{c}\text { Média } \\
\text { Mediana } \\
\text { Desvio-padrão } \\
\text { Mínimo } \\
\text { Máximo }\end{array}$ & $\begin{array}{c}0,1 \\
0 \\
0,3 \\
0 \\
1,0\end{array}$ & $\begin{array}{c}0,1 \\
0 \\
0,3 \\
0 \\
1,0 \\
\end{array}$ & $\begin{array}{c}0,2 \\
0 \\
0,4 \\
0 \\
1,0 \\
\end{array}$ & $0,771^{*}$ & 0,680 \\
\hline
\end{tabular}

* Teste Kruskal-Wallis.

Observou-se que apenas diante do conteúdo Botânico (Bot) houve diferença estatisticamente significativa entre os grupos, com reduzida magnitude de efeito (Eta parcial=0,119). Aplicando-se o teste post-hoc de Bonferroni à referida variável identificou-se diferença entre $\mathrm{G} 1$ e $\mathrm{G} 2(p=0,05)$, não sendo observadas outras diferenças entre os demais grupos entre si nesta variável. As mulheres de G1 (pretendentes à adoção) apresentaram maior frequência do conteúdo Bot nas respostas ao Rorschach, comparativamente às mulheres de G2 (mães adotivas).

A Tabela 29 nos mostra ainda que estas variáveis de Conteúdo no Rorschach tiveram frequência bastante baixa em todos os grupos, sendo numericamente pouco expressivas dentro do conjunto de fatores examinados neste método projetivo. Comparando-se estes achados 
com os apresentados pelo grupo normativo (Pasian, 2000), observou-se similaridade no padrão de respostas, com baixa incidência desses conteúdos específicos, reforçando a noção de concentração nas interpretações de conteúdos animais e humanos, como aqui também atestado.

Deste modo, pode-se dizer que, também nas variáveis referentes aos Conteúdos do Rorschach, as mulheres ora avaliadas apresentaram desempenho semelhante ao encontrado em seu grupo de referência. Depreende-se, portanto, funcionamento da personalidade compatível com o que é considerado frequente e comum na população geral, em todos os grupos, independente de sua condição frente à maternidade.

Por fim, focalizou-se a análise da frequência de respostas banais (Ban) no Rorschach. Para tanto, elaborou-se a Tabela 30.

Tabela 30. Resultados descritivos e comparação estatística das Banalidades no Rorschach, em função dos grupos de mulheres $(n=60)$.

\begin{tabular}{ccccccc}
\hline $\begin{array}{c}\text { Variáveis } \\
\text { Rorschach** }\end{array}$ & Resultados & Grupo 1 & Grupo 2 & Grupo 3 & Estatística & $p$ \\
& & & & & & \\
\hline \multirow{2}{*}{ Ban } & Média & 5,0 & 4,9 & 4,7 & $0,186^{*}$ & 0,911 \\
& Mediana & 5,0 & 4,5 & 5,0 & & \\
& Desvio-padrão & 1,5 & 1,5 & 1,7 & & \\
& Mínimo & 3,0 & 3,0 & 3,0 & & \\
& Máximo & 8,0 & 9,0 & 8,0 & & \\
& & & & & \\
& Média & 24,5 & 28,6 & 23,8 & $3,682^{*}$ & \\
Ban \% & Mediana & 25,6 & 26,7 & 24,4 & & \\
& Desvio-padrão & 8,0 & 7,1 & 8,1 & & \\
& Mínimo & 9,0 & 21,0 & 10,0 & & \\
& Máximo & 33,0 & 50,0 & 42,0 & & \\
& & & & & \\
&
\end{tabular}

*Teste Kruskal-Wallis.

A análise comparativa da frequência de respostas banais (Ban) no Rorschach apontou ausência de diferenças estatisticamente significativas entre os grupos. Ao se tomar as médias apresentadas nos grupos, observou-se que as participantes apresentaram perfil próximo a seu padrão de referência também no quesito Banalidades (Pasian, 2000). A comparação dos grupos no tocante à distribuição dos casos em função da classificação abaixo ou acima/na média normativa nas banalidades revelou inexistência de diferenças estatisticamente significativas (Qui-quadrado=5,631; $p=0,228$ ). 
Deste modo, é possível dizer que pretendentes à adoção, mães adotivas e mães biológicas apresentaram, em proporções similares, interpretações ao Rorschach compostas de "elementos bastante comuns, muitas vezes associados às características intrínsecas aos estímulos apresentados" (Pasian, 2000, p. 74). Assim, denotaram possibilidade de compartilhamento perceptivo acerca dos elementos da realidade, indicadores relacionados, do ponto de vista psicodinâmico, a adequado teste de realidade, independentemente de sua condição frente à maternidade.

Em seguida são apresentados resultados relativos a outros indicadores relevantes dentro do processo de análise da dinâmica afetiva presentes no Rorschach. Tratam-se das "Fórmulas Vivenciais", sendo que na Tabela 31 constam informações sobre o Tipo de Ressonância Íntima (TRI) deste método projetivo.

Tabela 31. Distribuição das mulheres em função do Tipo de Ressonância Íntima (TRI) no Rorschach $(n=60)$.

\begin{tabular}{|c|c|c|c|c|c|c|}
\hline \multicolumn{3}{|c|}{ Classificação do TRI } & Grupo 1 & Grupo 2 & Grupo 3 & Total \\
\hline \multirow{2}{*}{\multicolumn{2}{|c|}{ Ambigual }} & $f$ & 2 & 1 & 2 & 5 \\
\hline & & $\%$ & 10,0 & 5,0 & 10,0 & 8,3 \\
\hline \multirow{2}{*}{\multicolumn{2}{|c|}{ Coartativo }} & $f$ & 1 & 3 & 2 & 6 \\
\hline & & $\%$ & 5,0 & 15,0 & 10,0 & 10,0 \\
\hline \multirow[t]{4}{*}{ Extratensivo } & Puro & $f$ & 2 & 2 & 2 & 6 \\
\hline & & $\%$ & 10,0 & 10,0 & 10,0 & 10,0 \\
\hline & Dilatado & $f$ & 10 & 9 & 10 & 29 \\
\hline & & $\%$ & 50,0 & 45,0 & 50,0 & 48,3 \\
\hline \multirow[t]{4}{*}{ Introversivo } & Puro & $f$ & 1 & - & - & 1 \\
\hline & & $\%$ & 5,0 & - & - & 1,7 \\
\hline & Dilatado & $f$ & 4 & 5 & 4 & 13 \\
\hline & & $\%$ & 20,0 & 25,0 & 20,0 & 21,7 \\
\hline
\end{tabular}

Notou-se que a frequência dos diferentes Tipos de Ressonância Íntima foi bastante semelhante entre os grupos, sem diferenças estatisticamente significativas (Qui-quadrado $=0,454$, $p=0,490)$. O tipo mais frequente foi o Extratensivo, englobando $58,3 \%$ das mulheres avaliadas, ou seja, mais da metade das mesmas. Especificamente, em sua modalidade dilatada, referido tipo de ressonância íntima foi o mais comum, mostrando que a maioria das mulheres avaliadas 
apresentou tendência habitual a expressar sua afetividade de forma direta no ambiente, vivenciando satisfação nas experiências de contato com o mundo exterior.

O tipo Introversivo ocorreu em $23,4 \%$ das participantes, sendo que a maioria delas apresentou a modalidade dilatada. Assim, pouco menos de um quarto das participantes sinalizou vivenciar suas emoções habitualmente de forma mais reflexiva e interiorizada, embora com capacidade de exteriorização dos sentimentos e contato com o mundo exterior.

Uma parcela menor das participantes apresentou o estilo coartativo de vivenciar os afetos. Assim, aproximadamente 10\% das participantes demonstraram reagir ao Rorschach e, por conseguinte, aos estímulos da realidade (conforme fundamentação teórica do instrumento), de maneira restritiva e com poucas manifestações afetivas, sugerindo estilo evitativo de contato. Por fim, pequeno grupo de participantes apresentou estilo afetivo do tipo Ambigual. Desse modo, poucas mulheres $(8,3 \%)$ apresentaram tendência habitual de expressar seus sentimentos e afetos no ambiente em igual proporção a um modo mais reflexivo e introspectivo para lidar com emoções.

Na sequência de análise das fórmulas afetivas do Rorschach elaborou-se a Tabela 32. Ela mostra a distribuição das mulheres entre os tipos afetivos de acordo com suas Tendências Latentes (segunda fórmula afetiva) do Rorschach.

Tabela 32. Distribuição das mulheres em função da segunda fórmula afetiva (Tendências Latentes) do Rorschach $(n=60)$.

\begin{tabular}{|c|c|c|c|c|c|c|}
\hline \multicolumn{3}{|c|}{ Tendências Latentes } & Grupo 1 & Grupo 2 & Grupo 3 & Total \\
\hline \multirow{2}{*}{\multicolumn{2}{|c|}{ Ambigual }} & $f$ & 2 & 3 & 1 & 6 \\
\hline & & $\%$ & 10,0 & 15,0 & 5,0 & 10,0 \\
\hline \multirow{2}{*}{\multicolumn{2}{|c|}{ Coartativo }} & $f$ & 2 & 1 & 2 & 5 \\
\hline & & $\%$ & 10,0 & 5,0 & 10,0 & 8,3 \\
\hline \multirow[t]{4}{*}{ Extratensivo } & Puro & $f$ & 2 & 2 & - & 4 \\
\hline & & $\%$ & 10,0 & 10,0 & - & 6,7 \\
\hline & Dilatado & $f$ & 7 & 2 & 7 & 16 \\
\hline & & $\%$ & 35,0 & 10,0 & 35,0 & 26,7 \\
\hline \multirow[t]{4}{*}{ Introversivo } & Puro & $f$ & - & 1 & - & 1 \\
\hline & & $\%$ & - & 5,0 & - & 1,7 \\
\hline & Dilatado & $\mathrm{f}$ & 7 & 11 & 10 & 28 \\
\hline & & $\%$ & 35,0 & 55,0 & 50,0 & 46,7 \\
\hline
\end{tabular}


A análise comparativa da distribuição das mulheres entre os estilos afetivos captados pela segunda fórmula do Rorschach (Tendências Latentes) apontou ausência de diferenças estatisticamente significativas entre os grupos (Qui-quadrado=9,454, $p=0,490$ ). Desse modo, pretendentes à adoção, mães adotivas e mães biológicas sinalizaram perfil similar em seus recursos potenciais para lidar com os afetos.

Nessa análise das Tendências Latentes houve claro predomínio do estilo Introversivo de vivenciar os afetos, nomeadamente do tipo dilatado. Assim, a maioria das mulheres sinalizou riqueza e sensibilidade em seu mundo interior, com potencial para movimentos reflexivos e imaginativos, ainda que não seja esse seu estilo habitual de reação afetiva (visto que o estilo predominante no TRI foi Extratensivo).

Houve 33,4\% das participantes com Tendências Latentes do tipo Extratensivo, confirmando a presença de recursos internos voltados para os contatos e para a expressão mais direta de suas emoções. Os tipos Coartativo e Ambigual estiveram presentes em proporções próximas às encontradas na TRI, sendo também a minoria dos casos nas Tendências Latentes do Rorschach.

Resta analisar, no tocante às vivências afetivas, a chamada Terceira Fórmula (reatividade cromática) e a Fórmula da Angústia do Rorschach. Para tanto, elaborou-se a Tabela 33.

Tabela 33. Resultados descritivos e comparação estatística da Terceira Fórmula e da Fórmula da Angústia no Rorschach, em função dos grupos de mulheres $(n=60)$.

\begin{tabular}{ccccccc}
\hline Variável & Resultados & Grupo 1 & Grupo 2 & Grupo 3 & Estatística & $p$ \\
Rorschach & & & & & & \\
& & & & & \\
& Média & 30,6 & 29,3 & 31,7 & $0,481^{* *}$ & 0,621 \\
& Mediana & 30,4 & 27,7 & 31,7 & & \\
& Desvio-padrão & 8,9 & 8,3 & 6,1 & & \\
& Mínimo & 19,0 & 15,0 & 23,0 & & \\
Terceira Fórmula & Máximo & 48,0 & 44,0 & 42,0 & & \\
& & & & & & \\
& \% Introversivo & 50,0 & 65,0 & 45,0 & $3,346^{* * *}$ & \\
& \% Ambigual & 35,0 & 15,0 & 40,0 & & \\
\% Extratensivo & 15,0 & 20,0 & 15,0 & & \\
& & & & & \\
Fórmula & Média & 18,6 & 14,7 & 17,5 & $1,175^{*}$ & 0,556 \\
da & Mediana & 16,6 & 14,4 & 17,9 & & \\
Angústia & Desvio-padrão & 12,2 & 8,9 & 11,3 & & \\
& Mínimo & 4,0 & 0 & 0 & & \\
& Máximo & 50,0 & 33,0 & 42,0 & & \\
& & & & &
\end{tabular}

*Teste Kruskal-Wallis

**ANOVA

*** Qui-quadrado 
Os indicadores referentes à Terceira Fórmula do Rorschach, relativos à reatividade emocional, apontaram que os três grupos apresentaram resultados médios similares, sem diferenças estatisticamente significativas. A maioria das mulheres, em cada um dos três grupos, apresentou perfil do tipo introversivo ou ambigual, com poucos casos classificados como extratensivos.

Deste modo, é possível afirmar que as mulheres presentemente avaliadas, independentemente de sua condição frente à maternidade, apresentaram indicadores de reatividade emocional semelhante, com maior tendência a refletir e raciocinar antes de reagir aos estímulos (estilo introversivo), embora parte delas demonstre flexibilidade em sua forma de reagir ao ambiente (estilo ambigual). Por outro lado, houve algumas participantes que mostraram tendência a reagir de maneira mais direta diante das emoções e estímulos ambientais (estilo extratensivo).

O valor médio assumido pela Fórmula da Angústia nos três grupos de mulheres superou o valor teto de $12,0 \%$, sugerindo sinal importante de vivência de ansiedade. Não houve diferenças estatisticamente significativas entre os grupos nessa variável. Apesar desses indicadores de inquietação psíquica, os resultados foram próximos ao padrão normativo geral desta variável no Brasil (15,0\%, conforme Pasian, 2000). Desse modo, pode-se depreender que os sinais de angústia detectados não comprometem a capacidade geral de adaptação à realidade das mulheres avaliadas.

Diante deste percurso analítico, é possível afirmar que, no que concerne à avaliação das participantes pelo Rorschach, houve mais similaridades que diferenças entre os grupos G1, G2 e G3. As pretendentes à adoção, as mães adotivas e biológicas, ora avaliadas, apresentaram um perfil de personalidade semelhante, conforme sua avaliação por este instrumento projetivo, bem como aproximado ao padrão de referência, sem marcadores de qualquer disfuncionalidade psíquica.

\section{IV.4. Relativos ao Questionário Desiderativo}

Com relação ao Questionário Desiderativo, inicialmente serão apresentados os achados referentes à Análise de Conteúdo realizada com o objetivo de aprimorar o protocolo de codificação deste instrumento projetivo, como descrito no método. A síntese dos resultados alcançados por meio dessa análise de conteúdo relativa aos mecanismos de defesa do Questionário Desiderativo encontra-se sistematizada na Tabela 34. Os resultados estão apresentados em termos descritivos (em frequência simples), com base no sistema de 
categorização de defesas organizado por Kaplan, Saddock e Grebb (1997), como ponto de partida para os juízes.

Tabela 34. Descrição da Análise de Conteúdo (experts, $n=5$ ) referente aos mecanismos de defesa do Questionário Desiderativo.

\begin{tabular}{|c|c|c|c|c|}
\hline \multirow{2}{*}{\multicolumn{2}{|c|}{ Defesa psicológica }} & \multicolumn{3}{|c|}{ Voto dos especialistas (experts) } \\
\hline & & Sim & Não & Não sei \\
\hline \multirow{8}{*}{$\begin{array}{l}\text { Com base na } \\
\text { negação da } \\
\text { realidade }\end{array}$} & Atuação (acting-out) & 4 & 1 & - \\
\hline & Clivagem/Splitting & 4 & 1 & - \\
\hline & Idealização & 5 & - & - \\
\hline & Identificação Projetiva & 3 & 1 & 1 \\
\hline & Introjeção & 4 & 1 & - \\
\hline & Negação & 5 & - & - \\
\hline & Projeção & 5 & - & - \\
\hline & Regressão & 3 & 1 & 1 \\
\hline \multirow{11}{*}{$\begin{array}{l}\text { Com base na } \\
\text { repressão da } \\
\text { realidade }\end{array}$} & Anulação & 4 & 1 & - \\
\hline & Deslocamento & 2 & 1 & 2 \\
\hline & Dissociação & 5 & - & - \\
\hline & Inibição & 4 & - & 1 \\
\hline & Intelectualização & 4 & - & 1 \\
\hline & Formação Reativa & 5 & - & - \\
\hline & Racionalização & 5 & - & - \\
\hline & Repressão & 4 & 1 & - \\
\hline & Sedução & 5 & - & - \\
\hline & Sexualização & 4 & 1 & - \\
\hline & Sublimação & 5 & - & - \\
\hline \multirow{2}{*}{$\begin{array}{l}\text { Sugeridas } \\
\text { pelos experts }\end{array}$} & Distanciamento & 2 & - & - \\
\hline & Onipotência & 1 & - & - \\
\hline
\end{tabular}

Pode-se notar que não houve unanimidade entre os avaliadores no que se refere à pertinência de inclusão do conjunto de mecanismos de defesa inicialmente listados. Houve ainda duas defesas adicionais sugeridas por alguns dos experts, a saber: Onipotência e Distanciamento. Em oito das 19 defesas listadas houve concordância total dos examinadores, opinando de maneira favorável a sua inclusão no protocolo de codificação do Desiderativo. Segundo análise dos experts, devem compor a análise desse método projetivo os seguintes mecanismos de defesa: Negação, Projeção, Idealização, Racionalização, Dissociação, Formação Reativa, Sedução e Sublimação. 
Com o objetivo de diminuir as chances de discordância entre os examinadores no tocante aos referidos mecanismos de defesa, optou-se por destacar exemplos ilustrativos de respostas ao Questionário Desiderativo que as representem. Essas informações compõem o Quadro 1 e foram compiladas a partir dos exemplos clínicos dos especialistas consultados, configurando-se como resultado dessa etapa do processo de aprimoramento avaliativo deste método projetivo.

Quadro 1. Exemplos clínicos ilustrativos de mecanismos de defesa identificados a partir do Questionário Desiderativo, derivados da análise de conteúdo por experts.

\begin{tabular}{|c|c|}
\hline Defesas & Exemplos de respostas no Desiderativo \\
\hline Negação & $\begin{array}{l}\text { "Gostaria de ser uma bailarina porque é muito bonita" (falha lógica, negação do } \\
\text { pedido da pergunta) } \\
\text { "Gostaria de ser eu mesmo, não queria mudar" } \\
\text { "Gostaria de ser o céu, é um lugar de Deus, de gente boa, felicidade eterna, que só } \\
\text { os bons merecem" } \\
\text { "Não gostaria de ser luz, ofusca tudo, cega, faz bater o carro" } \\
\text { "Uma pedra. Ficou de repente escondida muitos anos até alguém cavar um buraco } \\
\text { e descobrir" } \\
\text { "Não gostaria de ser um objeto inanimado. Porque não teria vida" } \\
\text { "Gostaria de ser uma fada. Porque é mágica" }\end{array}$ \\
\hline Projeção & $\begin{array}{l}\text { "Não gostaria de ser uma cobra, porque é perigosa, falsa e traiçoeira" } \\
\text { "Não queria ser um burro de carga, pois ele é explorado pelas pessoas" } \\
\text { (e nas catexes negativas = "eu seria explorado...") } \\
\text { "Gostaria de ser uma planta carnívora, impõe respeito, é mais que especial, é } \\
\text { diferente de todas as outras" } \\
\text { "Não gostaria de ser óculos, é um objeto que vê tudo, o que quer e o que não } \\
\text { quer" } \\
\text { "Não gostaria de ser uma faca. Para não machucar ninguém" } \\
\text { "Um gato, porque parece um animal traiçoeiro" } \\
\text { "Um vírus. Porque tem vida curta e faz mal para todo mundo, é nocivo" } \\
\text { "Um rato. Porque é sujo, fica se escondendo, ninguém gosta dele" }\end{array}$ \\
\hline Idealização & $\begin{array}{l}\text { "Gostaria de ser uma pomba da paz porque é tudo de bom, tudo de bem, só traz } \\
\text { sorte o bem, só coisas boas pra gente" } \\
\text { "Cachorro, tem vida mansa e vida boa. Tem comida a hora que quer, pode fazer o } \\
\text { que quiser" } \\
\text { "Gostaria de ser uma sequoia, frondosa, daquelas que } 10 \text { pessoas juntas não } \\
\text { abraçam, vive séculos depois que o mundo acabar" } \\
\text { "Não gostaria de ser um vírus que mata, como o ebola, mata é implacável, vence a } \\
\text { medicina e a vida" } \\
\text { "A natureza. A natureza é tudo... É o mais importante" } \\
\text { "Uma bola, porque a bola é chutada" } \\
\text { "Um leão. Porque falam que ele é o rei da selva. Por ser um dos animais mais } \\
\text { fortes que existem" } \\
\text { "Queria ser uma máquina de datilografar, porque já foi muito importante ao } \\
\text { redigir documentos históricos" } \\
\text { "Revólver. Porque ele poderia ser usado para defender, matar pessoas ruins, } \\
\text { ladrão, estuprador" } \\
\text { "Gostaria de ser cachorro, é o melhor amigo do homem, é fiel, protege, agrada" }\end{array}$ \\
\hline
\end{tabular}




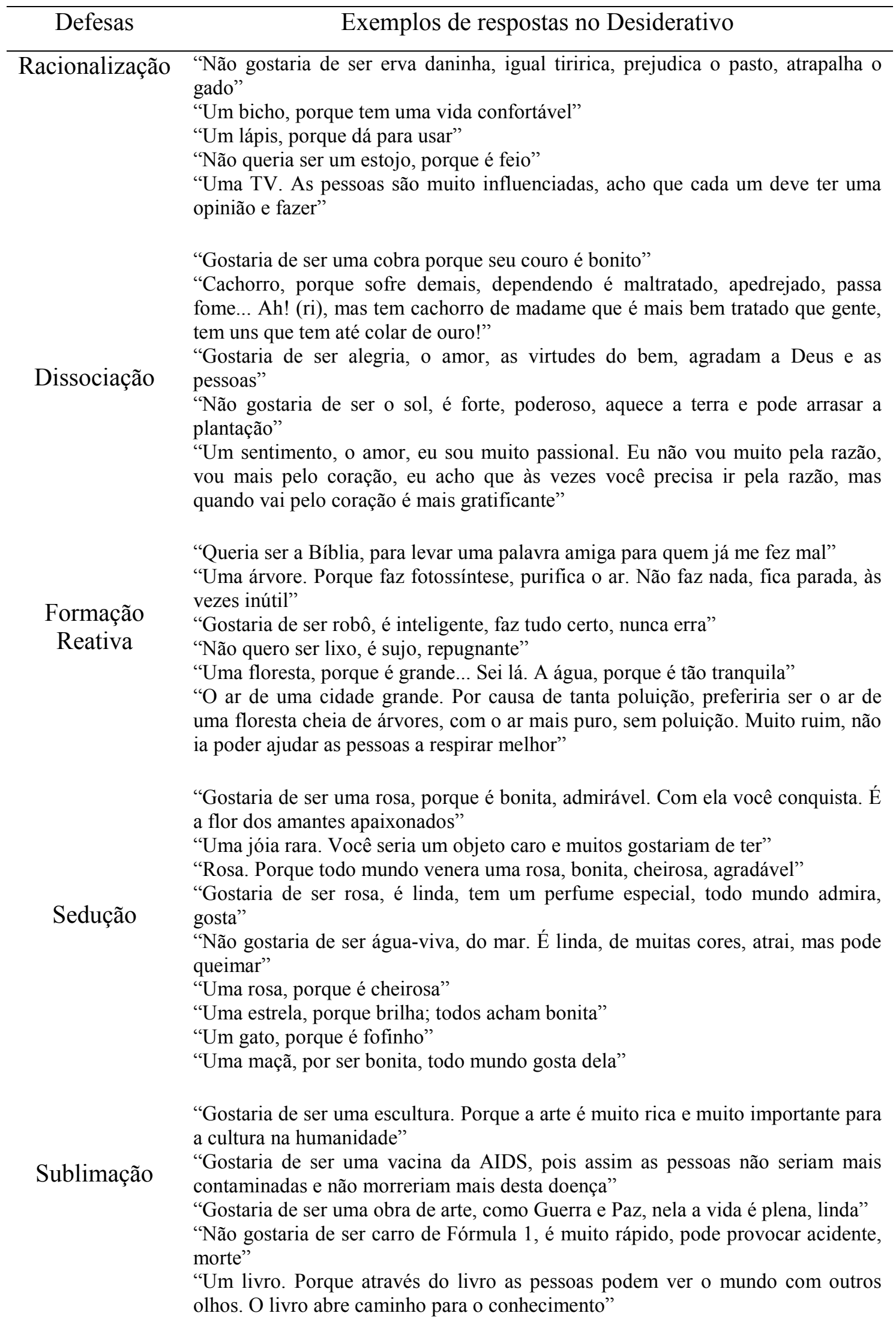


As respostas apresentadas pelos experts traduzem, no entendimento dos mesmos, a presença dos mecanismos de defesa apontados. Entretanto, como é possível observar pelo Quadro 1 e no APÊNDICE C, houve grande variabilidade entre os exemplos e, em diversos casos, seria possível avaliar que, nas respostas apontadas poderiam estar presentes outros mecanismos de defesa além daqueles descritos pelos especialistas consultados.

Como exemplo dessa dificuldade pode-se examinar a resposta "Não gostaria de ser óculos; é um objeto que vê tudo, o que quer e o que não quer”. Esse exemplo clínico foi apontado por um dos experts consultados como ilustração do mecanismo de defesa projeção. Entretanto, não se pode desconsiderar que tal resposta poderia também ser representante de outro mecanismo de defesa, nomeadamente idealização, pois está presente a exacerbação de características do objeto, dotando-o de poderes irreais e que não são próprios do mesmo (óculos não "veem tudo").

Outro exemplo clínico a ser examinado pode ser a resposta: "Gostaria de ser uma cobra, porque seu couro é bonito". Foi apontada por um dos juízes como representativa da defesa dissociação. Numa avaliação psicodinâmica também seria possível considerar esta resposta representativa da defesa sedução, pela valorização dos aspectos da beleza associados ao símbolo escolhido, na racionalização.

Nesse processo avaliativo há sempre que se considerar que o repertório individual de mecanismos de defesa inclui tipicamente diferentes estilos defensivos. Portanto, a identificação de dois mecanismos diferentes numa mesma resposta não seria algo incorreto ou teoricamente inesperado. Contudo, estes exemplos clínicos ilustram a dificuldade em se obter concordância entre examinadores na classificação de respostas ao Questionário Desiderativo no que se refere aos mecanismos de defesa, o que já foi apontado no trabalho de Guimarães, Pasian e Loureiro (2008). Mesmo com a apresentação de uma lista de mecanismos de defesa e sua definição (a partir de Kaplan, Saddock \& Grebb, 1997), a classificação dos experts foi pautada em sua própria experiência clínica e compreensão teórica, ocasionando variabilidade analítica.

Para além destas considerações, é preciso ponderar que alguns mecanismos de defesa seriam, pelos pressupostos teóricos do Desiderativo, subjacentes ao processo de responder ao instrumento. Como exemplo pode-se citar a projeção, a racionalização e a dissociação, processos psíquicos considerados fundamentais para a eleição de símbolos a serem escolhidos ou rejeitados, conforme as instruções da técnica.

Especificamente, a dissociação e a racionalização já são recursos classificados como Defesas Instrumentais no protocolo presentemente utilizado, baseado na proposição avaliativa de Nijamkin e Braude (2000). Sendo assim, em todas as respostas ao Questionário Desiderativo seria esperado verificar a presença destes mecanismos de defesa (em maior ou menor grau), sendo questionável a utilidade e o ganho informativo ao se registrar duplamente estas defesas no protocolo, acrescentando-as como parte do repertório defensivo individual do examinando. 
Neste raciocínio, excluindo as defesas "repetidas", cuja codificação específica seria redundante, foram selecionadas para compor o protocolo de codificação do instrumento as seguintes defesas: Negação, Idealização, Formação Reativa, Sedução e Sublimação. Assim, o psicólogo examinador deverá assinalar a presença ou ausência de cada uma destas defesas em cada resposta emitida pelo examinando. Ressalta-se que referida modalidade de codificação já foi utilizada no material analisado na presente investigação.

Finalizada essa etapa técnica, os resultados agora abordarão os achados derivados do material produzido pelas participantes diante do Desiderativo. Cada protocolo foi classificado por dois examinadores independentes, calculando-se seu índice de concordância (em porcentagem) para cada variável analisada. Esses dados compõem a Tabela 35.

Tabela 35. Resultados descritivos da Análise de Concordância entre examinadores independentes (em porcentagem), referentes à classificação das respostas ao Questionário Desiderativo $(n=60)$.

\begin{tabular}{|c|c|c|c|}
\hline \multicolumn{2}{|c|}{ Variável do Desiderativo } & \multirow{2}{*}{$\begin{array}{c}\text { \% Acordo } \\
99,2\end{array}$} & \multirow{2}{*}{$\frac{\% \text { Desacordo }}{0,8}$} \\
\hline Adequação ao real & Tempo & & \\
\hline & Sequência das escolhas & 97,6 & 2,4 \\
\hline & Necessidade de indução & 97,6 & 2,4 \\
\hline & Respostas Antropomórficas & 98,1 & 1,9 \\
\hline \multirow[t]{3}{*}{ Pensamento } & Conteúdo do Pensamento & 92,3 & 7,7 \\
\hline & Nível de organização & 72,8 & 27,2 \\
\hline & $\begin{array}{l}\text { Distinção entre realidade } \\
\text { interna e externa }\end{array}$ & 96,2 & 3,8 \\
\hline \multirow[t]{3}{*}{ Afetividade } & Autopercepção & 98,4 & 1,6 \\
\hline & Associação ideoafetiva & 98,8 & 1,2 \\
\hline & Interações & 82,1 & 17,9 \\
\hline Defesas & Dissociação & 95,6 & 4,4 \\
\hline \multirow[t]{2}{*}{ Instrumentais } & Identificação Projetiva & 90,9 & 9,1 \\
\hline & Racionalização & 96,8 & 3,2 \\
\hline \multirow[t]{6}{*}{ Defesas (outras) } & Negação & 98,7 & 1,3 \\
\hline & Idealização & 93,6 & 6,4 \\
\hline & Formação Reativa & 98,4 & 1,6 \\
\hline & Sedução & 97,3 & 2,7 \\
\hline & Sublimação & 92,5 & 7,5 \\
\hline & Média & 94,3 & 5,7 \\
\hline
\end{tabular}


$\mathrm{O}$ acordo entre examinadores foi igual ou superior a 70,0\%, atingindo valor médio superior a 94,0\% nas variáveis. Esses achados evidenciam elevado índice de precisão nas análises ora realizadas por meio do Questionário Desiderativo, o que confere confiabilidade aos dados e ao próprio sistema avaliativo proposto.

Com o objetivo de aprimorar a análise da precisão desse sistema avaliativo do Desiderativo, realizou-se o cálculo da correlação entre as codificações dos dois examinadores, para cada variável examinada. Desse modo, chegou-se aos dados apresentados na Tabela 36.

Tabela 36. Resultados das análises de Correlação (Spearman) entre as classificações das respostas ao Desiderativo pelos examinadores independentes $(n=60)$

\begin{tabular}{cccc}
\hline & Variável do Desiderativo & Rô Spearman & $p$ \\
\hline Adequação ao real & Tempo & 0,985 & $\leq 0,001$ \\
& Necessidade de indução & 0,895 & 0,04 \\
Respostas Antropomórficas & 0,895 & 0,04 \\
Pensamento & Conteúdo do Pensamento & 0,607 & $\leq 0,001$ \\
& Nível de organização & 0,688 & $\leq 0,001$ \\
Distinção entre realidade & 0,879 & $\leq 0,001$ \\
interna e externa & & \\
Afetividade & Autopercepção & 0,985 & $\leq 0,001$ \\
& Associação ideoafetiva & 0,902 & $\leq 0,001$ \\
Interações & 0,591 & $\leq 0,001$ \\
Defesas & Dissociação & 0,835 & $\leq 0,001$ \\
& Identificação Projetiva & 0,672 & $\leq 0,001$ \\
Racionalização & 0,695 & $\leq 0,001$ \\
& Negação & 0,794 & $\leq 0,001$ \\
& Idealização & 0,858 & $\leq 0,001$ \\
Defesas (outras) & Sedução & 0,615 & 0,04 \\
& Sublimação & 0,768 & $\leq 0,001$ \\
& Média correlações & 0,396 & 0,01 \\
& & 0,768 & \\
\hline & & &
\end{tabular}

Houve correlações estatisticamente significativas entre as duas codificações independentes em todas as variáveis analisadas do Desiderativo. Na maioria dessas variáveis, as correlações encontradas foram altas ou moderadas, com média de 0,768. Referidos indicadores reforçam os achados anteriores e confirmam indicadores de boa precisão nas análises das respostas ao Desiderativo. Confere-se, desse modo, adequada fidedignidade ao processo avaliativo proposto para esse método projetivo de avaliação psicológica. 
Passou-se, então, a analisar o padrão de respostas ao Questionário Desiderativo dos diferentes grupos de mulheres, descrevendo-os e comparando-os. Observou-se que em nenhuma das variáveis do Desiderativo houve distribuição normal nos resultados (teste de Shapiro-Wilk), razão que levou ao uso do teste de Kruskal-Wallis para análises estatísticas comparativas dos grupos em relação às variáveis numéricas. Nas variáveis categóricas, optou-se pelo teste Qui-quadrado.

A apresentação dos resultados seguirá o protocolo de codificação do Desiderativo. Iniciar-se-á pelas variáveis pertinentes à Adequação ao Real, conforme descrito na Tabela 37.

Tabela 37. Resultados descritivos e comparação estatística das variáveis referentes à Adequação ao Real no Desiderativo, em função dos grupos de mulheres ( $n=60)$.

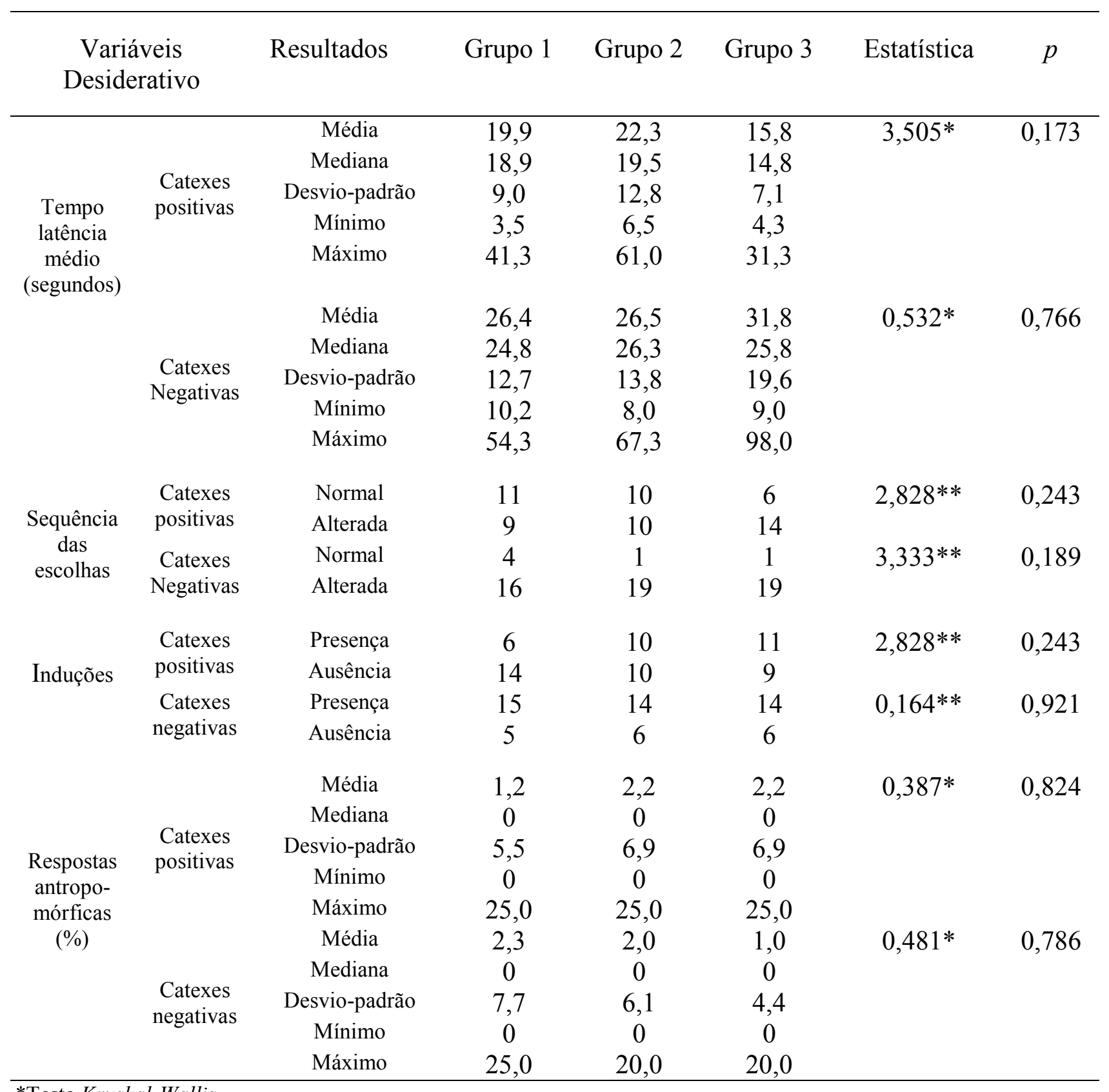

*Teste Kruskal-Wallis

**Qui-quadrado 
Não foram verificadas diferenças estatisticamente significativas entre os três grupos no que tange às variáveis referentes à Adequação ao Real do Questionário Desiderativo. Assim, considerando-se o significado projetivo da avaliação realizada por este instrumento, pretendentes à adoção, mães adotivas e biológicas apresentaram perfil semelhante em sua forma de adaptação à realidade, aparentemente adequada às demandas do cotidiano.

Conforme preconiza a fundamentação teórica do instrumento (Nijamkin \& Braude, 2000), seria esperado que cada participante emitisse três respostas às consignas positivas e outras três às negativas, passando pelos reinos animal, vegetal e inanimado, nesta ordem (preservação da vitalidade). Entretanto, como foi possível perceber na Tabela 37, houve alta prevalência de necessidade de indução, o que aponta para falhas ao responder, aumentando, portanto, o número de respostas em cada consigna. Neste estudo foi possível avaliar que em $45,0 \%$ dos casos houve mais de três respostas nas catexes positivas e, nas catexes negativas, em cerca de $62,0 \%$ dos casos. Ou seja, na maioria dos casos avaliados, houve falhas ao responder, apesar de se tratar de mulheres sem características psicopatológicas, adaptadas à realidade.

Com o objetivo de compreender as falhas lógicas ocorridas ao responder ao Desiderativo, ensejadoras das induções, destacou-se a ocorrência das chamadas perseverações de reino. Esse fenômeno foi observado em $71,7 \%$ das participantes $(n=60)$, não sendo observadas diferenças entre os grupos em relação à referida variável (Qui-quadrado=0,164, $p=0,921$ ).

Ao detalhar estes resultados, observou-se que 72,0\% destas perseverações de reino abrangeram respostas do tipo “objeto". Desta maneira, é possível afirmar que, no presente estudo, a perseveração do reino objeto foi fenômeno presente na maioria dos casos avaliados, representando, além disso, a principal causa de necessidade de indução durante a aplicação do instrumento.

Observou-se que os três grupos de mulheres avaliadas apresentaram sinais de maior mobilização emocional nas catexes negativas, indicada por: maior tempo de latência médio, maior necessidade de indução nestas respostas, maior frequência de sequência alterada de escolhas (qualquer sequência diferente de animal-vegetal-inanimado). Referidos achados sugerem que, diante do contato com elementos de rejeição interna (catexes negativas), houve maior tempo para as mulheres processarem internamente o impacto das instruções, bem como maior frequência de falhas ao responder (tornando necessárias as induções), quando comparado ao desempenho das mesmas diante das consignas positivas. As respostas antropomórficas, por sua vez, ocorreram numa frequência bastante baixa em todos os grupos, sem diferenças observáveis quanto ao tipo de catexe. 
Deste modo, as mulheres evidenciaram maior facilidade para identificar, projetivamente, seus recursos de preservação da identidade (respostas às catexes positivas). Sinalizaram mais dificuldades para apontar elementos sentidos como desintegradores (respostas às catexes negativas), sendo tal observação realizada no grupo como um todo $(n=60)$, independente de sua condição frente à maternidade.

Em continuidade à análise dos resultados obtidos por meio do Questionário Desiderativo têm-se os dados referentes ao funcionamento lógico. Estão descritos na Tabela 38.

Tabela 38. Resultados descritivos (em porcentagem) e comparação estatística das variáveis referentes ao Funcionamento Lógico no Desiderativo, em função dos grupos de mulheres $(n=60)$.

\begin{tabular}{|c|c|c|c|c|c|c|c|c|}
\hline \multicolumn{3}{|c|}{ Variáveis do Desiderativo } & Resultados & G1 & $\mathrm{G} 2$ & G3 & $\begin{array}{c}\text { Estatística } \\
*\end{array}$ & $p$ \\
\hline \multirow{24}{*}{$\begin{array}{l}\text { Conteúdo do } \\
\text { pensamento }\end{array}$} & \multirow{10}{*}{$\begin{array}{c}\text { Catexes } \\
\text { positivas }\end{array}$} & \multirow{5}{*}{ Lógico } & Média & 90,8 & 92,0 & 90,8 & 0,101 & 0,951 \\
\hline & & & Mediana & 100,0 & 100,0 & 100,0 & & \\
\hline & & & Desvio-padrão & 15,2 & 14,9 & 18,1 & & \\
\hline & & & Mínimo & 50,0 & 50,0 & 33,3 & & \\
\hline & & & Máximo & 100,0 & 100,0 & 100,0 & & \\
\hline & & \multirow{5}{*}{ Ilógico } & Média & 9,1 & 7,9 & 9,1 & 0,101 & 0,951 \\
\hline & & & Mediana & 0 & 0 & 0 & & \\
\hline & & & Desvio-padrão & 15,2 & 14,9 & 18,1 & & \\
\hline & & & Mínimo & 0 & 0 & 0 & & \\
\hline & & & Máximo & 50,0 & 50,0 & 66,6 & & \\
\hline & \multirow{10}{*}{$\begin{array}{c}\text { Catexes } \\
\text { negativas }\end{array}$} & \multirow{5}{*}{ Lógico } & Média & 91,0 & 90,9 & 76,9 & 5,279 & 0,071 \\
\hline & & & Mediana & 100,0 & 100,0 & 77,5 & & \\
\hline & & & Desvio-padrão & 15,0 & 15,3 & 24,9 & & \\
\hline & & & Mínimo & 50,0 & 50,0 & 33,3 & & \\
\hline & & & Máximo & 100,0 & 100,0 & 100,0 & & \\
\hline & & \multirow{5}{*}{ Ilógico } & Média & 8,9 & 9,0 & 22,9 & 5,279 & 0,071 \\
\hline & & & Mediana & 0 & 0 & 22,5 & & \\
\hline & & & Desvio-padrão & 15,0 & 15,3 & 24,9 & & \\
\hline & & & Mínimo & 0 & 0 & 0 & & \\
\hline & & & Máximo & 50,0 & 50,0 & 66,6 & & \\
\hline & \multirow{10}{*}{$\begin{array}{l}\text { Catexes } \\
\text { positivas }\end{array}$} & \multirow{4}{*}{ Concreto } & Média & 52,4 & 55,3 & 56,3 & 0,050 & 0,975 \\
\hline & & & Mediana & 41,6 & 66,6 & 63,3 & & \\
\hline & & & Desvio-padrão & 35,7 & 32,2 & 27,8 & & \\
\hline & & & Mínimo & 0 & & 0 & & \\
\hline \multirow{6}{*}{$\begin{array}{c}\text { Nível de } \\
\text { organização }\end{array}$} & & \multirow{6}{*}{ Abstrato } & Máximo & 100,0 & 100,0 & 100,0 & & \\
\hline & & & Média & 47,4 & 44,5 & 43,6 & 0,050 & 0,975 \\
\hline & & & Mediana & 58,3 & 33,3 & 36,5 & & \\
\hline & & & Desvio-padrão & 35,7 & 32,2 & 27,8 & & \\
\hline & & & Mínimo & 0 & 0 & 0 & & \\
\hline & & & Máximo & 100,0 & 100,0 & 100,0 & & \\
\hline
\end{tabular}




\begin{tabular}{|c|c|c|c|c|c|c|c|}
\hline \multicolumn{2}{|c|}{ Variáveis do Desiderativo } & Resultados & G1 & $\mathrm{G} 2$ & G3 & $\begin{array}{c}\text { Estatística } \\
*\end{array}$ & $p$ \\
\hline \multirow{10}{*}{$\begin{array}{l}\text { Catexes } \\
\text { negativas }\end{array}$} & \multirow{3}{*}{ Concreto } & Média & 71,4 & 75,3 & 66,8 & 0,418 & 0,811 \\
\hline & & Mediana & 75,0 & 76,7 & 75,0 & & \\
\hline & & Desvio-padrão & 29,2 & 23,1 & 3,7 & & \\
\hline & \multirow{7}{*}{ Abstrato } & Mínimo & 0 & 25,0 & 0 & & \\
\hline & & Máximo & 100,0 & 100,0 & 100,0 & & \\
\hline & & Média & 28,4 & 24,6 & 33,1 & 0,418 & 0,811 \\
\hline & & Mediana & 25,0 & 25,0 & 25,0 & & \\
\hline & & Desvio-padrão & 29,2 & 23,1 & 3,0 & & \\
\hline & & Mínimo & 0 & 0 & 0 & & \\
\hline & & Máximo & 100,0 & 75,0 & 100,0 & & \\
\hline \multirow{10}{*}{$\begin{array}{l}\text { Distinção } \\
\text { entre } \\
\text { realidade } \\
\text { interna e } \\
\text { externa }\end{array}$} & \multirow{5}{*}{ Adequada } & Média & 91,2 & 98,0 & 95,0 & 2,092 & 0,351 \\
\hline & & Mediana & 100,0 & 100,0 & 100,0 & & \\
\hline & & Desvio-padrão & 23,3 & 8,9 & 17,3 & & \\
\hline & & Mínimo & 0 & 60,0 & 25,0 & & \\
\hline & & Máximo & 100,0 & 100,0 & 100,0 & & \\
\hline & \multirow{5}{*}{ Inadequada } & Média & 8,7 & 2,0 & 5,0 & 2,092 & 0,351 \\
\hline & & Mediana & 0 & 0 & 0 & & \\
\hline & & Desvio-padrão & 23,3 & 8,9 & 17,3 & & \\
\hline & & Mínimo & 0 & 0 & 0 & & \\
\hline & & Máximo & 100,0 & 40,0 & 75,0 & & \\
\hline \multirow{10}{*}{$\begin{array}{l}\text { Catexes } \\
\text { negativas }\end{array}$} & \multirow{5}{*}{ Adequada } & Média & 88,8 & 85,7 & 76,0 & 4,027 & 0,133 \\
\hline & & Mediana & 100,0 & 100,0 & 75,0 & & \\
\hline & & Desvio-padrão & 19,0 & 20,3 & 24,0 & & \\
\hline & & Mínimo & 25,0 & 33,3 & 33,3 & & \\
\hline & & Máximo & 100,0 & 100,0 & 100,0 & & \\
\hline & \multirow{5}{*}{ Inadequada } & Média & 11,1 & 14,2 & 23,9 & 4,027 & 0,133 \\
\hline & & Mediana & 0 & 0 & 25,0 & & \\
\hline & & Desvio-padrão & 19,0 & 20,3 & 24,1 & & \\
\hline & & Mínimo & 0 & 0 & 0 & & \\
\hline & & Máximo & 75,0 & 66,0 & 66,6 & & \\
\hline
\end{tabular}

*Teste Kruskal-Wallis.

Não emergiram marcas específicas dos grupos de mulheres no que se refere ao funcionamento lógico, conforme sua avaliação pelo Desiderativo. Desse modo, pretendentes à adoção, mães adotivas e mães biológicas sinalizaram perfil semelhante no que se refere ao uso de seus recursos racionais e lógicos para modular os afetos e para se adaptar à realidade, independentemente de suas diferenças frente à maternidade.

Neste contexto, destacam-se as altas taxas médias de respostas com conteúdo lógico, bem como elevados índices de adequada distinção entre realidade interna e externa, apresentados pelas participantes. Tais indicadores apontam para a capacidade destas mulheres 
de, ao responder ao Desiderativo, elegerem características adequadas aos símbolos escolhidos ou rejeitados, que independem da opinião particular das mesmas e, portanto, são compartilhados pelo senso comum. Tal habilidade aponta para a possibilidade de distanciamento entre a percepção de si e o símbolo escolhido, sugerindo adequada consideração da realidade em sua adaptação ao meio, conforme seria esperado de mulheres adultas, sem indicadores psicopatológicos.

Especificamente em relação ao nível de organização do pensamento, as participantes emitiram respostas com características equilibradas em termos de concretude e abstração nas catexes positivas. Já nas negativas, houve maior incidência de respostas baseadas nas características palpáveis dos símbolos escolhidos. Ou seja, ao selecionar elementos mobilizadores de angústia para responder ao instrumento, as participantes deram mais destaque a conteúdos simbolicamente menos elaborados, cuja ameaça inerente se relacionava mais a seus atributos concretos.

A seguir serão examinadas as variáveis relacionadas às manifestações afetivas, conforme sistema avaliativo adotado para o Questionário Desiderativo. Esses dados compõem a Tabela 39.

Tabela 39. Resultados descritivos (em porcentagem) e comparação estatística das variáveis referentes às Manifestações Afetivas no Desiderativo, em função dos grupos de mulheres $(n=60)$.

\begin{tabular}{|c|c|c|c|c|c|c|c|}
\hline \multicolumn{2}{|c|}{ Variáveis do Desiderativo } & Resultados & G1 & $\mathrm{G} 2$ & G3 & $\begin{array}{c}\text { Estatística } \\
*\end{array}$ & $p$ \\
\hline \multirow{10}{*}{$\begin{array}{l}\text { Catexes } \\
\text { positivas }\end{array}$} & \multirow{5}{*}{ Valorizada } & Média & 97,5 & 100,0 & 98,7 & 1,018 & 0,601 \\
\hline & & Mediana & 100,0 & 100,0 & 100,0 & & \\
\hline & & Desvio-padrão & 11,1 & 0 & 5,5 & & \\
\hline & & Mínimo & 50,0 & 100,0 & 75,00 & & \\
\hline & & Máximo & 100,0 & 100,0 & 100,0 & & \\
\hline & \multirow{5}{*}{ Desvalorizada } & Média & 2,5 & - & 1,3 & 1,018 & 0,601 \\
\hline & & Mediana & 0 & - & 0 & & \\
\hline & & Desvio-padrão & 11,1 & - & 5,5 & & \\
\hline & & Mínimo & 0 & - & 0 & & \\
\hline & & Máximo & 50,0 & - & 25,0 & & \\
\hline \multirow{10}{*}{$\begin{array}{c}\text { Catexes } \\
\text { negativas }\end{array}$} & \multirow{4}{*}{ Valorizada } & Média & 2,5 & - & 1,3 & 2,070 & 0,355 \\
\hline & & Mediana & 0 & - & 0 & & \\
\hline & & Desvio-padrão & 7,7 & - & 5,5 & & \\
\hline & & Mínimo & 0 & - & 0 & & \\
\hline & \multirow{6}{*}{ Desvalorizada } & Máximo & 25,0 & - & 25,0 & \multirow{6}{*}{2,070} & \multirow{6}{*}{0,355} \\
\hline & & Média & 97,5 & 100,0 & 98,7 & & \\
\hline & & Mediana & 100,0 & 100,0 & 100,0 & & \\
\hline & & Desvio-padrão & 7,7 & 0 & 5,5 & & \\
\hline & & Mínimo & 75,0 & 100,0 & 75,0 & & \\
\hline & & Máximo & 100,0 & 100,0 & 100,0 & & \\
\hline
\end{tabular}




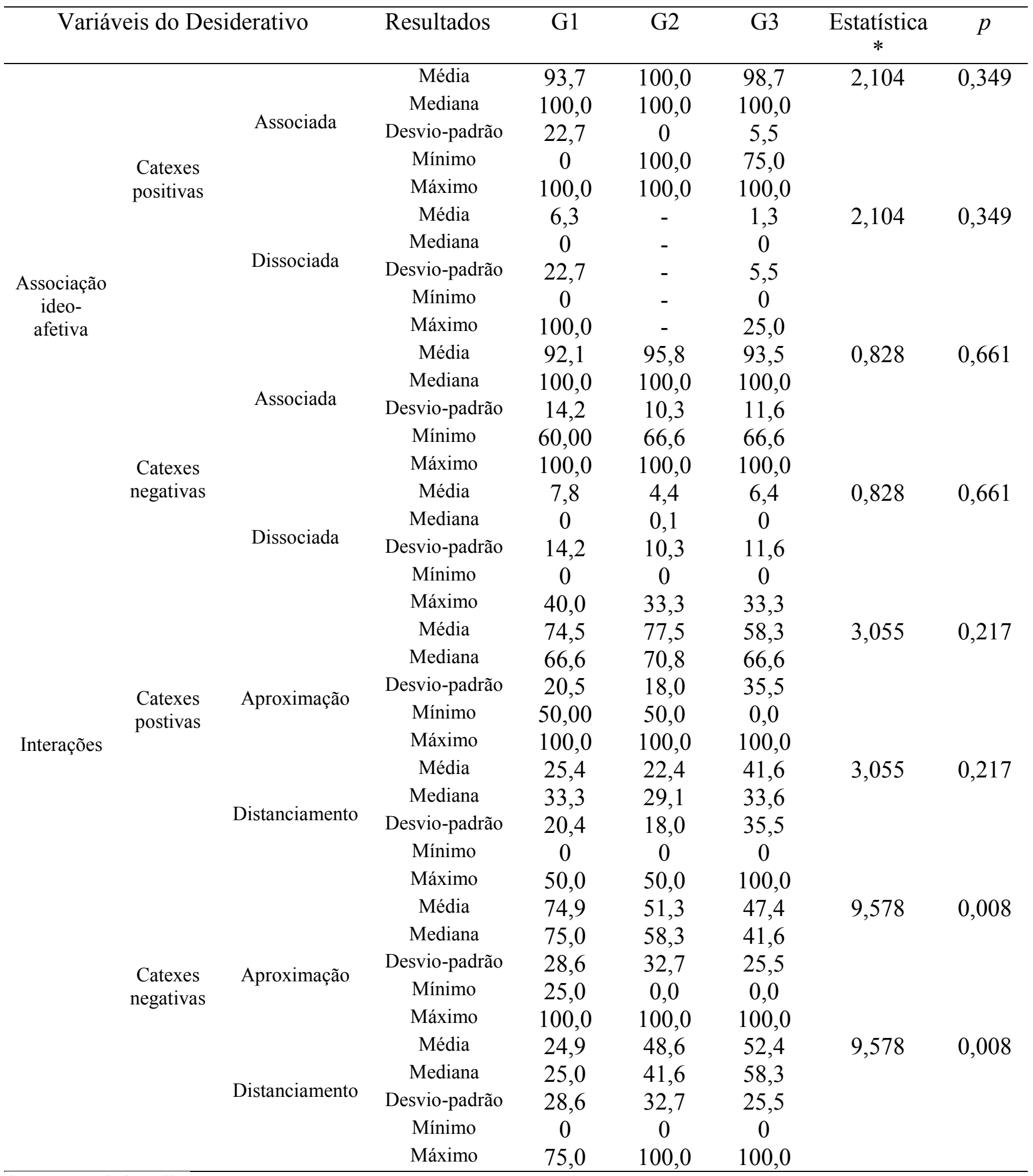

*Teste Kruskal-Wallis.

Nos indicadores do Desiderativo relativos às Manifestações Afetivas houve diferença estatisticamente significativa entre os grupos apenas no item "Interações", nomeadamente nas catexes negativas. Nos demais indicadores técnicos as mulheres presentemente avaliadas 
mostraram resultados muito semelhantes, sugerindo padrão geral comum em termos de vivência e manifestação dos afetos.

Observou-se que, quanto à autopercepção, tanto as pretendentes à adoção, como as mães adotivas e biológicas apresentaram indicadores compatíveis com os previstos teoricamente para indivíduos sem indicadores psicopatológicos. Assim, ao escolher e verbalizar símbolos que representassem seus recursos internos para se adaptar à realidade (catexes positivas), estas mulheres sinalizaram autopercepção positivamente valorizada na maioria das respostas emitidas. Por outro lado, ao responder sobre os elementos causadores de conflito e angústia, houve a projeção majoritária de atributos desvalorizados, o que também corresponde ao teoricamente esperado nas respostas a esse instrumento.

Em relação à associação ideoafetiva, conforme sua avaliação pelo Desiderativo, observou-se que o conjunto de mulheres avaliadas, independentemente de sua condição frente à maternidade, apresentou respostas cujo conteúdo afetivo correspondia ao teor das racionalizações apresentadas. Ou seja, ao emitir respostas referentes ao que gostariam de ser (catexes positivas), estas mulheres elegeram, na maioria das respostas, atributos positivos e, ao escolher o que não desejariam ser (catexes negativas), destacaram predominantemente atributos negativos, coordenando adequadamente ideias e afetos.

Por fim, no que se refere ao tipo de interações implícitas nas respostas das participantes, observou-se predomínio de conteúdos sinalizadores da valorização do contato com o outro na maioria das respostas às catexes positivas. Por outro lado, também nas negativas, interações de aproximação apresentaram presença marcante, o que sugere que o contato com o outro é, ao mesmo tempo, elemento desejado e valorizado, mas também temido e causador de angústia, nas participantes examinadas.

Especificamente, em relação às catexes negativas, houve diferenças significativas entre os grupos (teste post-hoc de Bonferroni=0,038 na comparação entre G1 e G2, e teste post-hoc de Bonferroni=0,012 na comparação entre G1 e G3). A magnitude de efeito verificada (Eta parcial=0,156) sinalizou ser tal diferença suficientemente relevante (Marôco, 2011), merecendo, portanto, destaque interpretativo. Observou-se que, conforme sua avaliação pelo Desiderativo, as pretendentes à adoção sinalizaram ver no contato com o outro (interações de aproximação) relevante fonte de angústia em maior frequência que as participantes que já eram mães (adotivas ou biológicas), não havendo diferenças estatisticamente significativas entre estas últimas. $\mathrm{O}$ distanciamento (enquanto estilo de interação), por sua vez, foi mais frequentemente referido como fonte de conflito e angústia nas participantes mães (biológicas ou adotivas), comparativamente às pretendentes à adoção. 
Em sequência às análises dos indicadores do Desiderativo alcançados para esse estudo, e adentrando a temática dos recursos defensivos das participantes, elaborou-se a Tabela 40. Ela traz informações referentes às chamadas Defesas Instrumentais.

Tabela 40. Resultados descritivos (em porcentagem) e comparação estatística das variáveis referentes às Defesas Instrumentais no Desiderativo, em função dos grupos de mulheres $(n=60)$.

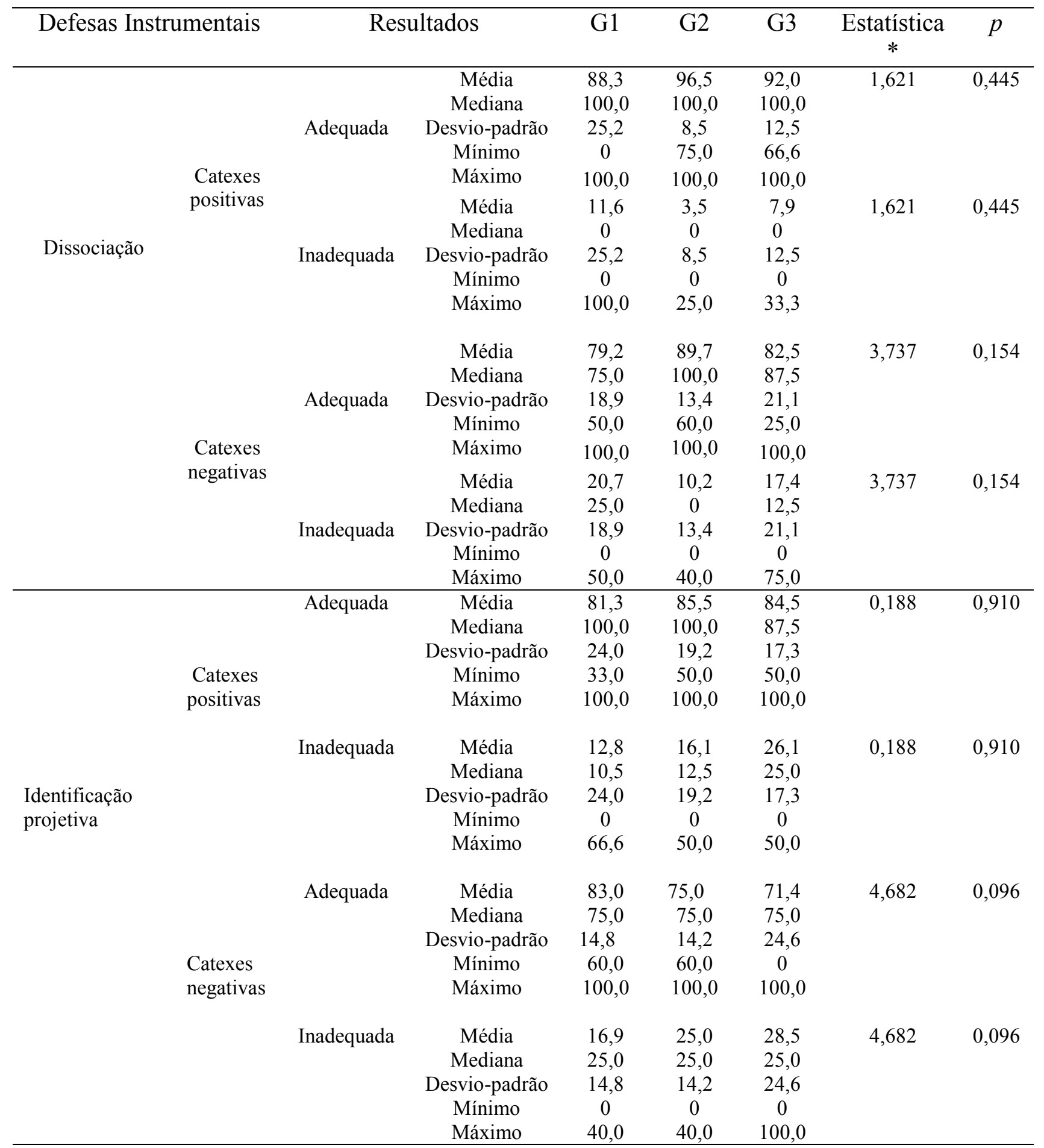




\begin{tabular}{|c|c|c|c|c|c|c|c|c|}
\hline \multicolumn{2}{|c|}{ Defesas Instrumentais } & \multicolumn{2}{|c|}{ Resultados } & G1 & $\mathrm{G} 2$ & G3 & Estatística & $p$ \\
\hline \multirow{4}{*}{ Racionalização } & $\begin{array}{l}\text { Catexes } \\
\text { positivas }\end{array}$ & Adequada & $\begin{array}{c}\text { Média } \\
\text { Mediana } \\
\text { Desvio-padrão } \\
\text { Mínimo } \\
\text { Máximo }\end{array}$ & $\begin{array}{c}90,8 \\
100,0 \\
17,2 \\
50,0 \\
100,0\end{array}$ & $\begin{array}{c}100,0 \\
100,0 \\
- \\
100,0 \\
100,0\end{array}$ & $\begin{array}{c}96,2 \\
98,6 \\
12,2 \\
50,0 \\
100,0\end{array}$ & 6,017 & 0,049 \\
\hline & & Inadequada & $\begin{array}{c}\text { Média } \\
\text { Mediana } \\
\text { Desvio-padrão } \\
\text { Mínimo } \\
\text { Máximo }\end{array}$ & $\begin{array}{c}9,1 \\
0 \\
17,2 \\
0 \\
50,0\end{array}$ & $\begin{array}{l}- \\
- \\
- \\
-\end{array}$ & $\begin{array}{c}3,7 \\
0 \\
12,2 \\
0 \\
50,0\end{array}$ & 6,017 & 0,049 \\
\hline & $\begin{array}{l}\text { Catexes } \\
\text { negativas }\end{array}$ & Adequada & $\begin{array}{c}\text { Média } \\
\text { Mediana } \\
\text { Desvio-padrão } \\
\text { Mínimo } \\
\text { Máximo }\end{array}$ & $\begin{array}{c}91,5 \\
100,0 \\
14,4 \\
50,0 \\
100,0\end{array}$ & $\begin{array}{c}96,0 \\
100,0 \\
9,8 \\
66,6 \\
100,0\end{array}$ & $\begin{array}{c}83,3 \\
75,0 \\
15,7 \\
66,6 \\
100,0\end{array}$ & 8,860 & 0,012 \\
\hline & & Inadequada & $\begin{array}{c}\text { Média } \\
\text { Mediana } \\
\text { Desvio-padrão } \\
\text { Mínimo } \\
\text { Máximo }\end{array}$ & $\begin{array}{c}8,5 \\
0 \\
14,2 \\
0 \\
50,0\end{array}$ & $\begin{array}{c}3,9 \\
0 \\
9,8 \\
0 \\
33,3\end{array}$ & $\begin{array}{c}16,7 \\
25,0 \\
15,7 \\
0 \\
33,3\end{array}$ & 8,860 & 0,012 \\
\hline
\end{tabular}

Nota-se que as participantes alcançaram sucesso no uso das Defesas Instrumentais no Desiderativo. Conseguiram executar as operações mentais necessárias para responder às instruções, evidenciando eficiência em sua organização psíquica para as demandas da realidade, como previsto pelos princípios desse método projetivo de avaliação psicológica.

A Dissociação, enquanto defesa instrumental no Desiderativo, representa o funcionamento no plano simbólico e, assim, a possibilidade de lidar com a "fantasia de morte" proposta pela técnica (deixar de ser o que é para assumir outra identidade). Deste modo, considerando-se os altos índices de adequadas Dissociações nas respostas das participantes dos três grupos, é possível afirmar que apresentaram boa capacidade de compreender o caráter simbólico das instruções e, com isso, renunciar temporariamente à identidade humana, abrindo-se para outras possibilidades de identificação, sinalizando, portanto, flexibilidade adaptativa. Referida observação estende-se ao conjunto de mulheres avaliadas $(\mathrm{n}=60)$, dada a inexistência de diferenças estatisticamente significativas entre os grupos.

O sentido da defesa instrumental Identificação Projetiva relaciona-se à possibilidade (ou não) da pessoa verbalmente representar uma ideia ou sentimento, recorrendo, portanto, a representações verbais e, assim, sinalizando capacidade de regular suas ações e 
comportamentos pelo pensamento. Visto o elevado índice de adequação no uso da Identificação Projetiva no Desiderativo pelos três grupos de mulheres, pode-se apontar que conseguiram selecionar símbolos integrados para neles projetarem suas características pessoais, diferenciando a própria identidade do símbolo escolhido ou rejeitado.

A Racionalização, enquanto defesa instrumental no Desiderativo, representa a capacidade de diferenciar fatores afetivos (que contribuíram para a escolha do símbolo selecionado) dos aspectos racionais e lógicos utilizados neste processo. É indicador do ajuste do pensamento à realidade. As mulheres avaliadas apresentaram adequado uso da racionalização, sugerindo suficiente capacidade de emitir justificativas lógicas e adequadas às escolhas e rejeições no Desiderativo, na maioria das respostas emitidas. No entanto, houve diferenças estatisticamente significativas entre os grupos avaliados no uso da Racionalização. A análise inferencial via teste post-hoc de Bonferroni confirmou diferença estatisticamente significativa nas catexes negativas entre mães biológicas e adotivas (Diferença média=12,770, $p=0,013$ ), com moderada magnitude de efeito (Eta parcial=0,137). As mães adotivas apresentaram maiores índices de respostas com adequada racionalização nas catexes negativas em comparação às mães biológicas, resultado específico que deve ser cautelosamente interpretado no conjunto dos demais indicadores do instrumento, visto ser muito arriscado inferir qualquer hipótese sobre esse dado isolado.

Ao examinar as Defesas Instrumentais observou-se que, nas catexes negativas, houve maior incidência de inadequações nas respostas quando comparado às catexes positivas, em todos os grupos examinados. Isso sugere que a instrução de tomar contato com símbolos mobilizadores de angústia e conflito, presentes nas catexes negativas, dificulta, em certa medida, a habilidade de raciocinar adequadamente e de diferenciar fantasia versus realidade, favorecendo mais falhas lógicas ao responder a essa parte do Desiderativo.

$\mathrm{Na}$ sequência de análise dos indicadores do Questionário Desiderativo se faz necessário abordar os mecanismos de defesa do repertório individual das participantes, conforme o protocolo de codificação utilizado na presente investigação. Esses achados compõem a Tabela 41. 
Tabela 41. Resultados descritivos (em porcentagem) e comparação estatística dos mecanismos de defesa no Desiderativo, em função dos grupos de mulheres $(n=60)$.

\begin{tabular}{|c|c|c|c|c|c|c|c|}
\hline \multicolumn{2}{|c|}{ Mecanismos de defesa } & Resultados & G1 & G2 & G3 & Estatística* & $p$ \\
\hline \multirow{10}{*}{ Negação } & \multirow{4}{*}{$\begin{array}{l}\text { Catexes } \\
\text { positivas }\end{array}$} & Média & 4,6 & 1,6 & 3,3 & 1,020 & 0,600 \\
\hline & & Mediana & 0 & 0 & 0 & & \\
\hline & & Desvio-padrão & 11,6 & 7,5 & 10,3 & & \\
\hline & & Mínimo & 0 & 0 & 0 & & \\
\hline & \multirow{6}{*}{$\begin{array}{l}\text { Catexes } \\
\text { negativas }\end{array}$} & Máximo & 33,6 & 33,6 & 33,6 & & \\
\hline & & Média & 5,7 & 2,0 & 5,04 & 2,411 & 0,300 \\
\hline & & Mediana & 0 & 0 & 0 & & \\
\hline & & Desvio-padrão & 10,2 & 8,9 & 12,0 & & \\
\hline & & Mínimo & 0 & 0 & 0 & & \\
\hline & & Máximo & 25,0 & 40,0 & 33,6 & & \\
\hline \multirow{10}{*}{ Idealização } & \multirow{5}{*}{$\begin{array}{l}\text { Catexes } \\
\text { positivas }\end{array}$} & Média & 65,4 & 65,9 & 70,4 & 0,191 & 0,909 \\
\hline & & Mediana & 70,8 & 83,3 & 70,8 & & \\
\hline & & Desvio-padrão & 33,6 & 37,2 & 32,1 & & \\
\hline & & Mínimo & 0 & 0 & 0 & & \\
\hline & & Máximo & 100,0 & 100,0 & 100,0 & & \\
\hline & \multirow{5}{*}{$\begin{array}{c}\text { Catexes } \\
\text { negativas }\end{array}$} & Média & 17,4 & 4,5 & 2,2 & 11,505 & 0,003 \\
\hline & & Mediana & 12,5 & 0 & 0 & & \\
\hline & & Desvio-padrão & 18,9 & 9,3 & 6,9 & & \\
\hline & & Mínimo & 0 & 0 & 0 & & \\
\hline & & Máximo & 50,0 & 25,0 & 25,0 & & \\
\hline \multirow{10}{*}{$\begin{array}{c}\text { Formação } \\
\text { reativa }\end{array}$} & \multirow{5}{*}{$\begin{array}{l}\text { Catexes } \\
\text { positivas }\end{array}$} & Média & - & - & - & 0,000 & 1,000 \\
\hline & & Mediana & - & - & - & & \\
\hline & & Desvio-padrão & - & - & - & & \\
\hline & & Mínimo & - & - & - & & \\
\hline & & Máximo & - & - & - & & \\
\hline & \multirow{5}{*}{$\begin{array}{c}\text { Catexes } \\
\text { negativas }\end{array}$} & Média & 1,2 & 12,6 & 6,6 & 3,230 & 0,199 \\
\hline & & Mediana & 0 & 0 & 0 & & \\
\hline & & Desvio-padrão & 5,5 & 28,1 & 13,6 & & \\
\hline & & Mínimo & 0 & 0 & 0 & & \\
\hline & & Máximo & 25,0 & 100,0 & 33,3 & & \\
\hline \multirow{10}{*}{ Sedução } & \multirow{3}{*}{$\begin{array}{l}\text { Catexes } \\
\text { positivas }\end{array}$} & Média & 25,8 & 21,7 & 20,9 & 0,125 & 0,940 \\
\hline & & Mediana & 0 & 0 & 25,0 & & \\
\hline & & Desvio-padrão & 32,6 & 27,7 & 19,9 & & \\
\hline & & Mínimo & 0 & 0 & 0 & & \\
\hline & \multirow{6}{*}{$\begin{array}{c}\text { Catexes } \\
\text { negativas }\end{array}$} & Máximo & 100,0 & 75,0 & 66,6 & & \\
\hline & & Média & - & 1,0 & - & 2,000 & 0,368 \\
\hline & & Mediana & - & 0 & - & & \\
\hline & & Desvio-padrão & - & 4,4 & - & & \\
\hline & & Mínimo & - & 0,0 & - & & \\
\hline & & Máximo & - & 20,0 & - & & \\
\hline \multirow{10}{*}{ Sublimação } & \multirow{4}{*}{$\begin{array}{l}\text { Catexes } \\
\text { positivas }\end{array}$} & Média & 4,5 & 6,6 & 17,5 & 4,467 & 0,107 \\
\hline & & Mediana & 0 & 0 & 0 & & \\
\hline & & Desvio-padrão & 11,3 & 14,4 & 24,3 & & \\
\hline & & Mínimo & 0 & 0 & 0 & & \\
\hline & \multirow{6}{*}{$\begin{array}{c}\text { Catexes } \\
\text { negativas }\end{array}$} & Máximo & 33,3 & 50,0 & 66,7 & & \\
\hline & & Média & 1,2 & - & 5,0 & 2,140 & 0,343 \\
\hline & & Mediana & 0 & - & 0 & & \\
\hline & & Desvio-padrão & 5,5 & - & 16,3 & & \\
\hline & & Mínimo & 0 & - & 0 & & \\
\hline & & Máximo & 25,0 & - & 66,7 & & \\
\hline
\end{tabular}

*Teste Kruskal-Wallis. 
$\mathrm{Na}$ maioria dos casos, a frequência dos cinco mecanismos de defesa foi bastante baixa nos três grupos, com exceção da Idealização, que alcançou níveis médios superiores a 60,0\% das respostas nas catexes positivas, sendo, portanto, uma estratégia defensiva bastante comum nestes grupos avaliados. A Sedução, enquanto estratégia defensiva, apareceu em segundo lugar, tendo frequência média de ocorrência por volta de $20,0 \%$ nas catexes positivas. As demais estratégias defensivas mostraram-se numericamente pouco expressivas em termos de caracterização do mundo interno destas mulheres.

Deste modo, é possível afirmar que, para o conjunto de mulheres presentemente avaliadas, a supervalorização de suas características positivas (Idealização) parece ser recurso psíquico frequente em sua forma adaptativa ao ambiente em que vivem. A valorização de atributos ligados à beleza física (Sedução) também mereceu destaque nesse processo, sugerindo que estes elementos são sentidos como meios de satisfação de suas necessidades internas, bem como formas úteis de evitar perigos reais ou fantasiados. Tais observações se mostraram independentes da condição destas mulheres frente à maternidade, não sendo observadas diferenças estatisticamente significativas entre os grupos na maioria das defesas analisadas.

Apenas diante da Idealização (nas catexes negativas) é que se identificou frequência estatisticamente maior no grupo de pretendentes à adoção (G1). Conforme revelou o teste post-hoc de Bonferroni, tanto na comparação com as mães adotivas (Diferença média=12,910, $p=0,007$ ), como com as mães biológicas (Diferença média $=15,160, p=0,001$ ), esta diferença foi estatisticamente significativa, com relevante magnitude de efeito (Eta parcial $=0,221$ ). Deste modo, na presente investigação, as mulheres sem filhos apresentaram maior tendência a utilizarem a Idealização como estratégia defensiva frente aos elementos causadores de angústia, que as participantes que já eram mães (adotivas ou biológicas). Não foram verificadas diferenças estatisticamente significativas entre os grupos de mães (G2 e G3) nesse quesito em análise.

\section{IV.5. Relativos às correlações entre instrumentos}

Como um objetivo específico deste trabalho procurou-se sistematizar indicadores de precisão e evidências de validade do Questionário Desiderativo enquanto instrumento adequado e cientificamente fundamentado para uso no Brasil. Indicadores de sua precisão já foram anteriormente apontados, de modo que nesse momento serão apresentadas as análises de correlação de variáveis do Questionário Desiderativo com o Método de Rorschach e com a 
Bateria Fatorial de Personalidade, visto abordarem construtos relacionados, embora por meio de atividades e tarefas específicas.

Como apontado nos procedimentos, as análises correlacionais seguiram método não paramétrico (Spearman, $p \leq 0,05$ ), tomando como base os resultados do conjunto de mulheres avaliadas $(n=60)$. A partir da combinação de variáveis relevantes do Questionário Desiderativo e do Método de Rorschach (especificadas anteriormente na seção Método) foi possível identificar os dados presentes na Tabela 42. São apresentadas as correlações que se mostraram estatisticamente significativas, embora outras combinatórias de variáveis tenham sido testadas (porém não apresentadas nesse momento).

Tabela 42. Correlações estatisticamente significativas entre variáveis do Desiderativo e Rorschach no total de mulheres avaliadas $(n=60)$.

\begin{tabular}{cccc}
\hline \multicolumn{2}{c}{ Variáveis dos Instrumentos } & \multicolumn{2}{c}{ Dados estatísticos } \\
Desiderativo & Rorschach & Correlação $(r)$ & $p$ \\
\hline Racionalização adequada & $\mathrm{R}$ & $-0,274$ & 0,034 \\
& Rec & 0,293 & 0,023 \\
& EF + E & $-0,261$ & 0,044 \\
Dissociação adequada & Bot & $-0,357$ & 0,004 \\
Associação ideoafetiva (associadas) & CF + C & 0,261 & 0,004 \\
Conteúdo lógico do pensamento & EF + E & $-0,265$ & 0,041 \\
& A $+(A)$ & 0,334 & 0,009 \\
\hline
\end{tabular}

$\mathrm{R}=$ número de respostas; $\mathrm{Rec}=$ número de recusas; $\mathrm{Bot}=$ respostas de conteúdo botânico.

Como primeiro comentário há que se notar que a força dessas correlações atingiu valores considerados moderados, compatíveis com o esperado para construtos relacionados. Os dados indicam que as variáveis do Desiderativo associadas ao controle racional dos afetos (Racionalização adequada, Dissociação adequada, conteúdo lógico do pensamento) mostraram-se positivamente associadas com variável do Rorschach sinalizadora de repressão e inibição (Recusas), além de respostas de conteúdo animal inteiro [A e (A)]. A associação ideoafetiva no Desiderativo também se mostrou correlacionada de modo direto com a presença de determinantes cromáticos $(\mathrm{CF}+\mathrm{C})$ nas respostas ao Rorschach, sugerindo 
interligações entre os indicadores de mobilização emocional desses dois métodos projetivos de avaliação psicológica, reforçando seus achados.

Foi possível identificar ainda associações negativas das variáveis ligadas ao controle racional no Desiderativo (Racionalização adequada, Dissociação adequada, conteúdo lógico do pensamento) com indicadores de mobilização afetiva do Rorschach, a saber: respostas determinadas pelo sombreado (representativas de ansiedade, como as respostas $\mathrm{EF}+\mathrm{E}$ ) e conteúdo primitivo (botânico=Bot). Outra correlação estatisticamente significativa, em sentido negativo, ocorreu entre número de respostas ao Rorschach $(\mathrm{R})$ e variáveis de controle racional no Desiderativo. Os achados apontaram que quanto maior controle lógico no Desiderativo menor a produtividade no Rorschach (menor número de respostas).

Para explorar analiticamente a associação entre variáveis destes dois instrumentos projetivos, análises de correlação foram elaboradas separadamente nos três grupos de mulheres ora avaliadas. As associações estatisticamente significativas encontradas nesta nova análise constam na Tabela 43. 
Tabela 43. Correlações estatisticamente significativas entre variáveis do Desiderativo e Rorschach em função dos grupos de mulheres avaliadas.

\begin{tabular}{|c|c|c|c|c|c|c|c|}
\hline \multicolumn{2}{|c|}{ Variáveis dos Instrumentos } & \multicolumn{6}{|c|}{ Grupos } \\
\hline \multirow[t]{2}{*}{ Desiderativo } & \multirow[t]{2}{*}{ Rorschach } & \multicolumn{2}{|c|}{ Grupo $1(n=20)$} & \multicolumn{2}{|c|}{ Grupo $2(n=20)$} & \multicolumn{2}{|c|}{ Grupo $3(n=20)$} \\
\hline & & $r^{*}$ & $p$ & $r^{*}$ & $p$ & $r^{*}$ & $p$ \\
\hline & $\mathrm{R}$ & 0,460 & 0,041 & - & - & - & - \\
\hline \multirow[t]{3}{*}{ Perseveração de reino } & $\mathrm{H}+(\mathrm{H})$ & $-0,554$ & 0,011 & - & - & - & - \\
\hline & Bot & 0,453 & 0,045 & - & - & $-0,603$ & 0,005 \\
\hline & Dbl & - & - & 0,533 & 0,015 & - & - \\
\hline Conteúdo lógico de & $\mathrm{F}+\%$ extenso & 0,496 & 0,026 & - & - & - & - \\
\hline \multirow[t]{5}{*}{ pensamento } & $\mathrm{EF}+\mathrm{E}$ & $-0,638$ & 0,002 & - & - & - & - \\
\hline & $\mathrm{H}$ & - & - & $-0,512$ & 0,021 & - & - \\
\hline & A & - & - & 0,633 & 0,003 & - & - \\
\hline & $\mathrm{A}+(\mathrm{A})$ & - & - & 0,703 & 0,001 & - & - \\
\hline & $\mathrm{CF}+\mathrm{C}$ & - & - & - & - & 0,599 & 0,022 \\
\hline Distinção adequada entre & $E F+E$ & $-0,575$ & 0,008 & - & - & - & - \\
\hline realidade interna e externa & A & - & - & 0,462 & 0,040 & - & - \\
\hline Racionalização adequada & A & - & - & 0,465 & 0,039 & - & - \\
\hline Dissociação adequada & $\mathrm{H}+(\mathrm{H})$ & - & - & - & - & 0,486 & 0,030 \\
\hline Associação ideoafetiva & Bot & 0,499 & 0,025 & - & - & & \\
\hline \multirow[t]{2}{*}{ (associada) } & $E F+E$ & - & - & - & - & $-0,470$ & 0,036 \\
\hline & $\mathrm{F}+\%$ extenso & 0,541 & 0,014 & - & - & - & - \\
\hline Interações & $E F+E$ & $-0,484$ & 0,031 & - & - & - & - \\
\hline \multirow[t]{3}{*}{ (Aproximação) } & A & 0,553 & 0,011 & - & - & - & - \\
\hline & $\mathrm{A}+(\mathrm{A})$ & 0,488 & 0,029 & - & - & - & - \\
\hline & FE & - & - & $-0,540$ & 0,014 & - & - \\
\hline \multirow[t]{3}{*}{ Induções } & Dbl & - & - & 0,450 & 0,046 & - & - \\
\hline & $\mathrm{A}+(\mathrm{A})$ & - & - & - & - & 0,482 & 0,031 \\
\hline & Bot & - & - & - & - & $-0,452$ & 0,045 \\
\hline Antropomórficas & FE & - & - & 0,503 & 0,024 & - & - \\
\hline \multirow[t]{2}{*}{ Idealização } & FE & - & - & $-0,450$ & 0,046 & - & - \\
\hline & A & - & - & 0,475 & 0,034 & - & - \\
\hline
\end{tabular}


Torna-se possível observar, a partir das Tabelas 42 e 43, que houve combinações distintas entre variáveis significativamente associadas do Desiderativo e do Rorschach a depender dos grupos de mulheres. Esse achado sugere que os instrumentos, conjuntamente, se mostraram mais sensíveis para as particularidades dos grupos de mulheres, o que fica menos evidente ao analisar isoladamente suas variáveis. Há que se comentar ainda que os valores das correlações entre as variáveis foram elevados, evidenciando que são construtos fortemente relacionados, como previsto teoricamente por esses materiais. Esses resultados reafirmam a validade clínica dos métodos projetivos utilizados, na medida em que conseguiram retratar especificidades de vivências de mulheres em diferenciadas condições de vida no tocante à maternagem (variável central do estudo).

Ao examinar as marcas específicas de cada grupo de mulheres, é possível elaborar uma síntese descritivo-interpretativa desses achados. Buscou-se, desta forma, dar sentido ao conjunto de indicadores identificados, tendo por base as características dos grupos de mulheres estudadas.

a) Grupo 1 (pretendentes à adoção): a perseveração de reino no Desiderativo se mostrou positivamente associada à produtividade $(\mathrm{R})$ no Rorschach, bem como a conteúdos simbolicamente primitivos (Bot), podendo sugerir dificuldades na flexibilização e na mudança de identidade. Outrossim, ainda neste grupo de pretendentes à adoção, observou-se que variáveis de ambos os instrumentos, teoricamente relativas ao controle racional dos afetos (conteúdo lógico de pensamento e $\mathrm{F}+\%$ extenso), mostraram-se empiricamente associadas entre si. O adequado uso da razão, no Desiderativo (conteúdo lógico de pensamento), apresentou significativa correlação com sinal de menor angústia no Rorschach (menos EF+E). Interações de Aproximação se mostraram positivamente associadas com indicadores do Rorschach relativos ao compartilhamento de impressões e percepções com o senso comum, bem como com a possibilidade de adequada precisão analítica da realidade $[\mathrm{A} \%$ e $\mathrm{A}+(\mathrm{A}) \%]$. Assim, a proximidade com o outro no Desiderativo pareceu elemento protetor da capacidade de raciocinar e de se adaptar ao meio nestas participantes. Além disso, essa aproximação com o outro mostrou-se, neste grupo de mulheres, como inversamente proporcional a um indicador de angústia no Rorschach $(\mathrm{EF}+\mathrm{E})$.

b) Grupo 2 (mães adotivas): observou-se significativa e positiva correlação entre variáveis do Rorschach e do Desiderativo vinculadas à oposição diante das instruções (perseveração de reino, Induções e Dbl), confirmando-se, empiricamente, a interpretação teórica conjunta 
destes indicadores (sinais de oposicionismo). Houve, também neste grupo, positiva associação entre variáveis relacionadas ao teste de realidade [conteúdo lógico de pensamento, distinção entre realidade interna e externa, racionalização adequada, $\mathrm{A} \%, \mathrm{~A}+(\mathrm{A}) \%]$, reforçando referida interpretação analítica (sinais de preservado vínculo com o real). Houve ainda significativa e positiva correlação entre indicadores do Desiderativo relacionados ao uso da lógica e da razão, com variáveis do Rorschach sinalizadoras de integridade da identidade $[\mathrm{H}+(\mathrm{H}) \%]$ e com sensibilidade afetiva $(\mathrm{CF}+\mathrm{C})$. $\mathrm{O}$ uso da Idealização como defesa, no Desiderativo, mostrou-se associado à redução, no Rorschach, de sinais de angústia de conteúdos animais.

c) Grupo 3 (mães biológicas): maior apego à identidade humana (respostas antropomórficas no Desiderativo) mostrou-se positivamente associado a maior mobilização de angústia, embora coordenada pela razão (FE, no Rorschach). Induções e perseverações de reino apareceram positivamente correlacionadas com indicador do Rorschach cuja interpretação pode se relacionar a estereotipia ao responder $[\mathrm{A}+(\mathrm{A}) \%]$, confirmando-se empiricamente a correspondência entre variáveis de ambos os instrumentos com significado relacionado de oposição às instruções e a menor flexibilização na identidade. Outrossim, a emissão de respostas de conteúdo botânico (Bot) no Rorschach se mostrou negativamente correlacionada com indicadores do Desiderativo ligados a falhas ao responder. Quanto ao funcionamento do pensamento, respostas com adequação lógica estiveram positivamente associadas à sensibilidade afetiva, neste grupo de participantes. A possibilidade de coordenar adequadamente ideias e afetos (no Desiderativo) foi positivamente associada a indicadores de integridade na personalidade (conteúdos humanos inteiros no Rorschach), e, por outro lado, negativamente associada a conteúdos carregados de angústia.

A partir destas análises, foram identificados marcadores específicos destes grupos de mulheres na medida em que apresentaram correlações estatisticamente significativas em determinadas combinações de variáveis. Pode-se inferir, portanto, que a combinação do Método de Rorschach com o Questionário Desiderativo conseguir captar características de personalidade dessas mulheres com diferentes experiências de maternagem. Houve alguma convergência na interpretação destas variáveis, sinalizando possibilidades de integração analítica entre indicadores destes dois métodos projetivos de avaliação psicológica, como seria esperado do ponto de vista teórico.

Com o objetivo de explorar outras possibilidades em termos de associação de variáveis entre instrumentos de avaliação psicológica, optou-se por testar, mediante análise estatística, 
possíveis correlações entre os cinco principais indicadores da Bateria Fatorial de Personalidade (Neuroticismo, Extroversão, Socialização, Realização e Abertura) e as variáveis do Desiderativo já selecionadas e utilizadas neste estudo para análises de correlação. A Tabela 44 traz as combinações em que foi detectada correlação significativa, considerandose o total de mulheres avaliadas $(n=60)$.

Tabela 44. Correlações estatisticamente significativas entre variáveis da Bateria Fatorial de Personalidade (BFP) e do Desiderativo no total de mulheres avaliadas $(n=60)$.

\begin{tabular}{cccc}
\hline \multirow{2}{*}{ BFP } & Variáveis & Estatística $(R \hat{o})$ & $p$ \\
& Desiderativo & & \\
\hline Neuroticismo & Racionalização adequada & $-0,283$ & 0,029 \\
Neuroticismo & Associação ideoafetiva (associadas) & 0,313 & 0,015 \\
\hline
\end{tabular}

Embora múltiplas variáveis tenham sido testadas em suas correlações, houve apenas duas combinações com resultado estatisticamente significativo, associando duas variáveis do Desiderativo com o indicador de Neuroticismo da BFP. A adequada racionalização (no Desiderativo) mostrou-se inversamente vinculada com o valor do Neuroticismo (na BFP). Em complemento, o Neuroticismo mostrou-se positivamente correlacionado com indicador de preservada associação ideoafetiva no Desiderativo. Embora aparentemente contraditórias essas correlações evidenciam a relevância do indicador de Neuroticismo enquanto característica de personalidade que interfere no modo adaptativo dessas mulheres. Em síntese, poder-se-ia pensar que, quanto maior o Neuroticismo, maior integração parece emergir entre afeto e razão, porém com risco de contaminação do pensamento (diminuição das adequadas racionalizações).

Com o objetivo de explorar outras possibilidades de associação entre variáveis, realizou-se também a análise de correlação entre as variáveis da BFP e do Desiderativo, separadamente pelos grupos avaliados. A Tabela 45 lista os resultados das combinações de variáveis em que foi detectada correlação estatisticamente significativa. 
Tabela 45. Correlações estatisticamente significativas entre variáveis da Bateria Fatorial de Personalidade (BFP) e do Desiderativo em função dos grupos de mulheres avaliadas.

\begin{tabular}{|c|c|c|c|c|c|c|c|}
\hline \multicolumn{2}{|c|}{ Variáveis dos Instrumentos } & \multicolumn{6}{|c|}{ Grupos } \\
\hline \multirow[t]{2}{*}{ BFP } & \multirow[t]{2}{*}{ Desiderativo } & \multicolumn{2}{|c|}{ Grupo $1(n=20)$} & \multicolumn{2}{|c|}{ Grupo $2(n=20)$} & \multicolumn{2}{|c|}{ Grupo $3(n=20)$} \\
\hline & & $r^{*}$ & $p$ & $r^{*}$ & $p$ & $r^{*}$ & $p$ \\
\hline \multirow{4}{*}{ Neuroticismo } & Racionalização adequada & $-0,477$ & 0,034 & - & - & - & - \\
\hline & Associação Ideoafetiva & 0,500 & 0,025 & - & - & - & - \\
\hline & Negação & - & - & 0,494 & 0,027 & 0,444 & 0,050 \\
\hline & Perseveração de Reino & - & - & - & - & $-0,570$ & 0,009 \\
\hline \multirow{3}{*}{ Extroversão } & $\begin{array}{l}\text { Conteúdo lógico do } \\
\text { pensamento }\end{array}$ & 0,540 & 0,014 & - & - & $-0,463$ & 0,040 \\
\hline & Antropomórficas & - & - & - & - & 0,461 & 0,041 \\
\hline & Dissociação adequada & - & - & - & - & $-0,488$ & 0,029 \\
\hline \multirow{3}{*}{ Abertura } & Racionalização adequada & 0,484 & 0,030 & - & - & - & - \\
\hline & Dissociação adequada & - & - & 0,662 & 0,001 & - & - \\
\hline & Recusas & - & - & - & - & $-0,522$ & 0,018 \\
\hline \multirow{2}{*}{ Socialização } & $\begin{array}{l}\text { Distinção adequada entre } \\
\text { realidade interna e externa }\end{array}$ & - & - & 0,507 & 0,022 & - & - \\
\hline & Antropomórficas & - & - & - & - & 0,488 & 0,029 \\
\hline
\end{tabular}

Torna-se possível observar a partir das Tabelas 44 e 45 que, nas análises de correlação entre BFP e Desiderativo, houve combinações distintas entre variáveis significativamente associadas em cada grupo de mulheres. Mais uma vez, reforça-se a ideia de que os dois instrumentos, conjuntamente, se mostraram mais sensíveis para as particularidades dos grupos de mulheres do que quando as variáveis foram isoladamente consideradas. Os valores de correlação encontrados nestas análises foram fortes e estatisticamente significativos, o que reitera a relevância dos atuais achados empíricos, fortalecendo a hipótese de convergência teórica entre os indicadores (variáveis latentes) destes dois instrumentos de avaliação de personalidade, ainda que pautados em modelos técnicos e teóricos diversos.

Uma tentativa de síntese interpretativa das correlações específicas identificadas entre BFP e Desiderativo nos três grupos de mulheres permite as afirmações a seguir apresentadas. a) Grupo 1 (pretendentes à adoção): indicadores do Desiderativo relativos à adequação no funcionamento lógico (conteúdo lógico de pensamento e racionalização adequada) apresentaram associação positiva com as variáveis Extroversão e Abertura. Assim, a possibilidade de se abrir para contatos e para exteriorizar ideias e sentimentos mostrou-se, neste grupo de mulheres, associada a bons recursos lógicos e de raciocínio. Por outro lado, o 
Neuroticismo apareceu negativamente associado à Racionalização adequada e, paralelamente, mostrou correlação positiva com a possibilidade de coordenar adequadamente ideias e afetos (associação ideoafetiva), no Desiderativo. Assim, relacionou-se ao mesmo tempo a possibilidade de um funcionamento adaptativo, bem como a instabilidade lógica (em momentos de maior mobilização emocional), mostrando peculiaridades desta faceta da personalidade neste grupo.

b) Grupo 2 (mães adotivas): variáveis referentes ao funcionamento lógico no Desiderativo (adequada Dissociação e distinção entre realidade interna e externa) mostraram-se positivamente associadas a indicadores da BFP referentes à abertura para o contato com o outro e para estímulos diversos (Abertura e Socialização). O Neuroticismo, por sua vez, mostrou-se positivamente associado à utilização de primitiva defesa psíquica (Negação), sinalizando relacionar-se, de alguma maneira, a prejuízos no funcionamento da personalidade neste grupo de mulheres.

c) Grupo 3 (mães biológicas): foi o grupo com mais correlações significativas entre os instrumentos em foco neste momento. As variáveis relativas à preservação do funcionamento lógico no Desiderativo apresentaram negativa correlação com variáveis sinalizadoras de possibilidades de abertura emocional conforme a BFP. Ou seja, quanto mais Extroversão e Abertura, menores índices de respostas lógicas e com adequada dissociação enquanto Defesa Instrumental, neste grupo de mulheres. Por outro lado, Extroversão e Socialização estiveram positivamente associadas com a emissão de respostas Antropomórficas, que representam, teoricamente, dificuldades em desvencilhar-se da identidade humana. Ainda, segundo as correlações significativas encontradas neste grupo de mulheres, quanto mais abertas aos estímulos e elementos da realidade (Abertura, conforme a BFP), menores as chances de bloqueios associativos e dificuldades para responder ao Desiderativo (recusas). O Neuroticismo mostrou ainda, neste grupo, associação negativa com as perseverações de reino, fenômeno tradicionalmente compreendido como uma falha lógica ao responder ao instrumento, entretanto, muito frequente na amostra ora estudada, o que permite afirmar que não se trata de característica desadaptativa à realidade.

Ao considerar o conjunto das análises presentemente efetivadas, é possível afirmar que, embora os instrumentos de avaliação psicológica utilizados possuam bases teóricas e técnicas específicas (métodos projetivos e técnica de autorrelato), os resultados empíricos corroboram algumas de suas premissas teóricas, caracterizando-se como evidências empíricas 
de sua validade. Essa sensibilidade clínica dos instrumentos oferece bases de sustentação para a interpretação psicodinâmica dos construtos examinados. Sinaliza-se, portanto, que é possível analisar características de personalidade por meio do Método de Rorschach, por meio do Questionário Desiderativo e pela Bateria Fatorial de Personalidade, com relevantes pontos de convergência entre os achados, reiterando a qualidade das informações fornecidas no tocante ao construto personalidade. 


\section{DISCUSSÃO}

Ao iniciar o processo de análise reflexiva sobre os achados da presente investigação, faz-se necessário retomar seus objetivos e, passo a passo, evidenciar o caminho trilhado frente à literatura científica da área. Nesse sentido, uma primeira observação se faz necessária: a escassez de publicações científicas, sobretudo no contexto do Brasil, relativas ao exame de variáveis relacionadas à personalidade de mulheres em processos de adoção, apesar da reconhecida relevância e impacto desse construto no desfecho dessa demanda judicial. Desse modo a interlocução possível entre trabalhos científicos fica limitada, relacionando estudos de natureza diversa e com variados focos analíticos.

Com base nessa realidade, procurar-se-á descrever, de forma integrada, os principais resultados encontrados, interpretando-os à luz dos fundamentos psicodinâmicos da avaliação psicológica, de modo a oferecer elementos para reflexão sobre a prática do psicólogo judiciário envolto em processos de adoção. O enfoque manterá uma dupla perspectiva, como apresentado na justificativa deste trabalho: tanto metodológica, investigando instrumento de avaliação psicológica (Questionário Desiderativo), quanto clínica, enquanto aplicação da avaliação psicológica no campo da adoção, podendo vir a contribuir para a prática profissional do psicólogo no Brasil.

Uma das questões iniciais deste estudo voltou-se à composição de sua amostra. Como deveria ser selecionada? Com base em quais critérios, tendo em vista o objetivo proposto para o trabalho? Como evitar constrangimentos e mobilizações emocionais nas participantes, para além do já experenciado por elas em seu percurso de vida? Com base em vários cuidados técnicos e éticos, pode-se considerar que a amostra alcançada para a presente investigação atendeu ao planejado inicialmente. Assim, foi possível concluir a avaliação psicológica de 60 mulheres com características sociodemográficas semelhantes (idade, escolaridade, estado civil), diferenciadas em função de sua condição de maternidade (mulheres inférteis que querem ser ou já são mães adotivas, e mães biológicas).

Ressalta-se que o perfil selecionado para as participantes tentou acompanhar as características etárias e de escolaridade mais frequentes entre as mulheres que se inscrevem como pretendentes à adoção na comarca de Ribeirão Preto (SP), local de realização deste estudo. Esse procedimento teve o objetivo de representar o grupo de pretendentes à adoção nesta comarca. Conforme assinalado anteriormente, trata-se de um perfil que inclui idade em torno de 40 anos de idade, escolaridade alta (ensino médio completo ou superior) e vivência de união conjugal. A partir dessas características procurou-se balancear os demais grupos, 
possibilitando sua comparação nos indicadores obtidos com os instrumentos de avaliação psicológica.

Este perfil sociodemográfico das pretendentes à adoção da comarca de Ribeirão Preto (conforme levantamento realizado no ano de 2012) mostrou-se comparável com o descrito em diversos estudos científicos na área. Em âmbito nacional, destacam-se os trabalhos de Cassin (2000) e Mariano e Rossetti-Ferreira (2008) que, também desenvolvidos em Ribeirão Preto, retrataram um perfil sociodemográfico de adotantes bastante semelhante, mesmo com anos de intervalo entre si. Já Huber e Siqueira (2010) focalizaram casais em fila de espera para adoção, com status conjugal e idade semelhante às focalizadas no presente estudo. Sonego e Lopes (2009) avaliaram mães adotivas com filhos por volta dos dois anos de idade, um perfil comparável ao das mães adotivas ora avaliadas. Em todos estes estudos mencionados (bem como em outros), a infertilidade apareceu como fator frequente entre os adotantes, e, não por acaso, tal elemento foi utilizado como critério de inclusão na amostra da presente investigação. Sendo assim, é possível afirmar que a amostra presentemente alcançada retrata um perfil comum existente entre mulheres envolvidas em processos de adoção de crianças no Brasil, o que favorece futuras comparações de seus resultados com outros estudos.

Em relação à idade das participantes, foi possível verificar que o grupo de comparação (G3) foi composto por mulheres significativamente mais jovens que as pretendentes à adoção e as mães adotivas (respectivamente G1 e G2), o que pode ser considerado algo esperado, visto não relatarem dificuldades para engravidar. As participantes de G1 e G2, no geral, levaram anos tentando engravidar e aguardaram outro período adicional (em anos) em fila de pretendentes à adoção para a chegada de seu filho, o que acabou por postergar a vivência da maternidade. Entretanto, é pouco provável que a diferença existente na idade média de G3 e os demais grupos implique em alterações significativas em termos de estrutura e funcionamento da personalidade, foco do presente estudo.

Ainda em relação ao perfil das participantes, observou-se que a maioria das mulheres avaliadas encontra-se inserida em alguma atividade laborativa, sendo que apenas a minoria se dedica unicamente ao lar e à família. Este resultado é compatível com tendência bastante recorrente nas últimas décadas, sobretudo nas sociedades ocidentais (Nascimento \& Térzis, 2010; Patias \& Buais, 2012). Sendo assim, trata-se de um grupo de mulheres que já acumula ou deseja acumular funções maternas com o trabalho fora do lar, sendo ambos os projetos de vida considerados igualmente relevantes dentro deste grupo avaliado.

Neste aspecto, Patias e Buais (2012) apontaram que nas últimas décadas tem diminuído a taxa de filhos por mulher, bem como aumentado a faixa etária da primeira 
gestação, além de ter havido um aumento da inserção de mulheres no mercado de trabalho. Nascimento e Térzis (2010), nesta mesma perspectiva, relataram sobre o adiamento da parentalidade com a finalidade de, antes de chegarem os filhos, poderem estar num relacionamento estável, ter completado os estudos, já terem alcançado situação financeira mais favorável, e ter emprego. Referido adiamento da maternidade foi também apontado em estudos internacionais, relacionado, entre outros fatores, a maior risco de infertilidade (Chen \& Landau, 2015; Guedes \& Canavarro, 2014; Mortensen et al, 2012).

Ao retomar a questão da maternidade, foco do presente estudo, pôde-se verificar que as mães ora avaliadas possuíam filhos com idade média de cinco anos, sendo que no caso das mães adotivas (G2) a média de idade de adoção da criança foi de dois meses de idade. Assim, as mulheres do G2 e G3 já estavam vivenciando a maternidade há um período de tempo semelhante no momento da coleta de dados, apesar dos diferentes percursos traçados pelas mesmas para terem um filho - o que, por sua vez, pode vir a fazer diferença no exercício cotidiano da maternagem (Chaves, 2002). Desse modo, considera-se que a composição balanceada de G2 e G3 favoreceu posterior análise comparativa dos achados, tendo em vista os cuidados técnicos tomados no estudo para minimizar o efeito de variáveis intervenientes.

As integrantes de G1, no entanto, vivenciavam a "não maternidade". Representam um grupo de mulheres que, tendo explorado sua identidade laborativa (alta escolaridade e inserção no mercado de trabalho), almejam ter um filho, entretanto, sem sucesso até o momento. Faz-se necessário destacar que estas características sociodemográficas correspondem ao descrito pela literatura científica da área de pretendentes à adoção, como apontaram Rosa (2008) e Ramires-Galvez (2009), entre outros autores. Os trabalhos sinalizam, inclusive, os fortes anseios vivenciados pelas mulheres inférteis no sentido de se completarem psiquicamente com o exercício da maternidade, derivando daí inquietações e sofrimento psíquico.

Nesta temática, diversos autores convergiram em afirmar sobre perdas afetivas e sofrimento emocional em mulheres vivenciando a infertilidade. Numa perspectiva psicanalítica, Accioly Patti, Peron e Barbieri (2014) versaram sobre abalos na estrutura narcísica da personalidade das mulheres atingidas pela infertilidade, bem como sobre a mesma sendo vista como obstáculo ao acesso à feminilidade, que seria viabilizado por meio da maternidade. Maux e Dutra (2009) ponderaram sobre os sentimentos de incompletude e frustração relacionados à impossibilidade de ter filhos como fatores complicadores das relações sociais e também da autoimagem de pessoas inférteis. 
Nesta mesma linha argumentativa, Trindade e Enumo (2002) focalizaram especificamente a infertilidade feminina e reiteraram haver evidências de que a mesma se relaciona a estresse, sentimentos de perda e prejuízos na autoestima, até problemas para o relacionamento conjugal, implicando em dificuldades no relacionamento social mais amplo, para as mulheres. Levinzon (2006) também discutiu a questão do ponto de vista da Psicanálise, enfatizando que a infertilidade, no caso específico das adoções de crianças, poderia ser um elemento complicador no vínculo entre pais e filhos adotivos. Diversos autores apontaram para os possíveis prejuízos adaptativos relacionados à vivência da infertilidade, o que a coloca como elemento relevante na avaliação de pretendentes à adoção, considerando-se ser esta uma das principais motivações pela busca desta via de maternidade.

Dada a complexidade das variáveis envolvidas nesse objeto de estudo aqui focalizado, pode-se afirmar que a amostra total alcançada incluiu três grupos de mulheres que possuem características em comum, mas que também se mostram bastante diferenciados entre si. Por um lado, mães adotivas (G2) e pretendentes à adoção (G1) compartilham o histórico de infertilidade e um percurso rumo à maternidade não raramente permeado de frustrações e sofrimento em torno do insucesso em gerar um filho, e também em torno dos procedimentos legais para habilitação à adoção. Já as mães adotivas (G2) e as biológicas (G3) compartilham da experiência concreta da maternidade, com seus desafios, alegrias e tristezas inerentes a este processo. Os três grupos, portanto, contemplam mulheres adultas, casadas ou em união estável, em pleno exercício de suas habilidades laborativas dentro e fora do lar, e envolvidas com a questão da maternidade, quer apenas pretendida e sonhada, quer já concretizada e em andamento.

Desse modo, considera-se que os cuidados metodológicos adotados na composição da amostra do presente trabalho oferecem suporte e valor para seus achados, sobretudo diante da diversidade de abordagens existente na literatura científica da área. Procurar-se-á, a partir de agora, destacar os principais resultados encontrados, organizando-os em tópicos para clareza do texto e facilitação de seu contraponto com outros estudos.

\section{V.1. Caracterização psicológica de mulheres com e sem experiência de maternidade}

Inicialmente há que se comentar que o objetivo de caracterização da estrutura e do funcionamento da personalidade de mulheres inférteis, envolvidas em processos de busca da realização da maternidade por meio da adoção, é amplo e complexo. Nesse sentido, procurou- 
se descrever, a seguir, os achados sintéticos alcançados com cada grupo de mulheres, tendo por base as informações específicas de cada instrumento de avaliação psicológica utilizado.

Desse modo, foi possível verificar, a partir dos resultados obtidos pelo Self Reporting Questionnaire (SRQ-20), que o total de voluntárias avaliadas alcançou pontuação média sinalizadora de ausência de indicadores psicopatológicos no momento dessa avaliação. Ao focalizar as mulheres de G1 e G2 (respectivamente pretendentes à adoção e mães adotivas), podese apontar que já vivenciaram uma ou mais avaliações psicológicas ao longo do processo em busca da adoção de uma criança. Portanto, estes resultados atuais de adequado nível de saúde mental reiteram avaliações técnicas realizadas anteriormente pelos psicólogos judiciários na comarca de Ribeirão Preto. Em relação a G3 (grupo de comparação, mães biológicas), a ausência de indicadores psicopatológicos fortalece a possibilidade de comparação entre os grupos, tanto que foi tomado como critério de seleção das voluntárias ao estudo.

A saúde mental dos indivíduos interessados em efetivar uma adoção é elemento relevante no processo de análise dos candidatos pela equipe técnica do Judiciário, visto que interfere diretamente no relacionamento conjugal e familiar, podendo criar variáveis de risco ao desenvolvimento dos futuros filhos adotivos, como aponta a literatura científica da área. Há que se lembrar que, no geral, crianças que aguardam adoção já vivenciam situação de vulnerabilidade por seu histórico de vida, incluindo muitas vezes vitimização prévia e outras experiências estressoras em seu desenvolvimento (Pemberton, Neiderhiser, Leve, Natsuaki, Shaw, Reiss, \& Ge, 2010; Roisko, Wahlberg, Hakko, Wynne, \& Tienari, 2011). Segundo estes trabalhos, a existência de psicopatologias em pais adotivos se mostrou elemento comprometedor da qualidade do diálogo familiar e também da supervisão exercida junto aos filhos, exacerbando vulnerabilidades já existentes. Diante dessas evidências empíricas, portanto, torna-se quase uma exigência técnica nos processos de análise de pretendentes à adoção a avaliação sistemática de indicadores de sua saúde mental, de modo a oferecer suporte psicossocial para o desenvolvimento infantil. Neste trabalho foi possível identificar que todos os casos de G1 e G2 mostraram indicadores positivos de preservado nível de saúde mental, reafirmando-se, assim, a relevância do trabalho de triagem realizado pelo psicólogo judiciário nos fóruns.

No tocante aos dados da Bateria Fatorial de Personalidade (BFP), deve-se inicialmente destacar que esse instrumento está baseado em informações autorrelatadas, ou seja, na visão que as próprias examinandas têm de seus comportamentos no cotidiano. As respostas a este instrumento passam, portanto, pelo crivo da consciência e da censura interna dos respondentes, podendo, em alguns casos, refletir uma imagem parecida com o que a pessoa 
pensa ou deseja ser/parecer, ou seja, permeada pelos efeitos da desejabilidade social nas respostas. No entanto, isso não é demérito para os dados, visto que tais características são compatíveis com a teoria dos Cinco Grandes Fatores, abordagem da personalidade na qual este instrumento se baseia, focalizada em elementos da identidade considerados relevantes nas relações interpessoais (Hauck Filho et al., 2012; Nunes et al., 1998).

No presente estudo, verificou-se que, na maioria das dimensões e facetas da personalidade avaliadas pela BFP, os três grupos de mulheres apresentaram escores semelhantes. Sendo assim, apesar das diferenças em relação à vivência (ou não) da maternidade nestas mulheres, sua forma de avaliar e descrever o próprio comportamento e jeito de ser cotidiano foi praticamente a mesma, com poucas exceções.

Deste modo, em relação ao conjunto de mulheres presentemente avaliadas, com base em suas respostas na BFP, pode-se em resumo dizer que, segundo a forma pela qual elas veem a si próprias:

a) acreditam ser emocionalmente independentes em relação aos demais, sugerindo que a opinião dos outros e a necessidade de agradá-los exercem pouca influência em suas ações e escolhas diárias. Veem seu humor como relativamente estável, com poucas manifestações de impulsividade e suficiente tolerância a frustrações. Eventualmente, reconhecem poder apresentar dificuldade para identificar eventos negativos e avaliar problemas, mas têm expectativa positiva acerca do futuro e acreditam ser capazes de resolver possíveis dificuldades que venham a encontrar.

b) consideram-se comunicativas e buscam ativamente contato com pessoas, mesmo que não sejam conhecidas. Acreditam ter facilidade para falar sobre seus sentimentos e vida pessoal, mesmo a pessoas que conhecem relativamente pouco. Além disso, consideram-se ativas e buscam deixar claras suas preferências e crenças para os demais.

c) acreditam ter facilidade para confiar nos demais, raramente suspeitando de suas intenções, além de se considerarem altruístas e preocupadas em ajudar os outros.

d) consideram possuir suficiente capacidade de realização, não se avaliando como exageradamente confiantes, nem tampouco autodepreciativas. Acreditam conseguir usar de ponderação ao falar e ao agir, sem ações irrefletidas, na maioria das ocasiões. Julgam conseguir se envolver de maneira mediana com suas atividades acadêmicas/laborativas, o suficiente para atingir seus objetivos.

e) acreditam ter padrão comum de curiosidade e criatividade, dentro da normalidade, conseguindo questionar suas próprias crenças e valores, não se mostrando excessivamente conservadoras nem demasiadamente liberais. 
Ao se comparar os resultados médios nos grupos avaliados com os padrões de referência constantes no manual da BFP (Nunes, Hutz \& Nunes, 2010) algumas especificidades emergiram. No grupo das mães adotivas (G2) verificou-se que tenderam a apresentar sinais de otimismo exagerado e dificuldades para perceber problemas reais, em alguns momentos. Nas dimensões Extroversão e Socialização, os três grupos apresentaram valores acima da média esperada para seu grupo de referência, sinalizando, por um lado, tendência a se abrir demais quanto ao que pensam e sentem, inclusive para desconhecidos, e confiar de maneira exagerada em quem não conhecem o suficiente, elementos que, em conjunto, podem gerar certa vulnerabilidade nos contatos. Por outro lado, características como otimismo, sinceridade/transparência e confiança apresentam conotação geral positiva nos contatos sociais e são adjetivos comumente valorizados. O aparecimento exagerado desse componente na presente avaliação pode estar relacionado, ao menos em parte, a algum grau de desejabilidade social presente nas respostas das mulheres avaliadas, bem como ao positivo contato interpessoal com as psicólogas que coletaram os dados.

Ao examinar esta temática relativa aos vínculos socioafetivos na literatura científica mais recente voltada à adoção, encontram-se evidências de diferentes efeitos da maternidade (ou ausência dela) sobre as mulheres. Por um lado, a infertilidade (enquanto fator mais frequentemente associado à busca pela adoção) pode se mostrar relacionada a pressões e cobranças internas e externas por não corresponderem ao socialmente esperado, ou seja, tornarem-se mães, desencadeando nessas mulheres sentimentos de inferioridade, frustração, inveja e irritação, prejudicando o convívio com familiares, amigos e colegas de trabalho (Fernandez-Sola et al., 2016; Nascimento \& Térzis, 2010). Nesta mesma linha argumentativa, a possibilidade de vivenciar a maternidade poderia ter efeito reparador sobre estas perdas vinculadas à infertilidade biológica, configurando-se como relevante conquista e realização pessoal, com incremento na autoestima e bem-estar geral, pelo alcance deste novo papel social: mãe (Bejenaru \& Roth, 2012).

Entretanto, a vivência concreta da maternidade carrega novas exigências e padrão adaptativo, mediante as profundas mudanças de vida que acompanham a chegada do primeiro filho. Esse processo, em alguns casos, pode se associar a aumento no nível de estresse e insatisfação pessoal e no relacionamento conjugal, e também a uma sensação de isolamento que pode acompanhar o afastamento de atividades laborativas e sociais (Bejenaru \& Roth, 2012). Desse modo, é preciso examinar o processo de vivências internas dessas experiências concretas da maternidade, pois inexiste um padrão adaptativo único diante da adoção de crianças. Assim, por mais que apareça como socialmente desejável e valorizada a adoção 
infantil, está imbuída de exigências próprias que precisam ser consideradas para favorecer seu positivo desfecho.

Quanto ao material produzido a partir da avaliação psicológica das participantes mediante o Método de Rorschach, inicialmente cabe destacar os significativos valores de concordância entre examinadores independentes alcançados no processo de classificação das respostas na presente investigação. Referidos resultados atribuem precisão e confiabilidade nas análises realizadas, reafirmando a qualidade dos cuidados metodológicos tomados neste estudo e da própria Escola Francesa (Escola de Paris) do Rorschach.

Observou-se que, no geral, também no Rorschach os três grupos mostraram-se praticamente homogêneos entre si, com poucas diferenças estatisticamente significativas entre os mesmos, apesar de suas específicas condições frente à maternidade. Deste modo, de acordo com os resultados globais do Método de Rorschach, é possível afirmar que as participantes apresentaram indicadores de adequado funcionamento lógico e racional, sugestivo de adaptação ao meio em que vivem e eficiência em seu teste da realidade, com boa precisão perceptiva. Além disso, houve indicadores de espontaneidade da vida psíquica e imaginativa destas mulheres (estilo extratensivo de vivência afetiva), preservando seu controle reflexivo dos impulsos (estilo introversivo), porém não como característica predominante em sua personalidade.

A maioria das mulheres avaliadas apresentou tendência a expressar sua afetividade de forma direta no ambiente, vivenciando predominantemente um estilo extratensivo de contato com o mundo exterior. Em complemento, sinalizaram recursos de sensibilidade para o mundo interior, com possibilidades de reflexão, vivência interiorizada dos afetos e processamento imaginativo, embora esses potenciais não sejam necessariamente utilizados em seu cotidiano de vida. Além disso, tanto as pretendentes à adoção, como as mães adotivas e biológicas ora avaliadas, apresentaram boas habilidades em coordenar racionalmente os afetos.

Em suma, as participantes apresentaram um perfil de respostas diante do Rorschach similar ao existente em seu padrão de referência normativo. Depreende-se, portanto, funcionamento da personalidade compatível com o que é considerado frequente e comum na população geral, em todos os grupos, independentemente de sua condição frente à maternidade.

No entanto, uma análise qualitativa e simbólica da produção no Rorschach apontou sinais de alguma imaturidade e projeção de conteúdos primitivos da personalidade, presentes nos três grupos de mulheres. Desse modo, pode-se depreender a existência de variáveis sugestivas de parcial aproveitamento dos recursos internos nas mulheres avaliadas, apesar de 
adultas, independentes e cognitivamente eficientes em suas atividades. Essa é a rica contribuição do Método de Rorschach enquanto instrumento de avaliação da personalidade, na medida em que oferece informações que ultrapassam o manifesto do cotidiano, como largamente apontado pela literatura científica da área (Freitas, 2016; Weiner, 2000)

No que se refere ao trabalho desenvolvido nesta investigação com o Questionário Desiderativo, serão inicialmente discutidos os resultados obtidos por este instrumento frente ao objetivo de conhecer características de personalidade de mulheres inférteis envolvidas em processos de adoção de crianças, bem como de realizar a comparação entre os grupos de participantes. Foi possível observar que, também no Desiderativo, na maioria das variáveis estudadas, os três grupos de participantes apresentaram características bastante semelhantes entre si.

O conjunto de mulheres ora avaliadas apresentou predomínio de respostas com conteúdos lógicos e associadas ideoafetivamente. Houve predomínio de autopercepção valorizada nas catexes positivas e desvalorizada nas negativas, bem como adequada utilização das defesas instrumentais ao responder ao Questionário Desiderativo.

É possível afirmar, portanto, que, no geral, nas variáveis analisadas do Desiderativo, assim como nos resultados dos instrumentos anteriormente descritos, as participantes apresentaram indicadores compatíveis com o teoricamente esperado para indivíduos saudáveis e sem prejuízos em temos adaptativos à realidade (Nijamkim \& Braude, 2000). Isso ocorreu de modo independente a sua experiência (ou não) de maternidade, ou seja, marcou as mulheres pretendentes à adoção $(\mathrm{G} 1)$, as mães adotivas $(\mathrm{G} 2)$ e as mães biológicas $(\mathrm{G} 3$, grupo de comparação).

Diante do conjunto dos resultados encontrados na presente investigação, a partir dos instrumentos de avaliação psicológica utilizados, poder-se-ia conjecturar que a homogeneidade observada nos achados de G1, G2 e G3 estaria, de alguma forma, vinculada apenas à similaridade em suas características sociodemográficas (idade, nível de escolaridade, status de relacionamento). No entanto, o rigoroso processo seletivo das participantes correspondeu a cuidadoso controle metodológico adotado neste estudo para possibilitar a comparação dos grupos nas variáveis relacionadas às características de personalidade que, sabidamente, ultrapassam variáveis do contexto sociocultural, embora sejam por elas influenciadas.

Desse modo, cumpre explorar algumas experiências relevantes relacionadas aos grupos específicos de mulheres avaliadas neste estudo. Faz-se importante reiterar, neste momento, que G1 e G2 foram formados por mulheres que, por estarem em processos judiciais 
de adoção de crianças, já foram submetidas, em diversos momentos, a avaliações psicológicas por peritos do Poder Judiciário, sendo consideradas aptas a adotarem crianças.

O histórico de vivência de infertilidade (G1 e G2) e da ausência de filhos (G1) estariam potencialmente relacionados, de acordo com a literatura científica consultada, tanto no âmbito nacional (Ghirardi, 2008; Nascimento \& Térzis, 2010; Ramirez-Galvez, 2009; Trindade \& Enumo, 2002), como internacional (Bejenaru \& Roth, 2012; Chen \& Landau, 2015; Fernandez-Sola et al., 2016; Kite 2012), a sofrimento emocional e prejuízos no funcionamento da personalidade. Entretanto, estas participantes parecem já ter alcançado nível suficiente e satisfatório de elaboração interna destas perdas, a ponto desses sinais não serem detectáveis pelos instrumentos projetivos utilizados. Estes resultados reiteram, empiricamente, a qualidade das avaliações técnicas realizadas pelos psicólogos judiciários do Fórum de Ribeirão Preto, envolvendo estas pretendentes à adoção.

Apesar de vivenciarem situação de infertilidade, as integrantes de G1 já estavam em fila de espera para adoção, ou seja, tratava-se apenas de uma questão de tempo até se tornarem mães por adoção. Esta situação pode, de certa maneira, representar um contexto geral de vida favorecedor à elaboração interna das perdas envolvendo a infertilidade, oferecendo esperanças da realização do projeto de vida relacionado à maternidade. Esta é outra possível explanação para os indicadores empíricos de preservada estrutura e funcionamento da personalidade. Sinalizaram suficientes recursos adaptativos para lidarem com as demandas da realidade, sem sinais de psicopatologias ou prejuízos na personalidade.

Estes resultados, em parte, confirmam a literatura científica da área ao apontar indicadores de preservação da saúde mental geral destas mulheres avaliadas, em se tratando de pretendentes à adoção ou mesmo mães adotivas já constituídas. Assim como anteriormente mencionado, a qualidade do funcionamento da personalidade e saúde mental das pessoas que buscam a adoção é elemento de fundamental relevância nas avaliações destes candidatos, uma vez que, conforme demonstram estudos na área, a presença de sintomas psicopatológicos nos pais adotivos poderia atuar como interveniente negativo na dinâmica conjugal e familiar (Pemberton, Neiderhiser, Leve, Natsuaki, Shaw, Reiss, \& Ge, 2010; Roisko, Wahlberg, Hakko, Wynne, \& Tienari, 2011; Wasinski, 2015;).

Por outro lado, os resultados da presente investigação diferem dos achados da literatura científica desse campo na medida em que seriam esperados indicadores relativos a prejuízos na personalidade ou a alterações na autoimagem ou autoestima de mulheres inférteis, sobretudo nas que ainda não eram mães (Accioly, Pati, Peron \& Barbieri, 2014; Levinzon, 2006; Ghirardi, 2008; Nascimento \& Térzis, 2010). Na presente investigação, a 
vivência de infertilidade e a ausência de filhos não resultou em marcas significativas na personalidade que pudessem diferenciar as pretendentes à adoção das demais participantes que já eram mães (adotivas ou biológicas), ao menos dentro dos limites informativos das técnicas utilizadas.

É possível conjecturar, por outro lado, que, caso as integrantes de G1 ainda não tivessem a aprovação formal como pretendentes à adoção ou vivenciassem a recémdescoberta da infertilidade, os resultados seriam diferentes. Fica, portanto, o estímulo a novos estudos na área, com mulheres em específicas vivências no processo de busca pela adoção (conforme realidade existente no Judiciário) e com diferentes experiências de vida frente a sua infertilidade.

\section{V.2. Especificidades de características de personalidade de mulheres envolvidas na adoção de crianças}

Os objetivos delineados para este trabalho primeiramente dirigiram-se à identificação de características da personalidade de mulheres com e sem experiência de maternidade, a partir da avaliação psicológica por meio dos métodos projetivos (Psicodiagnóstico de Rorschach e Questionário Desiderativo) e por instrumento de autorrelato (Bateria Fatorial de Personalidade). Em um segundo momento, almejou-se comparar as características afetivas e de funcionamento da personalidade dos três grupos distintos de vivências da maternidade: mulheres inférteis judicialmente habilitadas para adoção e que aguardam a chegada da criança (G1), mulheres inférteis e que são mães adotivas (legalmente instituídas, G2), e mães sem problemas de infertilidade (grupo de comparação, G3). Para atender a esse segundo objetivo específico do estudo adotou-se a estratégia de destacar e discutir, de cada instrumento de avaliação da personalidade, as especificidades de produção dos grupos, de modo a marcar eventuais particularidades nas características estruturais e funcionais das mulheres pretendentes à adoção frente à literatura científica da área.

Ao focalizar os achados derivados da Bateria Fatorial de Personalidade (BFP), foi identificada uma única diferença estatisticamente significativa entre os grupos: na subescala Liberalismo do Fator Abertura à Experiência. $\mathrm{O}$ valor de magnitude do efeito encontrado pode ser considerado médio, em se tratando de Ciências Sociais, conforme Marôco (2011). Deste modo, torna-se relevante atentar para esta diferença, analisando-a de forma pormenorizada. 
No tocante ao Liberalismo, G1 e G2 mostraram resultados classificados em nível inferior ao padrão mediano normativo, diferenciando-se de G3. Por sua vez, a diferença estatisticamente significativa entre os grupos foi identificada apenas entre as mães biológicas (G3) e as mães adotivas (G2, inférteis, mas já com filho adotivo), sendo que os maiores valores foram verificados entre as mães biológicas. Estas últimas apresentaram tendência a considerar que os valores sociais, éticos e legais podem ser relativizados, compreendendo, de maneira mais contundente, que não existem verdades absolutas ou valores inquestionáveis.

Por se tratar de um dado isolado, torna-se difícil realizar inferências interpretativas a seu respeito, podendo se tratar de diferença espúria entre os grupos, derivados de particularidades de sua composição. No entanto, a título de análise exploratória, poder-se-ia considerar que as mães biológicas, por terem idade inferior (média de 34,1 anos) aos demais grupos ( $\mathrm{G} 1=41,9$ anos; $\mathrm{G} 2=42,4$ anos), experimentam com mais flexibilidade os valores sociais contemporâneos, podendo se tratar de influência educacional. A chegada da quarta década de vida, no geral, pareceu agregar maior apego aos valores sociais, como identificado nas mulheres de G1 e G2.

Entretanto, apesar destas especificidades, o conjunto de mulheres avaliadas na presente investigação reconheceu seus próprios recursos no enfrentamento à realidade, atribuindo a si próprias características predominantemente positivas, sem, no entanto, deixar de identificar possíveis dificuldades advindas de seu modo de ser e agir. Segundo os dados obtidos pela BFP, parecem acreditar que são capazes de enfrentar os problemas surgidos, sinalizando suficiente capacidade crítica em seu modo de se adaptar à realidade.

Com base na literatura científica identificada na área, neste estudo inicialmente levantou-se a hipótese de que mulheres inférteis e candidatas à adoção (G1) poderiam apresentar resultados mais elevados nas subescalas componentes do Fator Neuroticismo da BFP. Isto porque, conforme proposição teórica associada ao instrumento, índices elevados nesta escala significariam propensão maior "a vivenciar, de forma mais intensa, sofrimento psicológico, instabilidade emocional e vulnerabilidade" (Nunes, Hutz \& Nunes, 2010, p. 126). Derivado dessa hipótese esperar-se-ia em G2 (mulheres inférteis e em exercício da maternidade adotiva) e em G3 (mães biológicas) os menores índices de Neuroticismo, comparativamente a G1.

Frente aos achados empíricos da BFP não foi possível comprovar essas hipóteses iniciais no tocante ao componente Neuroticismo de sua personalidade. A partir desse instrumento de avaliação psicológica, os três grupos mostraram mais similaridades do que diferenças em autorrelato acerca de suas próprias características de personalidade. Desse 
modo, não se confirmou aqui a hipótese do efeito negativo da infertilidade e/ou da ausência de filhos sobre o funcionamento da personalidade neste grupo de participantes, conforme sua avaliação pela BFP.

Na sequência reflexiva, há que se ponderar sobre a análise dos principais indicadores do Método de Rorschach em relação às hipóteses iniciais formuladas neste trabalho com relação a este método projetivo de avaliação da personalidade. A primeira hipótese levantada dizia que mulheres inférteis e candidatas à adoção (G1) sinalizariam mais indicadores de angústia no Rorschach, a saber: maior uso do detalhe branco (Dbl) nas localizações das respostas; maior proporção de determinantes do tipo sombreado e com disforia; maior frequência de conteúdos Anat, Sex, Hd, (Hd), Elem Fog, Frag em suas respostas. Esses indicadores destacados seriam mais frequentes em G1 do que em G2 e, por sua vez, menores em G3.

No que se refere a esta complexa hipótese, foi confirmado apenas o maior uso do detalhe branco nas localizações das respostas ao Rorschach nas mulheres pretendentes à adoção (G1) em relação às mães biológicas (G3). Não foram verificadas diferenças em relação às mães adotivas $(\mathrm{G} 2)$ quanto ao uso do detalhe branco em suas respostas ao Rorschach. Nas demais variáveis postuladas, não se confirmaram as expectativas sobre as variáveis deste método projetivo.

Apesar da baixa frequência deste modo de apreensão diante do total de respostas, a localização Dbl no Rorschach pode representar um marcador específico para mulheres à espera da adoção, atentando-se para o seu significado psicodinâmico ligado à angústia e à falta (Rausch de Traubenberg, 1998). Considerando-se que a principal característica das mulheres de G1, que as diferencia das demais participantes, é a ausência de filhos, o dado de maior Dbl com significado de angústia diante do vazio e da falta parece fazer sentido interpretativo, refletindo possíveis marcas destes eventos de vida sobre a personalidade.

Outra especificidade de produção de G1 (pretendentes à adoção) diante do Rorschach foi seu maior tempo de latência médio. Essas mulheres precisaram de mais tempo, em média, para processar internamente as instruções da técnica, bem como para absorver o impacto afetivo diante do instrumento, antes de emitir uma resposta ao Rorschach, quando comparada aos demais grupos avaliados.

Embora em caráter exploratório, este dado pode apontar que G1 efetuou maior controle em seu modo de responder, reduzindo de alguma maneira sua espontaneidade. É possível conjecturar que tal situação esteja relacionada a um possível desejo, por parte destas mulheres inférteis e pretendentes à adoção, em apresentar um perfil psicológico "adequado" 
para a psicóloga judiciária responsável pela pesquisa, a qual trabalha diretamente com a questão da adoção de crianças em sua rotina profissional no Fórum. Deste modo, apesar dos cuidados éticos em tranquilizar as voluntárias e garantir que a participação na pesquisa não interferiria de maneira alguma em seus processos judiciais de adoção, pode ter persistido a fantasia de que seria necessário convencer esta pesquisadora de que elas estão bem, do ponto de vista psicológico, a fim de que sejam mantidas na fila de adoção ou que não sejam prejudicadas por alguma característica pessoal "descoberta" por ocasião da avaliação nesta pesquisa. Trata-se de uma interpretação plausível para a variável do Rorschach, embora indicadores isolados tenham pouca sustentação técnico-científica, devendo ser relativizados em seu significado.

Outra diferença encontrada entre os grupos se referiu à presença de conteúdos botânicos (Bot) nas respostas do Rorschach. Nesse caso, as mulheres pretendentes à adoção (G1) apresentaram maior frequência desta categoria de respostas do que as mães adotivas (G2). Mais uma vez o sentido interpretativo dessa variável fica diluído em um conjunto de indicadores deste método projetivo, enfraquecendo qualquer possível interpretação clínica para esse achado empírico.

A segunda hipótese formulada nesta pesquisa com relação ao Método de Rorschach, baseou-se na possibilidade de resultados médios com mais indicadores de angústia em G1 nos cartões simbolicamente associados a identidade e feminilidade, a saber: cartão V (identidade superficial), cartão IX (identidade profunda), cartão VI (sexualidade) e cartão VII (imago feminina). Ao retomar esses resultados, tem-se que a comparação estatística da frequência dos sinais de ansiedade nestes cartões do Rorschach apontou reduzido número de diferenças estatisticamente significativas entre os grupos. Ocorreram apenas no cartão IX e em relação à resposta de conteúdo parcial humano $\mathrm{Hd}$ (maior frequência em G1, sem diferenças entre G2 e G3) e no Elemento Fogo (Elem Fog) (maior frequência em G3, sem diferenças entre G1 e G2). Diante dessas evidências empíricas, também essa segunda hipótese não se sustentou, apontando mais similaridades entre os grupos de mulheres do que especificidades em seus padrões de resposta ao Método de Rorschach.

Diante da baixa frequência de variáveis com diferenças estatisticamente significativas entre os grupos nessa análise específica por cartões do Rorschach, pode-se considerar que parecem casualidades, mais do que marcas específicas das mulheres avaliadas. Dessa forma, parece mais sensato apontar que inexistiram indicadores consistentes de maior angústia nas pretendentes à adoção $(\mathrm{G} 1)$ comparativamente às mães adotivas $(\mathrm{G} 2)$ e às mães biológicas 
(G3), sugerindo preservação de sua identidade e de sua feminilidade a partir do Método de Rorschach.

$\mathrm{Na}$ sequência dos achados derivados dos instrumentos de avaliação psicológica utilizados neste estudo, há que considerar as expectativas inicialmente formuladas a respeito do Questionário Desiderativo para os três grupos de mulheres avaliadas. Mais uma vez as hipóteses formuladas na presente investigação partiram da literatura científica referente à temática da maternidade adotiva, infertilidade e suas possíveis repercussões na personalidade. Dessa forma, ponderou-se que as mulheres de G1, ainda sem exercício da maternidade, poderiam apresentar sinais de sobrecarga interna, relacionadas a possível sofrimento e ferida narcísica, expressas por alterações na eficiência defensiva. Os indicadores do Desiderativo possíveis de expressar tais especificidades funcionais seriam:

a) tempos de resposta (desviantes para cima ou para baixo em G1);

b) sequência das escolhas (com falhas em G1);

c) falhas nas defesas instrumentais (em G1);

d) frequência diferenciada no uso dos mecanismos de defesa entre os três grupos, com predomínio de defesas mais primitivas em G1.

Os achados empíricos obtidos com as participantes diante do Questionário Desiderativo, no entanto, não confirmaram em G1 desvios nos tempos de resposta, nem alteração na sequência das escolhas desiderativas, sem maior frequência de falhas nas defesas instrumentais dessas mulheres pretendentes à adoção. No entanto, elas apresentaram, com significativa maior frequência, uso da Idealização como estratégia defensiva frente aos elementos causadores de angústia (catexes negativas), comparativamente às participantes que já eram mães (adotivas ou biológicas).

Embora aparentemente isolado, esse dado de maior uso da Idealização nas mulheres pretendentes à adoção encontra respaldo em outros estudos realizados nesse campo. Rosa (2008), que também estudou características de pais adotivos no Brasil, analisou fantasias emergentes nos mesmos em relação à adoção motivada pela infertilidade. Seu trabalho sugeriu que, nos casos de insuficiente elaboração do luto pelo filho biológico não nascido, a idealização dos pais em relação ao filho ideal poderia caminhar no sentido de uma forma de rejeição sentida pelo filho adotivo, real, com suas próprias limitações e fragilidades inerentes.

Referida temática também foi trazida por Huber e Siqueira (2010). Os autores mencionaram que a longa espera pelo filho adotivo pode ser vivenciada de forma desgastante e sofrida pelos casais, aumentando fantasias referentes à adoção e gerando inúmeros questionamentos. Conforme os autores, esta fase de transição para a parentalidade, na qual os 
indivíduos ainda não são pais, mas também não são pais em espera como ocorre na gravidez, favorece a idealização do filho e da relação que se dará com ele, desencadeando sentimentos ambivalentes e ansiogênicos (Huber \& Siqueira, 2010). As evidências do presente trabalho, na medida em que identificaram maior frequência do uso da Idealização no Questionário Desiderativo de G1, confirmou a Idealização enquanto marca afetiva das mulheres inférteis em fila de espera pela adoção de uma criança.

A análise comparativa dos resultados dos grupos no Desiderativo permitiu que outras peculiaridades emergissem destas análises, a saber:

a) as pretendentes à adoção (G1) sinalizaram vivenciar o contato com o outro (interações de aproximação) como relevante fonte de angústia em maior frequência que as participantes que já eram mães (adotivas ou biológicas), não havendo diferenças entre estas últimas. Por sua vez, o distanciamento nas interações foi referido como fonte de conflito e angústia no Desiderativo pelas participantes mães (biológicas ou adotivas), comparativamente às pretendentes à adoção.

b) as mães adotivas (G2) apresentaram maiores índices de respostas com adequada racionalização nas catexes negativas do que as mães biológicas (G3). Em complemento, essas mães biológicas apresentaram mais frequentemente falhas na Racionalização como Defesa Instrumental, nestas mesmas catexes. Em outras palavras, em G3 houve mais deslizes lógicos nas catexes negativas, comparativamente a G2.

Referidas peculiaridades, diante do amplo rol de variáveis analisadas do Questionário Desiderativo (e também no Rorschach), dificultam hipóteses interpretativas seguras. A ausência de outros trabalhos na literatura científica da área com base nesses recursos técnicos da Psicologia também limita a interlocução sobre os achados, permanecendo aqui como análise descritivo-interpretativa pautada pelos elementos teóricos que sustentam esses métodos projetivos de avaliação da personalidade. Espera-se que os atuais achados sejam estimuladores de novas investigações nesse campo para ampliar as possibilidades interpretativas a respeito dessas variáveis, no momento com interpretação limitada dentro da presente investigação.

\section{V.3. Evidências psicométricas sobre o Questionário Desiderativo}

Embora amplo e de difícil implementação, o terceiro objetivo específico deste trabalho procurou sistematizar indicadores de precisão e evidências de validade do Questionário Desiderativo enquanto instrumento adequado e cientificamente fundamentado para auxiliar 
processos de avaliação psicológica no campo da Psicologia Judiciária no Brasil, especificamente no âmbito dos processos de adoção. Nesse momento, portanto, focalizar-se-á análise do material obtido mediante as avaliações psicológicas realizadas buscando evidenciar as qualidades técnicas e psicométricas dos instrumentos (sobretudo do Questionário Desiderativo).

É relevante reiterar que, no presente estudo, buscou-se empreender esforços para aprimorar a codificação das respostas ao Questionário Desiderativo, recorrendo-se à estratégia de Análise de Conteúdo por experts (Urbina, 2007). Esta iniciativa procurou responder a dificuldade técnica identificada em estudo anterior (Guimarães, Pasian \& Loureiro, 2008) com este método projetivo, onde ficou clara a necessidade de revisar a sistemática de análise referente aos mecanismos de defesa. O objetivo foi disponibilizar, no material de análise do Questionário Desiderativo, alguns mecanismos de defesa para que o psicólogo assinalasse a presença ou ausência nas respostas ao instrumento.

Neste intuito foi possível delimitar cinco mecanismos de defesa para serem incluídos no protocolo de codificação do Questionário Desiderativo, a saber: Negação, Idealização, Formação Reativa, Sedução e Sublimação. Referidas diretrizes analíticas foram aplicadas na codificação dos dados do presente trabalho, sendo, portanto, testada esta proposta avaliativa na análise do material produzido pelas participantes.

A classificação dos protocolos do Desiderativo, realizada por examinadores independentes, evidenciou altos níveis de concordância e adequada precisão das análises realizadas, inclusive na codificação dos mecanismos de defesa. Neste ponto, pode-se afirmar que foi possível avançar nos indicadores de precisão do Questionário Desiderativo em relação a estudos anteriores (Guimarães, 2007). Desse modo conseguiu-se aprimorar o processo de codificação dos mecanismos de defesa a partir desse método projetivo, sendo fornecidos parâmetros de classificação específicos para tal finalidade. Deste modo, os resultados obtidos na presente investigação contribuíram para reafirmar empiricamente bons indicadores de fidedignidade no processo de codificação das variáveis do Desiderativo, a partir dos fundamentos teóricos baseados na obra de Nijamkin e Braude (2000), conforme compilação apresentada em Guimarães, Pasian e Loureiro (2008).

Nas tentativas de aperfeiçoamento do processo de análise e interpretação do Questionário Desiderativo, os atuais achados chamaram a atenção para uma variável que ocorreu com elevada frequência nos três grupos de mulheres avaliadas: a ocorrência de falhas ao responder, ensejando a necessidade de induções de categorias de respostas durante a aplicação do instrumento. Mais especificamente, observou-se que a perseveração do reino 
objeto foi um fenômeno presente na maioria dos casos avaliados, representando a principal causa de necessidade de indução no Desiderativo.

Este achado desperta-nos a necessidade de questionar o caráter técnico de "falha lógica" e "oposição às instruções", tradicionalmente atribuído à necessidade de indução de respostas no Questionário Desiderativo, sobretudo ao se analisar a perseveração do reino objeto. Ressalta-se que as instruções da técnica fazem uso da palavra "objeto" para se referir à categoria de respostas do tipo inanimadas. Neste "reino objeto" do Desiderativo estão incluídas respostas com conteúdos vinculados a elementos da natureza, sentimentos, abstrações e demais elementos inanimados. No entanto, essa diversidade de classes de respostas dificilmente é considerada, no senso comum, como categoria "objeto". Desse modo, é possível conjecturar que o respondente não estaria necessariamente se opondo às instruções nem cometendo falha lógica ou dissociativa ao perseverar o reino objeto (repeti-lo, porém com diferentes tipos de resposta). Diante destas considerações parece-nos forçoso relativizar o caráter de prejuízo no funcionamento lógico tradicionalmente atribuído às perseverações de reino objeto no Desiderativo.

Outra especificidade observada na totalidade das participantes deste estudo foi a ocorrência de maior tempo para processarem internamente o impacto das instruções, bem como maior frequência de falhas nas defesas instrumentais nas catexes negativas do Questionário Desiderativo. As participantes apresentaram maior facilidade para identificar, projetivamente, seus recursos de preservação da identidade (respostas às catexes positivas), reagindo com mais dificuldades para apontar elementos sentidos como desintegradores (respostas às catexes negativas).

Referidos achados reforçam a relevância de se atentar para estes dois conjuntos de catexes separadamente ao se analisar as respostas ao Desiderativo. Além do preconizado teoricamente acerca do significado diferenciado das respostas às catexes positivas e negativas (Nijamkin \& Braude, 2000), a presente investigação apresentou comprovações empíricas destas especificidades, reforçando a necessidade de cuidados técnicos específicos para sua adequada interpretação.

Além dessas observações e reflexões específicas referentes a técnica implícita no Questionário Desiderativo, há que considerar os achados empíricos relativos às correlações entre os instrumentos de avaliação psicológica ora utilizados. Essas análises tiveram o objetivo de avaliar a existência (ou não) de associação entre variáveis de diferentes tipos de técnicas de exame da personalidade (de autorrelato e projetivas), ou seja, abordando construtos relacionados. Buscou-se, desta forma, identificar evidências empíricas de validade 
em relação ao Questionário Desiderativo aplicado em indivíduos adultos (no caso mulheres), conforme preconizado por Nunes e Primi (2010).

A análise inicialmente realizada, tomando por base o conjunto total de mulheres avaliadas nesta investigação, revelou associação positiva e significativa entre variáveis do Desiderativo associadas ao controle racional dos afetos com variável do Rorschach sinalizadora de repressão e inibição. Houve ainda resultados sugestivos de interligações entre os indicadores de mobilização emocional desses dois métodos projetivos de avaliação psicológica, reforçando sua fundamentação enquanto técnicas avaliativas de características da personalidade.

Correlações significativas negativas também foram encontradas entre variáveis sinalizadoras de maior controle lógico no Desiderativo e de menor produtividade no Rorschach (menor número de respostas). Houve correlações que mostraram que, quanto mais controle racional, conforme sua avaliação pelo Desiderativo, menores índices de mobilização afetiva no Rorschach. A interpretação conjunta destes achados reforça hipóteses psicodinâmicas que fundamentam ambos os instrumentos, caracterizando-se como evidências empíricas da validade do Questionário Desiderativo a partir do reconhecido valor técnico das variáveis da Escola Francesa (Escola de Paris) do Método de Rorschach.

A análise de correlações entre o instrumento projetivo Desiderativo e o instrumento de autorrelato Bateria Fatorial de Personalidade também trouxe resultados promissores em termos da verificação de convergências avaliativas entre estas técnicas. Nomeadamente, na análise realizada considerando-se o total das participantes $(n=60)$, o Fator Neuroticismo da BFP mostrou-se positivamente associado com a capacidade de coordenar adequadamente ideias e afetos e, por outro lado, negativamente à utilização adequada da racionalização enquanto defesa instrumental no Desiderativo. Referidos achados mostram a influência dessas características de personalidade (neuroticismo) nos processos de adaptação psíquica (associação ideoafetiva) e no funcionamento lógico (uso da racionalização), como avaliados pelo Questionário Desiderativo. Constituem, portanto, indicadores positivos para sua validade, como detalhado nos resultados.

Diante do exposto, é possível afirmar que também entre Bateria Fatorial de Personalidade e Desiderativo houve associações estatisticamente significativas. Depreende-se, portanto, que apesar de se tratarem de instrumentos de natureza diversa (autorrelato e projetivo), ambos avaliam construtos relacionados, ou seja, características de personalidade, embora por meio de diferentes atividades e variados indicadores técnicos. 
Outros estudos brasileiros também realizaram análises correlacionais entre variáveis de diferentes instrumentos com o objetivo de verificar indicadores de validade. Dentre estes, destaca-se o estudo de Xavier (2009), que investigou validade de critério por grupos contrastantes nas técnicas CAT-A, Rorschach e DFH, bem como estudo de precisão entre avaliadores. Já o trabalho de Vilemor Amaral e Cardoso (2012) buscou indicadores de validade convergente para a classificação do Tipo de Vivência no Zulliger, por meio de correlações com um indicador específico do Rorschach. A análise de correlação entre variáveis destes instrumentos revelou, nas referidas pesquisas, assim como ocorreu na presente investigação, evidências positivas de validade entre os instrumentos avaliados, dentro de suas especificidades analíticas.

Para além destes achados que, em seu conjunto, apontam para evidências de validade do Questionário Desiderativo, é relevante refletir sobre as peculiaridades que emergiram a partir destas análises de correlação, em cada um dos grupos de participantes. Muito embora não se constitua como um dos objetivos inicialmente propostos para a presente investigação, foi possível detectar diferenças nos pareamentos entre variáveis com correlações estatisticamente significativas em cada grupo de mulheres. Ou seja, em cada um dos grupos ora avaliados, as variáveis se associaram de maneira distinta.

Deste modo, é possível conjecturar que os instrumentos de avaliação psicológica, utilizados em conjunto, parecem ter possibilitado a identificação de diferenças entre os grupos em termos de processos psicodinâmicos da personalidade. Referidas diferenças não haviam sido detectadas anteriormente, ao se examinar as variáveis de cada um deles, isoladamente. $\mathrm{O}$ uso conjunto dos instrumentos revelou especificidades dos grupos no quesito processos psicodinâmicos, ou seja, todos estão adaptados ao ambiente, mas cada um a sua maneira. Analisando variáveis isoladas (comparando médias nas variáveis, por exemplo), não verificamos diferenças estatisticamente significativas, mas as correlações diferentes nos grupos apontaram estas especificidades.

Deste modo, muito embora os três grupos de participantes tenham refletido igualmente mulheres com desenvolvimento da personalidade compatível com a normalidade, sem marcas psicopatológicas ou de relevantes prejuízos no funcionamento adaptativo, houve peculiaridades em sua forma adaptativa à realidade. Assim, os grupos de participantes diferiram entre si em termos da utilização de recursos internos para regular a afetividade e, assim, adaptar-se ao meio.

Como exemplo desse achado pode-se apontar que, no grupo das pretendentes à adoção (G1), houve indicadores de que um relevante recurso adaptativo utilizado pelas mesmas foi a 
abertura e a valorização dos contatos com o outro, associada à expressão das emoções, fatores significativamente relacionados, neste grupo, à boa utilização da lógica e do raciocínio e também à diminuição da angústia. Por outro lado, este mesmo recurso (contato com o outro), foi mais frequentemente percebido como fonte de angústia pelas pretendentes à adoção, o que sinaliza ambivalência nos contatos por parte destas participantes.

Já no grupo das mães adotivas (G2), o raciocínio lógico e o uso da razão pareceram favorecidos tanto pela abertura aos contatos, como pela sensibilidade afetiva e exteriorização das emoções. Assim, para este grupo de participantes, tomar contato com seus sentimentos e expressá-los favoreceu a capacidade de pensar adequadamente, assim como a proximidade com outras pessoas. Além disso, o distanciamento em relação aos outros foi significativamente mais referido, projetivamente, como fonte de conflito e angústia, para as participantes mães (biológicas ou adotivas). Além disso, a utilização da Idealização enquanto defesa psíquica pareceu, neste grupo de mulheres (G2), funcionar de forma a, por um lado, diminuir a angústia, mas, por outro, a aumentar o nível geral de desconforto psíquico (trata-se de defesa primitiva, com base na negação da realidade).

Enquanto isso, no grupo das mães biológicas (G3), o raciocínio lógico em si não pareceu diretamente favorecido pela abertura aos contatos ou pela exteriorização das emoções. Por outro lado, maior sensibilidade afetiva, bem como a capacidade de coordenar adequadamente ideias e afetos, além da tendência a mostrar aos demais os sentimentos e pensamentos, mostraram-se associadas significativamente, neste grupo de mulheres, à diminuição da angústia, bem como à diminuição de inibições e bloqueios associativos.

Referidos achados refletem evidências empíricas de que os três grupos de mulheres, embora vivenciem igualmente nível suficiente e adequado de adaptação à realidade, possuem funcionamento psicodinâmico com características peculiares neste processo adaptativo. Sendo assim, possuem suas próprias marcas e recursos psicodinâmicos, que, ao menos na presente investigação, variaram conforme sua condição frente à maternidade.

Para além destas considerações, os presentes achados reforçam as recomendações da utilização complementar de diferentes instrumentos de avaliação psicológica (como uma bateria avaliativa) para adequada compreensão dos processos psicodinâmicos subjacentes ao funcionamento da personalidade dos indivíduos. Os resultados ora encontrados trouxeram evidências empíricas de que, juntos, os instrumentos puderam detectar peculiaridades na personalidade destes grupos de mulheres, funcionando conjuntamente de maneira complementar, enriquecendo, assim, o processo avaliativo. 


\section{CONSIDERAÇÕES FINAIS}

Como consideração inicial neste fechamento do trabalho é relevante destacar que os resultados apontaram a boa qualidade das avaliações psicológicas realizadas pela equipe técnica do fórum de Ribeirão Preto, no sentido de selecionaram mulheres com preservado nível geral de saúde mental e adaptativo funcionamento psicodinâmico para adotarem crianças. Assim, a avaliação por meio de instrumentos padronizados confirmou as avaliações psicológicas prévias destas mesmas mulheres, realizadas em sua maioria apenas mediante entrevistas. Há que se pontuar que as pretendentes à adoção e as mães adotivas sinalizaram igualmente estas boas condições emocionais, esperadas para pessoas que acolheram ou deverão acolher crianças com histórico de rompimentos familiares e vitimizações de diversas ordens.

A partir da análise das variáveis dos instrumentos avaliativos utilizados, houve poucos indícios de confirmação das hipóteses teoricamente formuladas para mulheres inférteis à procura de adoção, com base na literatura científica na área. No grupo específico de pretendentes à adoção (G1) pode-se identificar, no Rorschach, maior frequência de respostas do tipo Dbl (espaço branco) e Bot (conteúdo botânico), maior tempo de latência médio, e mais respostas do tipo Hd (conteúdo parcial humano) no cartão IX, comparativamente aos demais grupos. No Desiderativo, por sua vez, observou-se apenas um indicador específico de G1, a saber: maior frequência de Idealização como defesa, comparativamente aos demais grupos. $\mathrm{Na} \mathrm{BFP}$, inexistiram indicadores que apontassem para maior angústia ou sofrimento psíquico em G1, em relação aos outros grupos.

Cumpre reiterar, neste momento, que referidas peculiaridades, sobretudo diante do amplo rol de variáveis analisadas, dificultam hipóteses interpretativas seguras. Diante da baixa frequência de variáveis com diferenças estatisticamente significativas entre os grupos, pode-se considerar que parecem peculiaridades amostrais e casualidades, não exatamente marcas específicas das mulheres avaliadas. Dessa forma, pode-se considerar terem inexistido indicadores consistentes de maior angústia nas pretendentes à adoção (G1) comparativamente às mães adotivas (G2) e às mães biológicas (G3), sugerindo preservação de sua identidade e de sua feminilidade, conforme informações advindas deste trabalho.

Em complemento, há que se apontar que a utilização conjunta dos instrumentos de avaliação psicológica possibilitou a identificação de peculiaridades nos processos psicodinâmicos dos grupos de mulheres aqui avaliados, distintos quanto à sua condição frente à maternidade. Portanto, é possível afirmar que estes resultados demonstraram empiricamente 
as vantagens da utilização conjunta e complementar de instrumentos de avaliação psicológica, já preconizada pela literatura científica da área, agora reiterada também como útil na atuação do psicólogo judiciário, frente a demandas pela adoção de crianças. Além disso, este trabalho apresenta achados empíricos da utilidade dos métodos projetivos de avaliação psicológica para a adequada compreensão das demandas e das necessidades de mulheres, sobretudo aquelas interessadas em adotar uma criança.

Faz-se relevante, nesse momento, apontar também os avanços ora obtidos em termos dos estudos psicométricos envolvendo o Questionário Desiderativo. Os positivos indicadores de fidedignidade, constatados por avaliação independente dos examinadores, reforçam a confiabilidade nas análises realizadas mediante esta proposição avaliativa de Nijamkin e Braude (2000), compilada e organizada por Guimarães, Pasian e Loureiro (2008).

Além disso, cabe destacar que a análise de conteúdo das respostas ao Desiderativo por examinadores experts possibilitou a inclusão, no protocolo de codificação deste instrumento, de cinco mecanismos de defesa, visando a padronizar e otimizar as classificações de respostas a esta técnica. Referido procedimento resultou em favoráveis indicadores de precisão também na avaliação destas defesas, algo que, em estudos anteriores, não havia sido possível, pela diversidade de experiências clínicas e repertório técnico para identificação de defesas de cada avaliador (Guimarães \& Pasian, 2009).

Por último, há que reiterar os indicadores de validade encontrados para o Questionário Desiderativo na presente investigação, por meio da verificação empírica da associação significativa entre variáveis deste instrumento e do Método de Rorschach. Houve também associações estatisticamente significativas entre variáveis do Desiderativo e da Bateria Fatorial de Personalidade que reforçam a concepção de que estes instrumentos de avaliação examinam componentes específicos, porém relacionados, da personalidade. O conjunto destes achados vem contribuir para o alcance das condições mínimas exigidas pelo Conselho Federal de Psicologia para utilização de testes psicológicos no Brasil (SATEPSI), no que tange ao Questionário Desiderativo. A falta de estudos voltados ao exame das características psicométricas desse método projetivo de avaliação psicológica no contexto do Brasil instituiu esse objetivo secundário na presente investigação. Deste modo, no presente momento, coube apontar os avanços obtidos a partir de estudos anteriores realizados pela própria autora com este instrumento.

Cabe aqui ponderar também sobre as dificuldades para comparar os atuais resultados com outros estudos científicos na área. Há escassez de pesquisas voltadas especificamente para o exame de características de personalidade de mulheres envolvidas na adoção de 
crianças, sobretudo mediante a utilização de métodos padronizados de avaliação psicológica. Desse modo, o diálogo entre os achados da presente investigação com a literatura científica disponível foi limitado, tendendo a circunscrevê-los e interpretá-los a partir de suas respectivas premissas teórico-técnicas.

Quanto a limites encontrados neste trabalho faz-se necessário comentar, como primeiro aspecto, o número de participantes de cada grupo $(n=20)$ e da amostra total $(n=60)$. Embora quantitativamente limitada, a amostra foi criteriosamente selecionada, tendo em vista os objetivos do trabalho, de modo que correspondeu a estratégia possível para adequada execução desta pesquisa.

Outro elemento que pode ser apontado como limite do trabalho é seu delineamento transversal, que possibilitou apenas uma avaliação pontual destas mulheres. Sendo assim, não foi possível verificar, por exemplo, prováveis diferenças na avaliação psicológica das mulheres, ora pretendentes à adoção, após se tornarem mães adotivas. É possível conjecturar que a vivência concreta da maternidade adotiva possa suscitar modificações no funcionamento psicodinâmico destas mulheres, algo que somente seria possível avaliar em um estudo longitudinal, com avaliações repetidas em momentos diferentes de vida destas mesmas mulheres.

$\mathrm{O}$ fato das mulheres pretendentes à adoção já terem sido previamente aprovadas pelo Judiciário, estando em fila de espera para a chegada de seu filho adotivo, pode ter contribuído para a constatação de funcionamento psicodinâmico sem marcas específicas relacionadas à infertilidade. Ou seja, estas mulheres já estavam lidando com as questões da ausência de filhos e da impossibilidade de conceber uma criança há alguns anos, e no momento ao menos parte destas perdas já poderiam estar minimamente elaboradas, uma vez que seria apenas uma questão de tempo até se tornarem mães. Além disso, o fato de boas condições de saúde mental e suficiente elaboração da infertilidade serem um pré- requisito comum em avaliações psicológicas para a inserção no cadastro de pretendentes à adoção, exerceu provável influência sobre os resultados ora encontrados.

É possível conjecturar, assim, que os métodos avaliativos utilizados poderiam mais facilmente detectar sinais do sofrimento psíquico diante da impossibilidade de gerar filhos em momentos anteriores de sua vida, tais como durante as avaliações médicas ou tratamento para reprodução assistida, ou logo após a ocorrência de abortos espontâneos ou de infrutíferas tentativas de fertilização. Nestes momentos de sobrecarga de estressores no contexto geral de vida destas mulheres, eventuais (e teoricamente pressupostos) sinais de angústia e/ou sofrimento psíquico (detectáveis por métodos projetivos) poderiam emergir, possibilitando contraste em relação aos demais grupos avaliados. 
Além disso, considerando-se a natureza quantitativa da presente avaliação, com foco na comparação de resultados médios de grupos nas variáveis de cada instrumento, fez com que as peculiaridades psicodinâmicas dos casos individuais fossem insuficientemente exploradas. É relevante ponderar que a realização de estudos de casos, delineados numa vertente avaliativa clínica, poderia examinar de modo minucioso características do funcionamento dinâmico da personalidade destas mulheres, revelando aspectos simbólicos e peculiaridades intrapsíquicas de maneira mais ilustrativa e aprofundada.

Diante destes argumentos, fica o estímulo a novas pesquisas científicas dentro desta temática, sobretudo com delineamentos longitudinais, bem como focalizando momentos distintos da vida destas mulheres que desejam ser mães e encontram obstáculos frente a este objetivo. Fica reforçada, ainda, a relevância de serem realizados estudos com enfoque clínico, que possibilitariam aprofundamento nas temáticas afetivas ligadas à infertilidade e à vivência da maternidade.

Por fim, é possível ponderar que a realização de investigações científicas envolvendo casos em que as adoções não foram bem-sucedidas poderiam fornecer relevantes informações para fundamentar o trabalho dos psicólogos judiciários. Entretanto, trata-se de temática que enseja questões éticas relevantes, dado a provável ansiedade que a retomada desses processos em uma investigação científica poderia disparar, gerando possível sofrimento psíquico nestas pessoas, sendo necessária uma avaliação entre riscos e benefícios inerentes a pesquisas com essa natureza retrospectiva.

Em suma, a partir dos objetivos propostos para o presente trabalho, é possível afirmar que os mesmos foram atingidos, mediante este percurso investigativo. Foi possível obter um panorama descritivo e comparativo das características de personalidade de mulheres inférteis, envolvidas em processos de adoção de crianças (em fila de espera ou com adoção efetivada), em relação a mães biológicas. Em complemento, o estudo evidenciou favoráveis indicadores de precisão e validade para o Questionário Desiderativo, sendo este um objetivo secundário da presente investigação.

Com isto, espera-se ter contribuído para o conhecimento científico que fundamenta ações de psicólogos judiciários no campo da adoção de crianças, bem como para o alcance de indicadores técnicos que possibilitem o uso futuro do Questionário Desiderativo por psicólogos brasileiros, de maneira cientificamente fundamentada. Referidas temáticas, pela complexidade de fatores envolvidos, merecem certamente a continuidade do investimento de pesquisadores na área, buscando garantir a adequada qualidade nos processos avaliativos em Psicologia. 


\section{REFERÊNCIAS}

Anzieu, D. (1986). Os métodos projetivos. (M. L. E. Silva, trad.). (5a ed.). Rio de Janeiro: Campus.

Azoulay, C., Emmanuelli, M., Rausch de Traubenberg, N., Corroyer, D., Rozencwajg, P. \& Savina, Y. (2007). Les données normatives françaises du Rorschach à l'adolescence et chez le jeune adulte. Psychologie Clinique et Projective, 13, 371-409.

Bègue, F. (2013). Grief and adoption: unconscious expectations of adoptive parentes without problem of fertility. Neuropsychiatrie de l'Enfance et de l'Adolescence, 61(2), 106117.

Bejenaru, A.; Roth, M. (2012) Romanian adoptive families: Stressors, coping strategies and resources. Children and Youth Services Review, 34(7), 1317-1324.

Brêga, F. M. P., Frazatto, L., \& Loureiro, S. R. (2001). Pacientes com características paranóides: funcionamento defensivo. Psico USF, 6, 85-94.

Cabrera, A. M. (1999). O Questionário Desiderativo. São Paulo: Casa do Psicólogo.

Callegari, R.; Fusacchia, M. G. \& Re, P. (2012). Fallimento adottivo e crisi adolescenziale: Un destino prevedibile? Interazioni, 2, 40-54.

Campos, N. M. V. \& Costa, L. F. (2004). A subjetividade presente no estudo psicossocial da adoção. Psicologia, Reflexão e Crítica, 17(1), 95-104.

Capitão, C. G., \& Zampronha, M. A. G. (2004). Câncer na adolescência: um estudo com instrumento projetivo. Revista da $S B P H$ [versão eletrônica], 7, 3-16.

Cassin, W. C. (2000). O psicólogo judiciário e a cultura da adoção: Limites, contradições e perspectivas. Dissertação de Mestrado, Faculdade de Filosofia, Cências e Letras de Ribeirão Preto, Universidade de São Paulo, Ribeirão Preto, SP.

Chabert, C. (2004). Psicanálise e Métodos Projetivos. Tradução: Álvaro José Lelé e Eliane Maria Almeida Costa e Silva. 1. ed. São Paulo: Vetor Editora Psico-pedagógica.

Chaves, V. P. (2002). A interação mãe-criança em famílias adotivas: um estudo comparativo. Dissertação de Mestrado. Universidade Federal do Rio Grande do Sul. Porto Alegre, RS. 
Chen, W.; Landau, R. (2015). First childbirth and motherhood at post natural fertile age: A persistent and intergenerational experience of personal and social anomaly? Social Work in Health Care, 54(1), 16-32.

Cohen, R. J.; Swwerdlik, M. E. \& Sturman, E. D. (2014) Testagem e avaliação psicológica: introdução a testes e medidas. 8a ed. Porto Alegre: AMGH.

Cury-Jacquemin, R. P. (2012) Padrões normativos do Psicodiagnóstico de Rorschach em adolescentes de 12 a 14 anos. Dissertação de Mestrado, Faculdade de Filosofia, Ciências e Letras de Ribeirão Preto, Universidade de São Paulo, Ribeirão Preto, SP.

Fabio, E.T.; Melão, M. J. R., \& Jorge, M. R.T. (2005). O Serviço Social e a Psicologia no judiciário. São Paulo: Cortez, $1^{\mathrm{a}}$ Ed.

Felício, J. L. (2002). Sobre a personalidade de homens com disfunção erétil ou ejaculação precoce: estudo comparativo com o Inventário Fatorial de Personalidade, o Questionário Desiderativo e o Teste Estilocrômico. Tese de Doutorado, Universidade de São Paulo, São Paulo (SP).

Fensterseifer, L. \& Werlang, B. S. G. (2008). Apontamentos sobre o status científico das técnicas projetivas. Em: Villemor-Amaral, A. E., Werlang, B. G. (Org.) (2008). Atualizações em métodos projetivos para avaliação psicológica. (1a ed.). São Paulo: Casa do Psicólogo, pp. 15-33.

Fernandes, S. (2010) Normas do Rorschach em crianças de seis a oito anos. Dissertação de Mestrado, Faculdade de Filosofia, Ciências e Letras de Ribeirão Preto, Universidade de São Paulo, Ribeirão Preto, SP.

Fernández-Sola, C.; Martínez-Caba, M. I.; Hernández-Padilla, J. M.; Carmona-Samper, E.; Granero-Molina, J. (2016) Experiences of Spanish women undergoing hysterosalpingography as part of the infertility process: A phenomenological study. Journal of Clinical Nursing, 25(3-4), 494-504.

Fonseca, R.; Silva, P. \& Silva, R. (2007). Acordo inter-juízes: O caso do coeficiente kappa. Instituto Superior de Psicologia Aplicada, Portugal. Laboratório de Psicologia, 5(1), $81-90$.

Franco, R. R. C., \& Villemor-Amaral, A. E. (2009). Ensaios de convergência entre provas de personalidade: Zulliger-SC e Pfister. Tese de Doutorado, Universidade de São Francisco, Itatiba, SP.

Gabbard, G. O. (1998). Psiquiatria psicodinâmica: baseado no DSM IV. Porto Alegre: Artmed, 1998. 
Ghirardi, M. L. A. M. (2008). A presença da Infertilidade no contexto da adoção: efeitos possíveis na relação pais/filhos adotivos. Em: Volich, R.M. Ferraz, F.C. Ranña, W. (Org.) (2008) Psicossoma IV - Corpo, História, Pensamento. São Paulo: Casa do Psicólogo.

Gibson, M. F. (2014) Adopting difference: Thinking through adoption by gay men in Ontario, Canada. Signs, 39(2), 407-432.

Gorgati, S. B., Holcberg, A. S, \& Oliveira, M. D. (2002). Abordagem psicodinâmica no tratamento dos transtornos alimentares. Revista Brasileira de Psiquiatria, 24(Suppl. $3), 44-48$.

Guedes, M.; Canavarro, M. C. (2014) Psychossocial adjustment of couples to first-time parenthood at advanced maternal age: An exploratory longitudinal study. Journal of Reproductive and Infant Psychology, 32(5), 425-440.

Guimarães, N. M., Pasian, S. R., \& Loureiro, S. R. (2008) O Questionário Desiderativo: Possibilidades teóricas e empíricas na atualidade. Em: Villemor-Amaral, A. E.; Werlang, B. S. G. (Org.) (2008). Atualizações em Métodos Projetivos para Avaliação Psicológica. 1 ed. São Paulo: Casa do Psicológo, pp. 391-414.

Guimarães, N. \& Pasian, S. R. (2009). Adequação ao Real de adolescentes: possibilidades informativas do Questionário Desiderativo. Psicologia: Teoria e Pesquisa, 25(3), 347355.

Hauck Filho, N.; Machado, W. L., Teixeira, M. A. P., \& Bandeira, D. (2012). Evidências de validade de marcadores reduzidos para a avaliação da personalidade no modelo dos cinco grandes fatores. Psicologia: Teoria e Pesquisa, 28(4), 417-423.

Huber, M. Z. \& Siqueira, A. C. (2010) Pais por adoção: a adoção na perspectiva dos casais em fila de espera. Psicologia: Teoria e Prática, 12(2), 200-216.

Hutz, C; Bandeira, D. R.; Trentini, C. M. \& Krug, J. S. (2016) Psicodiagnóstico. Porto Alegre: Artmed.

Hutz, C. S., Nunes, C. H., Silveira, A. D., Serra, J.; Anton, M. \& Wieczorek, L. S.. (1998). O desenvolvimento de marcadores para a avaliação da personalidade no modelo dos cinco grandes fatores. Psicologia: Reflexão e Crítica, 11(2), 395-411.

Hutz, C. S. (2009) Avanços e polêmicas em avaliação psicológica. São Paulo: Casa do Psicólogo, v. 1. 
Kaplan, H. I.; Sadock, B. J., \& Grebb, J. A. (1997). Compêndio de psiquiatria: Ciências do comportamento e psiquiatria clínica (7a ed.). Porto Alegre: Artes Médicas

Klevan, M. (2012). Resolving race: How adoptive parents discuss choosing the race of their child. Adoption Quarterly, 15(2), 88-115.

Iwata, H.; Mori, E.; Maekawa, T.; Maehara, K.; Sakajo, A.; Ozawa, H. \& Morita, A. (2012) Developing the Maternity Portfolio to promote maternal role attainment in women who have undergone artificial reproductive treatment. Japan Journal of Nursing Science, 9(2), 122-126.

Jabur, N. M. (2011) Competências Profissionais em Educação Física: relação entre os fatores de personalidade (e suas facetas) e a competência profissional percebida em professores de academia de ginástica. Tese de Doutorado, Faculdade de Filosofia, Ciências e Letras de Ribeirão Preto, Universidade de São Paulo, Ribeirão Preto, São Paulo.

Jardim-Maran, M. L. C. (2011). O Psicodiagnóstico de Rorschach em adolescentes: normas e evidências de validade. Tese de Doutorado, Faculdade de Filosofia, Ciências e Letras de Ribeirão Preto, Universidade de São Paulo, Ribeirão Preto, SP.

Jennings, S., Mellish, L., Tasker, F., Lamb, M., \& Golombok, S. (2014). Why adoption? Gay, lesbian, and heterossexual adoptive parent's reproductive experiences and reasons for adoption. Adoption Quaterly, 17(3), 205-226.

Kite, J. V. (2012). A case for analysis with the baby in the consulting room. Journal of the American Psychoanalytic Association, 60(3), 501-508.

Klevan, M. (2012). Resolving race: How adoptive parents discuss choosing the race of their child. Adoption Quarterly, 15(2), 88-115

Kuo, P. C.; Bowers, B.; Chen, Y. C.; Chen, C. H.; Tzeng, Y. L. \& Lee, M. S. (2013). Maternal-foetal attachment during early pregnancy in Taiwanese women pregnant by in vitro fertilization. Journal of Advanced Nursing, 69(11), 2502-2513.

Laplanche, J. \& Pontalis, J. B. (1996) Vocabulário de Psicanálise. São Paulo: Martins Fontes.

Leben-Loison, L. (2014). L'infertilité comme avatar du lien ravageant fille-mère./Infertility, a vicissitude of relations between daughter and mother, a theorical and clinical study. Cliniques méditerranéennes: Psychanalyse et Psychopathologie Freudiennes, 89(1), 61-74. 
Lee, F. I. \& Matarazzo, E. B. (2001). Prevalência de adoção intra e extrafamiliar em amostras clínica e não-clínica de crianças e adolescentes. Revista Brasileira de Psiquiatria, 23(3), 149-155.

Leve, L. D.; Harold, G.T.; Ge, X.; Neiderhiser, J. M.; Shaw, D.; Caramella, L. V., \& Reiss, D. (2009). Structured Parenting of Toddlers at High versus Low Genetic Risk: Two Pathways to Child Problems. Journal of the American Academy Child and Adolescent Psychiatry, 48(11), 1102-1109.

Levinzon, G. K. (2006). A adoção na clínica psicanalítica: O trabalho com os pais adotivos. Mudanças - Psicologia da Saúde, 14(1), 24-31.

Lins, P. G. A.; Patti, E. A. M. R.; Peron, A. C. \& Barbieri, V. (2014) O sentido da maternidade e da infertilidade: um discurso singular. Estudos de Psicologia, 31(3), 387-392.

Lipscomb, S.T.; Leve, L.D.; Shaw, D.S.; Neiderhiser, J.M.; Scaramella, L.V.; Ge, X.; Conger, R.D.; Reid, J.B., \& Reiss, D. (2012). Negative emotionality and externalizing problems in toddlerhood: Overreactive parenting as a moderator of genetic influences. Development and Psychopathology, 24, 167-179.

Mansur-Alves, M.; Silva, R. S., \& Fernandes, S. C. A. (2016). Impacto da Criação do Sistema de Avaliação dos Testes Psicológicos (SATEPSI) para as Publicações Científicas em Avaliação Psicológica. Psico-USF, 21(1), 179-188.

Mariano, F. N. \& Rossetti-Ferreira, M. C. (2008) Que perfil da família biológica e adotante, e da criança adotada revelam os processos judiciais? Psicologia: Reflexão $e$ Crítica, 21(1), 11-19.

Marôco, J. (2011). Análise estatística com o SPSS Statistics. (5a ed.). Pêro Pinheiro: Report Number.

Maux, A. A. B. \& Dutra, E. (2009). Do útero à adoção: a experiência de mulheres férteis que adotaram uma criança. Estudos de psicologia. Natal, 14, (2), 113-121.

Monzani, S. (2015). Filiations en IAD. Réflexions sur l'IAD a partir de la psychothérapie d'un enfant. La Psychiatrie de l'Enfant, 58(1), 103-138.

Mortensen, L. Le.; Hegaard, H. K.; Andersen, A. N. \& Bentzen, J. G. (2012). Attitudes towards motherhood and fertility awareness among 20-40-year-old female healthcare professionals. The European Journal of Contraception and Reproductive Health Care, $17(6), 468-481$. 
Mott, S. L.; Schiller, C. E.; Richards, J. G.; O’Hara, M. W., \& Stuart, S. (2011). Depression and anxiety among postpartum and adoptive mothers. Archives of Women's Mental Health, 14(4), 335-343.

Nascimento, F. R. M. \& Térzis, A. (2010). Adiamento do projeto parental: um estudo psicanalítico com casais que enfrentam a esterilidade. Psicologia em Revista, 16(1), 103-124.

Nijamkin, G. C. \& Braude, M. G. (2000). O Questionário Desiderativo (L. S. L. P. C. Tardivo, trad.). São Paulo: Vetor (Trabalho original publicado em 1996).

Nascimento, R. S. G. F. (2002). Estudo normativo do sistema compreensivo do Rorschach para a cidade de São Paulo. Psico-USF, 7(2), 127-141.

Noronha, A. P. P \& Vendramini, C. M. M. (2003). Parâmetros psicométricos: estudo comparativo entre testes de inteligência e de personalidade. Psicologia: Reflexão e Crítica, 16(1), 177-182.

Noronha, A. P. P.; Primi, R., \& Alchieri, J. C. (2005). Instrumentos de avaliação mais conhecidos/utilizados por psicólogos e estudantes de Psicologia. Psicologia: Reflexão e Crítica, 18(3), 390-401.

Nunes, C. H. S., Hutz, C. S., \& Giacomoni, C. H. (2009). Associação entre bem-estar subjetivo e personalidade no modelo dos cinco grandes fatores. Avaliação Psicológica, 8(1), 99-108.

Nunes, C. H. S. S.; Hutz, C. S., \& Nunes, M. F. O. (2010). Bateria Fatorial de Personalidade (BFP): manual técnico. São Paulo: Casa do Psicólogo.

Nunes, C. H. S. S. \& Primi, R (2010). Aspectos técnicos e conceituais da ficha de avaliação dos testes psicológicos. Em: Conselho Federal de Psicologia - CFP (Org.) (2010) Avaliação psicológica: diretrizes na regulamentação da profissão (101-128). Brasília: CFP.

Ocampo, M. L. S., Arzeno, M. E. G., \& Piccolo, E. G. (1985). O Processo diagnóstico e as técnicas projetivas (M. Felzenszwalb, Trad.). São Paulo: Martins Fontes (Trabalho original publicado em 1979).

Oliveira, K. L.; Noronha, A. P. P.; Dantas, M. A., \& Santarem, E. M. (2005). O psicólogo comportamental e a utilização de técnicas e instrumentos psicológicos. Psicologia em Estudo, 10(1), 127-135. 
Oliveira, R. A. (2000) Do vínculo às relações sociais: Aspectos psicodinâmicos. Análise Psicológica, 2(XVIII), 157-170.

Otuka, L. K.; Scorsolini-Comin, F. \& Santos, M. A. (2012). Adoção suficientemente boa: experiência de um casal com filhos biológicos. Psicologia: Teoria e Pesquisa, 28(1), 55-63.

Pace, C. S.; Santona, A.; Zavattini, G. C., \& Di Folco, S. (2014). States of mind with respect to attachment to the caregiver and the parter of couples during the pre-adoption assessment. Giornale Italiano di Psicologia, 41(2), 347-364.

Paiva, L. D. (2004). Adoção: significados e possibilidades. São Paulo: Casa do psicólogo, $1^{\mathrm{a}}$ Ed.

Pasian, S. R. (2000). O Psicodiagnóstico de Rorschach em adultos: Atlas, normas e reflexões. São Paulo: Casa do Psicólogo.

Patias, N. D. \& Buais, C. S. (2012). "Tem que ser uma escolha da mulher"! Representações de maternidade em mulheres não-mães por opção. Psicologia \& Sociedade, 24(2), 300306.

Paulo, M. S. L. L. (2005). Psicodiagnóstico e intervenção terapêutica de pacientes adultos com depressão. Em: Instituto Brasileiro de Avaliação Psicológica (Org.) (2005). Resumos do II Congresso Brasileiro de Avaliação Psicológica - Desafios para a formação, prática e pesquisa, pp. 2-3. Porto Alegre: Instituto Brasileiro de Avaliação Psicológica.

Pemberton, C.K.; Neiderhiser, J.M.; Leve, L.D.; Natsuaki, M.N.; Shaw, D.S.; Reiss, D., \& Ge, X. (2010). Influence of parental depressive symptoms on adopted toddler behaviors: An emerging developmental cascade of genetic and environmental effects. Development and Psychopathology, 22, 803-818.

Pianowski, G. \& Villemor-Amaral, A. E. (2010). Localização e qualidade formal do Rorschach-SC no Brasil: validade com não-pacientes. Psico-USF, 15(3), 333-343.

Primi, R. \& Nunes, C. H. S. S. (2010). O SATEPSI: propostas de aprimoramento. Em Conselho Federal de Psicologia - CFP (Org.) (2010) Avaliação psicológica: diretrizes na regulamentação da profissão, pp. 129-148. Brasília: CFP.

Ramírez-Gálvez, M. (2009). Corpos fragmentados e domesticados na reprodução assistida. Cadernos Pagu, 33, 83-115. 
Raspantini, R. L. (2010). Psicodiagnóstico de Rorschach em crianças de nove a 11 anos: normas e evidências de validade. Dissertação de Mestrado, Faculdade de Filosofia, Ciências e Letras de Ribeirão Preto, Universidade de São Paulo, Ribeirão Preto, SP.

Rausch de Traubenberg, N. (1998). A prática do Rorschach. (A. J. Lelé, trad.). São Paulo: Vetor.

Riggins-Caspers, K.M.; Cadoret, R.J.; Knutson, J.F., \& Langbehn, D. (2003). Biology Environment Interaction and Evocative Biology-Environment Correlation: Contributions of Harsh Discipline and Parental Psychopathology to Problem Adolescent Behaviors. Behavior Genetics, 33(3), 205.

Roisko, R.; Wahlberg, K-E.; Hakko, H.; Wynne, L., \& Tienari, P. (2011). Communication deviance in parents of families with adoptees at a high or low risk of schizophrenia spectrum disorders and its associations with attributes of the adoptee and the adoptive parents. Psychiatry Research, 185, 66-71.

Rosa, D. B. (2008). A narratividade da experiência adotiva: fantasias que envolvem a adoção. Psicologia Clínica, 20(1), 97-110.

Santos, K. O. B; Araújo, T. M., \& Oliveira, N. F. (2009). Estrutura fatorial e consistência interna do Self-Reporting Questionnaire (SRQ-20) em população urbana. Cadernos de Saúde Pública, 25(1), 214-222.

Scorsolini-Comin, F., Amato, L. M., \& Santos, M. A. (2006). Grupo de apoio para casais pretendentes à adoção: a espera compartilhada do futuro. Revista da SPAGESP, 7(2), 40-50.

Shine, S. (2005). Avaliação psicológica e a lei: adoção, vitimização, separação conjugal, dano psíquico e outros temas. São Paulo: Casa do Psicólogo.

Silva, I. B. \& Nakano, T. C. (2011). Modelo dos cinco grandes fatores da personalidade: análise de pesquisas. Avaliação Psicológica, 10(1), 51-62.

Simmel, C. (2007). Risk and Protective Factors Contributing to the Longitudinal Psychosocial Well-Being of Adopted Foster Children. Journal of Emotional and Behavioral Disorders, 15(4), 237 - 249.

Sonego, J. C. \& Lopes, R. C. S. (2009). A experiência da maternidade em mães adotivas. Aletheia, 29, 16-26.

South, S. C.; Foli, K. J., \& Lim, E. (2013). Predictors of relationship satisfaction in adoptive mothers. Journal of Social and Personal Relationship, 30(5), 545-563. 
Tardivo, L. S. L. P. C. (1999). A estruturação do ego: o estudo do grau de estruturação do ego de profissionais de saúde através do Questionário Desiderativo. Revista da Vetor Editora, 1, 28-34.

Trindade, Z. A. \& Enumo, S. R. F. (2002). Triste e Incompleta: Uma Visão Feminina da Mulher Infértil. Psicologia USP (São Paulo), 13(2), 151-182.

Van Zyl, L. \& Walker, R. (2013) Beyond altruistic and commercial contract motherhood: The professional model. Bioethics, 27(7), 373-381.

Villemor-Amaral, A. E. \& Cardoso, L. M. (2012) Validade convergente do tipo de vivência (EB) no Teste de Zulliger/SC. PSICO, 43(1), 109-115.

Wasinski, A. (2015). The experience of adoption in a biographical narration of adoptive parentes. Archives of Psychiatry and Psychotherapy, 17(1), 59-67.

Weiner, I. B. (1991). Editor's note: interscorer agreement in Rorschach research. Journal of Personality Assessment, 56, 1.

Weiner, I. B. (2000). Princípios da Interpretação do Rorschach. Tradução M. Cecília Vilhena M. Silva. São Paulo: Casa do Psicólogo.

Weismann-Arcache, C. (2013) Les mauvaises graines: Retentissement des problématiques d'infertilité sur le jeu des identifications croisées parents/enfants. Dialogue: Recherches sur le couple et la famille, 199, 33-41.

Werlang, B. S. G.; Villemor-Amaral, A. E., \& Nascimento, R. S. G. F. (2010). Avaliação psicológica, testes e possibilidades de uso. Em: Conselho Federal de Psicologia (2010). Avaliação Psicológica: diretrizes na regulamentação da profissão, pp. 87100. Brasília: CFP.

Xavier, M. F. (2009) Evidências de validade do CAT-A e Rorschach para avaliação da cognição. Tese de Doutorado, Universidade São Francisco, Itatiba - SP. 
ANEXOS

ANEXO 1

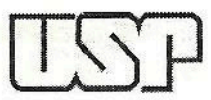

Universidade de São Paulo

Faculdade de Filosofia, Ciência e Letras de Ribeirão Preto

Departamento de Psicologia - Programa de Pós-graduação em Psicologia

Centro de Pesquisas em Psicodiagnóstico (CPP)

\section{CARTA DE APRESENTAÇ̃̃O}

Estamos desenvolvendo uma pesquisa em Ribeirão Preto (SP), intitulada "Maternidade adotiva e infertilidade: contribuições da avaliação psicológica" que tem por objetivo identificar e analisar características de personalidade de mulheres que procuram a adoção de crianças. Este trabalho será desenvolvido sob responsabilidade de Nicole Medeiros Guimarães Eboli, psicóloga judiciária nesta comarca, e aluna de Doutorado em Psicologia na Faculdade de Filosofia, Ciências e Letras de Ribeirão Preto (FFCLRP) da Universidade de São Paulo (USP), e da Prola. Dra. Sonia Regina Pasian, professora do Departamento de Psicologia desta mesma Faculdade.

Essa pesquisa estudará cerca de 40 mulheres envolvidas em processo de adoção de crianças, nesta cidade. Visto que os procedimentos legais relativos à adoção sc encontram centralizados nesta Vara da Infância, Juventude e Idoso, gostaríamos de contar com a colaboração de V. Excelência no sentido de autorizar o acesso desta pesquisadora a dados constantes em autos relativos ao cadastro de pretendentes à adoção.

Nossa atuação consistirá em consultas a processos judiciais relativos aos procedimentos para habilitação para adoção, a partir dos quais serão selecionadas possívcis participantes da pesquisa, com base nos critérios do estudo (detalhados em cópia do projeto anexa a esta carta). Com base nos dados de cadastro destas mulheres, entraremos em contato telefônico com as mesmas e explicaremos o projeto em linhas gerais, convidando-as a participarem voluntariamente da pesquisa. Será fornecida, para cada participante, um Termo de Consentimento Livre e Esclarecido para a pesquisa, documento que deverá ser devidamente lido e, caso concorde, assinado pela voluntária em duas vias, uma para a pesquisadora e outra para a participante do estudo.

Em seguida, a pesquisadora agendará diretamente com a participante um horário e um local em que possa realizar as atividades desta pesquisa. Scrão realizadas atividades de avaliação psicológica, processo que poderá ser realizado na própria casa da participante, caso prefira, ou no Centro de Psicologia Aplicada da FFCLRP-USP. Nesse contato, que durará cerca de 90 minutos, a pesquisadora fará uma breve conversa com cada participante e aplicará os instrumentos de avaliação psicológica que consistirão em responder a questionários sobre escolhas variadas do cotidiano e falar sobre opiniões a respeito de cartões com imagens específicas, próprias para este tipo de investigação. Não existe nenhum risco significativo em participar deste estudo, a não ser o próprio tempo e o investimento pessoal nas atividades, sendo que estas não interferirão nos procedimentos legais para habilitação e adoção de crianças. Todas as informações utilizadas são confidenciais e somente serão utilizadas para investigação científica, sem nenhuma identificação das pessoas que as forneceram.

A cooperação desta Vara da Infância e Juventude será imprescindívcl para que os objetivos deste estudo sejam alcançados. Este trabalho será uma contribuição voluntária e nenhum participante receberá pagamento por colaborar nesta pesquisa. As participantes poderão desistir da pesquisa a qualquer momento do trabalho, bem como solicitar os esclarecimentos adicionais que julgar necessários. Não reccberá nenhum benefício dircto por sua participação neste trabalho, embora este tipo de estudo seja útil para aprimorar os serviços psicológicos oferecidos neste contexto de trabalho 
em momento futuro. Assim, colaborar com essa pesquisa representa contribuir para um melhor conhecimento das condições psicológicas das pretendentes à adoção dessa região e isso poderá auxiliar em futuros processos de avaliação e cm planejamentos de intervenções psicológicas junto a esta população.

Desde já, agradecemos a atenção dispensada.

Cordialmente,

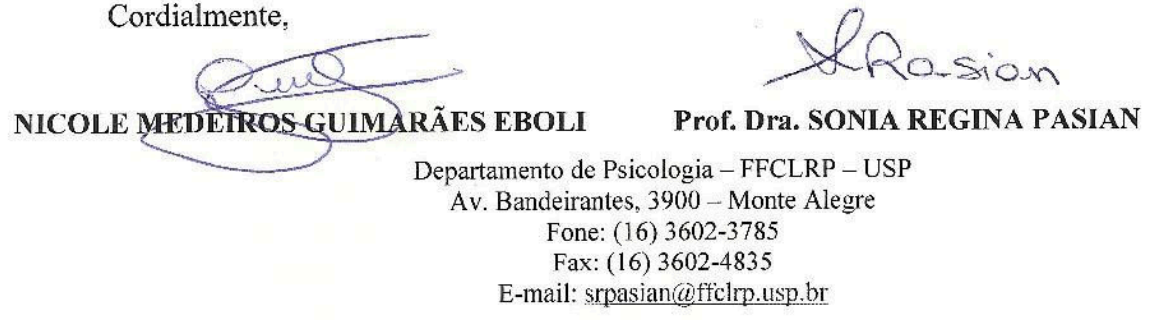

DECLARAÇÃO DE CONSENTIMENTO DA INSTITUIÇÃO JUDICIÁRIA PARA A PESQUISA

Eu, Dr. PAUlo CÉSAR GENTILE, RG $\$ 3.483914$, abaixo assinado, na função de Juiz de Direito da Vara da Infância, Juventude e Idoso de Ribeirão Preto, declaro estar de acordo com a realização do projeto de pesquisa "Matcrnidade adotiva e infertilidade", aceitando que sejam consultados, pela psicóloga judiciária responsável pela pesquisa, processos judiciais relativos à habilitação para adoção, a fim de buscar as informações necessárias à identificação de eventuais participantes voluntárias para a mesma. Autorizo também que a psicóloga responsável pelo projeto entre em contato telcfônico com essas participantes, para lhes propor o trabalho.

Diante do exposto, assino o presente termo, enquanto representante da Vara da Infância, Juventude e Idoso de Ribeirão Preto, declarando o consentinento livre e esclarecido para esta pesquisa.

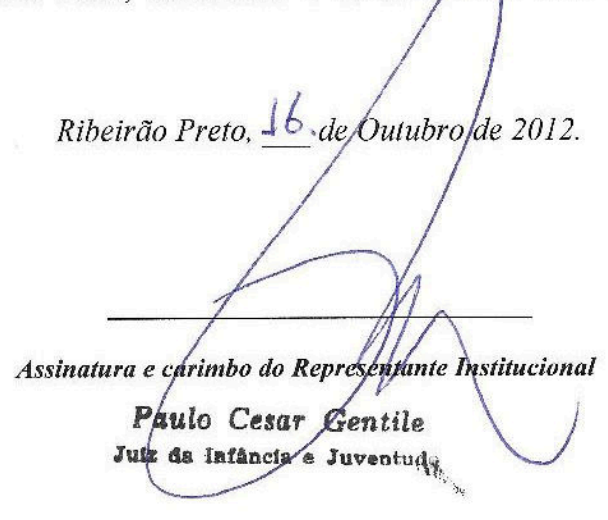




\section{ANEXO 2}

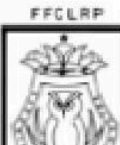

\section{FACULDADE DE FILOSOFIA, CIÊNCIAS E LETRAS DE RIBEIRÃO PRETO- USP}

Psicologia em sua atuação na área.

Considerações sobre os Termos de apresentação obrigatória:

Estão todos anexados e preenchidos adequadamente.

Recomendações:

Foram atendidas as recomendações solicitadas no parecer anteriormente realizado.

Conclusões ou Pendências e Lista de Inadequações:

Desta forma o projeto encontra-se aprovado.

Situação do Parecer:

Aprovado

Necessita Apreciação da CONEP:

Não

Considerações Finais a critério do CEP:

O projeto encontra-se APROVADO para execução. Pedimos atenção aos seguintes itens:

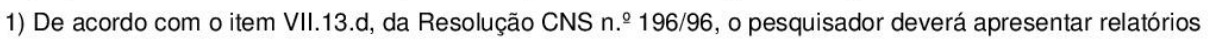
anuais (parciais ou finais, em função da duração da pesquisa).

2) Eventuais emendas (modificações) ao protocolo devem ser apresentadas, com justificativa, ao CEP de forma clara e sucinta, identificando a parte do protocolo a ser modificada.

RIBEIRAO PRETO, 29 de Abril de 2013

Assinador por:

Andréia Schmidt

(Coordenador)

Endereço: Av. Bandeirantes 3.900

Bairro: Monte Alegre

UF: SP Município: RIBEIRAO PRETO

Telefone: (16)3602-4811 Fax: (16)3633-2660 E-mail: coetp@ffclrp.usp.br 


\section{APÊNDICES}

\section{APÊNDICE A}

Universidade de São Paulo

Faculdade de Filosofia, Ciência e Letras de Ribeirão Preto

Departamento de Psicologia - Centro de Pesquisas em Psicodiagnóstico (CPP)

Av. Bandeirantes, 3900 - Monte Alegre - Ribeirão Preto (SP) - Fone: 3602-3785 ou 3602-3821

\section{TERMO DE CONSENTIMENTO LIVRE E ESCLARECIDO}

Estamos desenvolvendo uma pesquisa em Ribeirão Preto, cujo título é: "Maternidade adotiva e infertilidade: contribuições da Avaliação Psicológica", que pretende conhecer características do desenvolvimento emocional de mulheres que desejam ser mães adotivas e que tenham dificuldades para engravidar. Este trabalho será desenvolvido sob responsabilidade da psicóloga Nicole Medeiros Guimarães Eboli, aluna de Doutorado em Psicologia da Faculdade de Filosofia, Ciências e Letras de Ribeirão Preto (FFCLRP) da Universidade de São Paulo (USP) e da Profa. Dra. Sonia Regina Pasian, professora do Departamento de Psicologia desta mesma faculdade.

Essa pesquisa estudará cerca de 40 mulheres de Ribeirão Preto, que aguardam seu filho adotivo ou que já adotaram. Também participarão do estudo outras 20 mulheres que já tiveram seus filhos biológicos. O Fórum de Ribeirão Preto irá colaborar conosco nesta pesquisa. Desta forma, gostaríamos de contar com sua colaboração, como voluntária ao estudo. Cada mulher selecionada passará por uma breve avaliação psicológica, sendo que este processo implica em que a participante responda a perguntas sobre seu jeito de ser, além de interpretação de figuras com manchas imprecisas, e também outras perguntas que solicitarão o uso da imaginação, não apresentando riscos ou prejuízos para ela. O tempo estimado para realização destas atividades é de aproximadamente 90 minutos, sendo agendado conforme suas possibilidades. As atividades poderão ser interrompidas a qualquer momento do trabalho, bem como o consentimento poderá ser retirado em qualquer etapa do estudo, sem qualquer implicação e prejuízo a você.

Todas as informações desta pesquisa são confidenciais e somente serão utilizadas para investigação científica, sem nenhuma identificação das pessoas que as forneceram. A sua cooperação será muito valiosa e necessária para tornar possível esta pesquisa. Não será oferecido às participantes desta pesquisa nenhum pagamento por sua colaboração neste trabalho. Colaborar com essa pesquisa poderá ajudar a conhecer as características afetivas das pretendentes à adoção de Ribeirão Preto e isso poderá auxiliar no trabalho futuro envolvendo processos de adoção de crianças nesta região.

Desde já, agradecemos sua colaboração e estaremos disponíveis para outras informações, caso necessário.

Atenciosamente,

\section{Nicole Medeiros Guimarães Eboli \\ (CRP: 06/79113)}

\section{Profa. Dra. Sonia Regina Pasian}

(CRP: 06/24018-0)

$\mathrm{Eu}$,

declaro que concordo em participar como voluntária no projeto de pesquisa

"Maternidade adotiva e infertilidade:contribuições da Avaliação Psicológica", sob responsabilidade da psicóloga Nicole Medeiros Guimarães Eboli e da Profa. Dra. Sonia Regina Pasian, assim como estou ciente de que os registros relativos a esse trabalho serão utilizados como material de trabalho científico e poderão ser divulgados em congressos e publicados em revistas ou livros especializados, resguardando-se o devido sigilo quanto à minha identificação.

Ribeirão Preto, de de 201

Telefone para contato em caso de dúvidas adicionais: 16-8185-3711.

(Assinatura) 


\section{APÊNDICE B}

\section{PROTOCOLO DE CLASSIFICAÇÃO DO QUESTIONÁRIO DESIDERATIVO}

NOME:

SEXO:

ESCOLARIDADE:

DATA DE APLICAÇÃO:

APLICADOR:

TEMPO DE APLICAÇÃO:

1) ADEQUAÇÃO AO REAL

\begin{tabular}{|c|c|c|c|c|}
\hline $\begin{array}{c}\text { ADEQUAÇÃO AO } \\
\text { REAL }\end{array}$ & $\begin{array}{c}\text { TEMPO DE REAÇÃO } \\
\text { MÉDIO }\end{array}$ & $\begin{array}{c}\text { SEQUENCIA DAS } \\
\text { ESCOLHAS }\end{array}$ & $\begin{array}{c}\text { NECESSIDADE DE } \\
\text { INDUÇÃO }\end{array}$ & $\begin{array}{c}\text { RESPOSTAS } \\
\text { ANTROPOMÓRFICAS }\end{array}$ \\
\hline Catexes + & & & & \\
& & & & \\
Catexes - & & & & \\
& & & & \\
\hline
\end{tabular}

2) FUNCIONAMENTO LÓGICO

\begin{tabular}{|c|c|c|c|}
\hline $\begin{array}{c}\text { FUNCIONAMENTO } \\
\text { LÓGICO }\end{array}$ & $\begin{array}{c}\text { CONTEÚDO DO } \\
\text { PENSAMENTO }\end{array}$ & $\begin{array}{c}\text { NÍVEL DE } \\
\text { ORGANIZAÇÃO }\end{array}$ & $\begin{array}{c}\text { DISTINCCÃO ENTRE REALIDADE } \\
\text { INTERNA E EXTERNA }\end{array}$ \\
\hline Catexes + & & & \\
& & & \\
\hline Catexes - & & & \\
& & & \\
\hline
\end{tabular}

3) MANIFESTAÇÕES AFETIVAS

\begin{tabular}{|c|c|c|c|}
\hline $\begin{array}{c}\text { MANIFESTAÇÕES } \\
\text { AFETIVAS }\end{array}$ & AUTO-PERCEPÇÃO & $\begin{array}{c}\text { ASSOCIAÇÃO } \\
\text { IDEO-AFETIVA }\end{array}$ & INTERAÇÕES \\
\hline Catexes + & & & \\
\hline Catexes - & & & \\
\hline
\end{tabular}

4) SIGNIFICADO SIMBÓLICO

\begin{tabular}{|c|c|}
\hline CATEXES POSITIVAS & CATEXES NEGATIVAS \\
\hline 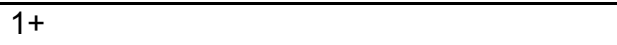 & 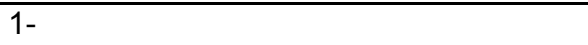 \\
\hline $2+$ & $2-$ \\
\hline
\end{tabular}




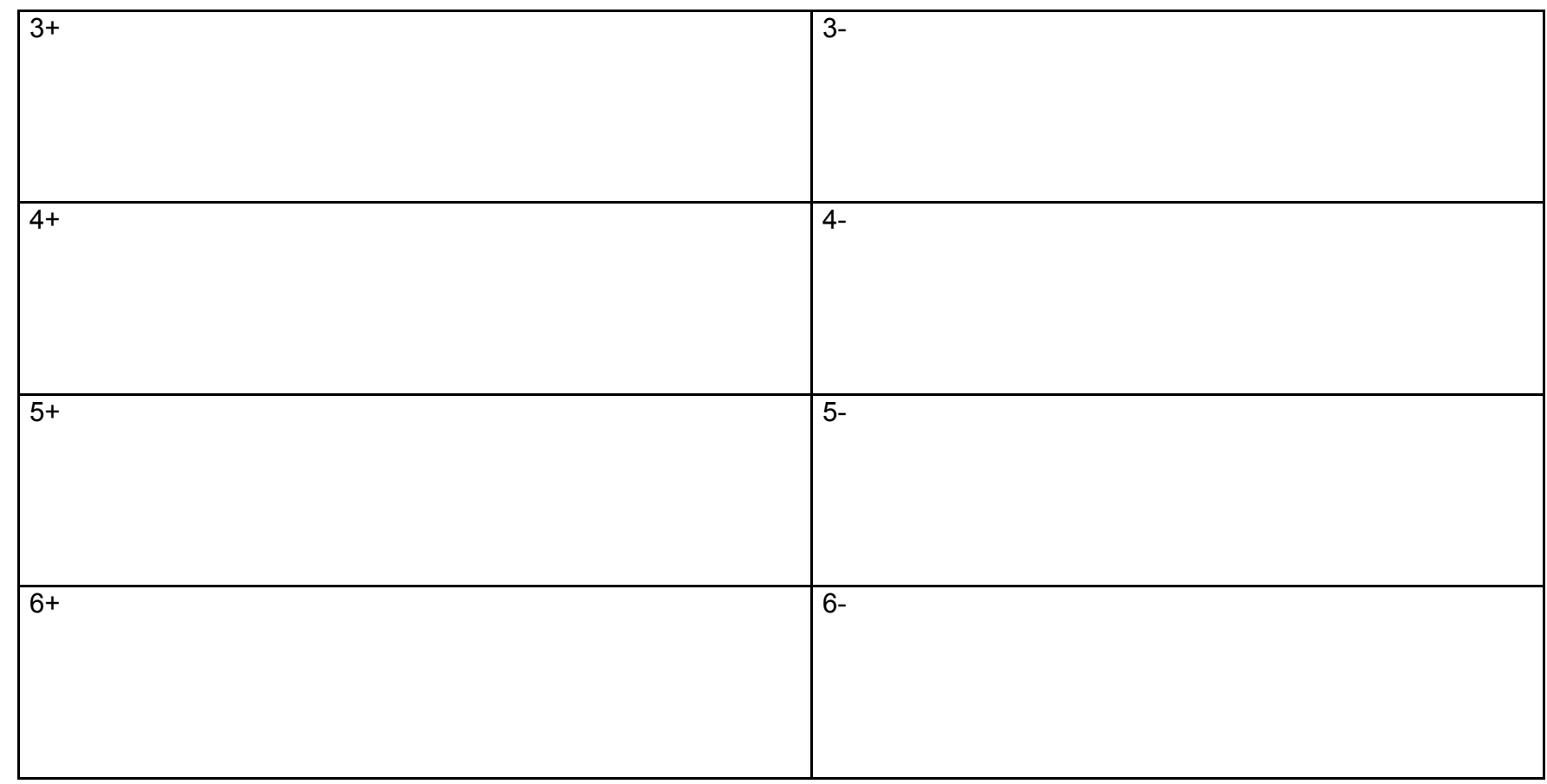

5) DEFESAS INSTRUMENTAIS E MECANISMOS DEFENSIVOS PREDOMINANTES

\begin{tabular}{|c|c|c|c|c|}
\hline DEFESAS & \multicolumn{3}{|c|}{ DEFESAS INSTRUMENTAIS } & $\begin{array}{c}\text { MECANISMOS } \\
\text { DEFENSIVOS } \\
\text { PREDOMINANTES }\end{array}$ \\
\hline & DISSOCIAÇÃO & $\begin{array}{c}\text { IDENTIFICAÇÃO } \\
\text { PROJETIVA }\end{array}$ & RACIONALIZAÇÃO & \\
\hline CATEXES + & & & & \\
\hline & & & & \\
CATEXES - & & & & \\
\hline
\end{tabular}

6) SÍNTESE DO FUNCIONAMENTO PSICODINÂMICO

\begin{tabular}{|c|c|}
\hline $\begin{array}{c}\text { CATEXES POSITIVAS / RECURSOS DE } \\
\text { INTEGRAÇÃO }\end{array}$ & CATEXES NEGATIVAS / FONTES DE CONFLITO \\
\hline & \\
& \\
\hline
\end{tabular}




\section{APÊNDICE C}

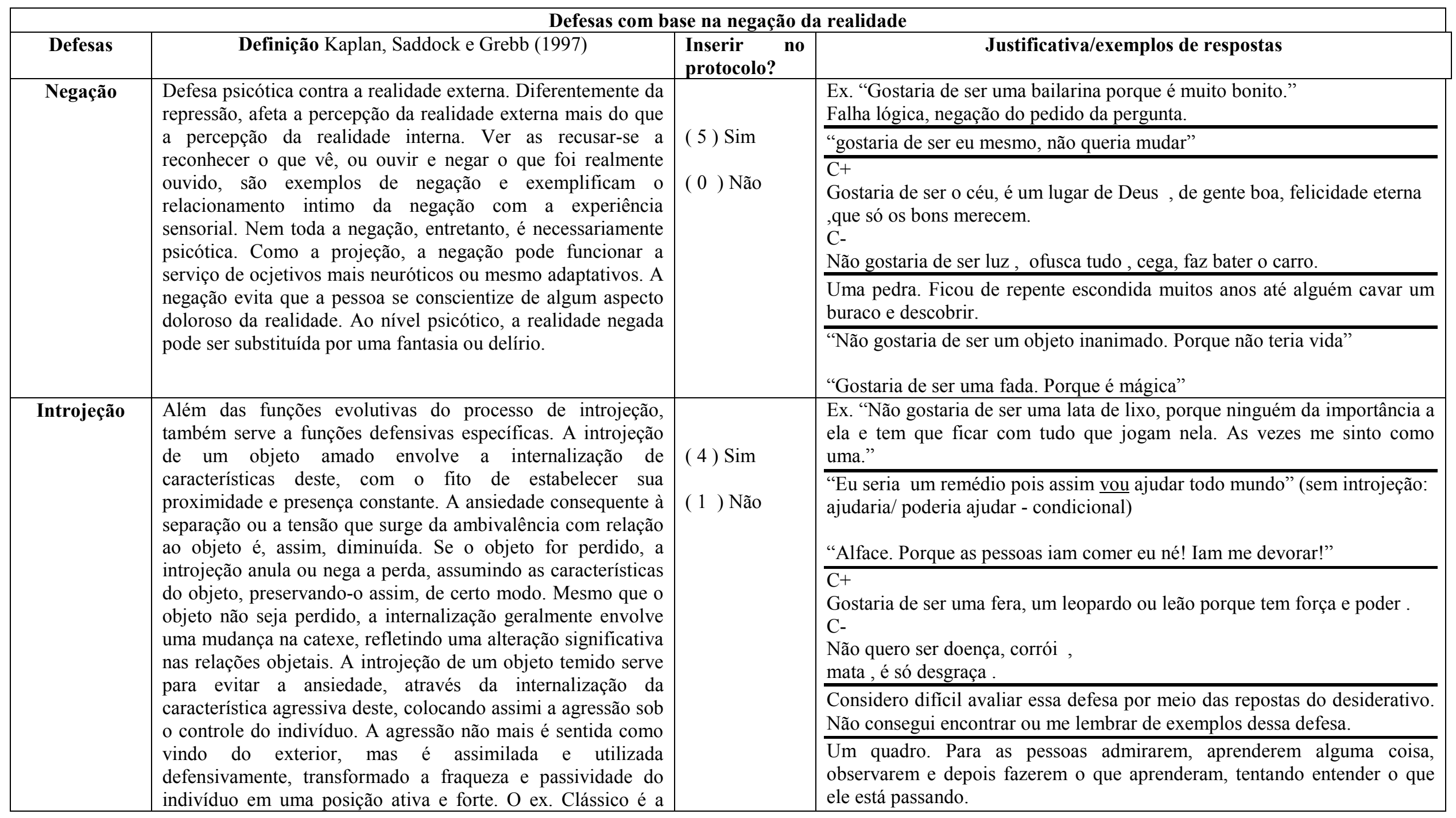




\begin{tabular}{|c|c|c|c|}
\hline & $\begin{array}{l}\text { identificação com o agressor. A introjeção também pode } \\
\text { surgir de um sentimento de culpa, no qual o introjeto de } \\
\text { autopunição é atribuível ao componente hostile destrutivo do } \\
\text { vínculo ambivalente com um objeto. Assim, as qualidades } \\
\text { autopunitivas do objeto são assumidas e estabelecidas dentro } \\
\text { do próprio indivíduo, como sintoma ou traço de caráter que } \\
\text { representa, efetivamente, tanto a destruição quanto a } \\
\text { preservação do objeto, o que também é chamado de } \\
\text { identificação com a vítima. }\end{array}$ & & \\
\hline \multirow[t]{5}{*}{ Projeção } & \multirow{5}{*}{$\begin{array}{l}\text { Perceber ou reagir a impulsos internos inaceitáveis e a seus } \\
\text { derivativos como se estivessem fora do self. Em um nível } \\
\text { psicótico, toma a forma de francos delírios sobre a realidade } \\
\text { externa, geralmente delírios de perseguição, incluindo a } \\
\text { percepção dos próprios sentimentos em outra pessoa, com } \\
\text { subsequente ação sobre a percepção (delírios psicóticos } \\
\text { paranóides). Os impulsos podem derivar-se do id ou do } \\
\text { superego (recriminações alucinatórias), mas podem sofrer } \\
\text { transformações no processo. Assim, de acordo com a análise } \\
\text { de Freud sobre as projeções paranóides, os impulsos libidinais } \\
\text { homossexuais são transformados em ódio e então projetados } \\
\text { no objeto do impulso homossexual inaceitável. Atribuir aos } \\
\text { outros os próprios sentimentos inadmitidos; inclui sério } \\
\text { preconceito, rejeição da intimidade através da suspeita, } \\
\text { excessiva cautela contra os perigos externos e coleção de } \\
\text { injustiças. A projeção opera em correlação com a introjeção, } \\
\text { de modo que o material da projeção deriva da configuração } \\
\text { internalizada dos introjetos. Em níveis superiores de } \\
\text { funcionamento, a projeção pode tomar a forma de comparação } \\
\text { ou interpretação errônea dos motivos, atitudes, sentimentos ou } \\
\text { intenções de outros. }\end{array}$} & \multirow{5}{*}{ (5) $\mathrm{Sim}$} & Ex. Não gostaria de ser uma cobra, porque é perigosa, falsa e traiçoeira. \\
\hline & & & $\begin{array}{l}\text { Aqui tenho uma certa dúvida, já que a projeção é naturalmente requerida } \\
\text { pela tarefa. Contudo, como na introjeção, a referência: } \\
\text { "Não queria ser um burro de carga pois ele é explorado explorado pelas } \\
\text { pessoas" - (e não: eu seria explorado...) }\end{array}$ \\
\hline & & & $\begin{array}{l}+ \\
\text { Gostaria de ser uma planta carnívora, impõe respeito, é mais que especial, } \\
\text { é diferente de todas as outras. } \\
\text { C- } \\
\text { Não gostaria de ser óculos, é um objeto que vê tudo, o que quer e o que não } \\
\text { quer }\end{array}$ \\
\hline & & & $\begin{array}{l}\text { "Não gostaria de ser uma faca. Para não machucar ninguém" } \\
\text { "Um gato, porque parece um animal traiçoeiro" } \\
\text { "Um vírus. Porque tem vida curta e faz mal para todo mundo, é nocivo..." }\end{array}$ \\
\hline & & & Um rato. Porque é sujo, fica se escondendo, ninguém gosta dele. \\
\hline \multirow[t]{4}{*}{$\begin{array}{l}\text { Identificação } \\
\text { projetiva }\end{array}$} & \multirow{4}{*}{$\begin{array}{l}\text { Aspectos indesejáveis do self são depositados em outrem, de } \\
\text { modo que a pessoa que os projeta sente-se como se fosse uma } \\
\text { só, com o objeto da projeção. Os aspectos expelidos são } \\
\text { modificados e recuperados, a partir daquele sobre quem foram } \\
\text { projetados. Esta defesa permite que o indivíduo se distancie e } \\
\text { se faça entender, exercendo pressão sobre outra pessoa, para }\end{array}$} & \multirow{4}{*}{$\begin{array}{l}\text { ( } 3 \text { ) Sim } \\
\text { ( } 1 \text { ) Não } \\
\text { ( } 1 \text { ) Não sei }\end{array}$} & $\begin{array}{l}\text { Ex. "Não gostaria de ser uma pedra, porque fica ali jogada, muda. Não } \\
\text { gosto de ser jogada de um canto para o outro." }\end{array}$ \\
\hline & & & "Insetos, pois assim como eu eles são desvalorizados pelas pessoas! \\
\hline & & & $\begin{array}{l}\text { Considero que a projeção contem } \\
\text { essa defesa ,e também é difícil diferenciá-la da projeção. }\end{array}$ \\
\hline & & & "Um raio. Porque ele causa muitos danos" \\
\hline
\end{tabular}




\begin{tabular}{|c|c|c|c|}
\hline & que esta experimente sentimentos similares aos seus. & & $\begin{array}{l}\text { PS: Considero difícil a distinção entre Projeção e IP por meio das repostas } \\
\text { ao instrumento. Acho que a avaliação da IP tem mais a ver com a qualidade } \\
\text { da resposta do que com seu conteúdo, o que fica difícil explicar através de } \\
\text { exemplo. } \\
\text { Um rio. Porque ele sempre segue em frente, é que eu gostaria de sempre r } \\
\text { em frente, alcançar objetivos. }\end{array}$ \\
\hline \multirow[t]{5}{*}{ Idealização } & \multirow{5}{*}{$\begin{array}{l}\text { Através deste mecanismo, os objetos externos que são vistos } \\
\text { como "completamente bons" ou "completamente maus" são } \\
\text { irrealisticamente dotados de grande poder. Mais comumente, o } \\
\text { objeto "completamente bom" é visto como onipotente ou } \\
\text { ideal, enquanto a maldade do objeto "completamente mau" é } \\
\text { imensamente inflamada. }\end{array}$} & \multirow{5}{*}{$\begin{array}{l}\text { (5) Sim } \\
\text { (0) Não }\end{array}$} & $\begin{array}{l}\text { Ex. "Gostaria de ser uma pomba da paz porque é tudo de bom, tudo de bem, } \\
\text { só traz sorte o bem, só coisas boas pra gente." }\end{array}$ \\
\hline & & & $\begin{array}{l}\text { "Cachorro - tem vida mansa e vida boa. Tem comida a hora que quer, pode } \\
\text { fazer o que quiser" }\end{array}$ \\
\hline & & & $\begin{array}{l}\mathrm{C}+ \\
\text { Gostaria de ser uma sequoia, frondosa, daquelas que } 10 \text { pessoas juntas não } \\
\text { abraçam, vive séculos depois que o mundo acabar. } \\
\text { C- } \\
\text { Não gostaria de ser um vírus que mata, como o ebola ,mata é implacável } \\
\text {,vence a medicina e a vida. }\end{array}$ \\
\hline & & & $\begin{array}{l}\text { "A natureza. A natureza é tudo... é o mais importante" } \\
\text { "Uma bola, porque a bola é chutada" }\end{array}$ \\
\hline & & & $\begin{array}{l}\text { Um leão. Porque falam que ele é o rei da selva. Por ser um dos animais } \\
\text { mais fortes que existem. }\end{array}$ \\
\hline \multirow[t]{4}{*}{$\begin{array}{l}\text { Clivagem } \\
\text { (splitting) }\end{array}$} & \multirow{4}{*}{$\begin{array}{l}\text { Os objetos externos são divididos em "completamente bons" e } \\
\text { "completamente maus", juntamente com a mudança abrupta } \\
\text { de um pbjeto de uma categoria extrema para outra, podendo } \\
\text { ocorrer a inversão súbita e completa dos sentimentos e } \\
\text { conceitualizações acerca de uma pessoa. A extrema oscilação } \\
\text { repetitiva entre autoconceitos contraditórios é uma outra } \\
\text { manifestação deste mecanismo. }\end{array}$} & \multirow{4}{*}{$\begin{array}{l}\text { ( } 4 \text { ) Sim } \\
\text { ( } 1 \text { ) Não }\end{array}$} & $\begin{array}{l}\text { Ex. "Não gostaria de ser uma ponte porque todos pisam nela, mas apesar } \\
\text { disso ela é muito importante porque ajuda a atravessar." }\end{array}$ \\
\hline & & & $\begin{array}{l}\text { "Um gato. Eu odeio gato. Ele pensa que é o dono da gente e o cachorro não, } \\
\text { ele pensa que a gente é o dono dele" } \\
\text { "Um anjo. Porque não sobra muitas opções. Se você não é uma pessoa você } \\
\text { seria um demônio ou um anjo" }\end{array}$ \\
\hline & & & $\begin{array}{l}\mathrm{C}+ \\
\text { Queria muito ser um diamante precioso, lindo ,valioso, mas hoje, ele é de } \\
\text { risco ,atrai disputas, roubo ,perigo ,cobiça. } \\
\text { C- } \\
\text { Hospital, não gostaria de ser, tem muita doença, sofrimento, mas é lugar } \\
\text { de cura de recuperação. }\end{array}$ \\
\hline & & & $\begin{array}{l}\text { Acredito que a clivagem tem mais relação com a clivagem do ego. Também } \\
\text { acho difícil exemplificar. } \\
\text { Talvez a comparação entre as catexes positivas e negativas possa ser }\end{array}$ \\
\hline
\end{tabular}




\begin{tabular}{|c|c|c|c|}
\hline & & & $\begin{array}{l}\text { interessante para observar a clivagem no conjunto do teste, mas não em } \\
\text { uma resposta única e específica. }\end{array}$ \\
\hline & & & $\begin{array}{l}\text { Nossa! Ser um anjo, cuidar de uma pessoa, um anjo de alguém, claro, um } \\
\text { anjo e não um demônio. }\end{array}$ \\
\hline \multirow[t]{4}{*}{$\begin{array}{c}\text { Atuação } \\
\text { (acting-out) }\end{array}$} & \multirow{4}{*}{$\begin{array}{l}\text { Expressão direta de um desejo ou impulso inconsciente, a fim } \\
\text { de evitar a consciência do afeto concomitante. A fantasia } \\
\text { inconsciente, envolvendo objetos, é manifestada } \\
\text { impulsivamente no comportamento, gratificando, deste modo, } \\
\text { mais o impulso do que sua proibição. Em nível crônico, a } \\
\text { atuação implica ceder aos impulsos para evitar a tensão que } \\
\text { resultaria do adiamento de sua expressão. }\end{array}$} & \multirow{4}{*}{ ( 4 ) $\mathrm{Sim}$} & $\begin{array}{l}\text { Ex. "Gostaria de ser uma abelha para picar bem ardido todo mundo que eu } \\
\text { não gosto." }\end{array}$ \\
\hline & & & $\begin{array}{l}\text { C+ } \\
\text { De verdade, gostaria de ser uma onça pintada ,é livre, ninguém se mete } \\
\text { com ela, ameaça ,pega ,come e assim vive. } \\
\text { C- } \\
\text { Não gostaria de ser um tsunami, um vulcão explodindo, como aquele que } \\
\text { passou na TV, destrói a face da terra ,não deixa nada inteiro, age e pronto } \\
\text {,acabou. }\end{array}$ \\
\hline & & & $\begin{array}{l}\text { "Um gavião. Porque ele é bonito, eu gosto (o que você gosta?) quando ele } \\
\text { pega pintinho" }\end{array}$ \\
\hline & & & $\begin{array}{l}\text { A Aids. É algo maléfico para nós e para a sociedade. Imagina você } \\
\text { descobrir que estão se protegendo contra você e que você ta matando as } \\
\text { pessoas. Eu não gostaria. }\end{array}$ \\
\hline \multirow[t]{5}{*}{ Regressão } & \multirow{5}{*}{$\begin{array}{l}\text { Um retorno a um estágio anterior do desenvolvimento ou } \\
\text { funcionamento, para evitar as ansiedades ou hostilidades } \\
\text { envolvidas em estágios posteriores. Um retorno a pontos } \\
\text { anteriores de fixação envolvendo modos de comportamento já } \\
\text { abandonados, frequentemente em consequencia de uma } \\
\text { ruptura no equilíbrio e uma fase posterior do } \\
\text { desenvolvimento. Reflete uma tendência básica a adquirir a } \\
\text { gratificação dos instintos ou escapar à tensão instintiva pelo } \\
\text { retorno a modos e níveis de gratificação anteriores, quando os } \\
\text { modos posteriores e mais diferenciados fracassam. }\end{array}$} & \multirow{5}{*}{ ( 3 ) Sim } & $\begin{array}{l}\text { Ex. "Gostaria de ser um pintinho pra ficar debaixo da asa da mãe no } \\
\text { quentinho." }\end{array}$ \\
\hline & & & $\begin{array}{l}\text { "Minha cachorra. Porque ela é como um bebê! Cuido dela, alimento, levo } \\
\text { para passear todo dia, dou carinho" }\end{array}$ \\
\hline & & & $\begin{array}{l}\text { Considero difícil avaliar, pois a definição pressupõe comparação no tempo } \\
\text { e a aplicação ocorre em tempo único. }\end{array}$ \\
\hline & & & $\begin{array}{l}\text { Também acho difícil conseguir exemplos isolados. Talvez seja um } \\
\text { mecanismo que precise ser avaliado no CONJUNTO das respostas, e } \\
\text { também tendo em consideração o estágio evolutivo do paciente (inclusive } \\
\text { sua idade, concretamente). } \\
\text { Possibilidade de exemplos (oralidade): } \\
\text { "Um coelho. Porque come bastante" }\end{array}$ \\
\hline & & & Uma cama, por ter sempre alguém por perto, cuidando, acariciando. \\
\hline
\end{tabular}




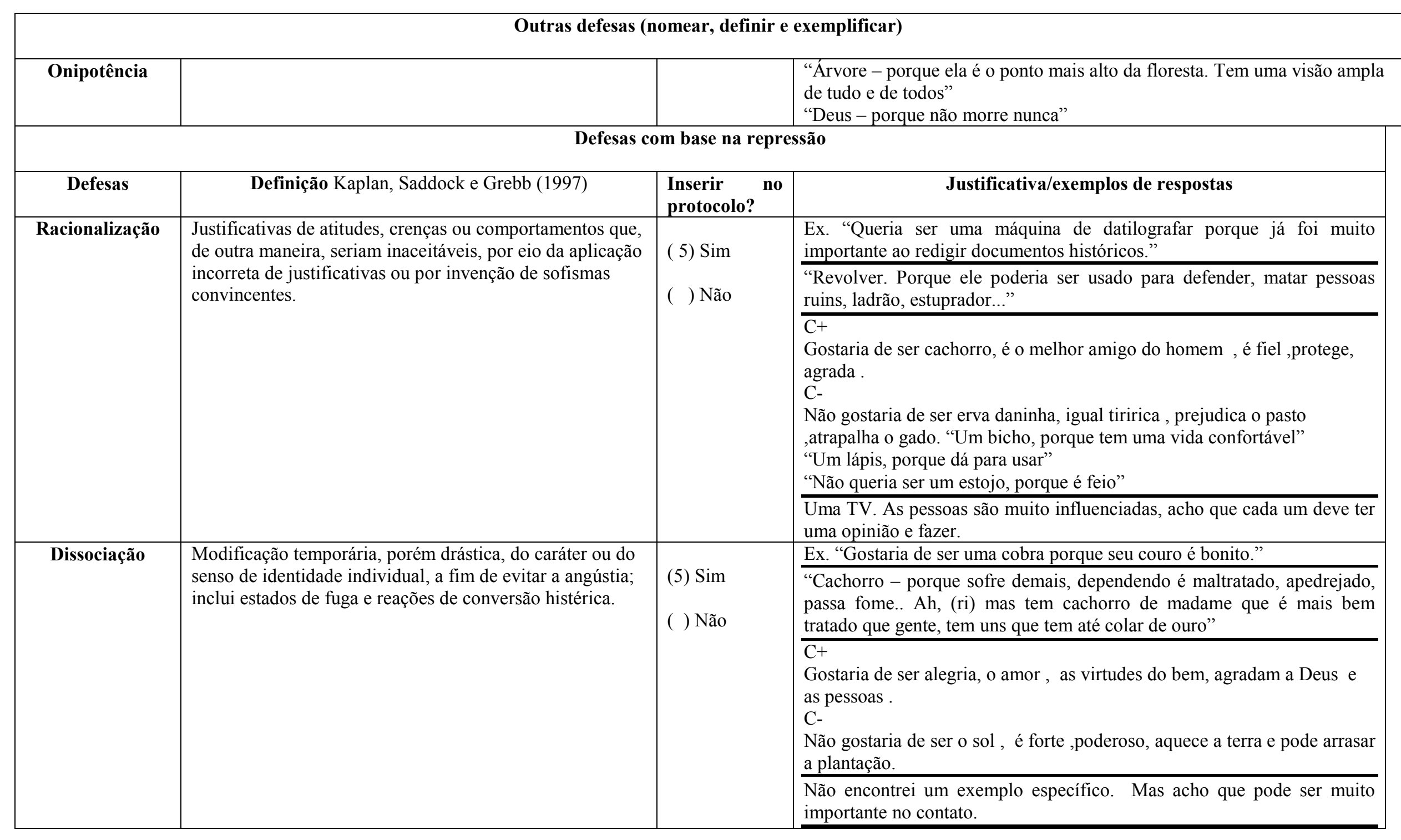




\begin{tabular}{|c|c|c|c|}
\hline & & & $\begin{array}{l}\text { Um sentimento, o amor, eu sou muito passional. Eu não vou muito pela } \\
\text { razão, vou mais pelo coração, eu acho que às vezes você precisa ir pela } \\
\text { razão, mas quando vai pelo coração é mais gratificante. }\end{array}$ \\
\hline \multirow[t]{5}{*}{ Inibição } & \multirow{5}{*}{$\begin{array}{l}\text { Limitação ou renúncia inconscientemente determinada de } \\
\text { funções específicas do ego, isoladamente ou em } \\
\text { combinação, para evitar a ansiedade originada do conflito } \\
\text { com impulsos instintuais, conflitos, humor, atitudes e } \\
\text { estilo de pensamento. É um mecanismo mais geral que a } \\
\text { projeção, que é definida por sua derivação e correlação } \\
\text { com introjetos específicos. }\end{array}$} & \multirow{5}{*}{$\begin{array}{l}\text { ( } 4 \text { ) Sim } \\
\text { ( } 0 \text { ) Não } \\
\text { (1 ) Não sei }\end{array}$} & Ex. “...Não sei, não consigo imaginar, não sei responder.” \\
\hline & & & $\begin{array}{l}\text { Aqui tenho dúvida.. pensei que resposta do tipo: "Não sei, não sei.. não } \\
\text { sei mesmo - classificada como fracasso lógico poderia ser também uma } \\
\text { atitude de inibição frente a tarefa. Um exemplo que talvez caiba: "Pedra, } \\
\text { pois não tem vida, é uma coisa parada" }\end{array}$ \\
\hline & & & $\begin{array}{l}\text { C+ } \\
\text { Gostaria de ser um cavalo de carroça, só porque é útil. } \\
\text { C- } \\
\text { Não gostaria der qualquer planta ,porque vira semente /muda e assim, } \\
\text { outra planta ,sem parar nunca. }\end{array}$ \\
\hline & & & $\begin{array}{l}\text { Não estou segura de que esse seja um bom exemplo. Ou se estou fazendo } \\
\text { uma interpretação incorreta do conceito. Será que teria algo a ver com } \\
\text { "restrição"??? (pensei no capítulo sobre restrição do ego, da Anna Freud) } \\
\text { "uma trepadeira. Porque fica grudada em todo lugar' } \\
\end{array}$ \\
\hline & & & $\begin{array}{l}\text { Um bicho nojento, um sapo. Não gosto de sapo, ele não tem } \\
\text { relacionamento, não faz nada, fica vegetando. }\end{array}$ \\
\hline \multirow[t]{5}{*}{ Deslocamento } & \multirow{5}{*}{$\begin{array}{l}\text { Envolve uma substituição proposital e inconsciente de um } \\
\text { objeto por outro, no interesse de resolver um conflito. } \\
\text { Embora o objeto tenha sido mudado, a natureza instintual } \\
\text { do impulso e sua finalidade permanecem inalterados. }\end{array}$} & \multirow{5}{*}{$\begin{array}{l}\text { ( } 2 \text { ) Sim } \\
\text { ( } 1 \text { ) Não } \\
\text { ( 2) Não } \\
\text { sei }\end{array}$} & $\begin{array}{l}\text { Ex. "Não gostaria de ser um leão, não quer dizer não gostaria de ser uma } \\
\text { raposa porque é selvagem pode atacar." }\end{array}$ \\
\hline & & & Não tenho exemplo \\
\hline & & & $\begin{array}{l}\text { C+ } \\
\text { O sol ,é o que gostaria ,tem brilho próprio, não depende de outros. } \\
\text { C- } \\
\text { Não gostaria de ser a lua, é só reflexo,não existe de fato ,depende do } \\
\text { sol. }\end{array}$ \\
\hline & & & $\begin{array}{l}\text { Acho difícil pensar em exemplos. } \\
\text { Segue uma resposta, em que o deslocamento poderia estar relacionado à } \\
\text { inadequação da característica atribuída ao objeto escolhido, como se } \\
\text { estivesse "deslocado", a serviço de outra função: } \\
\text { "Um cavalo (por quê?) Não sei..... porque não pede dinheiro para } \\
\text { ninguém..." }\end{array}$ \\
\hline & & & Não consegui exemplificar, pensar na sua expressão em respostas no QD. \\
\hline
\end{tabular}




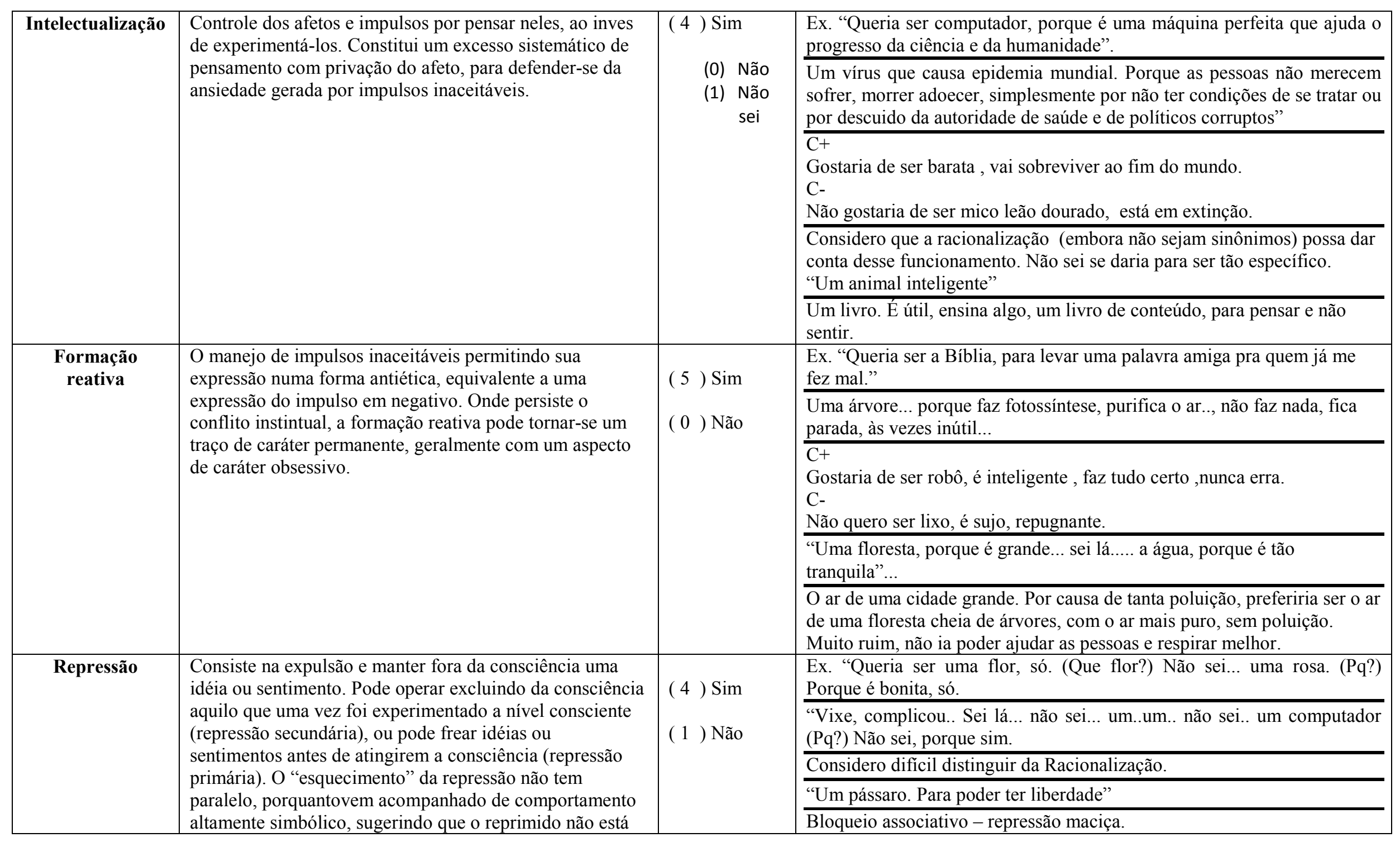




\begin{tabular}{|c|c|c|c|}
\hline & totalmente esquecido. & & $\begin{array}{l}\text { "Um animal, um pássaro. Voar sem rumo, pra qualquer lugar. Ir onde eu } \\
\text { quiser." }\end{array}$ \\
\hline \multirow[t]{5}{*}{ Anulação } & \multirow{5}{*}{$\begin{array}{l}\text { Uma pessoa simbolicamente faz ao contrário algo } \\
\text { inaceitável que já foi feito; é uma forma de ação expiatória } \\
\text { mágica. }\end{array}$} & \multirow{5}{*}{$\begin{array}{l}\text { (4) Sim } \\
\text { ( } 1 \text { ) Não }\end{array}$} & $\begin{array}{l}\text { Ex. "Gostaria de ser uma vela. Porque ascender velas e orar nos redime } \\
\text { dos pecados e nos livra do castigo de Deus." }\end{array}$ \\
\hline & & & $\begin{array}{l}\text { "Aranha e rato. É nojento, transmite doença. Mas rato eu dou um } \\
\text { desconto porque tem um valor na evolução, por isto dou um desconto" }\end{array}$ \\
\hline & & & $\begin{array}{l}\text { C+ } \\
\text { Gostaria de ser um burro chucro, selvagem ,um desafio para ser } \\
\text { amansado. } \\
\text { C- } \\
\text { Não gostaria de ser um documento, um papel rasgado, porque ele quebra } \\
\text {,apaga o acontecido. }\end{array}$ \\
\hline & & & Não consegui exemplificar respostas no QD. \\
\hline & & & $\begin{array}{l}\text { "Queria ser um pássaro. Porque eu tenho medo de voar e como pássaro } \\
\text { eu poderia voar" } \\
\text { (exemplo de contra-investimento.... penso que está relacionado com a } \\
\text { anulação, mas gostaria de saber se concordam...) }\end{array}$ \\
\hline \multirow[t]{5}{*}{ Sedução } & \multirow{5}{*}{$\begin{array}{l}\text { Tentativa de exercer controle sobre o outro pela } \\
\text { exacerbação de atributos impactantes relacionados à } \\
\text { beleza, atratividade, entre outros (a melhorar - não sei } \\
\text { explicar como esta defesa atuaria de forma a eliminar } \\
\text { ansiedades ligadas a impulsos específicos). }\end{array}$} & \multirow{5}{*}{$\begin{array}{l}\text { ( 5) Sim } \\
\text { ( } 0 \text { ) Não }\end{array}$} & $\begin{array}{l}\text { Ex. "Gostaria de ser uma rosa, porque é bonita, admirável. Com ela você } \\
\text { conquista. É a flor dos amantes apaixonados." }\end{array}$ \\
\hline & & & $\begin{array}{l}\text { "Uma joia rara. Vc seria um objeto caro e muitos gostaria de ter! } \\
\text { "Rosa - porque todo mundo venera uma rosa, bonita, cheirosa, } \\
\text { agradável..." }\end{array}$ \\
\hline & & & $\begin{array}{l}\text { C+ } \\
\text { Gostaria de ser rosa, é linda ,tem um perfume especial, todo mundo } \\
\text { admira ,gosta. } \\
\text { C- } \\
\text { Não gostaria de ser agua viva, do mar ,é linda ,de muita cores ,atrai ,mas } \\
\text { pode queimar. }\end{array}$ \\
\hline & & & $\begin{array}{l}\text { "Uma rosa, porque é cheirosa" } \\
\text { "Uma estrela, porque brilha, todos acham bonita" } \\
\text { "um gato, porque é fofinho" }\end{array}$ \\
\hline & & & Uma maçã, por ser bonita, todo mundo gosta dela. \\
\hline \multirow[t]{2}{*}{ Sexualização } & \multirow{2}{*}{$\begin{array}{l}\text { Dotar um objeto ou função de um significado sexual que } \\
\text { realmente nao possui ou que existe em menor grau, para } \\
\text { afetar ansiedades ligadas a impulsos proibidos. }\end{array}$} & \multirow{2}{*}{$\begin{array}{l}\text { (4) Sim } \\
\text { ( } 1 \text { ) Não }\end{array}$} & Ex. "Gostaria de ser um batom. Gosto do formato, da cor, acho sexy." \\
\hline & & & "Um carro. Quem sabe um loirão comprava eu!" \\
\hline
\end{tabular}




\begin{tabular}{|c|c|c|c|}
\hline & & & Considero difícil distinguir da Sedução. \\
\hline & & & $\begin{array}{l}\text { Considero uma avaliação importante, mas não encontrei um exemplo } \\
\text { específico. }\end{array}$ \\
\hline & & & $\begin{array}{l}\text { Uma rosa, porque é uma planta que mexe com os sentimentos, acho que a } \\
\text { cor vermelha é apaixonante. }\end{array}$ \\
\hline \multirow[t]{5}{*}{ Sublimação } & \multirow{5}{*}{$\begin{array}{l}\text { Gratificação de um impulso cuja finalidade é preservada, } \\
\text { mas cujo alvo ou objeto é convertido de socialmente } \\
\text { objetável em socialmente valorizado. A sublimação } \\
\text { libidinal implica em uma dessexualização dos impulsos } \\
\text { instintuais e a colocação de um juízo de valor que } \\
\text { substitua a valoração do superego ou da sociedade. A } \\
\text { sublimação dos impulsos agressivos ocorre através de } \\
\text { jogos ou esportes prazerosos. Ao contrário das defesas } \\
\text { neuróticas, a sublimação permite que os instintos sejam } \\
\text { canalizados, ao invés de represados ou desviados. Na } \\
\text { sublimação, os sentimentos são reconhecidos, modificados } \\
\text { e dirigidos para uma pessoa ou finalidade importante, } \\
\text { resultando daí uma modesta satisfação instintual. }\end{array}$} & ( 5 ) Sim & $\begin{array}{l}\text { Ex. "Gostaria de ser uma escultura. Porque a arte é muito rica e muito } \\
\text { importante para a cultura na humanidade." }\end{array}$ \\
\hline & & (1) Não & $\begin{array}{l}\text { "gostaria de ser uma vacina da AIDS, pois assim as pessoas não seriam } \\
\text { mais contaminadas e não morreriam mais desta doença" }\end{array}$ \\
\hline & & & $\begin{array}{l}\mathrm{C}+ \\
\text { Gostaria de ser uma obra de arte, como Guerra e Paz, nela a vida é plena } \\
\text {,linda. } \\
\text { C- } \\
\text { Não gostaria de ser carro de Fórmula } 1 \text { é muito rápido ,pode provocar } \\
\text { acidente,morte. }\end{array}$ \\
\hline & & & $\begin{array}{l}\text { Também tenho dificuldade para pensar em exemplos que pudessem } \\
\text { indicar esse mecanismo. } \\
\text { Considero que o tipo de tarefa do Desiderativo favorece esse tipo de } \\
\text { avaliação da sublimação. }\end{array}$ \\
\hline & & & $\begin{array}{l}\text { Um livro. Porque através do livro as pessoas podem ver o mundo com } \\
\text { outros olhos. O livro abre caminho para o conhecimento. }\end{array}$ \\
\hline \multicolumn{4}{|c|}{ Outras defesas (nomear, definir e exemplificar) } \\
\hline Distanciament & $\begin{array}{l}\text { Tendência ao afastamento e isolamento do indíviduo, } \\
\text { este se afasta das pessoas ou da situação conflitiva. } \\
\text { Ex. "Gostaria de ser um pássaro, para voar e estar lá } \\
\text { em cima no céu, longe das pessoas e desse mundo". } \\
\text { (Exemplo de resposta de intelectualização retirado do } \\
\text { material compilado para treinamento das } \\
\text { aprimorandas em psicologia para avaliação } \\
\text { psicodiagnóstica do HCFMRP-USP) }\end{array}$ & Sim & $\begin{array}{l}\text { Embora este mecanismo não seja literalmente um dos que estão listados } \\
\text { no Kaplan, referência que vocês estão usando, acho interessante haja } \\
\text { vista que este tipo de defesa pode estar presente em personalidades } \\
\text { obsessiva, esquizoide e psicopática (segundo material compilado no } \\
\text { treinamento do Desiderativo para o aprimoramento). Mas se só quiserem } \\
\text { trabalhar com os mecanismos do Kaplan, penso que este pode ser } \\
\text { representado pela "Repressão". Embora esse seja o conceito básico e não } \\
\text { destaque tanto esta tendência ao escapismo. Sugeri este mecanismo } \\
\text { porque tb era bastante frequente encontramos nos protocolos do } \\
\text { Desiderativo do HC. }\end{array}$ \\
\hline
\end{tabular}




\begin{tabular}{|c|l|l|}
\hline Distanciamento & $\begin{array}{l}\text { (Eu teria que pensar melhor no termo correto para } \\
\text { nomear essa "defesa". Talvez vocês estejam mais } \\
\text { indicadas para incluir esse funcionamento. } \\
\text { Na verdade, não sei se é uma defesa ou não, mas sei } \\
\text { que o desiderativo sempre me ajudou muito a avaliar, } \\
\text { de forma qualitativa, o nível de envolvimento ou } \\
\text { relacionamento com as pessoas. No caso desses } \\
\text { exemplos, eles me indicavam esse "afastamento" }\end{array}$ & "um animal....porque não precisa das pessoas..." \\
\hline
\end{tabular}




\section{APÊNDICE D}

\section{PROTOCOLO DE CLASSIFICAÇÃO DO QUESTIONÁRIO DESIDERATIVO}

NOME:

SEXO:

DATA DE APLICAÇÃO:

APLICADOR:

\section{1) ADEQUAÇÃO AO REAL}

\begin{tabular}{|c|c|c|c|c|}
\hline $\begin{array}{c}\text { ADEQUAÇÃO AO } \\
\text { REAL }\end{array}$ & $\begin{array}{c}\text { TEMPO DE REAÇÃO } \\
\text { MÉDIO }\end{array}$ & $\begin{array}{c}\text { SEQUENCIA DAS } \\
\text { ESCOLHAS (A, V, } \\
\text { O, REC, ANT) }\end{array}$ & $\begin{array}{c}\text { NECESSIDADE DE } \\
\text { INDUÇÃO } \\
\text { (S ou N e pq) }\end{array}$ & $\begin{array}{c}\text { RESPOSTAS } \\
\text { ANTROPOMÓRFICAS } \\
\text { (S ou N e listar) }\end{array}$ \\
\hline Catexes + & & & & \\
\hline Catexes - & & & & \\
\hline
\end{tabular}

2) FUnCIONAMENTO LÓgICO

ESCOLARIDADE:

REG:

TEMPO DE APLICAÇÃO

\begin{tabular}{|c|c|c|c|}
\hline $\begin{array}{c}\text { FUNCIONAMENTO } \\
\text { LÓGICO }\end{array}$ & $\begin{array}{c}\text { CONTEÚDO DO } \\
\text { PENSAMENTO } \\
\text { (Lógico ou llógico) }\end{array}$ & $\begin{array}{c}\text { NÍVEL DE } \\
\text { ORGANIZAÇÃO } \\
\text { (Concreto ou abstrato) }\end{array}$ & $\begin{array}{c}\text { DISTINÇÃO ENTRE REALIDADE } \\
\text { INTERNA E EXTERNA } \\
\text { (Adequada ou Inadequada) }\end{array}$ \\
\hline Catexes + & & & \\
\hline Catexes - & & & \\
& & & \\
\hline
\end{tabular}


3) MANIFESTAÇõES AFETIVAS

\begin{tabular}{|c|c|c|c|}
\hline $\begin{array}{c}\text { MANIFESTAÇÕES } \\
\text { AFETIVAS }\end{array}$ & $\begin{array}{c}\text { AUTO-PERCEPÇÃO } \\
\text { (Valorizada ou } \\
\text { desvalorizada) }\end{array}$ & $\begin{array}{c}\text { ASSOCIAÇÃO } \\
\text { IDEO-AFETIVA } \\
\text { (Associada ou dissociada) }\end{array}$ & $\begin{array}{c}\text { INTERAÇÕES } \\
\text { (Aproximação ou } \\
\text { distanciamento) }\end{array}$ \\
\hline Catexes + & & & \\
\hline Catexes - & & & \\
\hline
\end{tabular}

4) DEFESAS INSTRUMENTAIS E MECANISMOS DEFENSIVOS PREDOMINANTES

\begin{tabular}{|c|c|c|c|c|}
\hline DEFESAS & \multicolumn{2}{|c|}{$\begin{array}{c}\text { DEFESAS INSTRUMENTAIS } \\
\text { (Adequada ou inadequada) }\end{array}$} & $\begin{array}{c}\text { MECANISMOS } \\
\text { DEFENSIVOS } \\
\text { PREDOMINANTES } \\
\text { (assinalar se presente) }\end{array}$ \\
\hline CATEXES + & DISSOCIAÇÃO & $\begin{array}{c}\text { IDENTIFICAÇÃO } \\
\text { PROJETIVA }\end{array}$ & RACIONALIZAÇÃO & \\
\hline CATEXES - & & & $\begin{array}{c}\text { ( )Negação } \\
\text { () Idealização } \\
\text { ( ) Formação Reativa } \\
\text { () Sedução } \\
\text { () Sublimação }\end{array}$ \\
\hline
\end{tabular}


6) SÍNTESE DO FUNCIONAMENTO PSICODINÂMICO

\begin{tabular}{|c|c|}
\hline $\begin{array}{c}\text { CATEXES POSITIVAS / RECURSOS DE } \\
\text { INTEGRAÇÃO }\end{array}$ & CATEXES NEGATIVAS / FONTES DE CONFLITO \\
\hline & \\
& \\
\hline
\end{tabular}




\section{APÊNDICE E}

\section{Critérios adicionais para codificação das respostas ao Desiderativo}

Com o objetivo de padronizar a codificação às respostas ao Desiderativo, e partindo das principais dúvidas surgidas quando do estudo piloto realizado nesta investigação, elaborou-se algumas diretrizes adicionais, conforme listado a seguir:

1) Quando a resposta for antropomórfica, deve ser codificada normalmente, em todos os quesitos avaliados;

2) Quando for recusa, não deverá ser registrado nem tempo de latência, nem codificação, pois nenhuma resposta válida foi emitida;

3) Os tempos devem ser assinalados em segundos.

Especificamente sobre o funcionamento lógico, elaborou-se em conjunto com uma das examinadoras experts deste estudo, diretrizes específicas com o objetivo de facilitar a avaliação deste item no Questionário Desiderativo. Neste modelo de protocolo, o funcionamento lógico será avaliado em termos de: conteúdo do pensamento, nível de organização do pensamento e diferenciação entre realidade interna e externa.

\section{a) Conteúdo do Pensamento}

Nesta categoria buscar-se-á verificar, na análise da racionalização, se o atributo associado ao símbolo guarda um sentido e/ ou um significado próprio, plausível, e/ou pertinente a elementos existentes na realidade externa, expresso nas escolhas relativas aos reinos animal, vegetal e objeto. Avalia-se o conteúdo do pensamento em termos de: a) logicidade preservada, expressa por atributos que guardam associação com a realidade externa,); b) logicidade ausente e/ou comprometida ,expressa por atributos que não guardam associação com a realidade externa.

A avaliação em cada ítem deve ser mutuamente exclusiva, fazendo-se a categorização em logicidade preservada ou logicidade ausente e/ou comprometida. Quando necessário, utilizar as características predominantes relatadas na resposta, em termos numéricos. Por exemplo, se forem dadas cinco justificativas ao atributo, duas próprias/plausíveis/pertinentes e três não próprias/plausíveis/pertinentes, classificar-se-á a resposta como tendo logicidade ausente e/ou comprometida. 


\section{b) Nível de Organização}

Nesta categoria, buscar-se-á, na análise da racionalização, verificar o nível de elaboração do pensamento, enquanto a capacidade de escolher atributos que vão além das peculiaridades exclusivamente objetivas e/ou sensoriais dos elementos, o que se expressa nas escolhas relativas aos reinos animal, vegetal e objeto. A qualidade da organização do pensamento será avaliada em termos de: a) abstrato, expressa por atributos que referem conceitos, propriedades dos objetos ou fenômenos, que transcendem a realidade imediata, refletindo elaboração própria e b) concreto, expresso por atributos que referem propriedades dos objetos ou fenômenos que são pontuais, circunstanciais, particulares, refletindo a descrição dos atributos, enquanto apego às impressões observáveis externamente.

A avaliação em cada ítem deve ser mutuamente exclusiva, fazendo-se a categorização em abstrato ou concreto. Quando necessário, utilizar as características predominantes da resposta, em termos numéricos. Por exemplo, se houver cinco justificativas ao atributo, duas concretas e três abstratas, classificar a resposta como abstrata.

A escolha do símbolo pode revelar particularidades nos processos de pensamento, e por outro lado sua riqueza indica a dimensão do recurso psíquico.

\section{c) Interação com a Realidade (Distinção entre realidade interna e externa)}

Nesta categoria buscar-se-á verificar, na análise da racionalização, se os atributos associados ao símbolo guardam relação com o senso comum, enquanto uma característica /ideia /crença compartilhada pelo coletivo, pela maioria, com relação aos elementos, o que se expressa nas escolhas relativas aos reinos animal, vegetal e objeto.A interaçaõ com a realidade é avaliada em:a) adequada quando nas escolhas os atributos independem da opinião particular do respondente e, portanto, são partilhados pelo senso comum, e b) inadequada quando nas escolhas os atributos dependem exclusivamente da opinião particular do respondente, referindo particularizações do pensamento. A avaliação em cada ítem deve ser mutuamente exclusiva, fazendo-se a categorização em adequada ou inadequada. Quando necessário, utilizar-se-á as características predominantes das respostas, em termos numéricos. Por exemplo, se houver cinco justificativas ao atributo, duas adequadas e três inadequadas, classificar a resposta como inadequadas. 